\author{
UNIVERSIDADE DE SÃO PAULO \\ INSTITUTO DE FÍSICA DE SÃO CARLOS \\ DEPARTAMENTO DE FÍSICA E INFORMÁTICA
}

\title{
CONSTRUÇÃO DE UM SUSCEPTÔMETRO AC AUTOBALANCEADO E ESTUDO DE POLÍMEROS CONDUTORES ELETRÔNICOS POR SUSCEPTIBILIDADE MAGNÉTICA E RESSONÂNCIA MAGNÉTICA
}

Ruberley Rodrigues de Souza

Tese apresentada ao Instituto de Física de São Carlos, Universidade de São Paulo, para obtenção do título de Doutor em Ciências: Física aplicada.

Orientador: Prof. Dr. Claudio José Magon

São Carlos

1998 
Souza, Ruberley Rodrigues de

Construção de um Susceptômetro AC Autobalanceado e Estudo de Polímeros Condutores Eletrônicos por Susceptiblidade Magnética e Ressonância Magnética/Ruberley Rodrigues de Souza - São Carlos, 1998.

$174 \mathrm{p}$.

Tese (Doutorado) - Instituto de Física de São Carlos, 1998. 


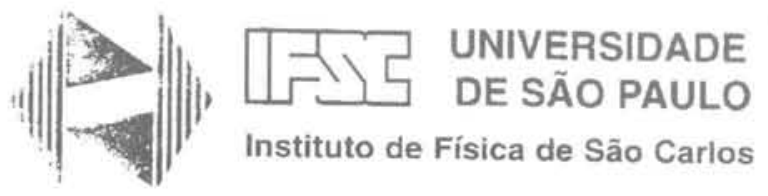

Av. Dr. Carios Botelho, 1465

CEP 13560-250 - São Carlos - SP Brasil

Fone (016) 274-3444

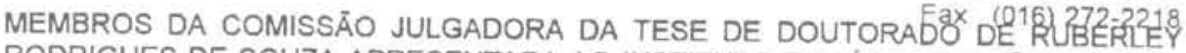
RODRIGUES DE SOUZA APRESENTADA AO INSTITUTO DE FISICA DE SÄO CARLOS, DA UNIVERSIDADE DE SÄO PAULO, EM O4 DE MARÇO DE 1998.

COMISSÃO JULGADORA:

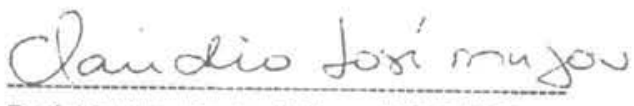

Prof. Dr. Claudio José Magon/IFSC-USP

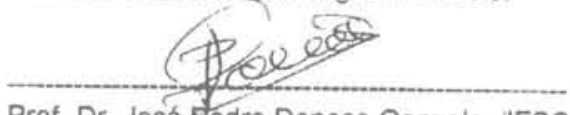

Prof. Dr. José-Pedro Donoso GonzalezilFSC-USP

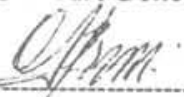

Dr. Clóvis Isberto Biscegli/EMBRAPA

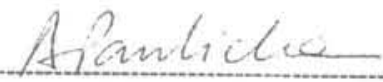

Profa. Dra. Agnieszka Joanna Pawlicka Maule/IQSC-USP

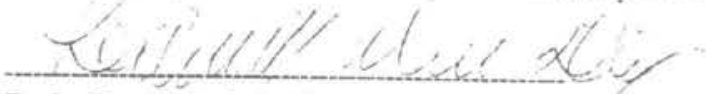

Profa. Dra. Ligia C de Moura Walmsiey/UNESP-RC 
Dedica este trabalha à Deus. aos meus pais, meus inmãos, cunhados e sobrinhos. 
“Amigos para sempre é o que nós iremos ser na primavera ou em qualquer das estações nas horas tristes nos momentos de prazer amigos para sempre”

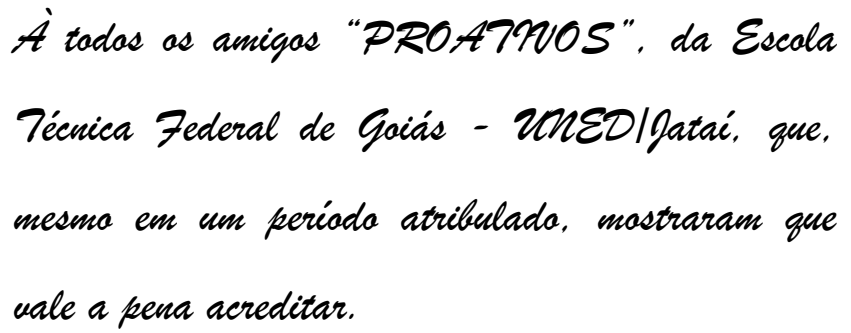

"Primeiro morre as esperanças, retorna das cinzas e os obrigam a fazer melhor para os novos discípulos que ingressam nessa mesma formação.”

“O Futuro não é o que se teme. O Futuro é o que se ousa." 


\section{AGRADECIMENTOS}

A realização desta tese não se deve exclusivamente a mim, mas sim a um trabalho em conjunto com diversas pessoas. Quero expressar aqui, a todos, o meu reconhecimento e gratidão pelo desenvolvimento profissional e humano que me proporcionaram.

\section{Meus sinceros agradecimentos:}

- ao prof. Dr. Claudio José Magon, pela orientação, apoio, paciência e principalmente pela amizade, que, neste período de quase oito anos em que foi desenvolvido meu trabalho de mestrado e doutorado, demonstrou acreditar em minha força de vontade e potencialidade, e apoiou-me quando resolvi retornar a Jataí, para assumir a função de professor na Escola Técnica Federal de Goiás - UNED/Jataí, mesmo sabendo que parte de meu trabalho poderia ser prejudicado;

- ao Dr. Clóvis Isberto Biscegli, pela amizade e pelo incentivo que muito me auxiliou nas horas de decisões;

- ao colega e grande amigo Paulo Henrique de Souza, pelo trabalho em conjunto com os polímeros poliparafenileno e pelo apoio dispensado na ETFGUNED/Jataí, que propiciaram o término deste doutorado;

- aos colegas de “república” Marcio Adriano R. Souza, Roberto W. Franco, João Vitor B. Ferreira e Sergio C. Saab, pela amizade, apoio e hospedagem no período final deste trabalho;

- aos profs. Drs. José Pedro Donoso e Tito José Bonagamba, pela amizade e pela colaboração no estudo de polímeros condutores eletrônicos;

- aos profs. Drs. Maristela Olson-Dyonísio e Sylvio Dyonísio de Souza, da UFSCar, pelas amostras de compostos intermetálicos;

- ao prof. Dr. Gaston Barberis, da UNICAMP, pela realização da medida de Susceptibilidade Magnética DC na amostra de $\mathrm{Tb}_{3} \operatorname{In}_{5}$;

- ao Ms. Claudio Carvalho, pelas amostras supercondutoras; 
- ao técnico José Fernando do Nascimento, do Laboratório de Química Analítica do IQSC, pela síntese das amostras de poliparafenileno;

- ao Dr. Luiz Henrique Mattoso, Dr. Francisco Malmonge e prof. Dr. Roberto Mendonça Faria, pelas amostras de poli(o-metoxianilina) e pelas frutíferas discussões sobre polímeros condutores eletrônicos;

- aos colegas e alunos da ETFG-UNED/Jataí, em especial às servidoras Simone e Maria Adelina que muito me auxiliaram, no período inicial de trabalho naquela unidade, de maneira a conciliar minha função de professor e meu trabalho de doutorado;

- aos professores, técnicos, secretária e colegas do grupo de Ressonância Magnética, por toda colaboração durante a realização deste trabalho e pela amizade que propiciou uma boa convivência no grupo;

- aos técnicos da oficina mecânica e seção de transformadores, pelos serviços indispensáveis na realização deste trabalho;

- aos técnicos da Criogenia, pelo fornecimento de Nitrogênio e Hélio líquido;

- às bibliotecárias Betânia, Célia, Mara, Neuza e Sibely, pela presteza e eficiência em servir e pela amizade;

- aos professores, colegas, secretárias, bibliotecárias e demais funcionários do Instituto de Física de São Carlos que contribuíram, de forma direta ou indireta, para a realização do presente trabalho;

- à ACESITA - Cia. de Aços Especiais Itabira, pela doação das chapas de ferro-silício utilizadas na blindagem magnética do "probe”;

- à CAPES, CNPq, FAPESP e FINEP pelo apoio financeiro, imprescindível para a realização deste trabalho;

- à todos amigos sãocarlenses, ou que por aqui passaram no período de desenvolvimento de minha pós-graduação, os quais propiciaram uma saldável estadia, tornado os dias, longe de casa, mais amenos e felizes;

- aos meus familiares, que sempre me apoiaram, incentivaram e acreditaram no sucesso deste empreendimento. 


\section{SUMÁRIO}

\section{LISTA DE FIGURAS}

LISTA DE TABELAS

\section{RESUMO}

\section{ABSTRACT}

1 - INTRODUÇÃO 1

2 - TÉCNICAS EXPERIMENTAIS 5

2.1 - Ressonância Paramagnética Eletrônica (RPE) 5

2.2 - Ressonância Magnética Nuclear (RMN) 10

2.3 - Programa de controle, aquisição e análise dados 16

3 - SUSCEPTÔMETRO AC AUTO-BALANCEADO 17

3.1 - Técnica de medida AC e DC 19

3.2 - Susceptibilidade AC ou Complexa 20

3.2.1 - Unidades da susceptibilidade magnética 21

3.3 - Princípio de funcionamento do susceptômetro AC 22

3.4 - Descrição do Equipamento 25

3.4.1 - Ponte de indutâncias mútuas $\quad 26$

3.4.2 - "Probe" 35

3.4.2.1 - Bobinas 36

3.4.2.2 - Blindagem Magnética $\quad 41$

3.4.3 - Movimento do "Probe" $\quad 42$

3.5 - Sistema de Resfriamento da Amostra 44

3.6 - Calibração Teórica $\quad 45$

3.7 - Calibração experimental 50

3.7.1 - Correção para o tamanho da amostra 53

3.8 - Avaliação do susceptômetro 55

3.8.1 - Homogeneidade do campo magnético 55

3.8.2 - Limitações em altas freqüências 57

3.8.3 - Estabilidade térmica 58 
3.8.4 - Tempo de medida $\quad 59$

$\begin{array}{ll}3.8 .5 \text { - Sensibilidade } & 60\end{array}$

4 - COMPOSTOS INTERMETÁLICOS 61

4.1 - Compostos intermetálicos do tipo $\mathrm{Tb}_{\mathrm{x}} \operatorname{In}_{\mathrm{y}} \quad 64$

4.2 - Compostos intermetálicos do tipo $\mathrm{ReAl}_{2}$

5 - POLIPARAFENILENO 78

5.1 - Polímeros condutores eletrônicos 78

5.2 - Poliparafenileno 81

5.2.1 - Preparação das amostras 83

5.3 - Susceptibilidade Magnética AC 84

5.4 - Ressonância Paramagnética Eletrônica 94

5.5 - Discussão 101

6 - POLI(O-METOXIANILINA) 108

6.1 - Preparação das amostras 110

6.2 - Susceptibilidade Magnética AC 112

6.3 - Ressonância Paramagnética Eletrônica (RPE) 115

6.3.1 - Condutividade elétrica 129

6.3.2 - Comparação entre as amostras em pó e em pastilhas 132

6.3.3 - Discussão 135

6.4 - Ressonância Magnética Nuclear 143

6.4.1 - Forma de linha 145

6.4.2 - Tempo de Relaxação Spin-Rede $\left(\mathrm{T}_{1}\right) \quad 151$

7 - CONCLUSÃO 159

$\begin{array}{ll}\text { ANEXOS } & 162\end{array}$

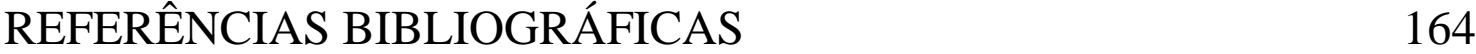

APÊNDICE 


\section{LISTA DE FIGURAS}

Figura 1 - Esquema em blocos da ponte de microondas utilizada no espectrômetro de RPE.

Figura 2 - Modulação do sinal de absorção.

Figura 3 - Componentes de absorção e dispersão da susceptibilidade magnética (a) e suas derivadas (b), as quais são o que se mede no espectrômetro de RPE. Onde $y=T_{2}\left(\omega-\omega_{0}\right)=2\left(H-H_{0}\right) / \Delta H_{1 / 2}$

Figura 4 - Definições das larguras $H_{1 / 2}$ e $\Delta H_{p p}$ e amplitudes para a linha de absorção (a) e sua derivada (b)

Figura 5 - Desenho esquemático da cavidade (de RPE) retangular acoplada ao tubo, de quartzo, do "Helitran". Nesta figura é mostrado também o posicionamento da amostra e do padrão.

Figura 6 - Diagrama em blocos do Espectrômetro de RMN.

Figura 7 - Diagrama de um circuito de proteção utilizando cabo de quarto de onda e diodos de chaveamento.

Figura 8 - Livre Decaimento da Indução (FID) e, na figura interna, sua Transformada de Fourier para o domínio de freqüências.

Figura 9 - Representação esquemática do conjunto de pulsos utilizados no método de

saturação-recuperação.

Figura 10 - Transformadas de Fourier de um conjunto de FIDs adquiridos durante a recuperação da magnetização de uma amostra. O gráfico interno mostra as intensidades integradas, das Transformadas de Fourier dos FIDs, em função do tempo de separação, $\tau$, entre o "pente" de saturação e o pulso de monitoramento.

Figura 11 - Sistema de Baixas Temperaturas. .15

Figura 12 - Diagrama mostrando a diferença entre a susceptibilidade AC obtida com e sem campo DC aplicado.

Figura 13 - Exemplo do método de indutâncias mútuas utilizando uma bobina secundária simples. 
Figura 14 - Exemplo do método de indutâncias mútuas utilizando uma bobina secundária com dois enrolamentos

Figura 15 - Princípio utilizado na medida da susceptibilidade magnética AC: a) exemplo da montagem, b) diagrama da voltagem induzida na bobina secundária $\left(V_{s}\right)$ e daquela utilizada para balancear a ponte de indutâncias mútuas $\left(V_{c}\right)$.

Figura 16 - Primeira versão da ponte de indutâncias mútuas, construída durante o desenvolvimento de minha dissertação de mestrado. DT72A e DT1145 são indutores mútuos variáveis.

Figura 17 - Desenho em blocos da ponte de indutâncias mútuas. .28

Figura 18 - Esquema da montagem do DACM, utilizados para variar a corrente da bobina primária. 30

Figura 19 - Esquema do pré-amplificador. 32

Figura 20 - Primeira tela do software de controle e aquisição de dados, denominado por SMAC (Susceptibilidade Magnética AC). A partir das opções no topo da tela pode-se ajustar os parâmetros ou começar a aquisição de dados. .33

Figura 21 - Tela de aquisição de dados do SMAC. .34

Figura 22 Seção transversal do "probe”. .35

Figura 23 - Seção transversal das fôrmas das bobinas. Unidades em milímetro. .36

Figura 24 - Fotos das bobinas do "probe”. Em a) são mostradas as bobinas primária e secundária, em b) é indicado como serão encachadas as bobinas, e em c) após a finalização da montagem do "probe”. Nestas fotos não é mostrado a blindagem magnética.

Figura 25 - Desenho esquemático do enrolamento das bobinas primária e secundária..38

Figura 26 - Diagrama esquemático do sinal balanceado (a) pela bobina de compensação e (b) pelos DACM.

Figura 27 - Blindagem magnética do “probe”. Unidades em milímetros.......................42

Figura 28 - Esquema da montagem para movimento do "probe”...................................43

Figura 29 - Desenho esquemático do sistema de resfriamento da amostra.

Figura 30 - a) bobinas secundárias (1 e 2) e primária (3), que compõem o "probe”; b) desenho esquemático dos enrolamentos das bobinas, o ponto indica 0 sentido da corrente elétrica.

Figura 31 - Esquema da montagem dos dois DACM, utilizados para balancear uma das fases. 
Figura 32 - Gráfico do inverso da susceptibilidade em função da temperatura, da amostra de Sulfato de Cobre penta-hidratado. Nesta medida foram utilizadas as Eq. (29), obtidas através da calibração teórica do susceptômetro.

Figura 33 - Gráfico do inverso da susceptibilidade molar em função da temperatura, da amostra de Sulfato de Cobre penta-hidratado, obtido por HOCKMAN et al. ...52

Figura 34 - Sinal de balanceamento, fornecido pelo DAC, em função da posição da amostra pontual, de ferro, em relação a bobina secundária. Medida utilizada na calibração do equipamento quanto ao tamanho da amostra.

Figura 35 - Correção para susceptibilidade magnética em função do tamanho da amostra. A linha cheia representa o ajuste dos pontos com uma função polinomial de $2^{\mathrm{a}}$ ordem.

Figura 36 - Gráfico mostrando o campo magnético no eixo central do "probe”: pontos experimentais (•) e cálculo teórico (linha cheia) antes da instalação da blindagem magnética; e pontos experimentais () após a instalação da blindagem magnética.

Figura 37 - Diferença de fase entre a voltagem induzida na bobina secundária e a corrente aplicada na bobina primária em função freqüência.

Figura 38 - Sinal de balanceamento (em fase e quadratura), necessário para a amostra de $\mathrm{CuSO}_{4}-5 \mathrm{H}_{2} \mathrm{O}$, em função do tempo.

Figura 39 - Sinal de balanceamento (em quadratura) em função da posição da amostra relativa ao "probe". Medida utilizada para a determinação, exata, da posição da amostra $\left(\mathrm{CuSO}_{4}-5 \mathrm{H}_{2} \mathrm{O}\right)$ em relação ao centro de cada uma das bobinas secundárias.

Figura 40 - Susceptibilidade magnética AC em função da temperatura da amostra de TbIn. Campo magnético DC nulo e campo magnético AC de 2 gauss de intensidade e freqüência de 98,9 Hz.

Figura 41 - Dependência com a temperatura da susceptibilidade molar recíproca do composto intermetálico de TbIn: $\square$ componente real da susceptibilidade AC medida sem campo DC e com campo AC de $2 \mathrm{G}$ de intensidade e 98,9 Hz de freqüência; · suscetibilidade DC, obtida por Lethuillier; Percheron-Guegan ${ }^{[54]}$, medida utilizando uma balança de Faraday com um campo magnético DC de

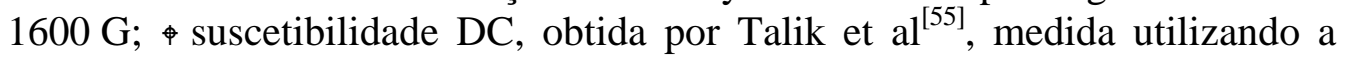
técnica de amostra vibrante.

Figura 42 - Susceptibilidade magnética AC em função da temperatura da amostra de $\mathrm{Tb}_{2} \mathrm{In}$. Campo magnético DC nulo e campo magnético AC de 2 gauss de intensidade e freqüência de $98,9 \mathrm{~Hz}$. O gráfico interno mostra a componente real e uma ampliação (por um fator 100) da componente imaginária da susceptibilidade AC. 
Figura 43 - Susceptibilidade molar em função da temperatura da amostra de $\mathrm{Tb}_{2} \mathrm{In}$. $\square$ componente real, e • componente imaginária da susceptibilidade AC, medida sem campo DC e com campo AC de $2 \mathrm{G}$ de intensidade e $98,9 \mathrm{~Hz}$ de freqüência; · suscetibilidade DC, obtida por Gamari-Seale et $\mathrm{al}^{[57]}$, medida utilizando um magnetômetro de amostra vibrante com um campo magnético DC de 1000 G. O gráfico interno mostra o inverso da componente real da susceptibilidade AC e da susceptibilidade DC em função da temperatura. Neste gráfico são mostrados também os ajustes, em altas temperaturas, para o comportamento de Curie-Weiss (linhas cheias).

Figura 44 - Susceptibilidade mássica em função da temperatura da amostra de $\mathrm{Tb}_{2} \mathrm{In}$. $\square$ componente real, e • componente imaginária da susceptibilidade AC, medida sem campo DC e com campo AC de $2 \mathrm{G}$ de intensidade e 98,9 Hz de freqüência; $\Delta$ suscetibilidade DC, obtida por Kawano et al, medida utilizando um magnetômetro de amostra vibrante com um campo magnético DC de 500 G; - suscetibilidade DC, obtida por Bazela; Szytula, medida utilizando uma balança de Faraday com um campo magnético DC de 10000 G. O gráfico interno mostra o inverso da componente real da susceptibilidade AC e da susceptibilidade DC em função da temperatura. Neste gráfico são mostrados também os ajustes, em altas temperaturas, para o comportamento de CurieWeiss (linhas cheias).

Figura 45 - Susceptibilidade magnética AC em função da temperatura da amostra de $\mathrm{Tb}_{3} \mathrm{In}_{5}$. Campo magnético DC nulo e campo magnético AC de 2 gauss de intensidade e freqüência de $98,9 \mathrm{~Hz}$. O gráfico interno mostra a componente real e uma ampliação (por um fator 20) da componente imaginária da susceptibilidade AC.

Figura 46 - Susceptibilidade mássica em função da temperatura da amostra de $\mathrm{Tb}_{3} \mathrm{In}_{5}$. $\square$ componente real, e • componente imaginária da susceptibilidade AC, medida sem campo DC e com campo AC de $2 \mathrm{G}$ de intensidade e 98,9 Hz de freqüência; · suscetibilidade DC obtida utilizando um magnetômetro SQUID com um campo magnético DC de 50 kG. O gráfico interno mostra o inverso da componente real da susceptibilidade AC e da susceptibilidade DC em função da temperatura, neste gráfico é mostrado também o ajuste, em altas temperaturas, para o comportamento de Curie-Weiss (linhas cheias)...............71

Figura 47 - Susceptibilidade magnética AC em função da temperatura da amostra de $\mathrm{GdAl}_{2}$. Campo magnético DC nulo e campo magnético AC de 2 gauss de intensidade e freqüência de $98,9 \mathrm{~Hz}$. O gráfico interno mostra a componente real e uma ampliação (por um fator 50) da componente imaginária da susceptibilidade AC.

Figura 48 - Susceptibilidade magnética AC em função da temperatura da amostra de $\mathrm{TbAl}_{2}$. Campo magnético DC nulo e campo magnético AC de 2 gauss de intensidade e freqüência de $98,9 \mathrm{~Hz}$. O gráfico interno mostra a componente real e uma ampliação (por um fator 30) da componente imaginária da susceptibilidade AC. 
Figura 49 - Susceptibilidade magnética AC em função da temperatura da amostra de $\mathrm{DyAl}_{2}$. Campo magnético DC nulo e campo magnético AC de 1 gauss de intensidade e freqüência de 98,9 Hz.O gráfico interno mostra a componente real e uma ampliação (por um fator 30) da componente imaginária da susceptibilidade AC.

Figura 50 - Susceptibilidade magnética AC em função da temperatura da amostra de $\mathrm{HoAl}_{2}$. Campo magnético DC nulo e campo magnético AC de 3 gauss de intensidade e freqüência de 98,9 Hz.O gráfico interno mostra a componente real e uma ampliação (por um fator 20) da componente imaginária da susceptibilidade AC.

75

Figura 51 - Inverso da componente real da susceptibilidade magnética AC em função da temperatura, dos compostos intermetálicos do tipo $\mathrm{ReAl}_{2}$. Campo magnético DC nulo e campo magnético AC de freqüência de $98,9 \mathrm{~Hz}$ e intensidade 2 gauss para Gd e Tb, 1 gauss para Dy e 3 gauss para Ho.

Figura 52 - Representação A) da ligação sigma $(\sigma)$, B) da ligação pi $(\pi)$ e C) do orbital hibridizado $s p^{2} p_{z}$ para o átomo de carbono.

Figura 53 - Condutividade em um polímero condutor, com $A$ indicando transporte de carga intracadeia, $B$ intercadeias e $C$ interpartículas. As setas mostram o caminho de uma carga migrando através do material. 80

Figura 54 - Escala de condutividade do poliparafenileno (PPP), poliparafenileno sulfide (PPS) e poliacetileno (PA) dopados com $\mathrm{AsF}_{5}$, comparada com a condutividade de alguns materiais convencionais. 81

Figura 55 - A) forma benzenóide e quinóide encontrada no poliparafenileno; B) cadeia polimérica do poliparafenileno ( 20 anéis) e os defeitos produzidos devido a introdução do dopante no polímero ( 5 anéis); e C) estrutura de banda do PPP puro, do polaron e do bipolaron.

Figura 56 - Gráfico da componente real da susceptibilidade magnética AC em função da temperatura para as amostras de PPP xFe, com x entre 0 e 0,005.

Figura 57 - Gráfico da componente real da susceptibilidade magnética AC em função da temperatura para as amostras de PPP xFe, com x entre 0,02 e 0,8.

Figura 58 - Gráfico da componente real da susceptibilidade magnética AC em função da temperatura para as amostras de PPP xFe, com x entre 1,1 e 1,8.

Figura 59 - Gráfico do produto da componente real da susceptibilidade magnética AC pela temperatura em função da temperatura $(\chi T \times T)$, para as amostras de PPP xFe, com x entre 0,8 e 1,8.

Figura 60 - Gráfico da Constante de Curie em função da concentração molar de Ferro na amostra de PPP. Linha cheia utilizada apenas como guia para os olhos......93 
Figura 61 - Gráfico da susceptibilidade de Pauli em função da concentração molar de Ferro na amostra de PPP. Linha cheia utilizada apenas como guia para os olhos.

Figura 62 - Evolução do espectro de RPE, da amostra de PPP dopada com 1,1 de Fe, em função da temperatura.

Figura 63 - Evolução do espectro de RPE, da amostra de PPP dopada com 1,8 de Fe, em função da temperatura.

Figura 64 - Ampliação da linha $C$ que se encontra sobreposta à linha $A$, vista nos espectros da Figura 62 e da Figura 63.

Figura 65 - Gráfico das larguras de linhas pico a pico, em função da temperatura, para os sinais de RPE do PPP dopado com $\mathrm{FeCl}_{3}$. Medidas realizadas nas amostras de PPP $x F e$, onde $x=1,1$ e 1,8 .

Figura 66 - Gráfico da largura de linha pico a pico, em função da temperatura, para a linha $A_{1}$. Medidas realizadas nas amostras de PPP xFe, onde $\mathrm{x}=1,1$ e 1,8. Linhas cheias utilizadas apenas como guia para os olhos.

Figura 67 - Gráfico da largura de linha pico a pico, em função da temperatura, para o sinal, de RPE, da linha $B$. Medidas realizadas nas amostras de PPP xFe, onde $\mathrm{x}=1,1$ e 1,8 . Linhas cheias utilizadas apenas como guia para os olhos. .98

Figura 68 - Gráfico do inverso da intensidade integrada da linha $B$, em função da temperatura.

Figura 69 - Gráfico do inverso da intensidade integrada da linha $C$, em função da temperatura.

Figura 70 - Gráfico do inverso da intensidade integrada da linha $A$, correspondente a soma de duas lorentzianas $\left(A_{1}+A_{2}\right)$, em função da temperatura. Linhas cheias utilizadas apenas como guia para os olhos.

Figura 71 - Gráfico do produto da temperatura pela intensidade integrada da linha $A$, correspondente a soma de duas lorentzianas $\left(A_{1}+A_{2}\right)$, em função da temperatura.

Figura 72 - Espectro de RPE da polianilina (PANI) dopada com $\mathrm{FeCl}_{4}$, obtido por Wan et $\mathrm{al}^{[84]}$.

Figura 73 - Valores de g efetivo para o Hamiltoniano de spin dado pela Eq. (47), calculados por Wickaman et $\mathrm{al}^{[87]}$.

Figura 74 - Estrutura básica da polianilina.

Figura 75 - Estrutura básica da derivada da polianilina devido a substituição do $H$, da posição orto do anel benzeno, por um dos radicais $(R)$ listados na Tabela 10.109 
Figura 76 - Diagrama esquemático do processo químico utilizado na síntese da PANI e POMA (ver referências [104] e [105]).

Figura 77 - Esquema da protonação da polianilina em meio ácido de HCl 1M. 112

Figura 78 - Dependência com a temperatura, da componente real, da susceptibilidade magnética AC das amostras POMA EB $(\diamond)$ e POMA dopada com TFA $(\bullet$ e $\bullet$ ) e $\mathrm{HCl}(\bullet)$. Medidas realizadas nas amostras na forma de pastilhas e com um campo AC de 8 gauss de intensidade e $98,9 \mathrm{~Hz}$ de freqüência. Nestas medidas $\chi^{\prime \prime} \approx 0$. 113

Figura 79 - Dependência com a temperatura do produto da componente real da susceptibilidade magnética AC, das amostras POMA EB ( $\diamond)$ e POMA dopada com TFA $(\bullet$ e •) e $\mathrm{HCl}(\bullet)$, pela temperatura. Medidas realizadas nas amostras na forma de pastilha e com um campo AC de 8 gauss de intensidade e 98,9 Hz de freqüência.

Figura 80 - Sinal de RPE, em temperatura ambiente, da amostra POMA dopada com TFA por $1 \mathrm{~h}$. Neste espectro são mostrados os sinais do polímero $(\mathrm{g} \cong 2,009)$ e do rubi, em baixo campo ( $\mathrm{g}=3,51$ ), utilizado como padrão. 116

Figura 81 - Evolução do espectro de RPE, da amostra POMA EB (pastilha), em função da temperatura.

Figura 82 - Linhas hiperfinas resolvidas para o sinal de RPE da POMA-EB na forma de pastilha e em temperatura de $12 \mathrm{~K}$.

Figura 83 - Estrutura hiperfina resolvida para o sinal de RPE de polianilina, na forma PNB (linha cheia) e EB (linha pontilhada), diluída em dioxane. Espectro em solução obtido, em temperatura ambiente, por Long et $\mathrm{al}^{[127]}$. 119

Figura 84 - Ilustração esquemática de um soliton neutro BNB (Benzenóide Nitrogênio Benzenóide) na base pernigranilina (PNB).

Figura 85 - Evolução do espectro de RPE, da amostra POMA dopada com TFA por 1h (pastilha), em função da temperatura.

Figura 86 - Evolução do espectro de RPE, da amostra POMA dopada com TFA por 24h (pastilha), em função da temperatura.

Figura 87 - Evolução do espectro de RPE, da amostra POMA dopada com $\mathrm{HCl}$ por 24h (pastilha), em função da temperatura.

Figura 88 - Intensidade integrada $(I)$ do sinal de RPE, da POMA EB $(\diamond)$ e da POMA dopada com TFA (• e •) e $\mathrm{HCl}(\bullet)$, em função da temperatura. Na escala da esquerda tem-se a intensidade integrada do sinal de RPE para a amostra POMA-EB (+) em escala ampliada. Resultados obtidos com as amostras na forma de pastilha, e normalizado pelo sinal do rubi e pela massa da amostra.123

Figura 89 - Inverso da intensidade integrada $(1 / I)$ do sinal de RPE, da POMA EB $(\diamond)$ (escala da direita) e da POMA dopada com TFA (• e •) e $\mathrm{HCl}(\bullet)$ (escala da 
esquerda), em função da temperatura. Resultados obtidos com as amostras na forma de pastilha. Linhas cheias utilizadas apenas como guia para os olhos..124

Figura 90 - Dependência com a temperatura do produto da intensidade integrada, do sinal de RPE da amostra POMA EB ( $\diamond$ ) e POMA dopada com TFA (• e •) e $\mathrm{HCl}(\bullet)$ pela temperatura. Resultados obtidos com as amostras na forma de pastilha.

Figura 91 - Gráficos de $\chi$ (proporcional à dupla integração do sinal de RPE) em função do inverso da temperatura. Comparação entre os resultados da dupla integração do sinal de RPE para a amostra POMA-EB ( $\bullet$ e POMA dopada com HCl (•), com os resultados obtidos por Wang et al ${ }^{[114]}$ para a amostra POT-EB $(+)$ e POTES (3), ambas na forma de filme. Escala da esquerda para as amostras POMA e da direita para as amostras POT.

Figura 92 - Dependência com a temperatura das larguras de linha pico a pico do sinal de RPE da amostra POMA EB ( $\bullet$ ) e dopada com TFA $(\bullet$ e •) e $\mathrm{HCl}(\bullet)$. Todas estas amostras estão na forma de pastilha. Linhas cheias utilizadas apenas como guia para os olhos.

Figura 93 - Comparação entre as larguras de linha pico a pico do sinal de RPE da amostra POMA-EB ( $\bullet$ e POMA dopada com $\mathrm{HCl}(\bullet)$ com os resultados obtidos por Wang et al ${ }^{[114]}$ para a amostra de POT-EB $(+)$ e POT-ES $(\boldsymbol{\theta})$, ambas na forma de filme. Medidas realizadas em temperaturas entre $5 \mathrm{~K}$ e temperatura ambiente.

Figura 94 - Relação entre a razão $A / B$, do sinal de RPE, e o coeficiente $\lambda$ da teoria de Dyson. Gráfico extraído do artigo de Walmsley ${ }^{[131]}$. 130

Figura 95 - Condutividade elétrica AC, medida a partir da assimetria do sinal de RPE (razão $A / B$ ), para as amostras POMA dopada com TFA (• e •) e $\mathrm{HCl}(\bullet)$. Amostras na forma de pastilha, com espessuras entre 350 e $650 \mu \mathrm{m}$. Freqüência: 9,26 GHz 131

Figura 96 - Evolução do espectro de RPE, da amostra POMA dopada com TFA por 24h (em pó), em função da temperatura.

Figura 97 - Dependências com a temperatura das larguras de linha pico a pico do sinal de RPE da amostra, POMA dopada com TFA por 24 h, em pó (•) e em pastilha $(\bullet)$. Linhas cheias utilizadas apenas como guia para os olhos 133

Figura 98 - Comparação entre a dependência com a temperatura do inverso da dupla integração do sinal de RPE da amostra, POMA dopada com TFA por 24 h, na forma de pó $(\bullet)$ e pastilha $(\bullet)$. Escala da direita para a amostra na forma de pó, e da esquerda para pastilha. No gráfico interno tem-se a dependência com a temperatura do produto da intensidade integrada pela temperatura para a amostra em pó e pastilha. 
Figura 99 - Transformadas de Fourier do FID do ${ }^{1} \mathrm{H}$ da amostra POMA-EB em pó. Figuras a) e b) adquiridas, respectivamente, em $77 \mathrm{~K}$ e $323 \mathrm{~K}$. Medidas realizadas na freqüência $36 \mathrm{MHz}$. 146

Figura 100 - Dependência com a temperatura da largura de linha, da Transformada de Fourier do FID, do ${ }^{1} \mathrm{H}$ da POMA-EB. Medida realizada em $36 \mathrm{MHz}$ 147

Figura 101 - Dependência com a temperatura da largura de linha, da Transformada de Fourier do FID, do ${ }^{1} \mathrm{H}$ na POMA dopada com $\mathrm{HCl}$. Medidas realizadas em $36 \mathrm{MHz}$. 149

Figura 102 - Dependência com a temperatura da largura de linha, da Transformada de Fourier do FID, do ${ }^{1} \mathrm{H}(\boldsymbol{4})$ e do ${ }^{19} \mathrm{~F}(\bullet)$ na POMA dopada com TFA por $1 \mathrm{~h}$. Medidas realizadas em $36 \mathrm{MHz}$. 149

Figura 103 - Taxa de relaxação $\left(1 / T_{1}\right)$ do ${ }^{1} \mathrm{H}$, da amostra POMA-EB, nas freqüências de (•) 24 e (•) $36 \mathrm{MHz}$ 152

Figura 104 - Taxa de relaxação $\left(1 / T_{1}\right)$ do ${ }^{1} \mathrm{H}$, da amostra POMA EB ( $)$ e POMA dopada com TFA (• e •) e $\mathrm{HCl}(\bullet)$. Medidas realizadas na freqüência de $36 \mathrm{MHz}$.

Figura 105 - Comparação entre as taxas de relaxação $\left(1 / T_{1}\right)$ de tempo curto, em função da temperatura, do ${ }^{19} \mathrm{~F}\left(+\mathrm{e}\right.$ 䊉) e do ${ }^{1} \mathrm{H}(\bullet$ e $\bullet$ ) na amostra POMA dopada com TFA por $1 \mathrm{~h}$. Medidas realizadas, em $36 \mathrm{MHz}$, antes e depois de secar a amostra a $60^{\circ} \mathrm{C}$ durante $12 \mathrm{~h}$. 155

Figura 106 - Taxas de relaxação $\left(1 / T_{1}\right)$ do ${ }^{1} \mathrm{H}$, da amostra POMA dopada com TFA (• e •) e $\mathrm{HCl}(\bullet)$ na freqüência de $36 \mathrm{MHz}$. 156

Figura 107 - Taxas de relaxação $\left(1 / T_{1}\right)$ do ${ }^{19} \mathrm{~F}$ da amostra POMA dopada com TFA, por $1 \mathrm{~h}(\bullet$ e •) e $24 \mathrm{~h}(\bullet$ e O), nas freqüências de 24 e $36 \mathrm{MHz}$. 157 


\section{LISTA DE TABELAS}

Tabela 1 - Dados das bobinas do "probe" 39

Tabela 2 - Alguns íons terra rara trivalentes 62

Tabela 3 - Temperatura de Curie-Weiss $(\theta)$, temperatura de transição de fase magnética $\left(T_{N}\right)$ e momento efetivo $(p)$ dos compostos intermetálicos do tipo $\operatorname{Tb}_{\mathrm{x}} \mathrm{In}_{\mathrm{y}}$. .72

Tabela 4 - Intensidade do campo AC aplicado e massa, de $\mathrm{ReAl}_{2}$, utilizada na medida da susceptibilidade magnética.

Tabela 5 - Temperatura de Curie-Weiss $(\theta)$, temperatura de transição de fase magnética $\left(T_{N}\right)$ e número de magneton de Bohr $(p)$ dos compostos intermetálicos do tipo $\mathrm{ReAl}_{2}$.

Tabela 6 - Constante de Curie $(C)$, susceptibilidade independente da temperatura $\left(\chi_{0}\right)$ e Temperatura de Curie-Weiss $(\theta)$ para as amostras de poliparafenileno dopado com Ferro em diversas concentrações, onde $x$ é a concentração nominal de Ferro e $p$ é a concentração (em porcentagem de massa) medida por Absorção Atômica. 88

Tabela 7 - Valores de Pascal. 90

Tabela 8 - Contribuições diamagnética e paramagnética de Curie-Weiss e Pauli para a susceptibilidade magnética AC do poliparafenileno dopado com Ferro, onde x a concentração nominal e y a concentração determinada por absorção atômica.92

Tabela 9 - Parâmetros encontrados pelo ajuste do espectro de RPE. 96

Tabela 10 - Denominação dada à derivados da polianilina devido a substituição do $H$, da posição orto do anel benzeno, por um dos radicais $(R)$ listados abaixo......109

Tabela 11 - Constante de Curie $(C)$ e susceptibilidade independente da temperatura $\left(\chi_{0}\right)$ para as amostras de poli(o-metoxianilina)

Tabela 12 - Contribuição diamagnética e de Pauli para a susceptibilidade da POMA.115

Tabela 13 - Especificações das pastilhas de poli(o-metoxianilina) utilizadas nas medidas de RPE. 


\section{RESUMO}

Neste trabalho, é descrito uma ponte de indutâncias mútuas que pode ser usada para medidas automáticas de susceptibilidade magnética AC, em freqüências até $1 \mathrm{kHz}$. Este susceptômetro utiliza um novo e alternativo arranjo para o "probe”. O conjunto de bobinas, mantido em temperatura ambiente, é movimentado de tal forma a posicionar a amostra no centro de cada uma das bobinas secundárias. A amostra, cuja posição é fixa, tem sua temperatura controlada por um criostato de fluxo de Hélio. O acoplamento magnético do "probe" com materiais na vizinhança foi minimizado com o uso de uma blindagem magnética. Este "probe" tem uma sensibilidade de $10^{-7} \mathrm{emu}$ com um campo magnético AC de $8 \mathrm{G}$ rms e freqüência de $100 \mathrm{~Hz}$. Neste trabalho, são apresentados também alguns resultados de susceptibilidade magnética AC, obtidos em supercondutores de alto $T_{C}$ e compostos intermetálicos de terras raras. A relação entre transporte de cargas e propriedades magnéticas, de poliparafenileno (PPP) dopado com $\mathrm{FeCl}_{3}$ e poli(o-metoxianilina) (POMA) dopada com TFA e $\mathrm{HCl}$, foi estudada utilizando as técnicas de Susceptibilidade Magnética AC (SMAC), Ressonância Paramagnética Eletrônica (RPE) e Ressonância Magnética Nuclear (RMN). Os resultados obtidos para o PPP foram interpretados em termos de três contribuições: presença do polaron paramagnético, cuja mobilidade aumenta com o aumento da temperatura; íons $\mathrm{Fe}^{3+}$ coordenados em sítios de baixa simetria da molécula $\mathrm{FeCl}_{3}$; e íons $\mathrm{Fe}^{3+}$ fortemente acoplados via interação de troca. A dependência com a temperatura do sinal de RPE da POMA pode ser entendido em termos da dinâmica dos polarons. O estreitamento da linha de RPE, devido a dopagem do material, pode ser explicada por dois processos diferentes. Em baixas temperaturas, predomina a interação de troca polaron-polaron, modulada pelas flutuações de spin. Em altas temperaturas o "motional narrowing” é provocado pelo aumento de mobilidade do polaron. Em temperaturas intermediárias, é observado um efeito anômalo: a largura de linha cresce abruptamente, produzindo um pico em torno de $220 \mathrm{~K}$. Este pico pode ser associado à contribuição não secular para a largura de linha. Acredita-se que o espalhamento do polaron por moléculas de oxigênio, promova um aumento no mecanismo de relaxação spin-rede. Os resultados de RMN para o ${ }^{1} \mathrm{H}$ e ${ }^{19} \mathrm{~F}$ mostram que as componentes espectrais da largura de linha, são associadas com as fases amorfa e cristalina da POMA. Neste material, a taxa de relaxação spin-rede do ${ }^{1} \mathrm{H}$ aumenta mais de uma ordem de grandeza com a dopagem. Isto pode ser explicado por um mecanismo de relaxação envolvendo acoplamento hiperfino núcleo-polaron. 


\begin{abstract}
A mutual inductance bridge which may be used for automatic measurement of ac magnetic susceptibilities from $4 \mathrm{~K}$ to room temperature, at frequencies up to $1 \mathrm{kHz}$, is described. The susceptometer employs an alternative and new arrangement for the probe. The coil set is kept at room temperature and moves in such a way to place the sample in the center of each of the secondary coils. The sample, motionless, has its temperature controlled by a helium flow refrigerator. Use of a magnetic shield minimizes coupling of the probe with nearby materials. This probe has a sensitivity of $10^{-7} \mathrm{emu}$ in an ac magnetic field of $8 \mathrm{G}$ rms and frequency of $100 \mathrm{~Hz}$. Typical results of ac magnetic susceptibility, obtained in high $T_{c}$ superconductors and rare earth intermetallic compounds are shown. AC Magnetic Susceptibility, Nuclear Magnetic Resonance (NMR) and Electron Paramagnetic Resonance (EPR) were used to study the relation between charge transport and magnetic properties of polyparaphenylene (PPP) doped with $\mathrm{FeCl}_{3}$ and poly(omethoxyaniline) (POMA) doped with TFA and $\mathrm{HCl}$. The results obtained in PPP can be interpreted in terms of three major contributions: the presence of the paramagnetic polaron, whose mobility increases with increasing temperature, $\mathrm{Fe}^{3+}$ ions coordinated in the low symmetry site of the $\mathrm{FeCl}_{3}$ molecule, and $\mathrm{Fe}^{3+}$ ions strongly coupled via exchange interaction. The temperature behavior of the EPR of POMA can be understood in terms of the dynamics of the polaron. Line narrowing, induced by doping the material, can be explained by two different processes. At low temperature, polarons are coupled via exchange interaction and the exchange narrowing of the line is caused by thermal spin fluctuations. At high temperature, motional narrowing is the most efficient mechanism. At intermediate temperatures, an anomalous effect is observed: linewidth increase abruptly, showing a peak at $220 \mathrm{~K}$. This peak can be associated to the non-secular contribution to the line width. It is assumed that the spinlattice relaxation mechanism is enhanced, at this temperature, due to the polaron scattering by paramagnetic oxygen molecules. ${ }^{1} \mathrm{H}$ and ${ }^{19} \mathrm{~F}$ NMR data shows that the linewidth spectral components are associated with the amorphous and crystalline phases of the POMA. ${ }^{1} \mathrm{H}$ spin-lattice relaxation rates, in this material, increases more than one order of magnitude after doping. This can be explained by a relaxation mechanism involving nucleus-polaron hyperfine coupling.
\end{abstract}




\section{1 - INTRODUÇÃO}

A partir da década de 80, alguns materiais poliméricos passaram a despertar grande interesse, no mundo inteiro, por possibilitarem um aumento da condutividade elétrica, de até 15 ordens de grandeza, sob dopagem química e ou eletroquímica. À esta nova classe de polímeros deu-se o nome de polímeros condutores. Ao longo dos últimos 20 anos o estudo desses materiais têm envolvido várias áreas do conhecimento, envolvendo principalmente a química, física, microeletrônica e engenharia dos materiais. Isto ocorreu devido aos desafios que o campo oferece e ao grande potencial tecnológico envolvido, principalmente relacionado com os processos de condutividade elétrica.

No desenvolvimento da pesquisa desses polímeros condutores, além das propriedades elétricas e óticas, alguns aspectos fundamentais devem ser considerados. Dentre eles: as propriedades de resistência mecânica; a estabilidade química; e a processabilidade em relação aos polímeros convencionais. A partir dos anos oitenta, os estudos abrangeram principalmente os mecanismos de dopagem, propriedades físicoquímicas, métodos de síntese, caracterização e aplicações tecnológicas. No caso das aplicações tecnológicas, as perspectivas são promissoras. Os trabalhos publicados, avaliando as potencialidades dos polímeros condutores em dispositivos eletrônicos ${ }^{[1]}$, em baterias ${ }^{[2,3]}$ e mais recentemente em dispositivos optoeletrônicos ${ }^{[4]}$, têm aumentado muito nos últimos anos.

A dinâmica de spins e as propriedades de transporte, para estes polímeros, têm sido amplamente estudadas, utilizando, entre outras, as técnicas espectroscópicas de Ressonância Paramagnética Eletrônica (RPE) e Ressonância Magnética Nuclear (RMN). Em alguns trabalhos, encontram-se também estudos do 
comportamento da susceptibilidade magnética estática, para várias clásses de polímeros condutores. Para estes estudos foram utilizados, geralmente, balanças de Faraday ou susceptômetros SQUID, que possuem uma sensibilidade muito alta. Entretanto a técnica de susceptibilidade magnética AC, bastante difundida com o desenvolvimento dos supercondutores de alto $\mathrm{T}_{\mathrm{c}}$, tem sido pouco utilizada nestes estudos.

A proposta do presente trabalho, é o estudo de propriedades magnéticas de polímeros condutores. Para este estudo foi utilizado, além das técnicas de ressonância eletrônica e nuclear, a técnica de susceptibilidade magnética AC (SMAC). Esta técnica, ao contrário das técnicas de ressonância, fornece informações do comportamento da magnetização macroscópica. Entretanto, para a realização destas medidas de susceptibilidade magnética, foi necessário, primeiramente, realizar várias melhorias no equipamento existente em nosso laboratório.

Desta forma, o presente trabalho pode ser, claramente, dividido em duas partes bem distintas. A primeira parte consiste na construção e automação de um susceptômetro autobalanceado para medidas da susceptibilidade magnética AC (Capítulo 3). A segunda parte engloba o estudo de propriedades magnéticas de polímeros condutores eletrônicos, utilizando as técnicas de ressonância eletrônica e nuclear e susceptibilidade magnética AC (capítulos 5 e 6).

No início deste trabalho, possuíamos em nosso laboratório apenas um primeiro protótipo do susceptômetro. Aquele protótipo foi resultado de um empreendimento iniciado em 1991, que culminou, em meados de 1992, em uma dissertação de mestrado ${ }^{[5]}$. Na construção do primeiro protótipo deparamos com vários problemas. Dentre eles, destacamos a adequação do conjunto de bobinas de medidas ao sistema de resfriamento da amostra. A proposta para resolver este problema resultou em uma solução inovadora e original, que é o movimento do conjunto de bobinas (“moving probe”) ${ }^{[6]}$, resultando assim em uma das grandes contribuições desta tese.

Com o primeiro protótipo já era possível a obtenção da susceptibilidade magnética de materiais supercondutores e alguns sais paramagnéticos, entretanto, devido sua baixa sensibilidade, não era possível a medida de susceptibilidade de materiais cuja magnetização fosse pequena $\left(\leq 10^{-6} \mathrm{emu}\right)$, como por exemplo a maioria dos polímeros condutores eletrônicos. 
No decorrer da construção do susceptômetro atual, foram estudados vários tipos de materiais. Dentre eles destacamos os supercondutores de alto $\mathrm{T}_{\mathrm{c}}$, os compostos intermetálicos e os polímeros condutores eletrônicos. Nesta tese serão apresentados, além do estudo de polímeros condutores, alguns resultados obtidos para amostras supercondutoras de alto $\mathrm{T}_{\mathrm{c}}$ e para compostos intermetálicos.

$\mathrm{O}$ estudo dos supercondutores de alto $\mathrm{T}_{\mathrm{C}}$ foi fruto de uma colaboração com o grupo de materiais do IFSC. Este estudo restringiu-se na determinação da qualidade do supercondutor, ou seja, na verificação da temperatura de transição supercondutora e das fases supercondutora presentes no material.

O estudo dos compostos intermetálicos foi fruto de uma colaboração com o Instituto de Física da Universidade Federal de São Carlos, nas pessoas dos professores Maristela Olson-Dyonísio e Sylvio Dyonísio de Souza. Para este estudo foram realizadas medidas de susceptibilidade magnética AC em compostos do tipo $\mathrm{Tb}_{\mathrm{x}} \mathrm{In}_{\mathrm{y}}\left(\mathrm{com} \mathrm{x}-\mathrm{y}=1-1,2-1\right.$ e 3-5) e $\operatorname{ReAl}_{2}$ (com $\mathrm{Re}=\mathrm{Gd}$, Tb, Ho e Dy). Entretanto, este estudo faz parte de um trabalho ainda não concluído. Por este motivo, seus resultados serão apresentados de forma descritiva, comparando-os com resultados obtidos por outras técnicas, encontrados na literatura. Os resultados obtidos nestes materiais serviram também para testar a versatilidade, confiabilidade e reprodutibilidade do susceptômetro.

Os polímeros estudados nesta tese pertencem a duas classes de polímeros condutores eletrônicos: os poliparafenilenos (PPP); e as poli(ometoxianilina) (POMA), que são polímeros derivados das polianilina.

O estudo de propriedades magnéticas nos poliparafenilenos, dopados com cloreto de Ferro $\left(\mathrm{FeCl}_{3}\right)$ em várias concentrações, já vinham sendo estudados, por Espectroscopia de Alta Resolução e por Ressonância Paramagnética Eletrônica, pelo aluno de doutorado, do Grupo de Ressonância do DFI/IFSC, Paulo Henrique de Souza. No estudo tinham sido realizadas medidas de RMN em função da temperatura e da concentração de dopante, e de RPE em função da concentração. No presente trabalho (Capítulo 5), serão mostrados e discutidos os resultados de susceptibilidade magnética AC em função da temperatura e da concentração, e os resultados de RPE em função da temperatura.

Por último, foi iniciada uma nova linha de pesquisa em nosso laboratório: o estudo de propriedades magnéticas de derivados de polianilina, por 
susceptibilidade AC, RPE e RMN. A amostra utilizada neste estudo foi a POMA não dopada (EB) e dopada com ácido clorídrico $(\mathrm{HCl})$ ou ácido trifluoracético $\left(\mathrm{CF}_{3} \mathrm{COOH}\right.$ - TFA). Estas amostras foram sintetizadas no Grupo de Polímeros do DFCM/IFSC. 


\section{2 - TÉCNICAS EXPERIMENTAIS}

O estudo das propriedades dos polímeros condutores eletrônicos, constitui atualmente um campo de pesquisas muito ativo. A caracterização físicoquímica destes materiais é realizada utilizando-se várias técnicas experimentais, dentre as quais: a calorimetria diferencial; a espectroscopia ótica; a difração de raios-X; o espalhamento de nêutrons; a relaxação dielétrica; a condutividade elétrica AC e DC; a ressonância magnética nuclear e eletrônica e a susceptibilidade magnética.

No presente trabalho, fizemos um estudo de propriedades magnéticas desses polímeros, utilizando as técnicas de Ressonância Paramagnética Eletrônica (RPE), Ressonância Magnética Nuclear (RMN) e Susceptibilidade Magnética AC (SMAC).

Vários autores têm discutido em detalhes a teoria e as técnicas de

espectroscopia por RPE e $\mathrm{RMN}^{[7-11]}$. Por isso, neste capítulo nos limitaremo a uma descrição dos espectrômetros, de RPE e RMN, utilizados no estudo de polímeros condutores eletrônicos.

Por ser uma contribuição importante desta tese, a técnica de Susceptibilidade Magnética AC (SMAC) será descrita em um capítulo a parte. No Capítulo 3 será descrito o tipo de informação obtida da susceptibilidade magnética, as características do susceptômetro, seu funcionamento e sua calibração.

\section{1 - Ressonância Paramagnética Eletrônica (RPE)}

O espectrômetro de RPE, existente em nosso laboratório, é um equipamento convencional, banda $X(\lambda \cong 3 \mathrm{~cm}, v \cong 9 \mathrm{GHz})$, no que se refere ao seu funcionamento básico, mas difere dos comerciais na montagem, pois, trata-se de um 
equipamento cujos módulos eletrônicos e as partes que compõe a ponte de microonda foram adquiridas separadamente. Essa opção traz a vantagem da versatilidade onde diferentes configurações de detecção, por exemplo, são possíveis. Não serão aqui explicados em detalhes o funcionamento dos módulos do espectrômetro de RPE porque o uso dessa técnica está bastante difundido entre os especialistas e usuários de RPE e uma vasta literatura existe sobre o assunto ${ }^{[12,13]}$. Na Figura 1 é mostrado um esquema em blocos, simplificado, da ponte de microondas utilizada no espectrômetro de RPE. Um estudo detalhado sobre operação, funcionamento, tipos de detecção, vantagens, desvantagens e características das diferentes configurações desse espectrômetro de RPE pode ser visto na referência $\left[{ }^{14}\right]$.

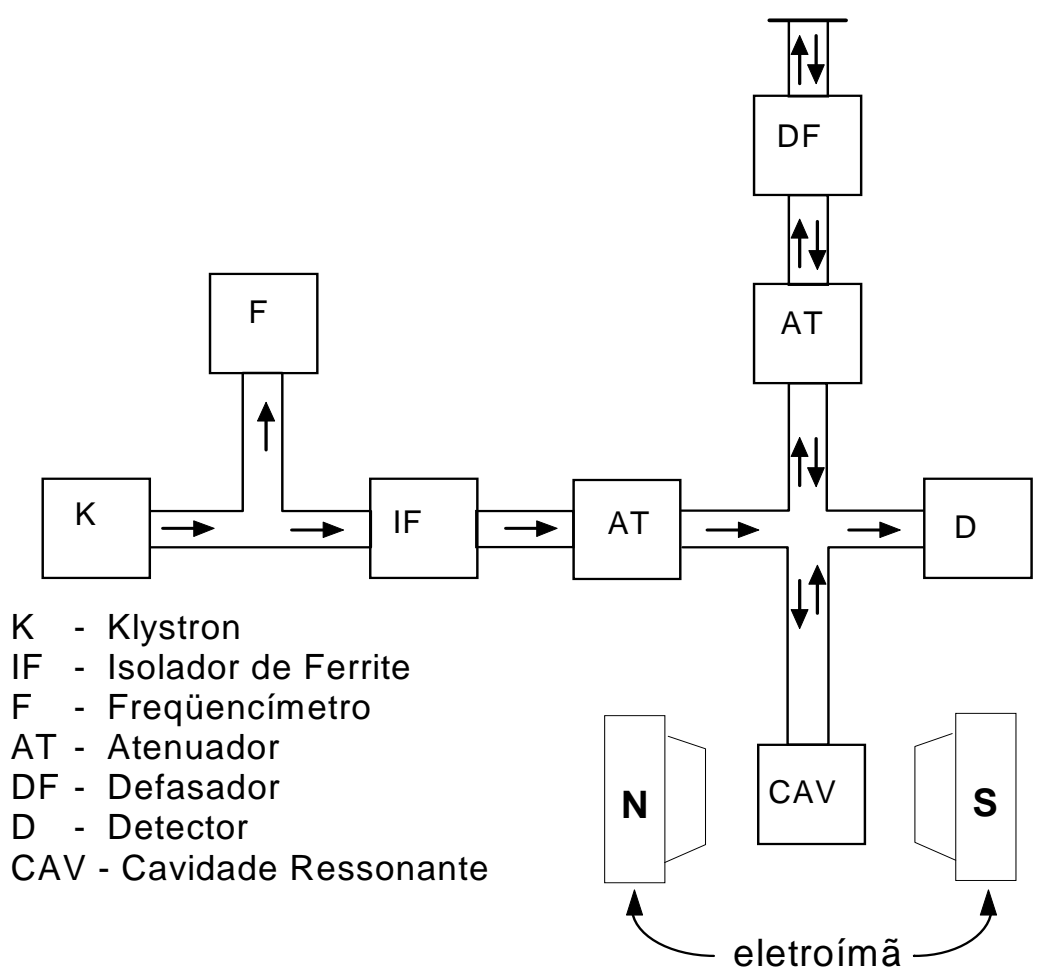

Figura 1 - Esquema em blocos da ponte de microondas utilizada no espectrômetro de RPE.

Nos espectrômetros de RPE convencionais, a freqüência do campo oscilante, $\vec{H}_{1}(t)$, (microondas) é mantida fixa e varia-se o campo magnético externo, $H_{0}$, a fim de obter-se a condição de ressonância $\left(h v=g \beta H_{0}\right)$. O sinal de RPE possui uma largura intrínseca determinada pelo inverso do tempo de relaxação spin-spin. 
Além disso, no material tem-se uma quantidade muito grande de spins precessionando em torno do campo aplicado, e estes movimentos de precessão não possuem, exatamente, a mesma freqüência, $\omega_{L}$, e sim uma distribuição de freqüências centrada na freqüência de Larmor, o que contribui para um alargamento adicional do sinal de RPE. Assim sendo a condição de ressonância não é obtida somente para um único valor do campo externo, mas para um certo intervalo de campo, centrado em torno de um valor de campo denominado campo central $H_{0}$. Esta distribuição, de campos de ressonância, em torno de $H_{0}$ é, em muitos casos, uma função do tipo Lorentziana ou Gaussiana.

Entretanto há outras interações que contribuem para o alargamento ou estreitamento da linha de RPE, resultando em outras formas de linhas dadas por funções do tipo combinações de Gaussianas e Lorentzianas e, no caso de condutores (metais), Dysonianas.

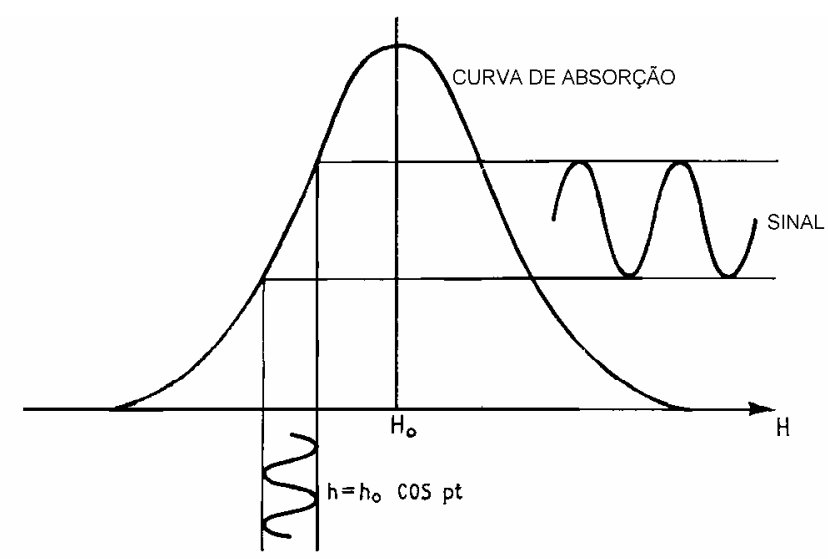

Figura 2 - Modulação do sinal de absorção.

O sinal detectado pelo detector $(D)$, na maioria dos casos, é extremamente ruidoso, e para melhorar a relação sinal/ruído utiliza-se uma técnica chamada detecção sensível à fase. Esta técnica é implementada com o auxílio de um amplificador "lock-in” e de uma bobina de modulação de campo. Com o auxílio desta bobina, aplica-se um campo alternado, $h(t)$, paralelo ao campo externo, $H$, de tal forma a produzir pequenas variações no campo $H$. Dessa forma, teremos um sinal da amostra que oscila na mesma freqüência do campo de modulação (ver Figura 2), resultando assim em um sinal alternado na saída do detector. Este sinal alternado é fornecido a um amplificador “lock-in”, cuja referência é o próprio sinal de modulação, que por sua vez 
fornece, em sua saída, um sinal com um nível de ruído bem mais baixo, e que corresponde à derivada do sinal que seria obtido sem a modulação.

Na Figura 3a são mostradas as curvas das componentes de absorção, $\chi^{\prime \prime}(\omega)$, (resultado da mudança no fator de qualidade da cavidade) e dispersão, $\chi^{\prime}(\omega)$, (resultado da mudança na freqüência da cavidade) da susceptibilidade magnética. Na maioria dos espectrômetros mede-se apenas a componente de absorção, e o valor da susceptibilidade estática $\chi_{0}$ pode ser calculado, a menos de um fator de calibração, através da área da curva de absorção mostrada na Figura 3a. Como o sinal de RPE medido é a derivada da curva de absorção, então o valor de $\chi_{0}$ será dado pela dupla integração do sinal de RPE, mostrado na Figura 3b.

a)

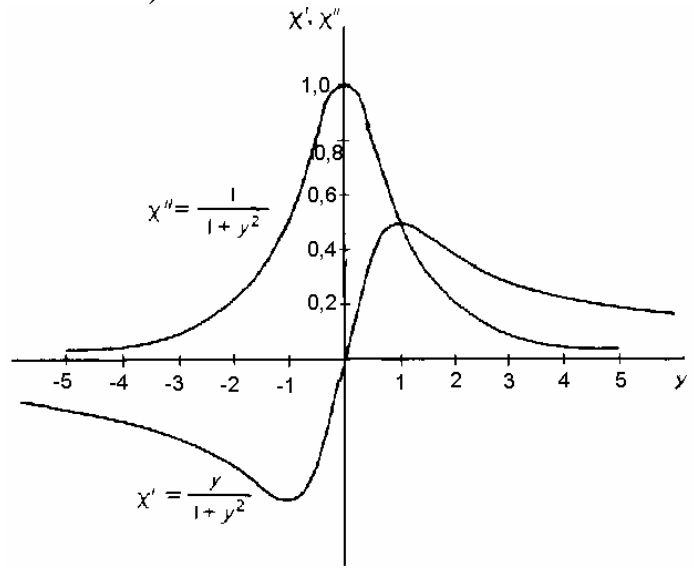

b)

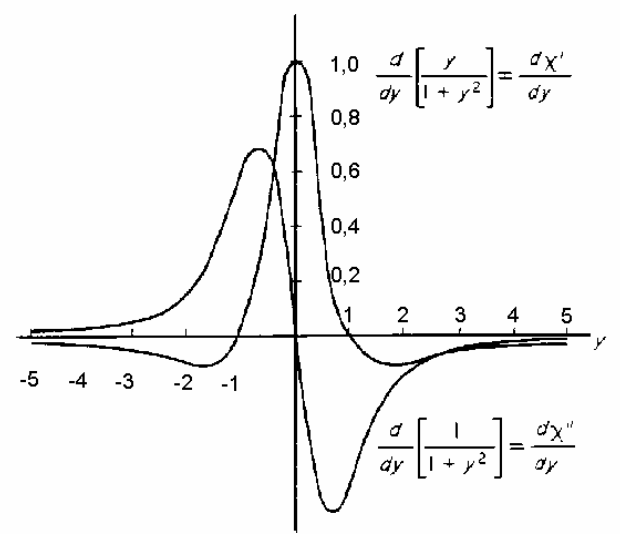

Figura 3 - Componentes de absorção e dispersão da susceptibilidade magnética (a) e suas derivadas (b), as quais são o que se mede no espectrômetro de RPE. Onde $y=T_{2}\left(\omega-\omega_{0}\right)=2\left(H-H_{0}\right) / \Delta H_{1 / 2}$

Após um cálculo teórico da área de uma função Lorentziana, observamos que esta área pode ser obtida também através de alguns parâmetros de sua derivada. Medindo-se, como mostra a Figura 4, a largura $\left(\Delta H_{p p}\right)$ e a amplitude $\left(A_{p p}=y_{m_{1}}^{\prime}+y_{m_{2}}^{\prime}\right)$ pico a pico de uma linha de RPE Lorentziana, podemos obter a área (I) da absorção através da seguinte relação:

$$
I=\frac{\pi}{\sqrt{3}} A_{p p} \Delta H_{p p}^{2}
$$


Para linhas gaussianas e lorentzianas, pode-se obter um valor proporcional a $\chi$, através do produto da amplitude pelo quadrado da largura de linha do sinal de RPE.

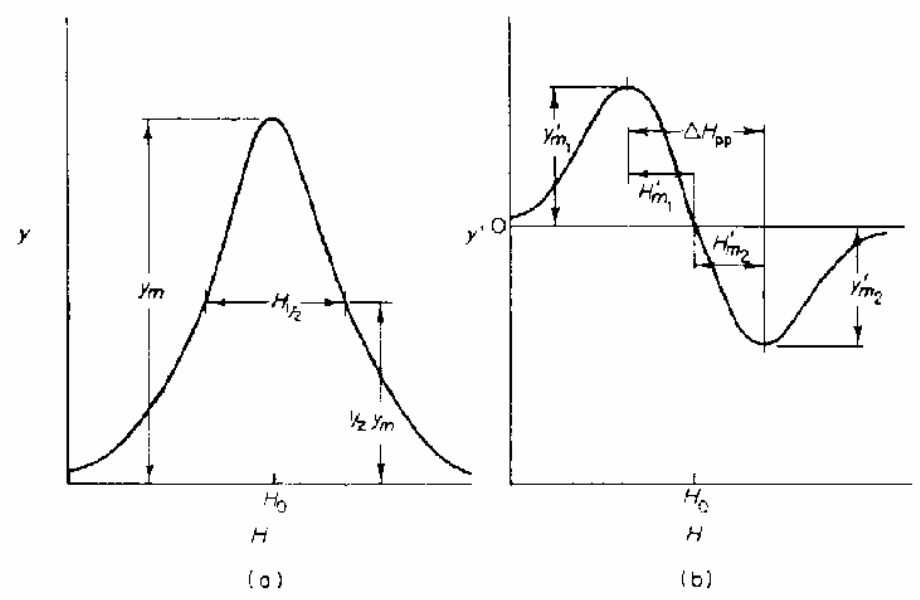

Figura 4 - Definições das larguras $H_{1 / 2}$ e $\Delta H_{p p}$ e amplitudes para a linha de absorção (a) e sua derivada (b)

A realização de experimentos de RPE onde se necessita comparar intensidades de espectros, de amostras diferentes, ou variar temperatura, é muito problemática. Alterações ocorridas na sintonia do espectrômetro de RPE contribuem para mudanças nas intensidades dos espectros. Estas alterações impossibilitam comparações confiáveis entre intensidades de espectros registrados em temperaturas, ou amostras, diferentes. Para evitar erros nestas comparações, coloca-se dentro da cavidade ressonante, junto a amostra a ser estudada, uma outra amostra cujo espectro é conhecido. Desta forma, pode-se minimizar esse tipo erro normalizando a intensidade integrada do sinal da amostra que se deseja estudar $(I)$ pela do padrão $\left(I_{0}\right)$, ou seja $I / I_{0}$.

Em nossos experimentos utilizou se o rubi $\left(\mathrm{Al}_{2} \mathrm{O}_{3}: \mathrm{Cr}^{3+}\right)$ como amostra padrão. Este padrão foi colocado no interior da cavidade ressonante, porém, como mostra a Figura 5, em uma região externa ao sistema de resfriamento da amostra.

O sistema de resfriamento, da amostra, utilizado é um equipamento comercial, destinado especialmente para experimentos de RPE e RMN, cujo acoplamento com a cavidade de RPE é mostrado na Figura 5. Este equipamento, denominado "Helitran”, é o mesmo sistema utilizado no susceptômetro AC, e que será 
melhor discutido no capítulo 3. Por este motivo deixou-se a descrição, deste sistema ${ }^{{ }^{\beta}}$, reservada apenas ao capítulo destinado à descrição do susceptômetro. O fluxo de Nitrogênio seco é necessário para evitar o acúmulo de umidade no interior da cavidade.

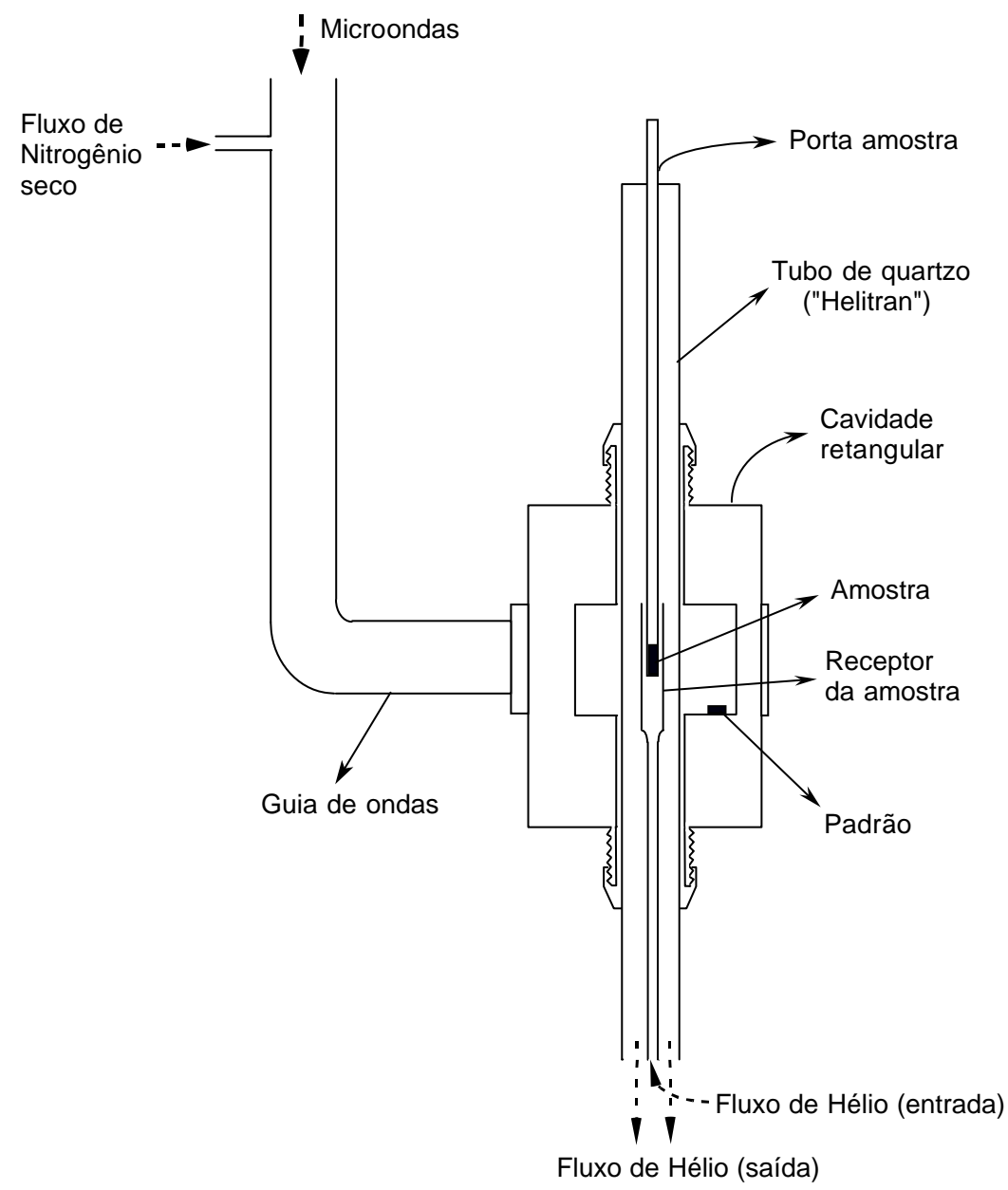

Figura 5 - Desenho esquemático da cavidade (de RPE) retangular acoplada ao tubo, de quartzo, do "Helitran". Nesta figura é mostrado também o posicionamento da amostra e do padrão.

\section{2 - Ressonância Magnética Nuclear (RMN)}

O espectrômetro de RMN utilizado, pode ser dividido em duas partes: uma composta dos circuitos de transmissão e recepção de Rádio Freqüência (RF); e

\footnotetext{
Uma melhor descrição do "Helitran", e detalhes de seu funcionamento e montagem, podem ser obtidas nas referências [5] e [15].
} 
outra composta dos circuitos de controle, aquisição e processamento de dados. Na Figura 6 é mostrado o diagrama em blocos deste espectrômetro ${ }^{\star}$.

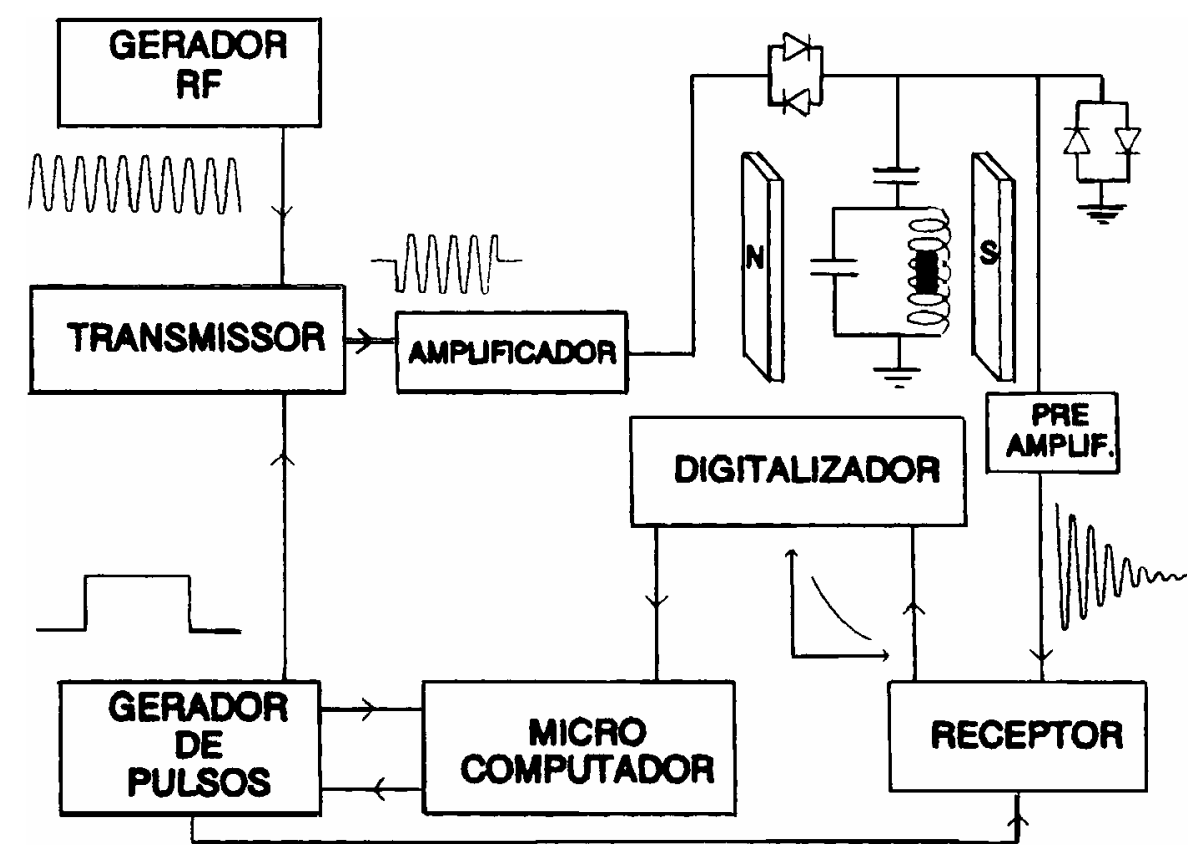

Figura 6 - Diagrama em blocos do Espectrômetro de RMN.

O magneto resistivo, utilizado por este espectrômetro, possui um espaçamanto útil entre as peças polares (“Gap”) de aproximadamente $5 \mathrm{~cm}$, e gera um campo magnético estático entre 0 e 20 kG.

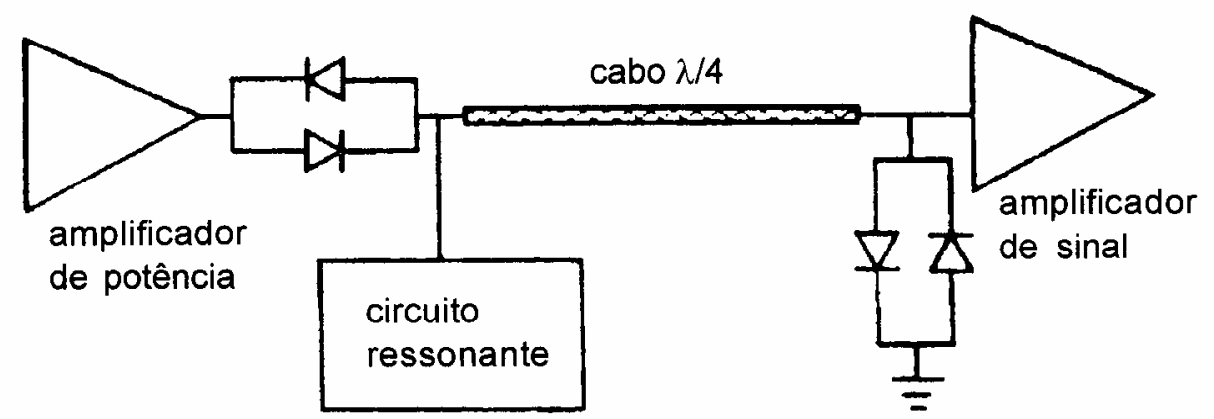

Figura 7 - Diagrama de um circuito de proteção utilizando cabo de quarto de onda e diodos de chaveamento.

\footnotetext{
^ Maiores detalhes deste espectrômetro podem ser obtidos nas referências [16] e [17].
} 
O receptor tem um primeiro estágio amplificador de baixo nível e baixa figura de ruído que está conectado diretamente ao circuito ressonante (ou sonda) conforme mostra a Figura 7. Durante o pulso de excitação, a potência de RF aplicada pelo transmissor pode chegar a picos de centenas de Watts, o que seguramente pode destruir os estágios de baixo nível do receptor. Para evitar este problema é incluído entre o circuito ressonante e o receptor, um circuito de proteção.

Tipicamente o princípio de operação deste circuito assemelha-se a uma chave, que deve ser aberta no momento da aplicação do pulso de RF e que, imediatamente após a finalização deste, seja fechada, para permitir a passagem do sinal de RMN para o receptor.

Os tempos de chaveamento, para as aplicações em RMN, são da ordem de microssegundos, e a possibilidade de chaveamento mecânico fica descartada. Porém, tanto a literatura em geral quanto a especializada para $\mathrm{RMN}^{[18]}$, fornecem sugestões de natureza eletrônica para “desconectar” o receptor no momento da aplicação de potência em sua entrada.

As soluções mais comuns utilizam as propriedades dos cabos coaxiais de quarto de onda para circuitos de detecção com uma única bobina, como é ilustrado na Figura 7. Esta linha de transmissão, de um quarto de onda ( $\lambda / 4)$, apresenta uma propriedade elétrica de grande importância em trabalhos práticos. Ela produz uma inversão da impedância elétrica presente em um de seus extremos ${ }^{[19]}$.

Observando a Figura 7, vê-se a presença de um conjunto de diodos cruzados em paralelo com a entrada do receptor, e um outro conjunto em série com a saída do amplificador de potência. Na condição onde o amplificador aplica potência, a tensão no circuito aumenta e a barreira de potencial dos diodos em série é vencida, aparecendo um sinal no circuito ressonante e numa das extremidades do cabo. A presença deste sinal no cabo faz com que os diodos que ficam em paralelo com a entrada do receptor também entrem em condução. Neste instante aparece, para o sinal de RF, uma baixa impedância para o terra neste ponto e, pela propriedade do cabo de quarto de onda aparecerá no outro extremo uma impedância alta, que está em paralelo com a sonda. Portanto, praticamente toda a potência do amplificador irá para a sonda, a menos de uma pequena parte que será necessária para manter os diodos em condução. Quando o amplificador para de aplicar potência, os diodos deixam de conduzir e o 
circuito da sonda fica conectado diretamente à entrada do amplificador de sinal. Este é um circuito típico para aplicações em RMN, é simples e fácil de construir e sintonizar, porém tem suas limitações quanto a trabalhar em freqüências baixas, devido ao comprimento excessivo do cabo nessas freqüências (quanto menor a freqüência mais longo deverá ser o cabo).

Ao aplicar-se um pulso de $\mathrm{RF}$, de $\pi / 2$, com uma freqüência, $v_{0}$, coincidente com a freqüência de Larmor, $v_{L}$, dos spins nucleares da amostra, a magnetização gira ao plano transversal (xy). Após a interrupção do pulso, observa se o retorno da magnetização, para a situação de equilíbrio. A projeção desta magnetização no plano xy, responsável pelo sinal detectado, decai à zero com um tempo de relaxação efetivo $T_{2}^{*}$, determinado pelo tempo de relaxação spin-spin, $T_{2}$, e pela não homogeneidade do campo magnético. Esse sinal detectado é denominado de Decaimento livre da Indução, que é abreviadamente conhecido por FID ("Free Induction Decay”). Entretanto, se a freqüência do pulso de $\pi / 2$ for um pouco diferente da freqüência de Larmor $\left(v_{0} \neq v_{L}\right)$, estão o FID, como mostra a Figura 8, aparecerá modulado em freqüência $\left|v_{0}-v_{L}\right|$.

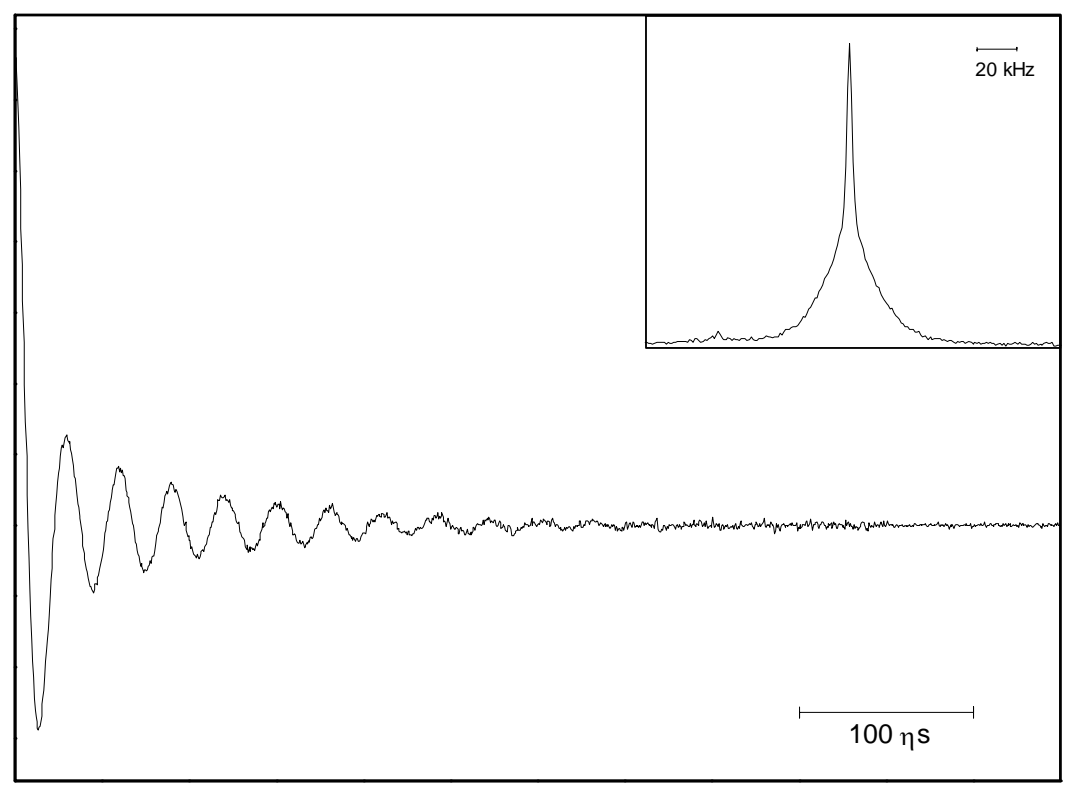

Figura 8 - Livre Decaimento da Indução (FID) e, na figura interna, sua Transformada de Fourier para o domínio de freqüências. 
$T_{2}^{*}$ representa apenas a perda de coerência, distribuição aleatória, dos spins. A magnetização retornará, realmente, a situação de equilíbrio após transcorrer um tempo, maior que $T_{2}^{\star}$, necessário para haver transferência de energia do sistema de spins para a rede. Este tempo é designado por tempo de relaxação spin-rede, $T_{1}$.

A determinação do tempo de relaxação efetivo, $T_{2}^{*}$, pode ser realizada diretamente da largura de linha da Transformada de Fourier do FID, $\Delta v_{1 / 2}=1 / \pi T_{2}^{*}$, mostrada na parte interna da Figura 8. Entretanto, para a medida do tempo de relaxação spin-rede, $T_{1}$, devem ser utilizados processos indiretos, dentre os quais destacamos os métodos de saturação progressiva, inversão-recuperação e saturação-recuperação.

O procedimento utilizado no método de saturação-recuperação está esquematizado na Figura 9. Este método, utilizado neste trabalho, consiste na aplicação de um conjunto de pulsos próximos de $90^{\circ}(\pi / 2)$, formando um “pente”, que leva a magnetização a zero (saturação do sinal). Feito isto, aplica-se um pulso de $90^{\circ}(\pi / 2)$ para monitorar a recuperação da magnetização. Após a aquisição do FID (decaimento livre da indução), aguarda-se um certo intervalo de tempo e o processo é repetido variando o tempo de espera, entre o "pente" de pulsos e o pulso de monitoramento, e acompanhando o retorno da magnetização ao equilíbrio. O intervalo de tempo que se deve aguardar, entre duas repetições concecutivas, é da ordem de sete vezes o tempo de relaxação $T_{1}$.

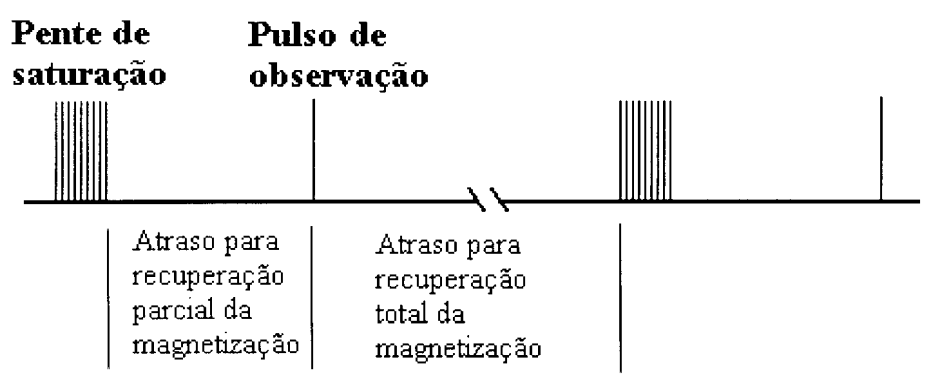

Figura 9 - Representação esquemática do conjunto de pulsos utilizados no método de saturação-recuperação.

Após a aquisição dos FIDs, calcula-se a Transformada de Fourier de cada um (ver Figura 10), e faz-se um gráfico de suas intensidades integradas (áreas) em função do tempo de espera (gráfico interno da Figura 10). Este gráfico é então ajustado 
por uma, ou mais, funções exponenciais, em cujos parâmetros estão contidos o tempo de relaxação spin-rede $\left(T_{1}\right)$.

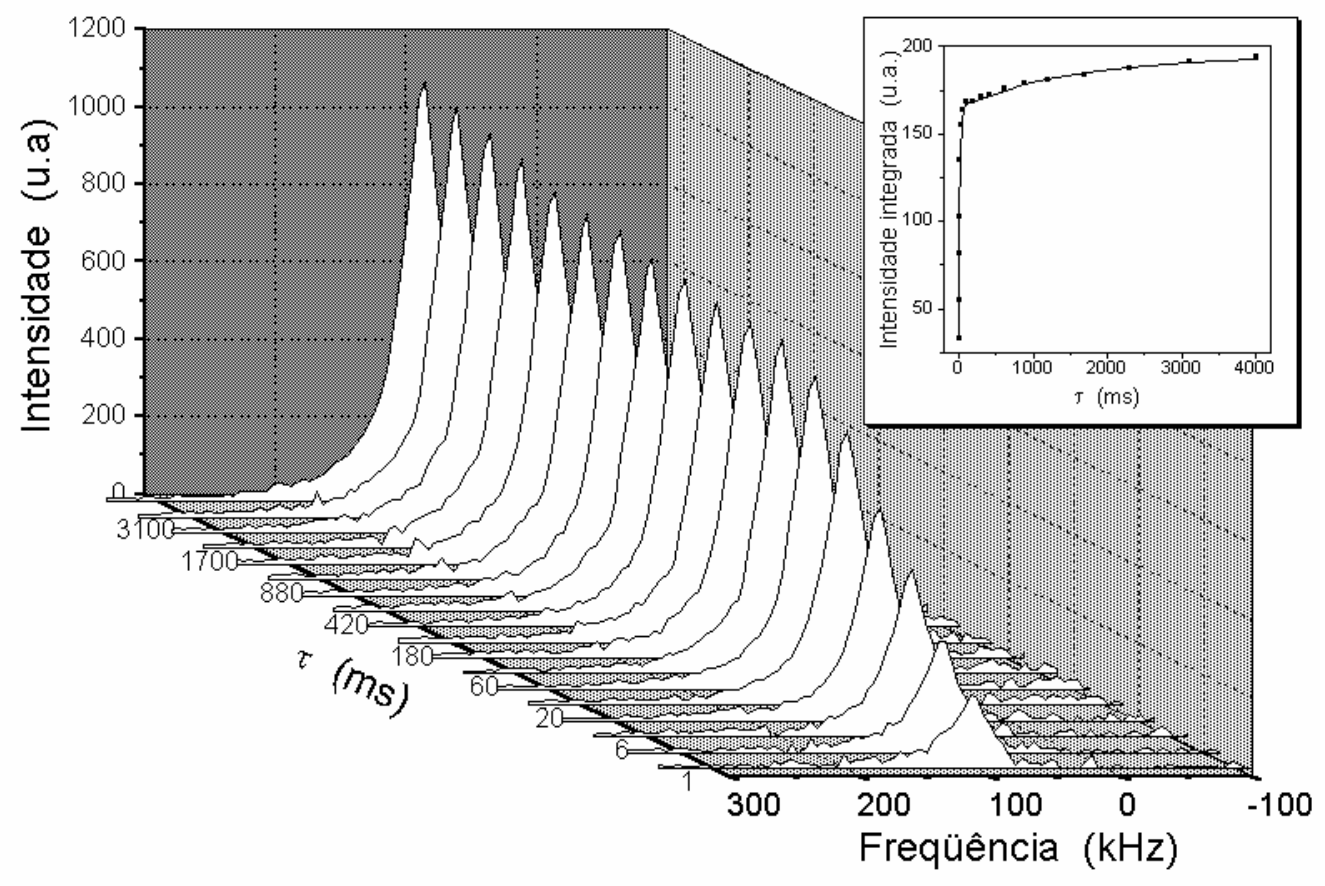

Figura 10 - Transformadas de Fourier de um conjunto de FIDs adquiridos durante a recuperação da magnetização de uma amostra. O gráfico interno mostra as intensidades integradas, das Transformadas de Fourier dos FIDs, em função do tempo de separação, $\tau$, entre o "pente” de saturação e o pulso de monitoramento.

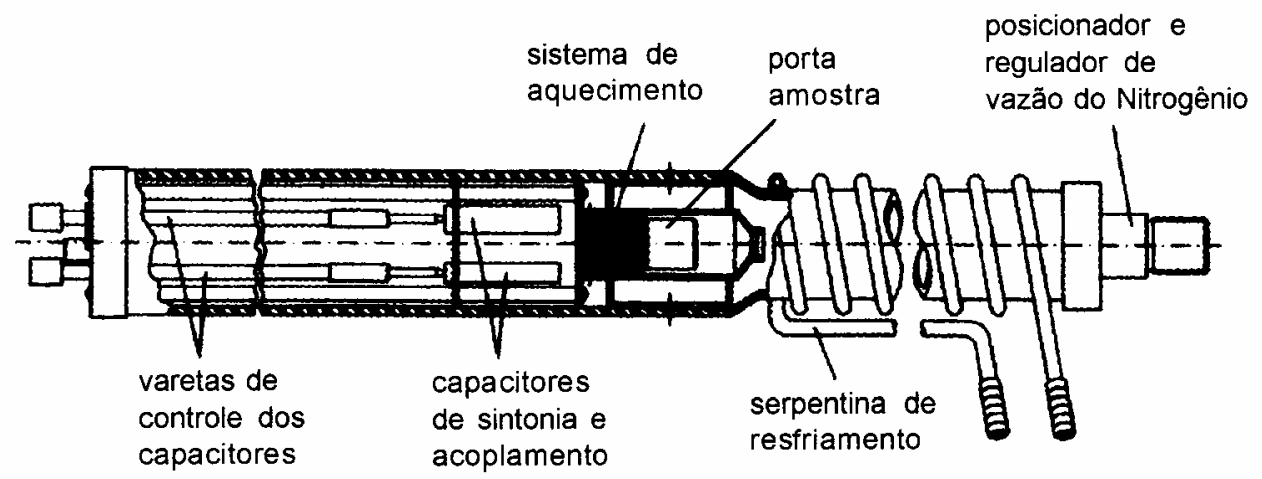

Figura 11 - Sistema de Baixas Temperaturas.

Em nossos experimentos, as medidas de tempos de relaxação spin-rede foram realizadas em temperaturas entre $77 \mathrm{~K}$ e $323 \mathrm{~K}$. Para isto utilizou-se um sistema 
de baixas temperaturas, desenvolvido em nosso laboratório, que pode ser operado em temperaturas na faixa de $77 \mathrm{~K}$ a $393 \mathrm{~K}$. Este sistema, como mostra a Figura 11, faz com que um fluxo frio de $\mathrm{N}_{2}$ seja conduzido através de uma linha de transferência em direção ao "probe”. Este fluxo, mantido constante, é controlado por uma válvula de agulha localizada entre a linha de transferência e o "probe”. Junto ao porta amostra há um sensor de temperatura e uma resistência elétrica utilizada como fonte quente. $\mathrm{O}$ ajuste da temperatura na amostra é realizado por um controlador de temperatura, do tipo PID, que controla a corrente elétrica aplicada à resistência elétrica da fonte quente.

\section{3 - Programa de controle, aquisição e análise dados}

Os softwares para controle, aquisição e análise de dados dos espectrometros de RPE e RMN foram desenvolvidos, em nosso laboratório, em linguagem C. Estes softwares possuem uma interface com o usuário de fácil comunicação.

O software para o espectrômetro de RPE, denominado EPR ("Electron Paramagnetic Resonance”). Além das funções de controle e aquisição do espectrômetro, este sofware possibilita também a análise dos resultados, com rotinas que realizam, entre outras funções, a integração numérica, correção de linha de base e ajuste dos espectros com funções, ou combinação de funções, conhecidas.

O software para o espectrômetro de RMN compõe-se de dois programas principais: PSP e NMR. O módulo PSP (“pulse sequence program”) realiza o controle do espectrômetro, gerando as diversas sequências de pulsos, e aquisição de dados. O módulo NMR ("Nuclear Magnetic Resonance”) é utilizado para análise dos dados, adquiridos pelo PSP, através de diversas ferramentas úteis, tais como: "Fast Fourier Transform” (FFT); correção de linha de base; preenchimento com zeros; correção de fase; predição linear do tempo morto; deslocamento de freqüência; ajuste por mínimos quadrados com as funções de sua biblioteca.

Estes softwares não estão, ainda, completamente finalizados. Eles têm sido constantemente aprimorados a fim de serem aplicáveis a todos os diferentes tipos de experimentos realizados em nosso laboratório. 


\section{3 - SUSCEPTÔMETRO AC AUTO-BALANCEADO}

Com desenvolvimento dos supercondutores de alto $T_{c}$, houve um grande aumento na pesquisa e desenvolvimento de equipamentos para medir a susceptibilidade magnética AC. Surgiram assim, novos equipamentos com maior sensibilidade e facilidade na aquisição de dados, passando então de equipamentos manuais (onde eram utilizados transformadores e indutores mútuos variáveis) para equipamentos cada vez mais automatizados e controlados por microcomputadores.

Uma análise da susceptibilidade complexa pode fornecer informações acerca dos processos de relaxação que podem estar ocorrendo no sistema em estudo. Por exemplo, ela é usada para estudar fenômenos de relaxação spin-rede em compostos paramagnéticos, movimento dos domínios em sistemas metamagnéticos, e tem contribuído para um melhor entendimento de sistemas “spin-glass” e na determinação da qualidade de supercondutores de alto $\mathrm{T}_{\mathrm{c}}$.

Neste capítulo é descrito a construção e automação de um susceptômetro para medidas de susceptibilidade magnética AC. O principal objetivo desta construção foi acrescentar ao nosso laboratório uma nova técnica, de medida da susceptibilidade magnética ${ }^{[20-22]}$, que complementasse às técnicas já existentes, de ressonância magnética eletrônica e nuclear.

O método usual de medida de susceptibilidade magnética AC utiliza uma ponte de indutâncias mútuas, cuja forma básica foi primeiro introduzida por Hartshort ${ }^{[23]}$. A amostra é situada no interior de uma bobina secundária de um transformador, em que o secundário é um gradiômetro de primeira ordem, consistindo de dois solenóides, enrolados em direções opostas. Todas as bobinas são geralmente do tipo solenoidal, e a bobina primária é enrolada externamente a secundária. A indutância mútua entre as bobinas primária e secundária é idealmente nula quando nenhuma amostra está situada no interior 
das bobinas. Quando uma amostra é introduzida no interior de um dos enrolamentos secundário, ela induz uma fem no circuito secundário que depende da magnetização da amostra, e portanto da susceptibilidade magnética da amostra.

Vários tipos diferentes de conjuntos de bobinas ("probe”) e circuitos eletrônicos foram apresentados na literatura, e a escolha da melhor configuração, em cada caso, baseia-se principalmente nas condições experimentais tais como a variação de temperatura, tipo de amostra, limitações no tamanho do "probe”, entre outras. Mas todos eles têm duas características em comum: em primeiro lugar o anseio por alta sensibilidade, precisão e automação; em segundo, o “probe”, em todos sistemas vistos até o momento, é fixo e um mecanismo de movimento da amostra possibilita situá-la no centro de cada uma das bobinas secundárias. O valor absoluto da susceptibilidade pode ser medido balanceando a ponte com a amostra situada em cada uma das bobinas secundárias, e verificando seu correspondente sinal de compensação em ambas situações. Em vários casos, o sistema de bobinas é imerso em nitrogênio ou hélio líquido a fim de se obter estabilidade térmica e diminuição da resistência ôhmica das bobinas secundárias. Nestes casos necessitam-se de um criostato com um grande espaço para acomodar a amostra e ambas bobinas primária e secundária.

No presente trabalho a ponte de indutâncias mútuas utilizada segue as características das pontes eletrônicas descritas na literatura. Já o "probe” utilizado tem inovações originais ${ }^{[6]}$. O sistema de resfriamento da amostra utilizado é um "helitran", que é desenhado especificamente para experimentos de RPE em baixas temperaturas. Este tipo de sistema é muito útil, principalmente devido a sua simplicidade, fácil operação, baixo consumo de Hélio e pela facilidade de trocar a amostra. Contudo, devido ao fluxo de Hélio, a amostra é situada em uma região de grande gradiente de temperatura. Isto produz uma certa incerteza na leitura da temperatura, mas o principal problema é o movimento da amostra que causaria uma grande variação em sua temperatura. Devido a este fato, o movimento da amostra, citado anteriormente, não pode ser realizado.

Por esse motivo uma solução inovadora foi proposta: como o movimento da amostra não é possível, por que não movimentar o “probe”? Nossa primeira impressão acerca deste movimento foi que “ele não iria funcionar”. A razão é simples: correntes induzidas em algum metal na vizinhança do “probe” e, particularmente, momentos magnéticos induzidos em materiais magnéticos próximos, produzirão campos magnéticos de volta nas bobinas secundárias, mascarando o sinal da susceptibilidade da amostra. 
Contudo, após um cuidadoso projeto, construimos um "probe" com uma eficiente blindagem magnética, para minimizar as interações com os materiais próximos.

Este sistema, descrito a seguir, já foi utilizado, com sucesso, em diversos experimentos e tipos de amostras, tais como supercondutores de alto $T_{c}$ (Apêndice), compostos intermetálicos (Capítulo 4) e polímeros condutores eletrônicos (Capítulos 5 e $6)$.

\section{1 - Técnica de medida AC e DC}

Ambas técnicas AC e DC são importantes, fornecendo meios diferentes para o entendimento das propriedades magnéticas dos materiais ${ }^{[24-28]}$. A principal diferença entre as técnicas AC e DC decorre do fato da técnica DC fornecer o momento magnético total de uma amostra, $m$, medido em um particular campo magnético DC aplicado, $H_{D C}$, enquanto que na técnica $\mathrm{AC}$ são medidas as variações no momento magnético, ou seja $\Delta m$. Portanto, a susceptibilidade magnética $\mathrm{AC}$ fornece uma indicação da declividade $(d m / d H)$ da curva de magnetização.

$$
\begin{aligned}
& D C: \quad \text { Sinal } \propto M\left(H_{D C}\right) \\
& \text { AC: } \quad \text { Sinal } \propto\left(\frac{d M}{d H}\right)_{H=H_{D C}} H_{A C}
\end{aligned}
$$

onde $M$ (Magnetização da amostra) é o momento magnético total por unidade de volume ( $M=m / v_{s}$, sendo $v_{s}$ o volume da amostra) e $H_{A C}$ é o campo de modulação. Nossas medidas de susceptibilidade AC são realizadas com $H_{D C}=0$.

Como a medida AC, em baixa freqüência, fornece a declividade da curva de magnetização, esta técnica pode ser extremamente útil no estudo de materiais desconhecidos, ou sistemas magnéticos não lineares, e também de transições de fase magnética. Qualquer mudança na declividade da curva de magnetização dos materiais será facilmente refletida na susceptibilidade AC do material (ver Figura 12). 


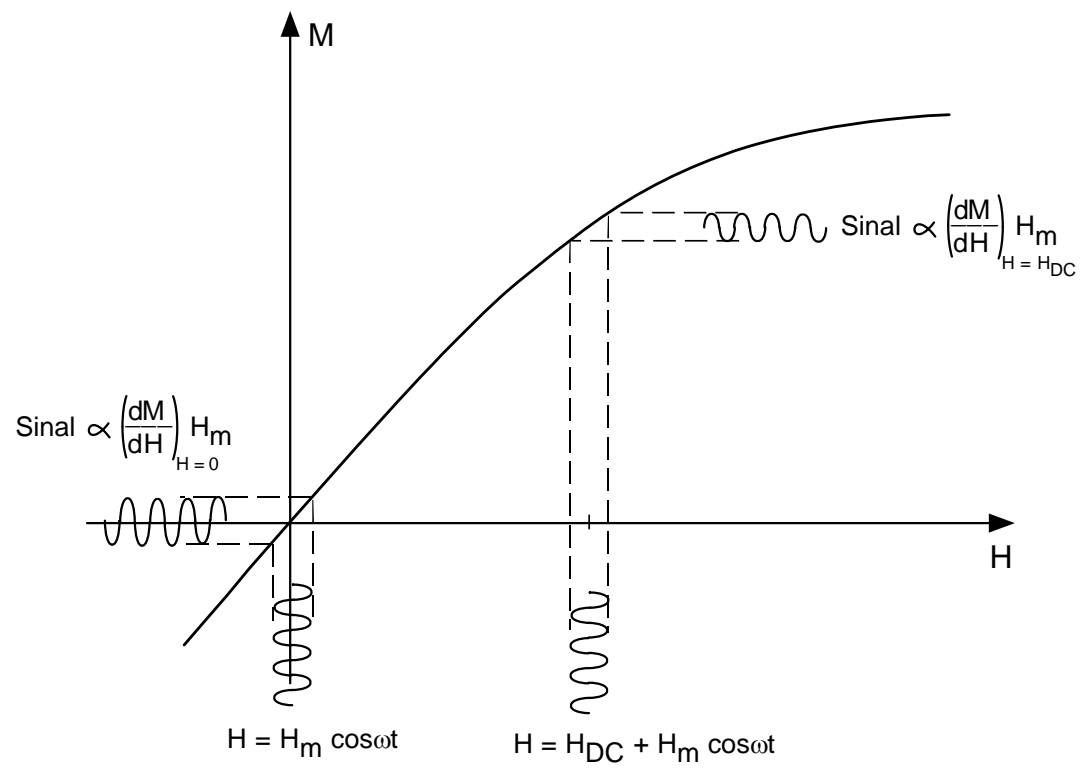

Figura 12 - Diagrama mostrando a diferença entre a susceptibilidade AC obtida com e sem campo DC aplicado.

\section{2 - Susceptibilidade AC ou Complexa}

Em uma medida de magnetização AC, o campo aplicado tem um termo AC com a forma $H_{A C}=H_{0} \cos \omega t$. O momento magnético resultante da amostra devido a este campo AC é dado por $m=m_{0} \cos (\omega t-\theta)$, onde $\theta$ é a diferença de fase entre o campo aplicado e a magnetização. Essa expressão pode também ser escrita como:

$$
m=\chi_{T}^{\prime} H_{0} \cos \omega t+\chi_{T}^{\prime \prime} H_{0} \operatorname{sen} \omega t
$$

onde $\chi_{T}^{\prime}=\left(m_{0} / H_{0}\right) \cos \theta$ e $\chi_{T}^{\prime \prime}=\left(m_{0} / H_{0}\right) \operatorname{sen} \theta$ são, respectivamente, a componente real (ou em fase) e imaginária (ou fora de fase) da susceptibilidade magnética total. Elas combinam para formar a susceptibilidade magnética complexa:

$$
\hat{\chi}_{T}=\chi_{T}^{\prime}-j \chi_{T}^{\prime \prime}
$$

onde, $\chi_{T}^{\prime}$ é uma medida da fração do momento magnético induzido, que consegue acompanhar, simultaneamente, a oscilação do campo magnético aplicado, e $\chi_{T}^{\prime \prime}$ é uma medida das perdas dissipativas ocorridas no sistema magnético em estudo, ou seja, é uma medida da energia absorvida, do campo magnético, pela amostra. 
A susceptibilidade magnética total, $\chi_{T}$, é uma medida de quanto magnético é o material, e representa a resposta do material a um campo magnético, $H$, aplicado. Seu valor é dado pela razão entre o momento magnético total e o campo aplicado, $\chi_{T}=m / H$. Entretanto, com a finalidade de comparar diferentes materiais, ou amostras de diferentes tamanhos, a quantidade macroscópica de interesse é a magnetização, ou momento magnético total por unidade de volume, $M=m / v_{s}$. A partir desta magnetização, determina-se a susceptibilidade magnética por unidade de volume, ou simplesmente susceptibilidade volumétrica:

$$
\chi_{V}=\frac{\chi_{T}}{v_{s}}=\frac{m}{H V}=\frac{M}{H}
$$

A susceptibilidade magnética pode ser também fornecida em unidades de massa, $\chi_{m}$, denominada susceptibilidade mássica ou susceptibilidade de massa, ou em

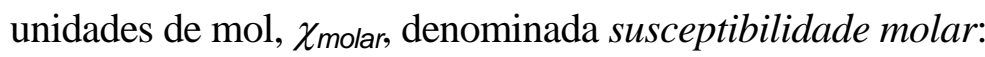

$$
\begin{aligned}
& \chi_{m}=\frac{\chi_{T}}{m_{s}}=\frac{\chi_{V} v_{s}}{m_{s}}=\frac{\chi_{V}}{\rho} \\
& \chi_{\text {molar }}=\frac{\chi_{T}}{n^{\circ} \mathrm{mol}}=\frac{\chi_{T}}{m_{s} / P_{M}}=\frac{\chi_{T}}{m_{s}} P_{M}=\chi_{m} P_{M}=\frac{\chi_{V}}{\rho} P_{M}
\end{aligned}
$$

onde $m_{s}$ é a massa da amostra e $\rho=m_{S} V_{s}$ é a densidade do material e $P_{M}$ é o peso molecular do material.

\subsection{1 - Unidades da susceptibilidade magnética}

Ao deparar-se com os textos sobre susceptibilidade magnética o leitor poderá defrontar-se com uma grande confusão no que diz respeito às unidades utilizadas para esta grandeza. A idéia desta seção não é realizar um estudo profundo a respeito das diversas unidades utilizadas para a susceptibilidade magnética, mas sim um breve esclarecimento acerca das unidades utilizadas neste trabalho.

Como visto a partir da Eq. (5) a susceptibilidade magnética volumétrica é uma constante de proporcionalidade entre a magnetização $(M)$ e o campo magnético aplicado $(H)$. Entretanto, no sistema de unidades gaussianas (cgs), estas duas grandezas 
têm a mesma unidade (gauss), o que leva a conclusão que a susceptibilidade volumétrica é uma grandeza adimensional (que é emu/ $\mathrm{cm}^{3}$ ).

Seguindo este mesmo raciocínio obtém-se:

- Susceptibilidade total

- Susceptibilidade volumétrica $\rightarrow v_{s}$ em $\mathrm{cm}^{3}$

- Susceptibilidade mássica

$\rightarrow m_{s}$ em $g$

$\rightarrow P_{M}$ em $\mathrm{g} / \mathrm{mol}$
$\Rightarrow \chi$ em $\mathrm{cm}^{3}$ ou emu

$\Rightarrow \chi \mathrm{em} \mathrm{emu/ \textrm {cm } ^ { 3 }}$

$\Rightarrow \quad \chi \mathrm{em} e \mathrm{mu} / \mathrm{g}$

$\Rightarrow \chi \mathrm{em} \mathrm{emu} / \mathrm{mol}$

\section{3 - Princípio de funcionamento do susceptômetro AC}

O princípio de funcionamento do susceptômetro AC baseia-se na técnica de indutâncias mútuas ${ }^{[5]}$. Este método, como mostra a Figura 13, consiste em colocar uma bobina sonda (bobina secundária) no interior de uma bobina que gera um campo magnético AC (bobina primária). Desta forma ao introduzir-se uma amostra no interior dessa bobina sonda, será induzida uma pequena voltagem adicional, que poderá ser detectada por um voltímetro ligado aos terminais desta bobina.

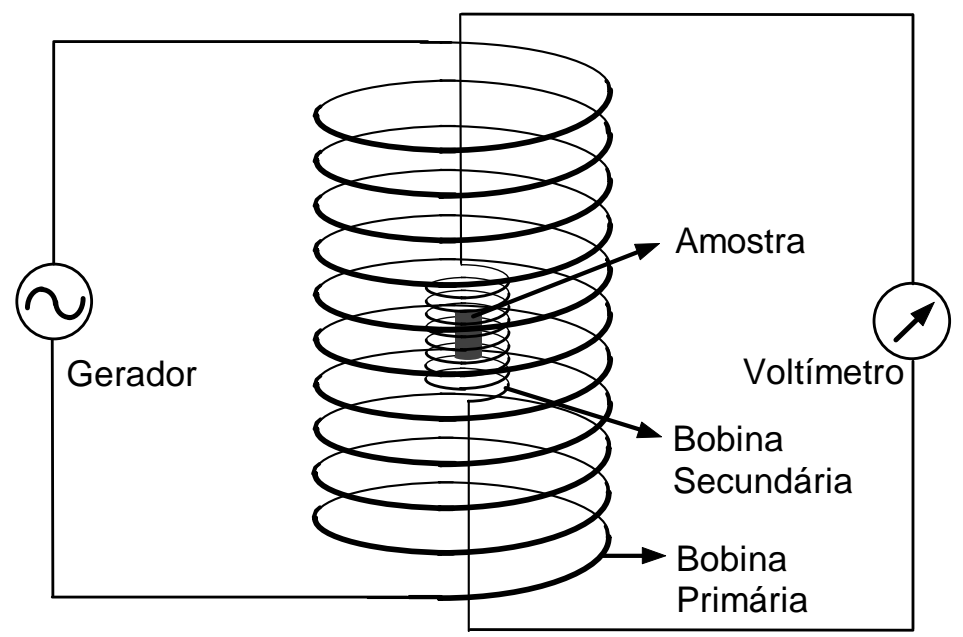

Figura 13 - Exemplo do método de indutâncias mútuas utilizando uma bobina secundária simples.

A voltagem medida pelo voltímetro será o resultado da soma da voltagem induzida, na bobina sonda, sem amostra $\left(V_{s}=j \omega M_{0} I_{P}\right)$ e a voltagem devido a amostra $\left(\Delta V=j \omega M_{0} 4 \pi \eta \hat{\chi}_{V} I_{P}\right):$ 


$$
V=V_{s}+\Delta V
$$

onde $M_{0}$ é a indutância mútua entre as bobinas primária e secundária, $I_{P}$ é a corrente elétrica na bobina primária e $\omega$ sua freqüência angular, e $\eta$ é o fator de preenchimento, que, em primeira aproximação, pode ser determinado pela razão entre os volumes da amostra e da bobina secundária $\left(\eta=v_{S} / v\right)$.

Entretanto, há um grande problema que impossibilita a medida do sinal da amostra através desta montagem simples (ver Figura 13). Este problema consiste no fato da voltagem induzida na bobina secundária, sem amostra, $\left(V_{s}\right)$ ser muito maior que aquela devido apenas à amostra $(\Delta V)$. Desta forma, não é possível a visualização de praticamente nenhuma deflexão no voltímetro, quando a amostra é introduzida na bobina sonda, impossibilitando assim a medida do sinal da amostra.

Para solucionar este problema, sugere-se a colocação de uma outra bobina secundária no interior da primária (ver Figura 14) conectada em série com a anterior. Esta segunda bobina secundária é construída com as mesmas dimensões e o mesmo número de espiras que a anterior, porém enrolada em sentido oposto. Assim sendo, a voltagem induzida nas bobinas secundárias (na ausência da amostra) são de mesma amplitude, porém defasadas de $180^{\circ}$. Ou seja, enquanto em uma das bobinas secundárias é induzida uma voltagem $V_{s}^{(1)}$ na outra é induzida uma voltagem $V_{s}^{(2)}=-V_{s}^{(1)}$.

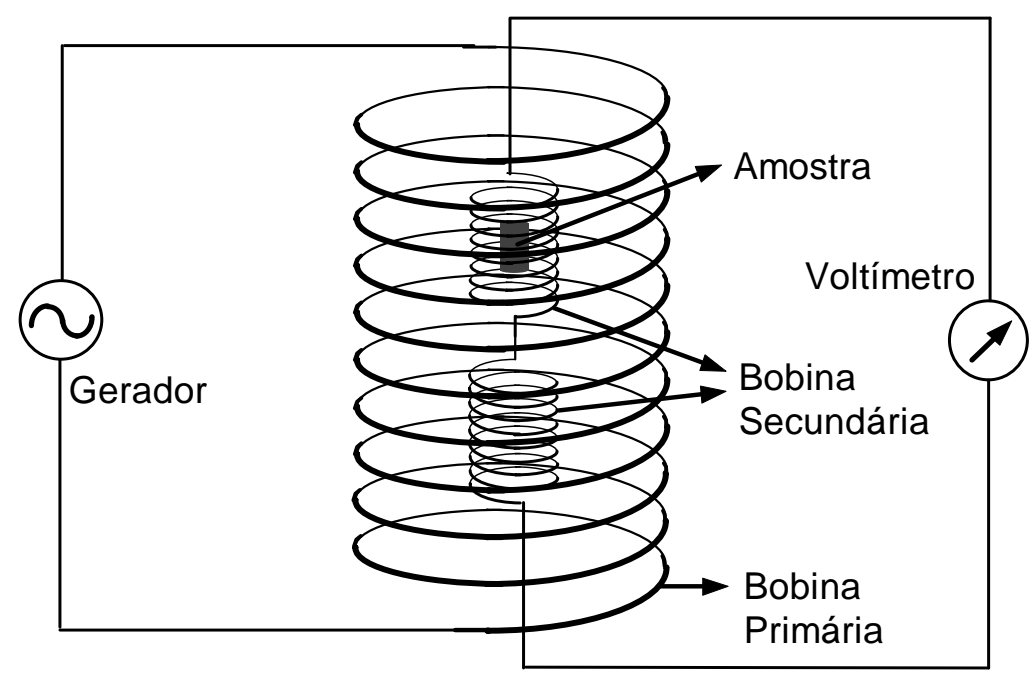

Figura 14 - Exemplo do método de indutâncias mútuas utilizando uma bobina secundária com dois enrolamentos. 
Em um caso ideal, ao ligar-se essas duas bobinas secundárias (sem amostra) em série, não é observada nenhuma indicação no voltímetro. Desta forma, ao introduzir-se a amostra, em uma das bobinas secundária, é observada uma pequena indicação no voltímetro, a qual é devido, apenas, ao sinal da amostra: $\Delta V=j \omega M_{1} 4 \pi \eta \hat{\chi}_{V} I_{P}$, onde $M_{1}$ é a indutância mútua entre a bobina primária e a bobina secundária na qual introduziu-se a amostra.

Entretanto, a construção de duas bobinas idênticas envolve parâmetros demasiadamente complexos, dentre eles destaca-se: o posicionamento exato de cada uma das espiras em relação as demais e as pequenas irregularidades nos fios utilizados. Estas complexidades tornam impraticável a construção de duas bobinas secundárias idênticas. Em conseqüência deste fato, as voltagens induzidas em cada uma das bobinas secundárias, sem amostra, não serão exatamente de mesma amplitude. Ou seja, mesmo na ausência da amostra, o voltímetro continuará indicando uma pequena voltagem $\left(V_{s}\right)$ que, por mais que se tente igualar as duas bobinas, será maior que a voltagem devido ao sinal da maioria das amostras $(\Delta V)$. Em outras palavras, mesmo com esta voltagem remanescente, seria possível a medida da susceptibilidade de amostras cuja magnetização seja grande, porém não seria possível a medida daquelas que apresentassem uma magnetização pequena.

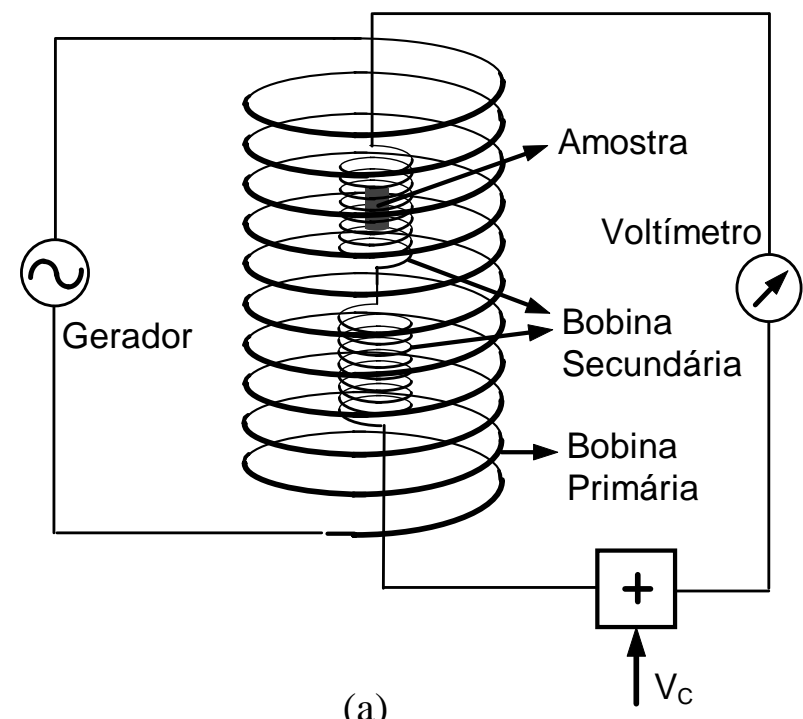

(a)

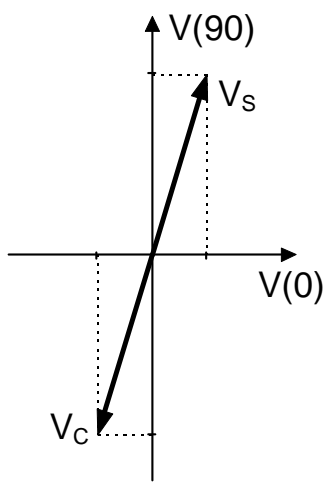

(b)

Figura 15 - Princípio utilizado na medida da susceptibilidade magnética AC: a) exemplo da montagem, b) diagrama da voltagem induzida na bobina secundária $\left(V_{s}\right)$ e daquela utilizada para balancear a ponte de indutâncias mútuas $\left(V_{c}\right)$. 
Assim sendo, para possibilitar a medida da susceptibilidade magnética, tanto de amostras de magnetização grande quanto de magnetização pequena, é necessário que esta voltagem remanescente seja anulada. Ou seja, é necessário o adicionamento de uma voltagem de mesma amplitude, porem defasada de $180^{\circ}$ com relação a voltagem remanescente no circuito secundário (ver Figura 15), resultando assim em um sinal nulo indicado pelo voltímetro. Desta forma, ao introduzir-se a amostra em uma das bobinas secundárias, o sinal indicado pelo voltímetro será exclusivamente devido a magnetização da amostra.

\section{4 - Descrição do Equipamento}

A opção pela construção de um susceptômetro AC e não um DC, foi devido a vários motivos. Dentre eles destaca-se o fato de já se possuir as técnicas de ressonâncias, no Laboratório de Ressonância do IFSC, a qual utiliza campos relativamente altos. Assim seria de grande utilidade a aquisição de uma técnica de baixo campo, que possibilitaria o estudo de materiais, como por exemplo supercondutores de alto $\mathrm{T}_{\mathrm{c}}$, que não podem ser submetidos a altos campos.

A seguir são listadas algumas das principais características do equipamento construído no decorrer deste trabalho:

a) baixo custo;

b) utilização de Conversores Analógico Digital Multiplicativos (DACM) de 12 bit para o balanceamento da ponte de indutâncias mútuas. Estes DACM foram utilizados em substituição aos indutores mútuos variáveis, ou décadas de transformadores, e potenciômetros;

c) ponte continuamente balanceada por meio de uma realimentação que controla o sinal de saída dos DACM;

d) leitura simultânea das componentes real $\left(\chi^{\prime}\right)$ e imaginária $\left(\chi^{\prime \prime}\right)$ da susceptibilidade magnética complexa;

e) manutenção da posição fixa da amostra, e movimento de todo conjunto de bobinas, durante a medida, de tal forma a possibilitar o posicionamento da amostra ora em uma das bobinas secundária ora em outra; 
f) bobinas de medidas mantidas à temperatura ambiente, sem controle de temperatura;

g) variação da temperatura da amostra entre 4,2 e 300 K;

h) variação na freqüência, do campo magnético AC aplicado, desde alguns $\mathrm{Hz}$ até cerca de $800 \mathrm{~Hz}$, com uma defasagem menor que 0,5 grau;

i) variação no campo aplicado desde 0,01 gauss à 16 gauss.

j) sensibilidade pouco inferior à dos equipamentos comerciais $\left(10^{-7} \mathrm{emu}\right)$

Por questões didáticas, dividiremos a descrição do equipamento em duas partes: na primeira parte será descrita a ponte de indutâncias mútuas ${ }^{\star}$, mostrando as inovações realizadas e comparando-a com outras pontes descritas na literatura; na segunda parte será descrito o "probe" utilizado no susceptômetro, mostrando todas as inovações, suas vantagens e desvantagens e explicando os motivos que levaram a optar pelo modelo utilizado em sua construção.

\subsection{1 - Ponte de indutâncias mútuas}

A técnica utilizada no projeto da ponte é muito semelhante àquelas encontradas na literatura ${ }^{[29,30]}$, e que está descrita nesta seção. Esta ponte trabalha essencialmente como um detector de nulo de banda larga e é capaz de medir simultaneamente as duas componentes (em fase e quadratura com o campo magnético AC aplicado) da susceptibilidade magnética complexa, com mesma sensibilidade e precisão. Para isto foi utilizado interfaces padrões, um computador pessoal (PC) para controle da ponte, motor de passo e um controlador de temperatura.

A forma básica da ponte de indutâncias mútuas foi inicialmente introduzida por Hartshorn ${ }^{[23]}$. Desde então várias outras versões de pontes de indutâncias mútuas foram desenvolvidas ${ }^{[31-36]}$. As pontes mais comuns $^{[37]}$ são compostas

\footnotetext{
^ Na divisão que adotamos, a ponte de indutâncias mútuas engloba os circuitos utilizados para gerar corrente e balancear a ponte, e também a parte de controle e aquisição de dados, realizado pelo microcomputador.

• O “probe” é a parte do equipamento, que engloba as bobinas, responsável por captar do sinal da amostra. Este "probe” é inédito, e é nossa principal contribuição para o desenvolvimento de equipamentos para medir a susceptibilidade magnética AC.
} 
basicamente de transformadores e indutores mútuos variáveis (ver Figura 16), os quais são utilizados para balancear o sinal induzido pela amostra na bobina secundária.

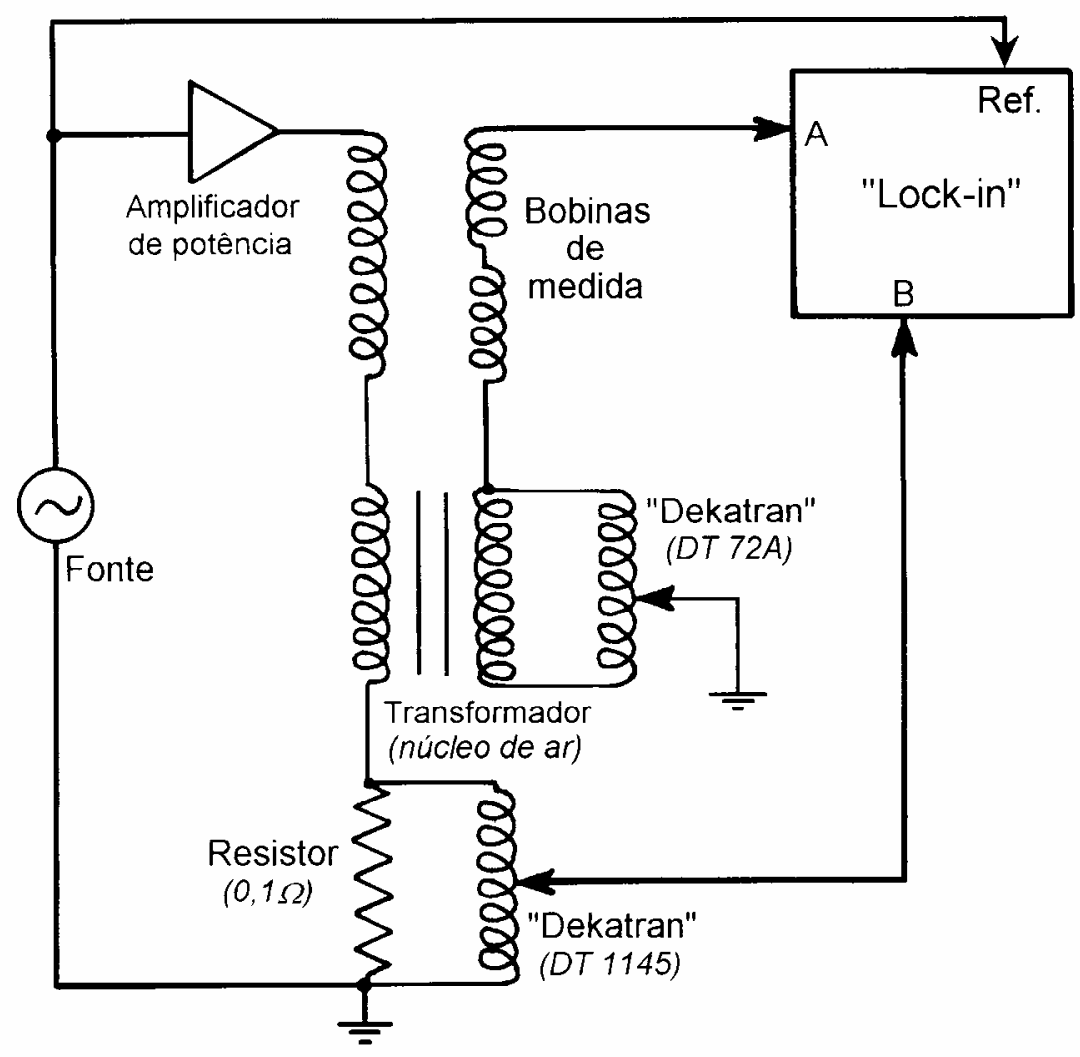

Figura 16 - Primeira versão da ponte de indutâncias mútuas, construída durante o desenvolvimento de minha dissertação de mestrado. DT72A e DT1145 são indutores mútuos variáveis.

Entretanto, esses transformadores e indutores mútuos prossuem acoplamentos capacitivos entre seus enrolamentos primário e secundário e entre as espiras de cada enrolamento. Estes acoplamentos capacitivos, somados com o problema de correntes de fuga através de ponto em comum entre os circuitos primário e secundário, provocam defasagens, que inviabilizam a separação correta entre as componentes real e imaginária da susceptibilidade magnética. Para solucionar estes problemas, a partir da década de 80, foram desenvolvidas novas versões de ponte de indutâncias mútuas, onde os transformadores e indutores foram substituídos por componentes eletrônicos ${ }^{[31-36]}$. Além da vantagem quanto ao problema de defasagem, estas pontes eletrônicas têm também a 
vantagem de serem de baixo custo, de possuírem alta sensibilidade e, principalmente, de facilitar sua automação através de microcomputadores.

Atualmente, praticamente, todas as pontes de indutâncias mútuas descritas na literatura utilizam circuitos eletrônicos e microcomputadores para controle ${ }^{[29,30,34,38]}$. A ponte que descrevemos nesta seção também utiliza circuitos eletrônicos e um microcomputador para controle e aquisição de dados. O circuito eletrônico embora com algumas diferenças daquelas pontes contidas na literatura, segue o mesmo conceito das demais.

A Figura 17 mostra o desenho em blocos da ponte de indutâncias mútuas. Nesta ponte a estabilidade, a sensibilidade e o nível de ruído, bem como o limite superior da freqüência do campo aplicado (da ordem de $1 \mathrm{kHz}$ ), são basicamente determinados pelo conjunto de bobinas primária e secundária, utilizadas, respectivamente, para gerar o campo magnético e medir o sinal da amostra.

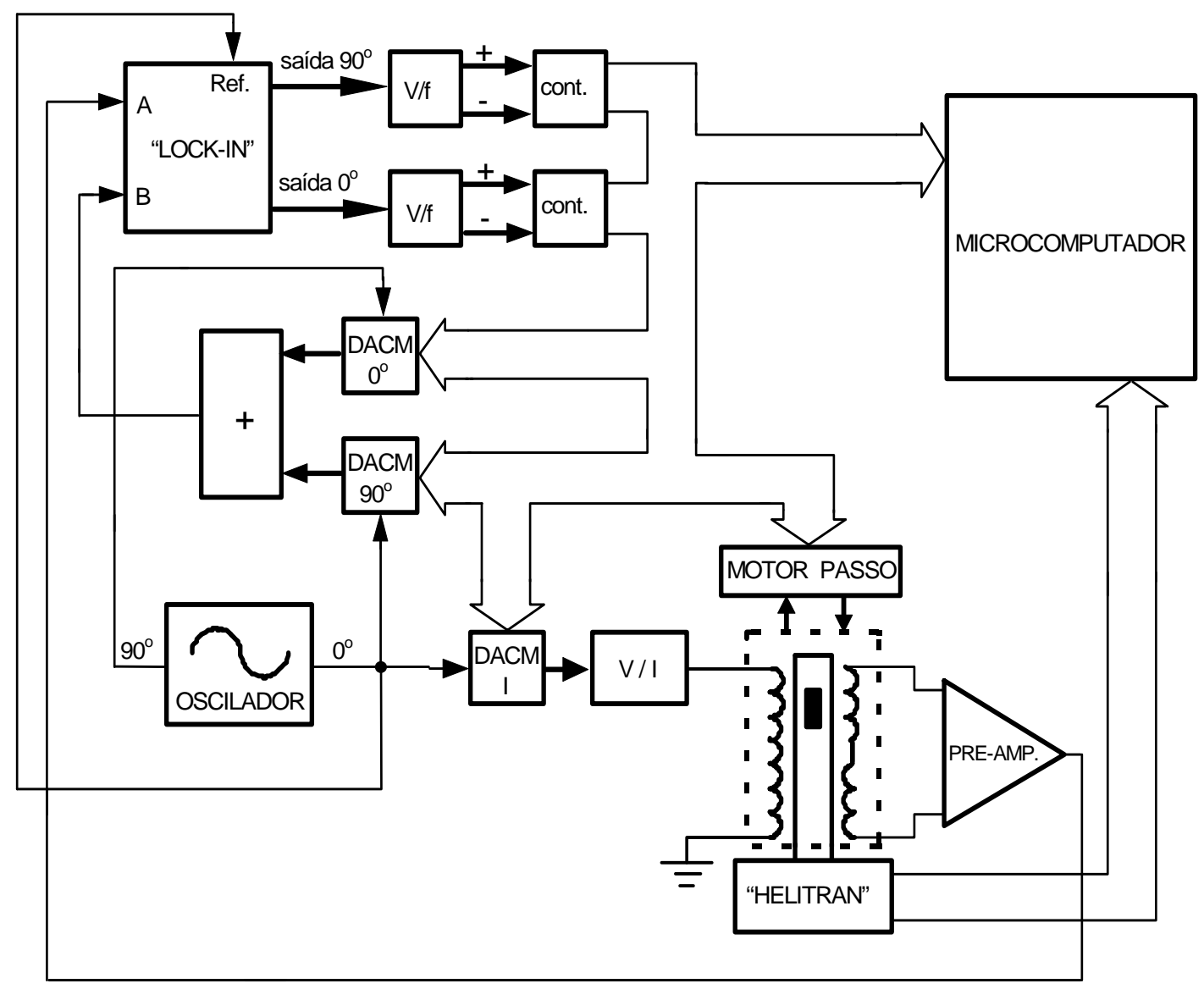

Figura 17 - Desenho em blocos da ponte de indutâncias mútuas. 


\section{DACM}

Os Conversores digital analógico multiplicativos são divisores de tensão controlados digitalmente ${ }^{\natural}$. Ou seja, a voltagem de saída (para um DACM de 12 bit) é dada por:

$$
V_{o}=-\frac{N}{4096} V_{R}
$$

onde $N(0 \leq N \leq 4095)$ é um número digital que controla a voltagem de saída do DACM e $V_{R}$ é a voltagem de referência.

O uso desses DACM possibilitaram o total controle da ponte de indutâncias mútuas através de um microcomputador. Estes DACM foram utilizados não só para o balanceamento da ponte de indutâncias mútuas (ver Figura 17), mas também na fonte de corrente, a fim de se controlar a corrente aplicada na bobina primária.

\section{Fonte de corrente}

Em susceptômetros típicos a bobina primária é alimentada por uma fonte de voltagem AC. O campo AC resultante gerado pela bobina primária é portanto uma função da impedância do circuito primário, que depende da freqüência e da resistência (ou seja da temperatura) do circuito primário. Desta forma, para cada freqüência e temperatura medidas, o ângulo de fase entre corrente e tensão pode variar prejudicando a separação correta e precisa das componentes real e imaginária da susceptibilidade.

Sendo a bobina primária alimentada por uma fonte de corrente, o campo AC resultante depende somente da estabilidade na saída desta fonte de corrente, e não há complicadas relações de dependência da fase com a freqüência ou a temperatura.

Como mostra a Figura 17, nossa fonte de corrente é composta de um oscilador (que fornece um sinal em fase e quadratura), um $D A C M$ de 12 bit e um Conversor Voltagem Corrente (V/I).

O oscilador utilizado foi um Burn Brown modelo 4423, que fornece, simultaneamente, dois sinais $90^{\circ}$ fora de fase um com outro e cuja freqüência pode variar desde 0,002 Hz até $20 \mathrm{kHz}$. O uso deste oscilador de duas fases elimina a necessidade de

\footnotetext{
${ }^{\text {}}$ O que diferencia um DACM de um outro conversor não multiplicativo (DAC) é o fato da voltagem de referência em um DACM poder ser variável, enquanto que em um DAC ela é geralmente fixa.
} 
implementar circuitos defasadores que possuem a desvantagem de necessitarem de ajustes a cada freqüência selecionada, o que dificultaria a automação do equipamento e provocaria um aumento, demasiado, no tempo necessário para realização de cada medida.

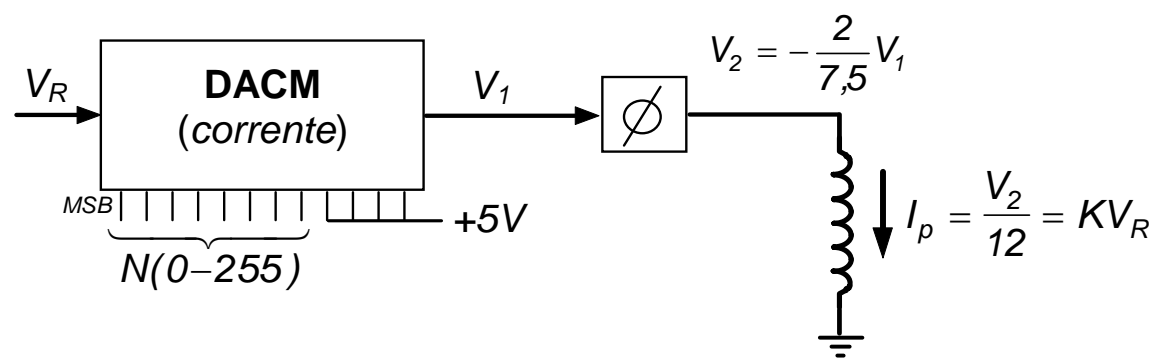

Figura 18 - Esquema da montagem do DACM, utilizados para variar a corrente da bobina primária.

O DACM foi utilizado com a finalidade de variar, através de um microcomputador, a corrente elétrica na bobina primária, e conseqüentemente o campo magnético alternado aplicado na amostra. Para melhor entender o funcionamento deste conversor a Figura 18 mostra um esquema simplificado de sua montagem.

Observando a Figura 18 e utilizando a Eq. (8), monta-se a seguinte equação, para fornecer o valor da tensão elétrica, e conseqüentemente da corrente elétrica, aplicada na bobina primária:

$$
V_{2}=-\frac{2}{7,5} V_{1}=\frac{2}{7,5} \frac{15+16 C}{4096} V_{R}
$$

Sendo $I_{p}=\frac{V_{2}}{12}=K V_{R}$, então a constante de conversão de voltagem para corrente elétrica será dada por:

$$
K=\frac{1}{45} \frac{15+16 C}{4096} \quad C=0,1,2, \ldots, 255
$$

\section{“LOCK-IN"}

Para a detecção, construiu-se um amplificador "lock-in”, dedicado, que fornece a leitura simultânea das duas fases (sinal em fase e em quadratura com a corrente na bobina primária). Este “lock-in”, cujo circuito elétrico está mostrado em anexo, foi 
construído utilizando-se componentes eletrônicos comerciais. A leitura simultânea das duas fases possibilita o balanceamento automático da ponte de indutâncias mútuas, o qual é realizado através de uma realimentação entre cada uma das saídas do "lock-in” e o respectivo DACM (ver Figura 17).

A fim de obter-se uma maior resolução, utilizou-se, para cada uma das fases, dois DACM de 12 bit, ligados em série. Utilizando-se estes dois DACM, foi possível simular um conversor de 16 bit para balanceamento do sinal induzido na bobina secundária.

\section{Conversor Voltagem-freqüência}

O conversor Voltagem-freqüência utilizado é semelhante àquele descrito por Ocio et $\mathrm{al}^{[29]}$, cuja finalidade é manter a ponte continuamente balanceada. Quando a ponte é desbalanceada, surge uma voltagem na saída do amplificador "lock-in”, que é transformada, pelo conversor Voltagem-Freqüência ( $V / f)$, em uma seqüência de pulsos, cuja freqüência é proporcional a amplitude da voltagem. Então estes pulsos são utilizados para, dependendo da polaridade do sinal detectado, incrementar (“up”) ou decrementar (“down”) o valor de dois contadores binários de 12 bits, responsáveis pelo controle da voltagem de saída dos DACM, que fazem o balanceamento da ponte. Se $V_{0}$ é positivo o número do contador em fase é aumentado, se negativo este valor é diminuído. Da mesma forma ocorre com o contador em quadratura quando $V_{90}$ é, respectivamente, positivo ou negativo.

A finalidade da utilização do computador neste processo é a realização de uma promediação do número responsável pelo incremento ou decremento do valor dos contadores. Este método de processamento do sinal é interessante porque permite a integração digital ${ }^{[29]}$ das saídas do “lock-in”, melhorando assim a relação sinal-ruído.

\section{Pré-amplificador}

Trabalhar com sinais de baixo níveis (sinais de pequena amplitude) é muito problemático no que se refere a relação sinal-ruído. A captação de ruídos através dos componentes eletrônicos ou cabos utilizados na ligação entre partes da ponte podem mascarar o sinal induzido pela amostra, piorando assim a sensibilidade da ponte. 
Uma das possíveis soluções para o aumento dessa relação sinal-ruído é a utilização de bobinas secundárias com um número muito grande de espiras. Entretanto este artifício pode causar o aparecimento de acoplamentos capacitivos entre as espiras, e, conseqüentemente, uma redução no limite de freqüências de operação do “probe”. Uma outra solução é o uso de amplificadores eletrônicos de baixo ruído.

Utilizando-se desta segunda solução, para o aumento do sinal induzido pela amostra, colocou-se um pré-amplificador bem próximo ao “probe”. Este préamplificador, com um ganho de 400 (veja esquema na Figura 19), foi construído com um amplificador de instrumentação comercial (Burn_Brown INA-101).

A utilização de um ganho tão grande só foi possível porque a voltagem induzida na bobina secundária, sem amostra, foi minimizada por uma bobina de compensação, que será descrita na seção 3.4.2.1.

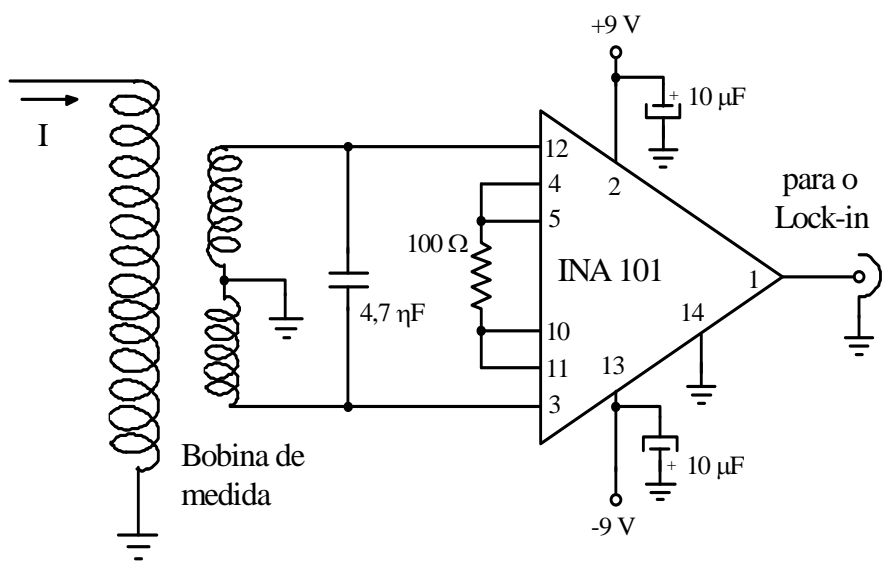

Figura 19 - Esquema do pré-amplificador.

\section{Programa de controle e aquisição de dados}

O software de controle da ponte de indutâncias mútuas e a aquisição de dados, foi todo desenvolvido em linguagem C. Para o funcionamento deste software necessitou-se também o desenvolvimento de hardware de comunicação, o que possibilitou a total automatização da medida da susceptibilidade magnética em função da temperatura. Este software, em conjunto com o hardware, realiza automaticamente o balanceamento da ponte, o movimento do "probe”, o ajuste da posição do "probe” relativo a amostra, a aquisição dos dados, a leitura da temperatura e os gráficos das componentes real e imaginária da susceptibilidade magnética em função da temperatura. Através deste 
software pode-se também variar a intensidade do campo magnético aplicado, na amostra, bem como alterar a amplitude da voltagem de balanceamento, possibilitando assim medidas de susceptibilidade magnética de amostras que possuem magnetização grande ou pequena.

Este software de controle e aquisição, denominado SMAC (Susceptibilidade Magnética AC), possui uma interface de fácil interação com o usuário. Ele possui várias telas, as quais possuem menus que possibilitam ao usuário escolher a função desejada. Ao executar-se este software, será apresentada uma primeira tela, mostrada na Figura 20, que possui um menu, na parte superior, onde o usuário pode escolher a realização da aquisição de dados ou o ajuste dos parâmetros.

\begin{tabular}{|c|c|c|c|c|}
\hline $\begin{array}{l}\text { Run } \\
\text { Temperatura }\end{array}$ & $\begin{array}{l}\text { Auto zero } \\
\text { File }\end{array}$ & $\begin{array}{l}\text { Scale } \\
\text { Data }\end{array}$ & Probe & About \\
\hline
\end{tabular}

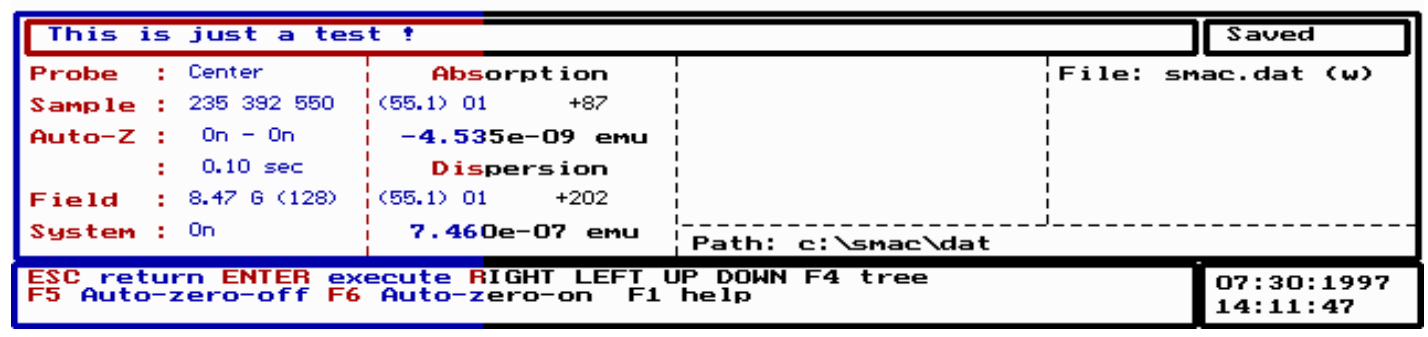

Figura 20 - Primeira tela do software de controle e aquisição de dados, denominado por SMAC (Susceptibilidade Magnética AC). A partir das opções no topo da tela pode-se ajustar os parâmetros ou começar a aquisição de dados.

Através das opções existentes nesse menu (ver Figura 20) pode-se executar as seguintes funções:

- “Run” $\rightarrow$ Abrir um outro menu, no qual possui duas opções: a primeira opção (“Scan”) possibilita que o microcomputador ajuste as posições do "probe”, de tal 
forma que ao movimentá-lo a amostra fique ora em um secundário, ora noutro; a outra opção (“Measure”) é responsável pela aquisição de dados (ver Figura 21).

- "Auto zero" $\rightarrow$ Ativar ou desativar o balanceamento automático da ponte.

- "Scale" $\rightarrow$ Ajustar a escala do sinal de balanceamento da ponte, possibilitando-se a medida de sinais grandes e pequenos. Este ajuste é feito, independentemente, para cada uma das fases (fase e quadratura).

- "probe" $\rightarrow$ Abrir um outro menu onde são fornecidas outras opções, relativas ao "probe”, tais como: ajustar manualmente a posição do "probe”; movimentar o "probe”; e variar a corrente na bobina primária.

- “About” $\rightarrow$ Mostra algumas informações sobre o software.

• "Helitran” $\rightarrow$ Esta opção é utilizada, quando o software não estiver realizando aquisições de dados, para processar a leitura dos parâmetros do controlador de temperatura. Durante a aquisição de dados esta leitura é feita automaticamente.

- "File" $\rightarrow$ Abrir um outro menu onde são fornecidas opções para realizar-se alterações no arquivo onde serão salvos os dados. Neste menu contem opções de: salvar arquivo; mudar o nome do experimento ou do arquivo; e até mesmo editar os valores contidos no arquivo.

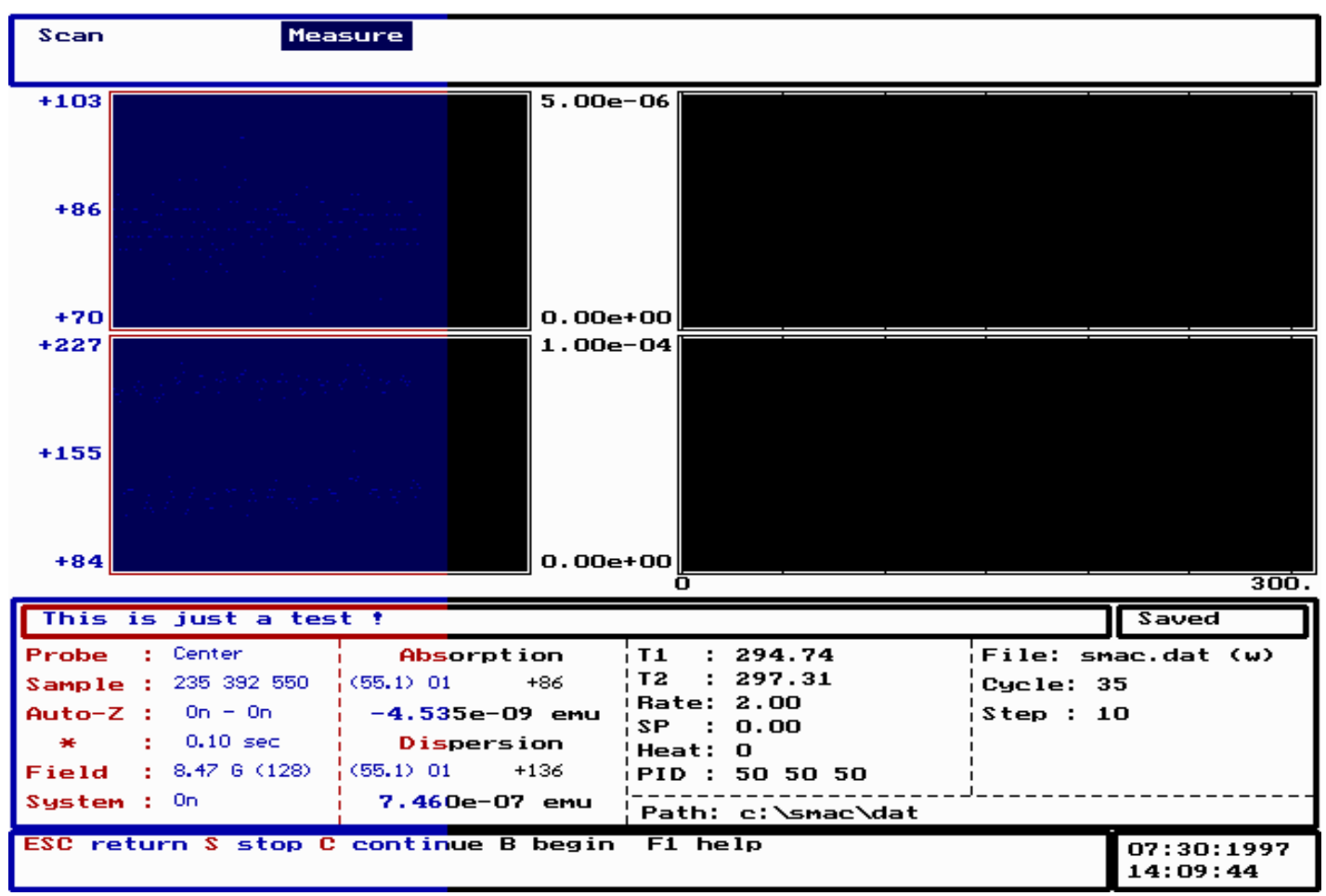

Figura 21 - Tela de aquisição de dados do SMAC. 


\subsection{2 - "Probe"}

Todos os susceptômetros descritos na literatura utilizam técnicas semelhantes no que diz respeito ao procedimento de medida. O conjunto de bobinas é mantido fixo e refrigerado a Nitrogênio ou Hélio líquido. O porta amostra é móvel e permite que a amostra se movimente ${ }^{[39,40]}$ entre três posições particulares: fora do secundário e nos centros de cada um dos dois solenóides que compõem o secundário. Balanceando a ponte nestas três posições e registrando os sinais de compensação correspondentes é possível calcular a susceptibilidade em valores absolutos. Este sistema tem a vantagem de possuir alta estabilidade térmica e baixa resistência ôhmica do secundário e conseqüente melhora da relação sinal-ruído.

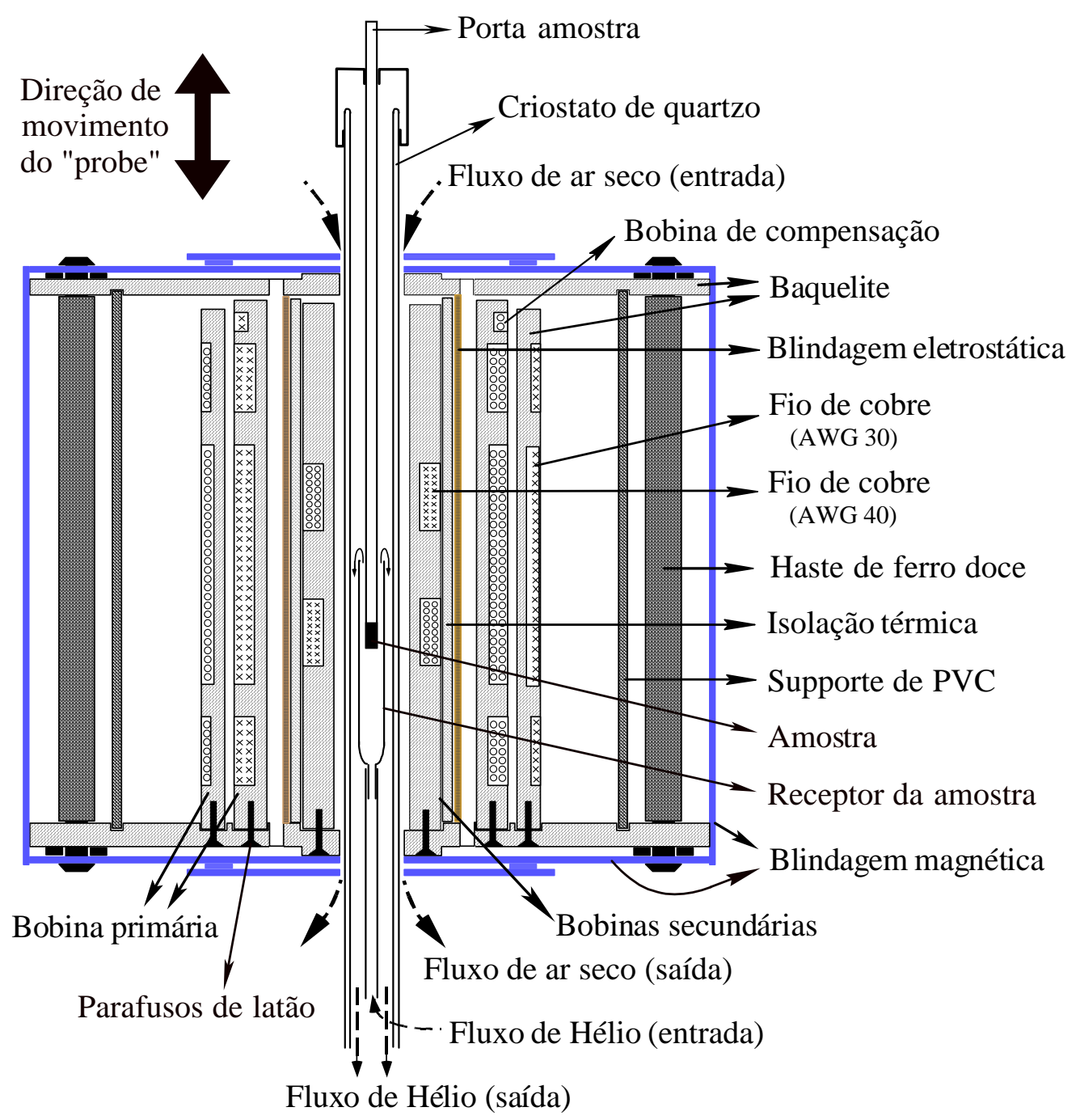

Figura 22 Seção transversal do "probe”. 
Entretanto, o sistema de resfriamento da amostra, existente no laboratório de ressonância do IFSC, não permite o movimento da amostra, por este motivo foi necessário optar-se por um arranjo alternativo. Optou-se então por manter a amostra em uma posição fixa, relativa ao criostato, enquanto que o conjunto de bobinas ("probe”), mostrado na Figura 22, movimenta-se (acionado por um motor de passo, controlado por microcomputador) posicionando, relativamente à amostra, em cada uma das três posições já mencionadas. Este arranjo, além de mais simples e econômico, permite um melhor controle da temperatura da amostra ${ }^{[41]}$. Entretanto, tem a desvantagem de ser altamente sensível à presença de metais, magnéticos ou não, na vizinhança. Para resolver este problema foi projetado um "probe”, que será descrito a seguir, com uma eficiente blindagem magnética.

\subsubsection{1 - Bobinas}

O conjunto de bobinas (ver fotos na Figura 24) é constituído de: uma bobina primária, utilizada para gerar um campo magnético alternado, dividida em várias seções; uma bobina de compensação, utilizada para minimizar as diferenças existentes entre as duas seções da bobina secundária; e uma bobina secundária, utilizada para captar o sinal da amostra, dividida em duas seções.

BOBINA PRIMÁRIA

INTERNA

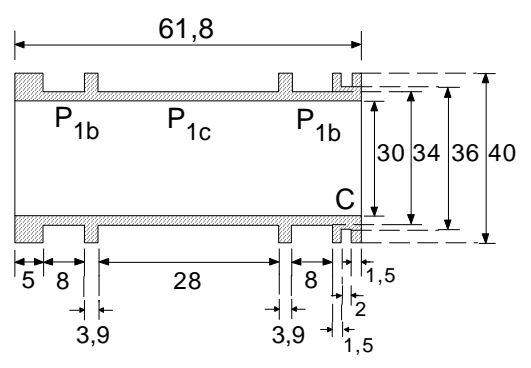

BOBINA SECUNDÁRIA

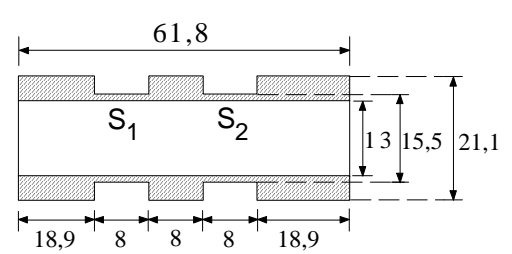

EXTERNA

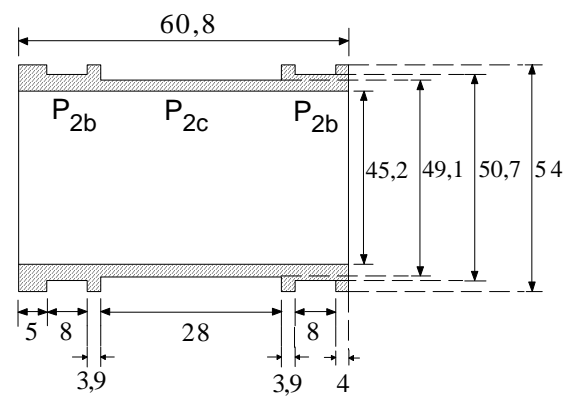

C - Bobina de compensação

$\mathrm{P}_{1 b}$ - Bobina primária interna da borda

$\mathrm{P}_{2 b}$ - Bobina primária externa da borda

$P_{1 c}$ - Bobina primária interna central

$\mathrm{P}_{2 \mathrm{c}}$ - Bobina primária externa central

$\mathrm{S}_{1}$ - Bobina Secundária 1

$\mathrm{S}_{2}$ - Bobina Secundária 2

Figura 23 - Seção transversal das fôrmas das bobinas. Unidades em milímetro. 

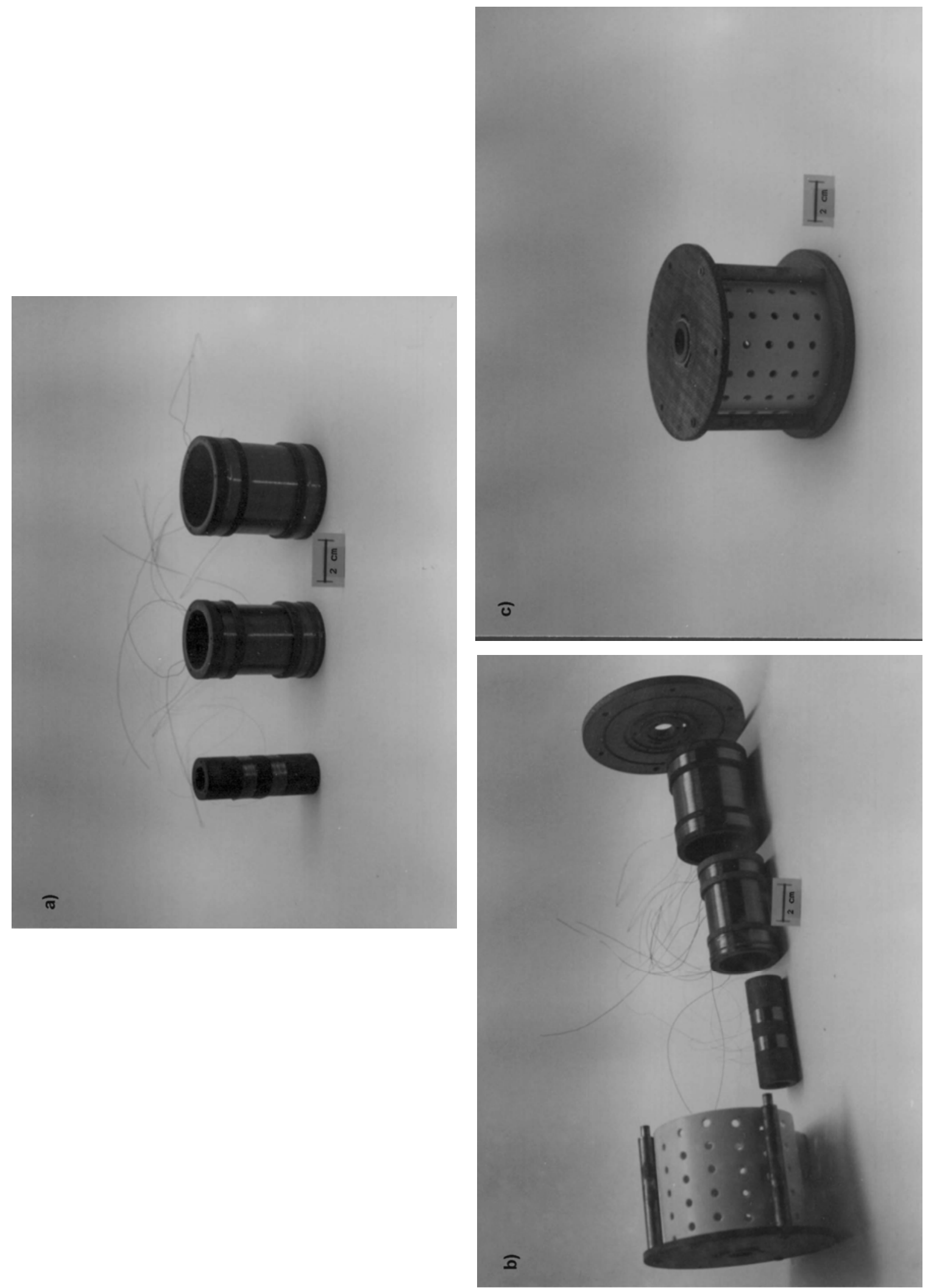

Figura 24 - Fotos das bobinas do "probe”. Em a) são mostradas as bobinas primária e secundária, em b) é indicado como serão encachadas as bobinas, e em c) após a finalização da montagem do "probe". Nestas fotos não é mostrado a blindagem magnética. 
As bobinas foram enroladas em fôrmas de bakelite (ver Figura 23) e mantidas em temperatura ambiente. As bobinas primária e de compensação foram enroladas com fio de cobre de 0,284 mm de diâmetro (AWG30) e a secundária com fio de cobre de 0,094 mm de diâmetro (AWG40).

A fim de minimizar instabilidades provocadas por dilatações da bobina secundária, devido às flutuações térmicas da bobina primária, tomou-se o cuidado de montar as bobinas primária e secundária em blocos distintos e isolados termicamente entre si, por uma camada de isopor (ver Figura 22).

O espaço entre o criostato de quartzo (ver Figura 22 e Figura 28) e a bobina secundária é muito reduzido. Quando o “probe” é movimentado em relação ao criostato, ocorre uma variação de temperatura entre estas posições do criostato, e esta variação de temperatura provoca alterações nas dimensões da bobina secundária, a qual induz sinais espúrios na mesma. Para evitar isto, colocou-se um tubo de látex flexível (revestindo o criostato de quartzo) entre a parte superior do "probe" e a extremidade superior do criostato, e outro entre a parte inferior do "probe" e a extremidade inferior do criostato. Desta forma, um fluxo de ar seco pode ser aplicado entre o "probe” e o criostato de quartzo (ver Figura 22), com a finalidade de manter-se constante a temperatura em toda a extensão do criostato.

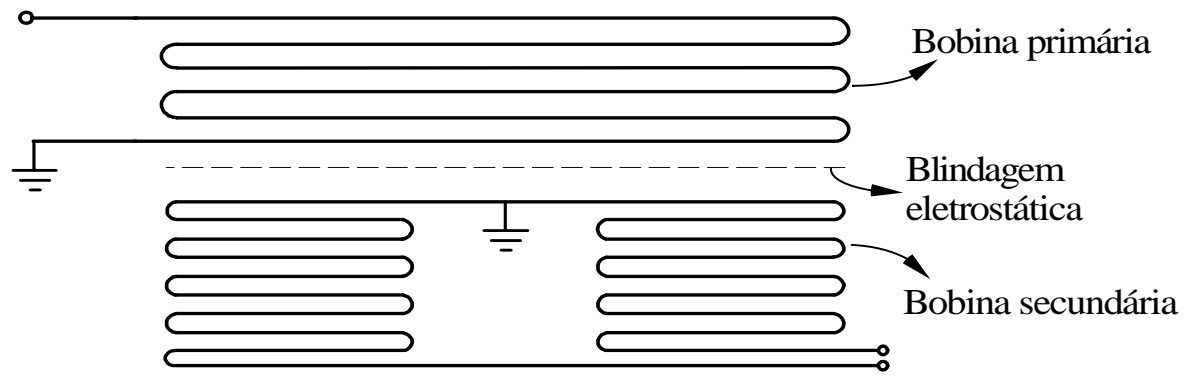

Figura 25 - Desenho esquemático do enrolamento das bobinas primária e secundária.

As bobinas primária e secundária foram enroladas como mostra o esquema da Figura 25, para se evitar o surgimento de capacitâncias parasitas entre elas. As espiras do enrolamento primário e secundário, mais próximas entre si, foram submetidas a um mesmo potencial ${ }^{[42]}$. Ou seja, a camada, de espiras, mais externa da bobina secundária e a mais interna da primária estão em um potencial terra. Colocou-se 
também uma blindagem eletrostática entre as bobinas secundária e primária. Na Tabela 1 são fornecidos os números de espiras e os diâmetros interno e externo de cada uma das bobinas que constituem o "probe”.

Tabela 1 - Dados das bobinas do “probe”.

\begin{tabular}{||l|r|r|r|r|r|r||}
\hline \multirow{2}{*}{ bobina } & \multicolumn{4}{|c|}{ primária } & \multirow{2}{*}{ secundária } & \multirow{2}{*}{ compensação } \\
\cline { 2 - 5 } & \multicolumn{2}{|c|}{ externa } & \multicolumn{2}{|c||}{ interna } & & \\
\cline { 2 - 5 } & borda & central & borda & central & & 2 \\
\hline comprimento (mm) & 8 & 28 & 8 & 28 & 8 & 36 \\
\hline diâm. interno (mm) & 50,7 & 49,1 & 34 & 34 & 15,5 & 38,7 \\
\hline diâm. externo (mm) & 53,4 & 50,2 & 39,3 & 36,1 & 20,3 & 0,284 \\
\hline diâm. do fio (mm) & 0,284 & 0,284 & 0,284 & 0,284 & 0,094 & 5 \\
\hline número de camadas & 5 & 2 & 10 & 4 & 26 & 30 \\
\hline número de espiras & 125 & 184 & 250 & 368 & 2200 & \\
\hline \hline
\end{tabular}

\section{Bobina primária}

A bobina primária é constituída de três pares de enrolamentos coaxiais adjacentes (ver Figura 23). Cada par, feito de dois enrolamentos opostos, coaxiais e concêntricos, de mesmo comprimento e raios $r_{1}$ e $r_{2}$. Segundo alguns autores ${ }^{[35,43-45]}$ cada um destes pares atua como um par astático quando:

$$
N_{1} r_{1}^{2}=N_{2} r_{2}^{2}
$$

onde $N_{1}$ e $N_{2}$ são, respectivamente, os números de espiras do enrolamento interno e externo. Cada par astático produz um campo magnético que decai como um quadrupolo magnético em regiões próximas às bordas da bobina primária, e como um octupolo em regiões distantes.

Fez-se o enrolamento interno de cada par astático, com o dobro de espiras do enrolamento externo (ver Tabela 1), e escolheu-se seus diâmetros de tal forma que os enrolamentos adaptassem ao sistema de resfriamento da amostra e à Eq. (11).

Para que houvesse um decaimento mais rápido do campo magnético fora da bobina primária, e uma maior homogeneidade, deste campo, no interior da bobina secundária, fez-se o par astático central com um maior comprido e um menor número de 
espiras que os outros dois pares externos ${ }^{\text {pu }}$. Tal procedimento resultou em um campo magnético, praticamente, homogêneo na região onde posicionou-se a bobina secundária (ver Figura 36).

\section{Bobina secundária}

A bobina secundária, colocada no interior da primária, é constituída de dois enrolamentos opostos, coaxiais e adjacentes, de mesmo comprimento, mesmo raio e igual número de espiras. Deste modo, em um caso ideal (solenóides idênticos), a tensão induzida no circuito secundário, na ausência da amostra, é nula.

No caso real isso não ocorre. As diferenças na geometria, provocada por diferenças nos enrolamentos, e na homogeneidade do campo do primário provocam um pequeno sinal induzido no circuito secundário (sem amostra). Este sinal pode ser minimizado com a retirada, ou acréscimo, de algumas espiras de um dos dois enrolamentos que compõem a bobina secundária (tornando-os mais parecidos). Entretanto, com este procedimento não é possível anular por completo as diferenças entre os enrolamentos, o máximo que se pode conseguir é uma diminuição da voltagem induzida, no circuito secundário, para um valor, de voltagem, que corresponde a um milésimo (1/1000) daquela voltagem induzida em apenas um dos enrolamentos ${ }^{[32]}$.

\section{Bobina de compensação}

O restante da voltagem, não anulada pelo procedimento citado anteriormente, poderá ser balanceada com a utilização de circuitos eletrônicos e/ou com o acrescimo de uma outra bobina (bobina de compensação) na qual pode-se ajustar a corrente aplicada.

No equipamento descrito neste trabalho, a bobina de compensação, $C$, (ver Figura 23) é utilizada para cancelar um provável desequilíbrio, da ponte de indutâncias mútuas, causado por pequenas diferenças, na geometria dos dois solenóides que compõem a bobina secundária. Estas pequenas diferenças, que não foram possíveis de serem canceladas com o procedimento citado anteriormente (retirada, ou acréscimo, de espiras de um dos dois solenóides), induz uma voltagem no circuito secundário que, embora pequena, é comparável ao sinal induzido pela amostra.

\footnotetext{
Pu A escolha dos números de espiras, diâmetros e comprimentos de cada enrolamento, foi feita com o auxílio de um programa de computador listado em minha dissertação de mestrado (ver referência [5]).
} 
Controlando a amplitude e a fase da corrente, $I_{c}$, que flui nesta bobina, é possível anular completamente o sinal induzido no circuito secundário (na ausência da amostra). Assim, ao introduzir-se a amostra, no interior da bobina secundária, o sinal induzido no circuito secundário é somente devido a magnetização da amostra. Ou seja, um sinal que é proporcional a suscetibilidade magnética AC da amostra.

Desse modo é possível conseguir um maior ganho no pré-amplificador, sem que haja problemas de saturação do mesmo. Outra vantagem deste procedimento foi o aumento da resolução dos DACM, uma vez que , como mostra a Figura 26, eles passaram a ser utilizados somente para balanceamento do sinal da amostra.

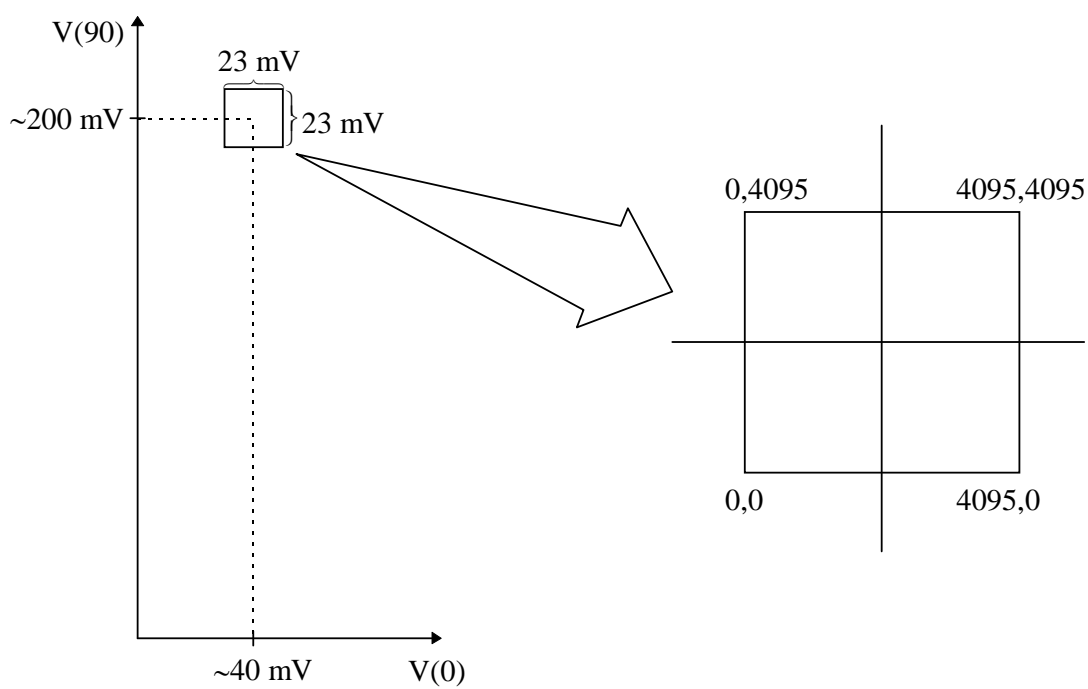

(a)

(b)

Figura 26 - Diagrama esquemático do sinal balanceado (a) pela bobina de compensação e (b) pelos DACM.

\subsubsection{2 - Blindagem Magnética}

Para tornar-se mais efetivo o decaimento do campo magnético fora do “probe”, foi confeccionada, além do enrolamento duplo para a bobina primária, uma blindagem magnética em volta do conjunto de bobinas (ver Figura 22).

Esta blindagem, mostrada na Figura 27, é constituída de dois discos circulares duplos, feitos com uma chapa de $\mu$-metal (de $1 \mathrm{~mm}$ de espessura), suportados por 3 hastes de ferro doce (aço 1010), que servem para fechar o fluxo magnético. Envolvendo os discos e as hastes foi rigidamente colocada uma casca cilíndrica feita de 
ferro-silício ${ }^{\text {t }}$ (de $1 \mathrm{~mm}$ de espessura). Para haver uma boa ventilação na bobina primária, fez-se nesta casca cilíndrica vários furos, de tal forma a evitar-se variações geométricas e térmica da bobina secundária causadas por excessivo aquecimento da bobina primária.
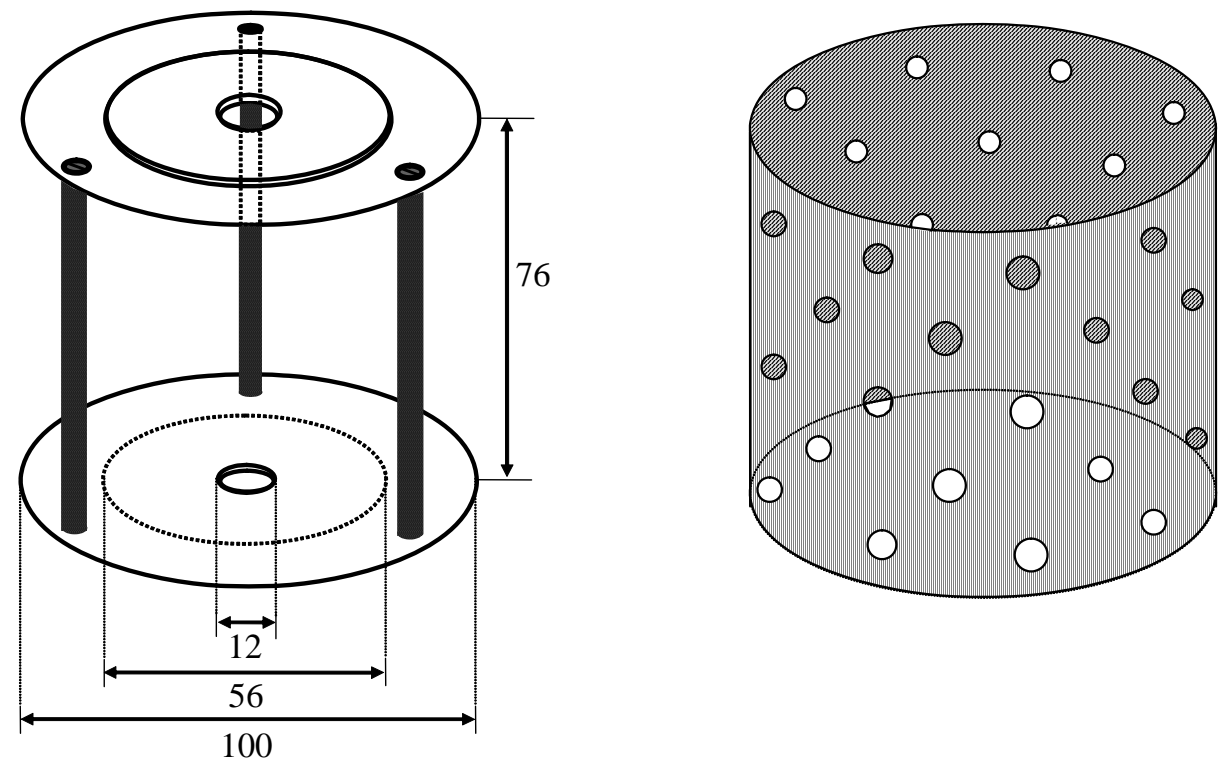

Figura 27 - Blindagem magnética do “probe”. Unidades em milímetros.

Esta blindagem, em conjunto com o enrolamento duplo (em oposição) da bobina primária, proporcionaram, como mostra o gráfico da Figura 36, um excelente decaimento, externamente ao “probe”, do campo magnético gerado pela bobina primária. Com isso foi possível minimizar o acoplamento magnético com metais nas proximidades do "probe”, possibilitando o movimento do mesmo sem que houvesse desequilíbrio da ponte de indutâncias mútuas.

\subsection{3 - Movimento do "Probe"}

Para o movimento do "probe” realizou-se a montagem mostrada na Figura 28. Nesta figura é mostrado também parte do sistema de resfriamento da amostra. Colocou-se, em torno do tubo de quartzo (criostato de quartzo) do "helitran”, três hastes de latão para servirem de guia para o movimento do "probe”.

\footnotetext{
๘ Chapa de ferro-silício com grão orientado, tipo M4, fabricado pela ACESITA - Cia. de Aços Especiais Itabira - Itabira - MG (número serial P990A).
} 
O pouco espaço, limitado pelo sistema de resfriamento da amostra, obrigou-nos a construir a bobina primária com uma dimensão reduzida e, conseqüentemente, a bobina secundária ficou com um comprimento comparável com o da amostra. Por este motivo, para evitar erros na medida da susceptibilidade magnética AC, o posicionamento da amostra, em relação a bobina secundária, deve ser muito preciso.

Para se evitar erros, devido ao posicionamento do "probe" relativo a amostra, utilizou-se um motor de passo, controlado por microcomputador, para realizar o movimento do "probe". Esta montagem pode ser melhor entendida observando-se Figura 28, onde os três fios, fixos na parte superior do "probe”, são de baixo coeficiente de elasticidade. A engrenagem utilizada, é girada por meio de um motor de passo que executa passos de $1,8^{\circ}$ (cada passo corresponde a um movimento do "probe" de aproximadamente 0,0508 mm). Para movimentar o "probe” de tal forma que a amostra seja deslocada do centro de um dos enrolamentos da bobina secundária para o outro (uma distância de $\cong 16 \mathrm{~mm}$ ), devem ser executados cerca de 315 passos.

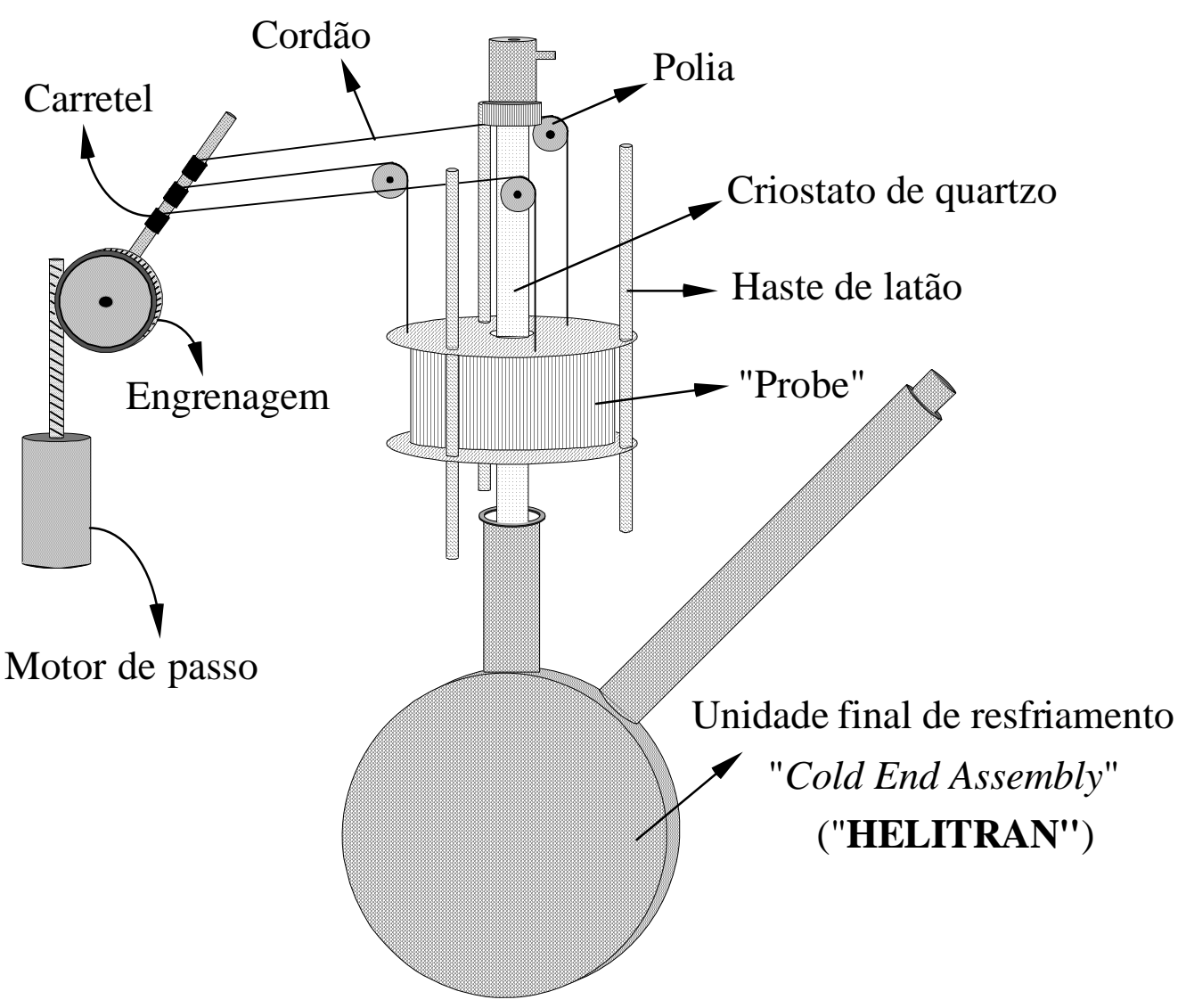

Figura 28 - Esquema da montagem para movimento do "probe”. 


\section{5 - Sistema de Resfriamento da Amostra}

Para resfriamento da amostra foi utilizado um sistema comercial, “HELITRAN" modelo LTR-3, da APD Criogenics Inc., próprio para uso em equipamentos de Ressonância Paramagnética Eletrônica. Para facilitar seu transporte e sua transferência para o espectrômetro de RPE, este sistema, mostrado na Figura 29, está todo montado em um único rack. Com este sistema é possível obter-se uma variação de temperatura de 2,5 à $300 \mathrm{~K}$. O controle de temperatura é feito por uma unidade microprocessadora da Scientific Instruments Inc. (Series 5500), a qual é ligada ao microcomputador através de uma placa padrão GPIB.

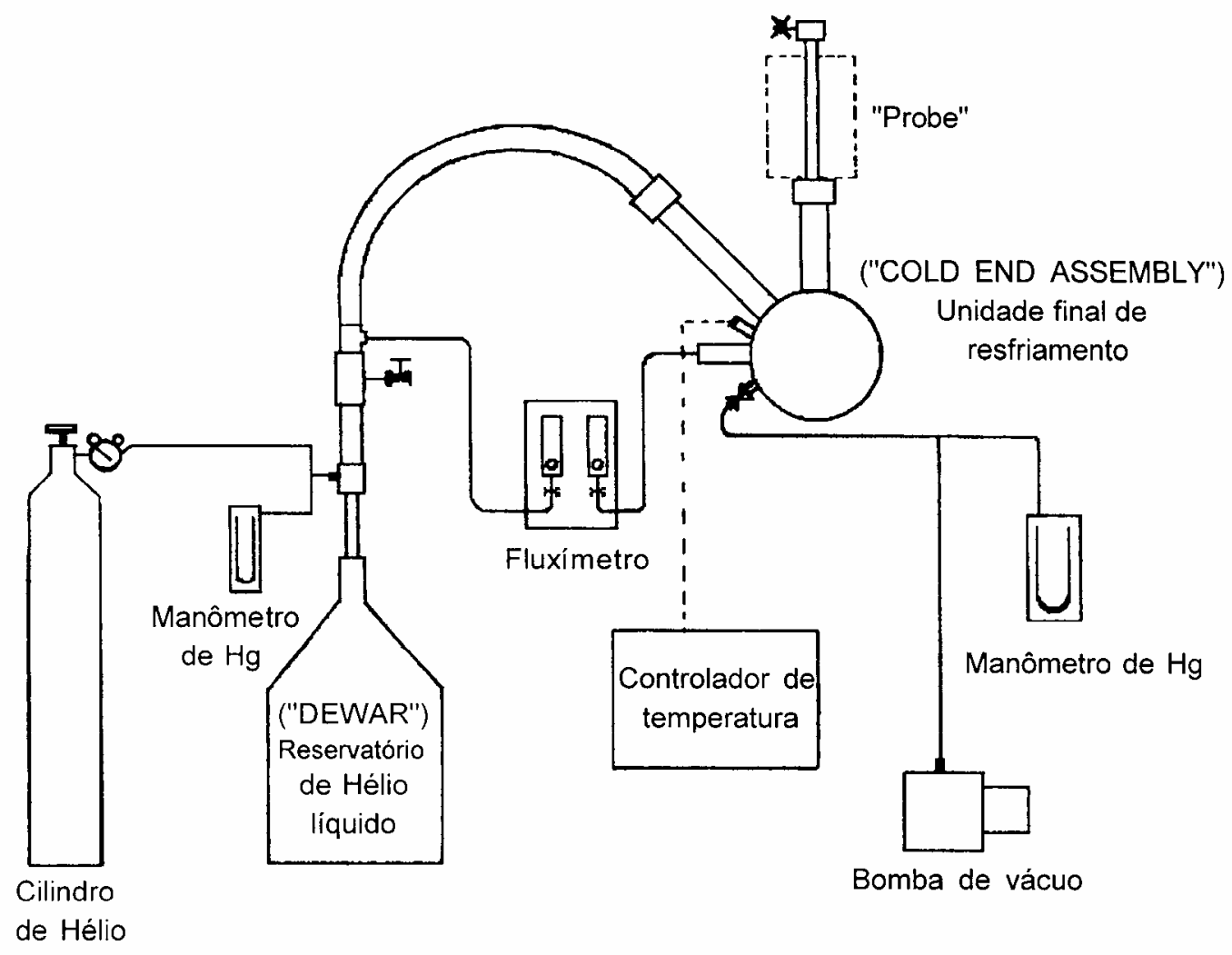

Figura 29 - Desenho esquemático do sistema de resfriamento da amostra.

Este sistema possui uma desvantagem relacionada às dificuldades no controle de temperatura. Como ele não possui um sensor de temperatura junto da amostra, o controle de temperatura depende do fluxo de gás, o que torna complicado sua estabilização e a determinação precisa da mesma. Para a determinação desta temperatura, é necessário a utilização de uma expressão que depende da leitura de dois sensores, 
colocados abaixo da amostra, e do fluxo de gás. Isto acarreta erros, de aproximadamente $5 \mathrm{~K}$, nos valores das temperaturas medidas.

Por outro lado este sistema possui uma grande vantagem, que está relacionada a facilidade na troca de amostra. Isto possibilita a realização de medidas em uma grande quantidade de amostra sem que haja a necessidade de complicados e demorados procedimentos ${ }^{\star}$.

\section{6 - Calibração Teórica}

Por uma questão didática, vamos inicialmente determinar como são as tensões elétricas nos terminais das bobinas secundárias e primária, que compõem o "probe".

A diferença de potencial (V) nos terminais de uma bobina, na qual há uma variação do fluxo magnético, é dada, em unidades do cgs, por:

$$
V=\frac{N}{C} \frac{d \phi}{d t}=\frac{N}{c} \frac{d \phi}{d l} \frac{d l}{d t}
$$

onde $N$ é o número de espiras da bobina, $c$ é a velocidade da luz, I a corrente elétrica e $\phi$ o fluxo magnético.

Observando a Figura 30b nota-se que a variação do fluxo magnético em cada bobina pode ser causada pela corrente que flui nela mesma ou nas outras bobinas. Para o caso de três bobinas, a Eq. (12) será mais corretamente escrita da seguinte forma:

$$
V_{i}=\frac{N_{i}}{c} \sum_{j=1}^{3} \frac{d \phi_{i}}{d l_{j}} \frac{d l_{j}}{d t}
$$

Utilizando a auto-indutância, $L_{i}=\left(N_{i} / c\right) /\left(d \phi / d l_{i}\right)$, e a indutância mútua, $M_{i j}=M_{j i}=\left(N_{i} / c\right) /\left(d \phi / d l_{j}\right)$, obtém-se, a partir da equação anterior, as expressões para as voltagens nas bobinas primária e secundárias da Figura 30.

Maiores detalhes da montagem e do funcionamento do "Helitran" podem ser obtidos nas referências [5] e [15]. 


$$
\begin{aligned}
& V_{1}=L_{1} \frac{d l_{1}}{d t}+M_{12} \frac{d l_{2}}{d t}+M_{13} \frac{d l_{3}}{d t} \\
& V_{2}=M_{21} \frac{d l_{1}}{d t}+L_{2} \frac{d l_{2}}{d t}+M_{23} \frac{d l_{3}}{d t} \\
& V_{3}=M_{31} \frac{d l_{1}}{d t}+M_{32} \frac{d l_{2}}{d t}+L_{3} \frac{d l_{3}}{d t}
\end{aligned}
$$

a)

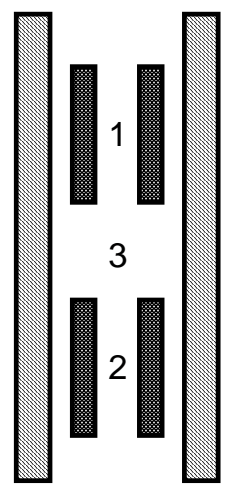

b)

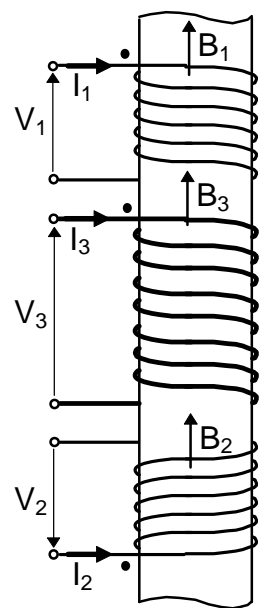

Figura 30 - a) bobinas secundárias (1 e 2) e primária (3), que compõem o "probe”; b) desenho esquemático dos enrolamentos das bobinas, o ponto indica o sentido da corrente elétrica.

Alterando a notação de bobina 3 para bobina primária, ou seja $I_{3}=I_{P}$ e $V_{3}=V_{p}=K I_{p}$, onde $K$ é uma constante cujo valor é determinado pela Eq. (10), e utilizando as condições iniciais, imposta ao susceptômetro: $I_{1}=I_{2}=0$ e $V_{s}=V_{1}-V_{2}$. Desta forma, as expressões para as tensões nas bobinas primária $\left(V_{P}\right)$ e secundária $\left(V_{S}\right)$ reduzem a: $V_{P}=L_{P}\left(d I_{P} / d t\right)$ e $V_{s}=\left(M_{1}-M_{2}\right)\left(d l_{P} / d t\right)$, onde $M_{1}=M_{13}$ e $M_{2}=M_{23}$.

Para efeito de cálculos, trabalharemos com as equações escritas no plano complexo. Consideraremos como parte real os fatores em fase com a corrente elétrica na bobina primária e como parte imaginária $(j)$ os fatores em quadratura com esta corrente. Sendo assim, as voltagens nas bobinas primária e secundária, apresentadas anteriormente, poderão ser reescritas da seguinte forma:

$$
\begin{aligned}
& V_{p}=j \omega L_{p} I_{p} \\
& V_{s}=j \omega\left(M_{1}-M_{2}\right) I_{p}
\end{aligned}
$$


onde $\omega=2 \pi f$ é a freqüência angular da corrente elétrica aplicada na bobina primária.

Na ausência da amostra, a condição de fluxo nulo na bobina secundária, como ilustra a Eq. (16), foi conseguido com o auxílio de uma bobina de compensação, cuja indutância mútua, com relação a bobina secundária, vale $M_{c}$. O balanceamento da ponte de indutâncias mútuas é obtido alterando a corrente, $I_{c}$, que flui nesta bobina.

$$
V_{s}=\left\{j \omega\left(M_{1}-M_{2}\right) I_{p}-j \omega M_{c} I_{c}\right\} G=0
$$

Ao introduzirmos a amostra no interior de uma das seções da bobina secundária, sua indutância mútua inicial, $M_{i}$, será alterada para $M=M_{i}\left(1+4 \pi \eta \hat{\chi}_{v}\right)$, onde $\eta$ é o fator de preenchimento. Esta alteração provoca um desequilíbrio da ponte de indutâncias mútuas, induzindo assim uma voltagem no circuito secundário dada por:

$$
\begin{aligned}
& V_{s}^{(1)}=j \omega\left\{\left[M_{1}\left(1+4 \pi \eta \hat{\chi}_{v}\right)-M_{2}\right] I_{p}-M_{c} I_{c}\right\} G \\
& V_{s}^{(2)}=j \omega\left\{\left[M_{1}-M_{2}\left(1+4 \pi \eta \hat{\chi}_{v}\right)\right] I_{p}-M_{c} I_{c}\right\} G
\end{aligned}
$$

onde os índices (1) e (2) indicam que a amostra está posicionada, respectivamente, no enrolamento 1 e 2 da bobina secundária, e $G$ é o ganho do pré-amplificador, colocado na saída da bobina secundária. Para cada uma dessas situações, amostra no interior do enrolamento 1 ou 2, a ponte de indutâncias mútuas é novamente balanceada. Para estes balanceamentos é necessário somar, ao circuito secundário, uma voltagem, $V_{B}$, de mesmo módulo porém defasada de $180^{\circ}$ com relação a voltagem induzida pela amostra.

$$
V_{B}=\alpha V_{R}(0)+\beta V_{R}(90)
$$

onde $V_{R}(0)$ e $V_{R}(90)$ são as voltagens de referência aplicadas nos DACM utilizados para balancear, respectivamente, as componentes em fase e em quadratura com a corrente na bobina primária, e $\alpha$ e $\beta$ são os números digitais aplicados nos DACM para balancear a ponte de indutâncias mútuas. Desta forma teremos duas voltagens diferentes: uma para cada posicionamento da amostra (enrolamento 1 e 2). O objetivo de medir estes dois sinais é fazer com que o equipamento fique imune às flutuações térmicas do conjunto de bobinas. Isto é conseguido devido ao fato da susceptibilidade magnética ser calculada 
através da diferença entre as voltagens induzidas em cada um dos enrolamentos secundários.

Os valores de $\alpha$ e $\beta$ podem ser determinados a partir de uma análise dos circuitos de balanceamento da ponte de indutâncias mútuas. Entretanto, os circuitos de balanceamento de ambas componentes, fase e quadratura, são iguais, sendo assim necessário a analise de apenas um deles.

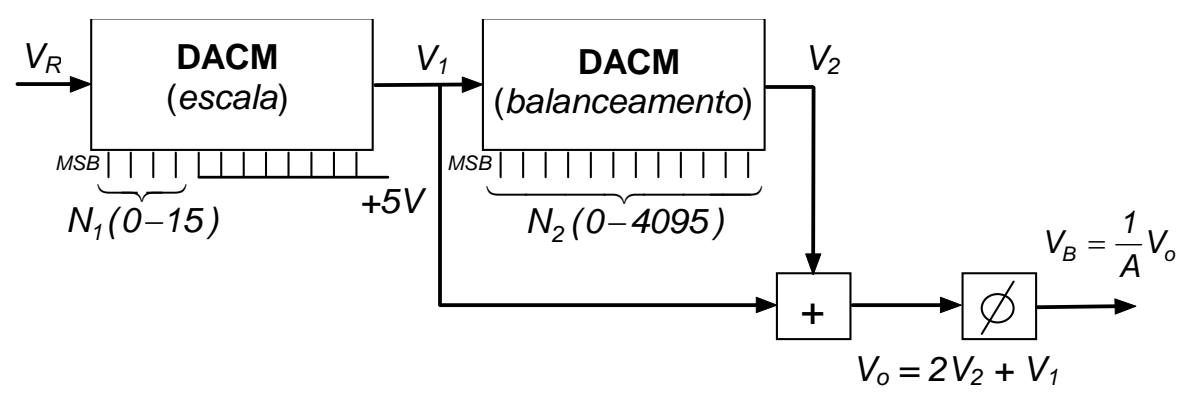

Figura 31 - Esquema da montagem dos dois DACM, utilizados para balancear uma das fases.

Na montagem de um dos circuitos de balanceamento, como mostra a Figura 31, foi utilizado dois DACM, colocados em série. O primeiro é utilizado apenas para fornecer a escala adequada e o segundo é quem, realmente, realiza o balanceamento do sinal induzido pela amostra. Utilizando a expressão para a voltagem de saída de um DACM, ver Eq. (8), e a escala, $N_{s}$, fornecida pelo primeiro DACM, onde $N_{s}=255+$ $256 N_{1}=256\left(N_{1}+1\right)-1$, podemos montar as seguintes equações:

$$
\begin{gathered}
V_{1}=-\frac{N_{s}}{4096} V_{R}=-\left[\frac{256 \cdot\left(1+N_{1}\right)}{4096}-\frac{1}{4096}\right] V_{R} \cong-\frac{1+N_{1}}{16} V_{R} \\
V_{2}=-\frac{N_{2}}{4096} V_{1}=\frac{N_{2}}{4096} \frac{1+N_{1}}{16} V_{R}=\frac{1+N_{1}}{65536} N_{2} V_{R} \\
V_{0}=2 V_{2}+V_{1}=\frac{1+N_{1}}{32768}\left(N_{2}-2048\right) V_{R}
\end{gathered}
$$

fazendo: $S=1+N_{1}$ e $N=N_{2}-2048$ e sendo $V_{B}=\frac{V_{0}}{A}$, onde $A$ é uma atenuação na entrada do "lock-in”, então a voltagem de balanceamento, dada pela Eq. (18), pode ser escrita da seguinte forma: 


$$
V_{B}=\frac{1}{A} \frac{1}{32768}\left(S^{0} N^{0} V_{R}(0)+S^{90} N^{90} V_{R}(90)\right)
$$

Comparando a Eq. (18) com a Eq. (22), obtém-se os valores de $\alpha$ e $\beta$ dados por:

$$
\begin{aligned}
& \alpha=\frac{1}{A} \frac{1}{32768} S^{0} N^{0} \\
& \beta=\frac{1}{A} \frac{1}{32768} S^{90} N^{90}
\end{aligned} \quad\left\{\begin{array}{l}
S=1,2, \ldots, 16 \\
N=-2048, \ldots 0, \ldots+2047
\end{array}\right.
$$

Assim, após introduzir-se a amostra em cada um dos enrolamentos da bobina secundária e efetivar o balanceamento da ponte de indutâncias mútuas, teremos as seguintes equações para o sistema:

$$
\begin{aligned}
& V_{s}^{(1)}+V_{B}^{(1)}=j \omega\left\{\left[M_{1}\left(1+4 \pi \eta \hat{\chi}_{V}\right)-M_{2}\right] I_{p}-M_{c} l_{c}\right\} G+\alpha_{1} V_{R}(0)+\beta_{1} V_{R}(90)=0 \\
& V_{s}^{(2)}+V_{B}^{(2)}=j \omega\left\{\left[M_{1}-M_{2}\left(1+4 \pi \eta \hat{\chi}_{V}\right)\right] I_{p}-M_{c} I_{c}\right\} G+\alpha_{2} V_{R}(0)+\beta_{2} V_{R}(90)=0
\end{aligned}
$$

onde os índices 1 e 2 indicam a amostra posicionada, respectivamente, no enrolamento 1 e 2 da bobina secundária.

Subtraindo as duas equações anteriores, obtém-se:

$$
j \omega 4 \pi \eta \hat{\chi}_{V}\left(M_{1}+M_{2}\right) l_{p} G+\left(\alpha_{1}-\alpha_{2}\right) V_{R}(0)+\left(\beta_{1}-\beta_{2}\right) V_{R}(90)=0
$$

Para simplificar as expressões, será usada, novamente, a notação no plano complexo para as voltagens de referência em fase e quadratura. Sendo estas voltagens de, praticamente, mesma intensidade, então podemos usar: $V_{R}(0)=V(0)$ e $V_{R}(90)=j V(0)$. Utilizando também $I_{p}=K V(0)$, onde $K$ é o ganho do conversor voltagem corrente dado pela Eq. (10), e $\hat{\chi}=\chi^{\prime}+\chi^{\prime \prime}$, podemos reescrever a Eq. (25) da seguinte forma:

$$
\begin{aligned}
& j \omega 4 \pi \eta \chi_{V}^{\prime}\left(M_{1}+M_{2}\right) G K V(0)+\omega 4 \pi \eta \chi_{V}^{\prime \prime}\left(M_{1}+M_{2}\right) G K V(0)+ \\
& +j\left(\beta_{1}-\beta_{2}\right) V(0)+\left(\alpha_{1}-\alpha_{2}\right) V(0)=0
\end{aligned}
$$

Separando a parte real e a parte imaginária na Eq. (26), obtém-se uma equação para cada uma das componentes, $\chi_{v}^{\prime}$ e $\chi_{v}^{\prime \prime}$, da susceptibilidade magnética complexa: 


$$
\chi_{v}^{\prime}=\frac{\left(\beta_{2}-\beta_{1}\right)}{\omega 4 \pi \eta\left(M_{1}+M_{2}\right) K G} \quad \chi_{v}^{\prime \prime}=\frac{\left(\alpha_{2}-\alpha_{1}\right)}{\omega 4 \pi \eta\left(M_{1}+M_{2}\right) K G}
$$

Substituindo $\omega=2 \pi f, \quad \eta=v_{S} / v^{\square}$ e as expressões para $\alpha$ e $\beta$ (dada pela Eq. (23)) e para $K$ (dada pela Eq. (10)) na Eq. (27), obtém-se:

$$
\begin{aligned}
& \chi_{v}^{\prime}=\frac{1}{A} \frac{1}{32768} \frac{S^{90}\left(N_{2}^{90}-N_{1}^{90}\right) v}{2 \pi f 4 \pi v_{s}\left(M_{1}+M_{2}\right) G} \frac{7,5}{2} \frac{12 \cdot 4096}{15+16(C+1)} \\
& \chi_{v}^{\prime \prime}=\frac{1}{A} \frac{1}{32768} \frac{S^{0}\left(N_{2}^{0}-N_{1}^{0}\right) v}{2 \pi f 4 \pi v_{s}\left(M_{1}+M_{2}\right) G} \frac{7,5}{2} \frac{12 \cdot 4096}{15+16(C+1)}
\end{aligned}
$$

A partir da Eq. (28), e utilizando os valores das contantes, obtidas do circuito elétrico da nossa ponte de indutâncias mútuas, $M_{1} \cong M_{2} \cong 4 \mathrm{mH}, \mathrm{G}=401$, A $=52,1$ e $v \cong 2,013 \mathrm{~cm}^{3}$, podemos escrever as expressões teóricas, para as componentes real e imaginária da susceptibilidade magnética total, da seguinte forma:

$$
\begin{aligned}
& \chi_{V}^{\prime}=\chi_{V}^{\prime} v_{s}=8,58 \cdot 10^{-4} \frac{1}{f} \frac{S^{90}\left(N_{2}^{90}-N_{1}^{90}\right)}{15+16(C+1)} \\
& \chi_{V}^{\prime \prime}=\chi_{V}^{\prime \prime} v_{s}=8,58 \cdot 10^{-4} \frac{1}{f} \frac{S^{0}\left(N_{2}^{0}-N_{1}^{0}\right)}{15+16(C+1)}
\end{aligned} \quad\left\{\begin{array}{l}
S=1,2, \ldots, 16 \\
N=-2048, \ldots,+2047 \\
C=1,2, \ldots, 256
\end{array}\right.
$$

\section{7 - Calibração experimental}

Para calibração do susceptômetro utilizou-se, como amostra padrão, a amostra de Sulfato de Cobre penta-hidratado $\left(\mathrm{CuSO}_{4}-5 \mathrm{H}_{2} \mathrm{O}\right)$. A amostra, na forma de uma pastilha cilíndrica de $4 \mathrm{~mm}$ de diâmetro por $4 \mathrm{~mm}$ de espessura, foi obtida a partir da prensagem, de 111,3 mg de amostra em pó, sob uma pressão de 4 ton/ $\mathrm{cm}^{2}$.

O gráfico da Figura 32 foi obtido medindo-se o valor da componente real da susceptibilidade magnética a cada temperatura entre $5 \mathrm{~K}$ e $300 \mathrm{~K}$. A componente imaginária da susceptibilidade, para esta amostra, é nula. Para essa medida foram utilizadas as Eq. (29), cujas variáveis são $f=98,9 \mathrm{~Hz}, S=1, C=128$ e os valores de $N$

\footnotetext{
${ }^{\square}$ onde $v_{s}$ é o volume da amostra e $v$ é o volume de uma das bobinas secundárias.
} 
variam, a cada temperatura, a medida que a susceptibilidade da amostra varia. $S=1$ representa a maior sensibilidade e $C=128$ corresponde a um campo magnético aplicado na amostra de 8 gauss de intensidade, o que equivale a uma corrente na bobina primária de aproximadamente $90 \mathrm{~mA}$. Como os resultados obtidos a partir da Eq. (29) fornecem o valor da susceptibilidade magnética total, é então necessário multiplicá-los pelo Peso Molecular, $P_{M}$, e dividir pela massa da amostra, $m_{s}$, obtendo assim o valor da susceptibilidade por unidades de mol.

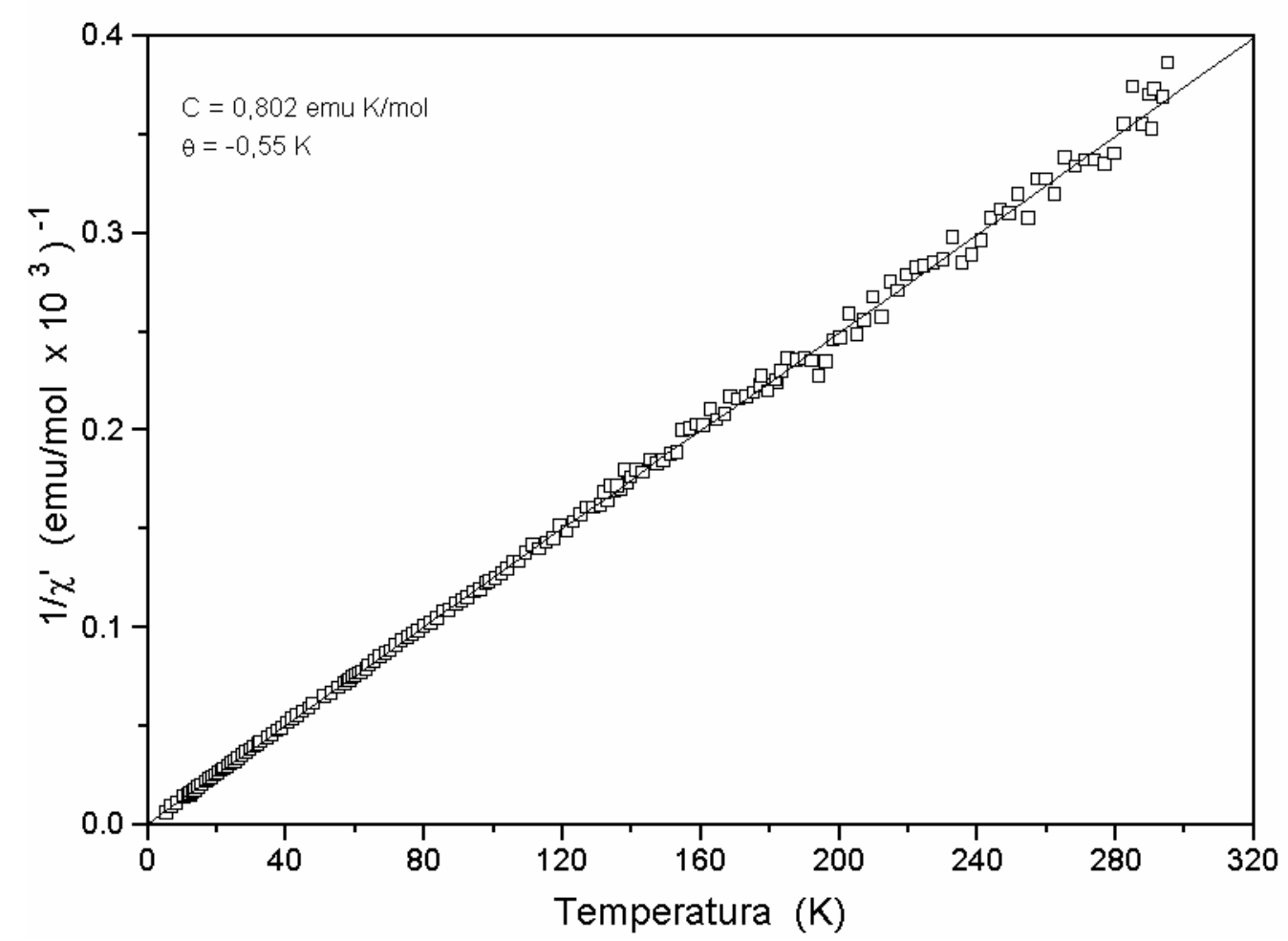

Figura 32 - Gráfico do inverso da susceptibilidade em função da temperatura, da amostra de Sulfato de Cobre penta-hidratado. Nesta medida foram utilizadas as Eq. (29), obtidas através da calibração teórica do susceptômetro.

Comparando nossos resultados (ver Figura 32) com aqueles obtidos por Hockman et $\mathrm{al}^{[46]}$ (ver Figura 33), notamos que há uma pequena diferença entre as temperaturas de Curie-Weiss $(\theta)$, que pode ser explicada por erros ocorrido na extrapolação do comportamento linear, em altas temperaturas, para susceptibilidade recíproca (ajuste linear realizado nos gráficos de $1 / \chi \times T$ ). A diferença entre as constantes de Curie $(C)$, pode ser devido a erros ocorridos ao estimarmos os valores das constantes, $M_{1}, M_{2}, G$, A e $v$, substituidas na Eq. (28). 


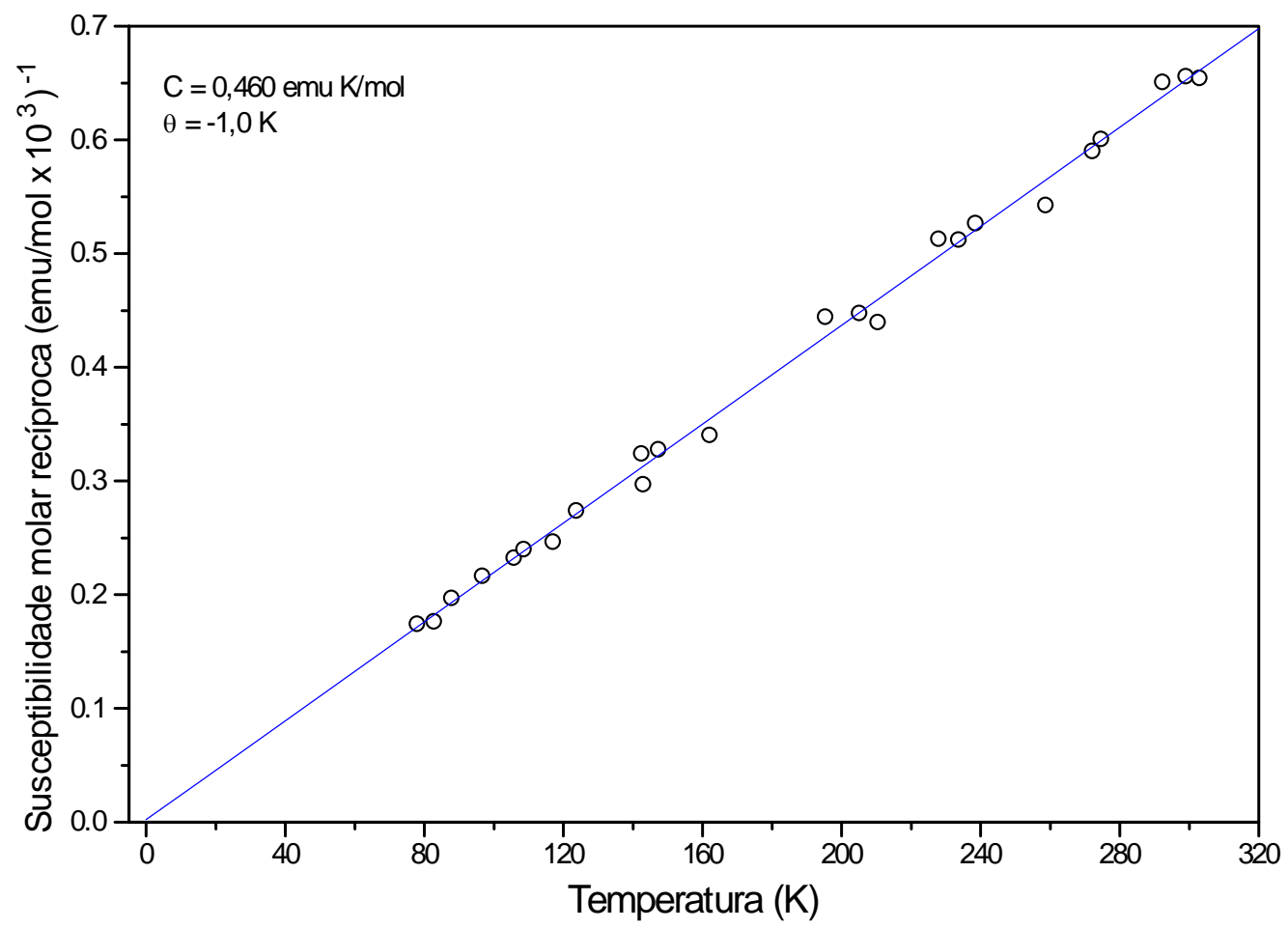

Figura 33 - Gráfico do inverso da susceptibilidade molar em função da temperatura, da amostra de Sulfato de Cobre penta-hidratado, obtido por HOCKMAN et al.

Considerando como corretos os resultados obtidos por Hockman, podemos, a partir da comparação com nossos resultados, obter um fator experimental de calibração, $\kappa=1,743$, para a susceptibilidade magnética total. Desta forma, o fator multiplicativo 8,58.10 ${ }^{-4}$, contido na Eq. (29), passa a valer $1,495 \cdot 10^{-3}$. Supondo que a componente imaginária, da susceptibilidade magnética, possua o mesmo fator experimental, podemos então reescrever a Eq. (29) da seguinte forma:

$$
\begin{aligned}
& \chi_{T}^{\prime}=1,495 \cdot 10^{-3} \frac{1}{f} \frac{S^{90}\left(N_{2}^{90}-N_{1}^{90}\right)}{15+16(C+1)} \\
& \chi_{T}^{\prime \prime}=1,495 \cdot 10^{-3} \frac{1}{f} \frac{S^{0}\left(N_{2}^{0}-N_{1}^{0}\right)}{15+16(C+1)}
\end{aligned} \quad\left\{\begin{array}{l}
S=1,2, \ldots, 16 \\
N=-2048, \ldots,+2047 \\
C=1,2, \ldots, 256
\end{array}\right.
$$

onde os resultados fornecidos por estas equações são dados em emu. Sendo necessário, apenas, decidi-los pela massa para obtê-los em emu/g, ou multiplicá-los pelo peso molecular e dividir pela massa para obtê-los em emu/mol. 


\subsection{1 - Correção para o tamanho da amostra}

A partir da medida com a amostra padrão, $\mathrm{CuSO}_{4}-5 \mathrm{H}_{2} \mathrm{O}$, determinou-se um coeficiente de calibração, $\kappa=1,743$, com o qual o valor da susceptibilidade magnética pode ser calculado como:

$$
\chi=\kappa S
$$

onde S é o valor obtido a partir da calibração teórica, Eq. (29), a qual depende apenas das características elétricas da ponte. Entretanto a validade desta aproximação não pode ser extrapolada, para qualquer tamanho de amostra, com um único valor de $\kappa$. O cálculo teórico deste coeficiente de calibração para amostras grandes, com diferentes geometrias, leva-nos a um problema matemático muito complexo e de difícil solução, podendo, inclusive, fornecer resultados errados.

Por outro lado, observou-se que amostras cilíndricas de mesmo tamanho e diâmetros diferentes (compreendidos entre 0 e $5 \mathrm{~mm})^{k_{2}}$ produz, aproximadamente, mesmos valores de $\kappa$, com diferenças menores que $1 \%$. Isto indica que podemos considerar $\kappa$ independente do diâmetro da amostra. Entretanto, há uma dependência do coeficiente de calibração com o comprimento da amostra que deve ser determinado.

Para isso foi utilizada uma pequena amostra de ferro, quase invisível a olho nu, cuja intensidade da susceptibilidade magnética é muito grande. Este tamanho é tão pequeno que pode ser considerado como uma amostra pontual. Com esta amostra, determinou-se então, como mostra a Figura 34, o sinal induzido, na ponte de indutâncias mútuas, quando a amostra é colocada nas diversas posições relativas a bobina secundária. Utilizando-se estes resultados, e supondo que uma amostra longa é constituída de uma superposição de várias amostras pontuais, podemos calcular o fator de correção através da integração da função normalizada, obtida dos resultados para o pedaço de ferro, sobre todo o comprimento da amostra longa. Este procedimento foi realizado considerando amostras de diversos comprimentos. A partir desses cálculos obteve-se as correções, mostradas na Figura 35, necessárias para diversos tamanhos de amostras.

\footnotetext{
${ }^{\text {B }}$ O diâmetro interno do local onde é colocado a amostra, receptor da amostra (ver Figura 22) no interior do "Helitran", limita o diâmetro da amostra em 5 mm.
} 


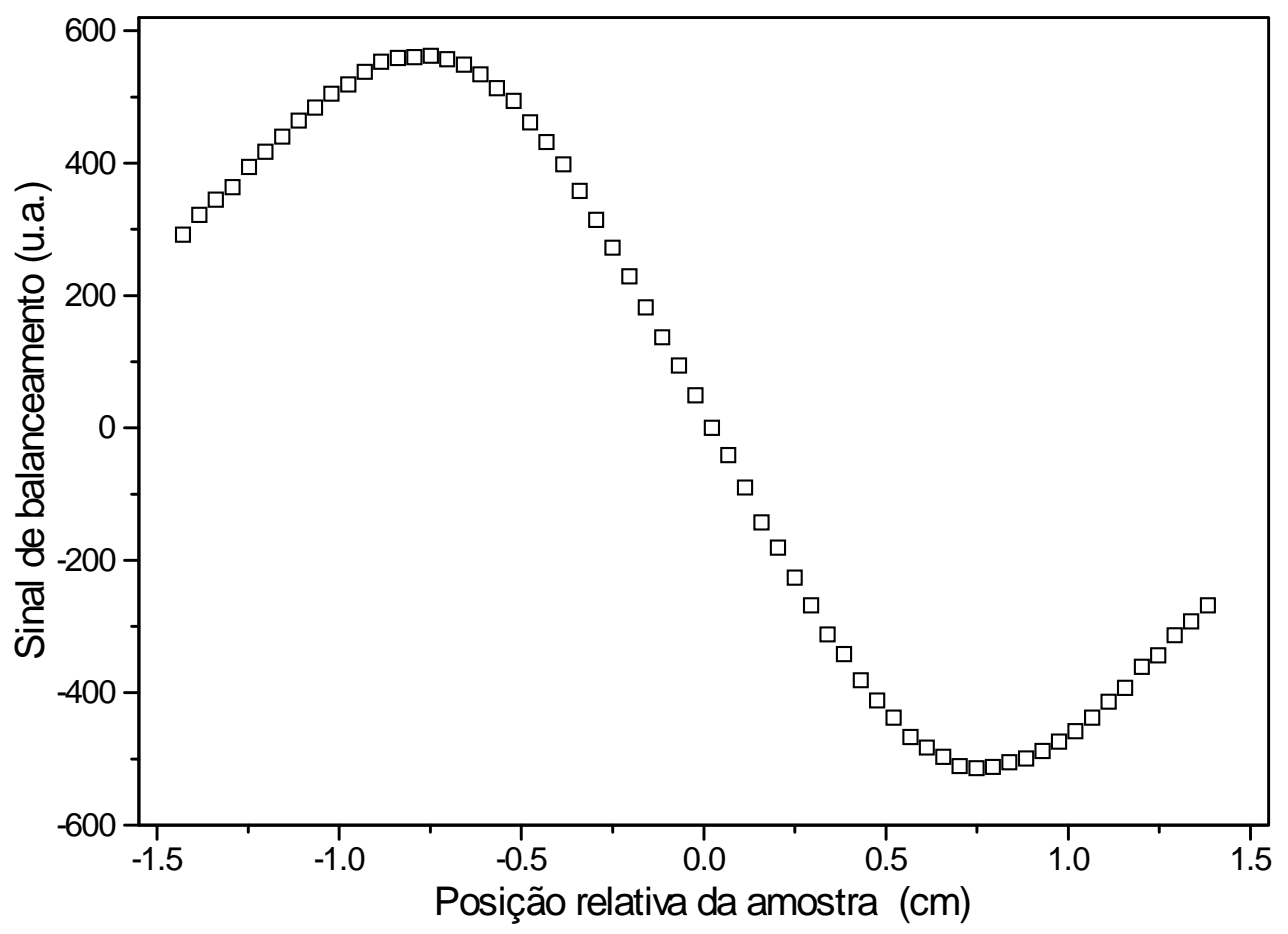

Figura 34 - Sinal de balanceamento, fornecido pelo DAC, em função da posição da amostra pontual, de ferro, em relação a bobina secundária. Medida utilizada na calibração do equipamento quanto ao tamanho da amostra.

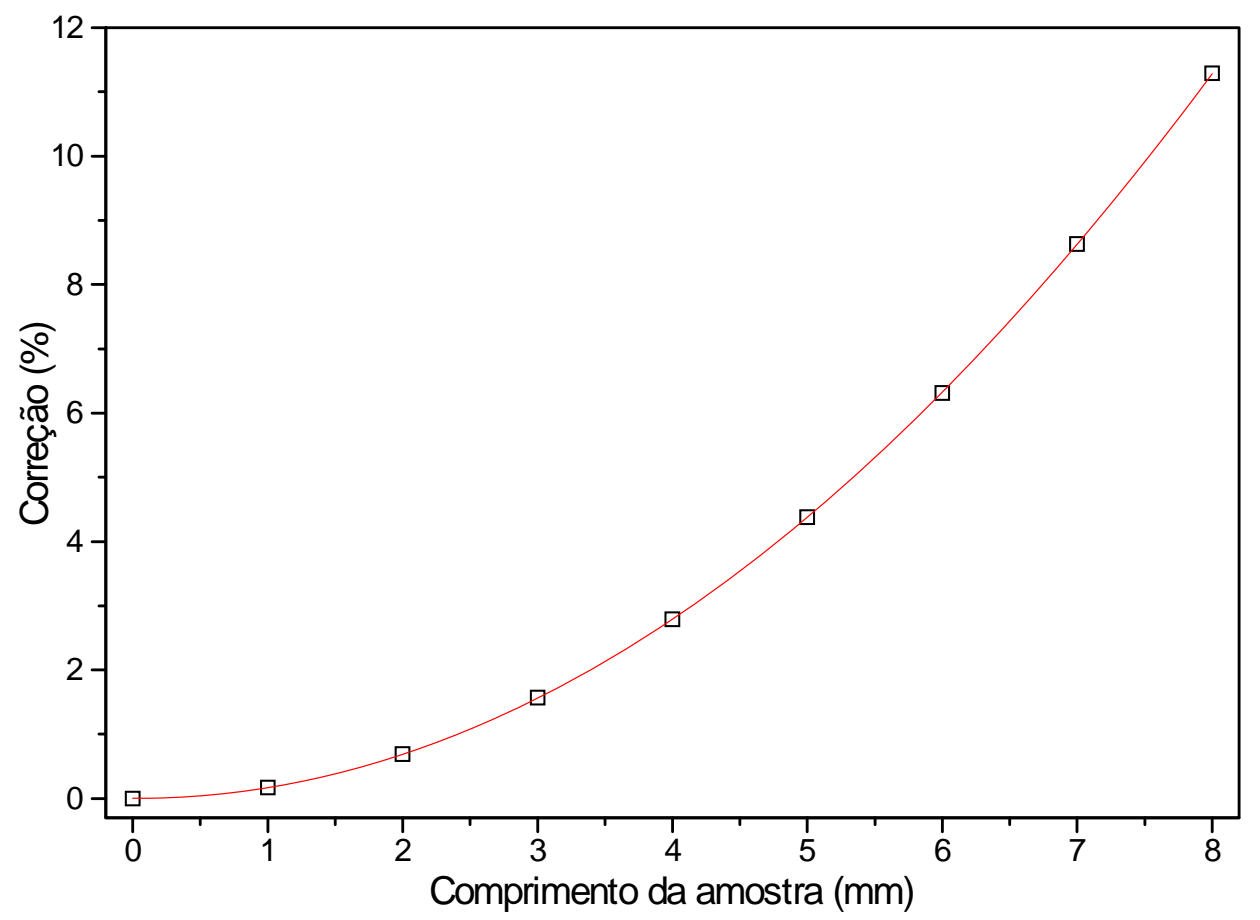

Figura 35 - Correção para susceptibilidade magnética em função do tamanho da amostra. A linha cheia representa o ajuste dos pontos com uma função polinomial de $2^{\mathrm{a}}$ ordem. 
A determinação da relação entre os valores de $\kappa$ para uma amostra de comprimento $h$ e para a mesma amostra com comprimento $h \rightarrow 0\left(\kappa_{0}\right)$, foi obtida ajustando os resultados, apresentados da Figura 35, com uma função polinomial de $2^{\mathrm{a}}$ ordem. A partir deste obteve-se a seguinte relação:

$$
\frac{\kappa}{\kappa_{0}}=1,0+10^{-4}\left(17,8 h^{2}-1,7 h\right)
$$

com $h$ dado em milímetros. De acordo com este resultado o fator de correção é cerca de 3\% para uma amostra de $4 \mathrm{~mm}$ e aumenta para $11 \%$ para uma amostra de $8 \mathrm{~mm}$. Desta forma, para uma amostra de comprimento $h$ (em milímetros), a Eq. (30) pode ser reescrita da seguinte forma:

$$
\begin{aligned}
& \chi_{T}^{\prime}=1,457 \cdot 10^{-3} \kappa \frac{1}{f} \frac{S^{90}\left(N_{2}^{90}-N_{1}^{90}\right)}{15+16(C+1)} \\
& \chi_{T}^{\prime \prime}=1,457 \cdot 10^{-3} \kappa \frac{1}{f} \frac{S^{0}\left(N_{2}^{0}-N_{1}^{0}\right)}{15+16(C+1)}
\end{aligned} \quad\left\{\begin{array}{l}
S=1,2, \ldots, 16 \\
N=-2048, \ldots,+2047 \\
C=1,2, \ldots, 256
\end{array}\right.
$$

sendo $\kappa$ calculado a partir da expressão: $\kappa=1+\left(17,8 h^{2}-1,7 h\right) 10^{-4}$.

\section{8 - Avaliação do susceptômetro}

Para avaliação do desempenho do susceptômetro foram realizados alguns testes com a finalidade de determinar a homogeneidade do campo magnético aplicado na amostra, a máxima freqüência que pode ser utilizada em uma medida, e a sensibilidade e estabilidade térmica do "probe".

\subsection{1 - Homogeneidade do campo magnético}

Um dos fatores que mais contribuem para erros na medida da susceptibilidade magnética, de uma amostra, é a não homogeneidade do campo magnético aplicado. Por isso é de grande interesse a verificação dessa homogeneidade, na região 
onde está posicionada a amostra. A curva do campo magnético no eixo central do "probe" foi obtida, com o auxílio de uma pequena bobina, antes e depois de colocar a blindagem magnética. Os valores medidos sem a blindagem, como mostra o gráfico da Figura 36, concorda com os cálculos teóricos, realizados ao projetar a bobina primária (linha cheia). Neste gráfico, observamos também que, ao colocar-se a blindagem magnética, houve um decaimento ainda mais acentuado do campo magnético no exterior da bobina, sem contudo alterar, significativamente, o campo magnético em seu interior.

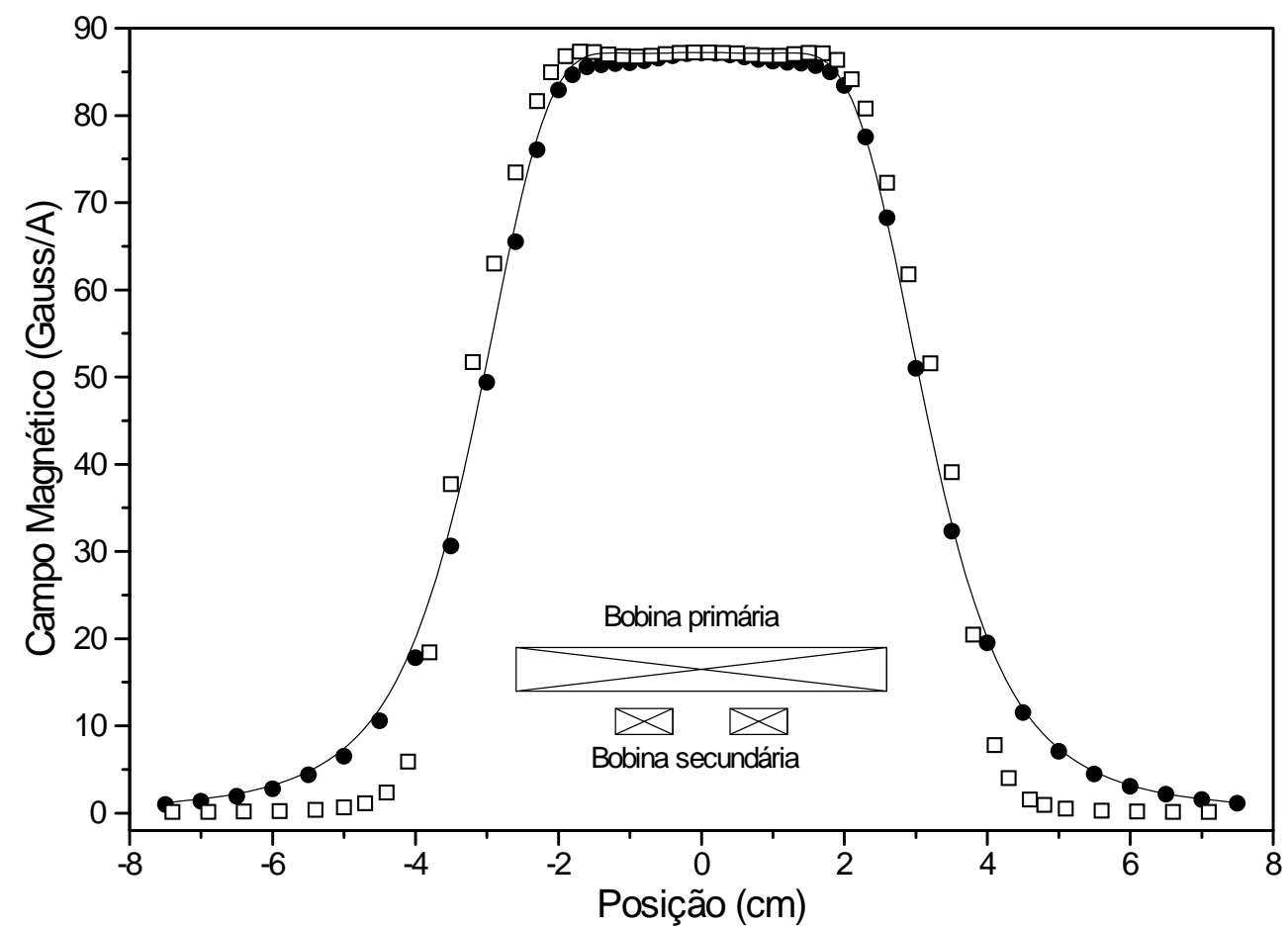

Figura 36 - Gráfico mostrando o campo magnético no eixo central do "probe": pontos experimentais (•) e cálculo teórico (linha cheia) antes da instalação da blindagem magnética; e pontos experimentais ( $\square$ ) após a instalação da blindagem mannótins

Utilizando os resultados obtidos para as medidas realizadas após a instalação da blindagem magnética, concluimos que, na região onde é posicionada a bobina secundária, o desvio na homogeneidade do campo magnético é menor que $1 \%$.

Outro fator importante na caracterização do “probe”, é a determinação da faixa de amplitudes de campo magnético AC possíveis de ser aplicado na amostra. Sendo 180 mA, a máxima corrente elétrica que pode ser aplicada na bobina primária, e, como mostra a Figura 36, o campo magnético por unidade de corrente, na região da bobina 
secundária, de 87 gauss/A, então o máximo campo magnético máximo que poderá ser aplicado na amostra e de aproximadamente 16 gauss.

\subsection{2 - Limitações em altas freqüências}

A separação precisa entre as componentes em fase (real) e quadratura (imaginária) da susceptibilidade magnética, depende fortemente da diferença de fase entre a corrente elétrica na bobina primária e a voltagem induzida na bobina secundária. Em um caso ideal esta diferença de fase é de $90^{\circ}$. Em baixas freqüências, uma diferença de fase desta ordem é conseguida. Entretanto, a medida em que a freqüência é aumentada, o valor desta diferença de fase passa a sofrer pequenos desvios, provocados por efeitos expúrios, tais como acoplamentos capacitivos. Na Figura 37 é mostrada a dependência dessa diferença de fase com a freqüência da corrente aplicada na bobina primária. Observando esta figura, notamos que em freqüências abaixo de $800 \mathrm{~Hz}$ o desvio sofrido, pela diferença de fase, é menor que 0,5 grau, em $1000 \mathrm{~Hz}$ fica em torno de 0,5 grau e a partir de $1200 \mathrm{~Hz}$ este desvio torna-se muito grande, o que inviabilizaria a separação correta das componentes em fase e quadratura da susceptibilidade magnética AC. Portanto, podemos concluir que este “probe” pode ser utilizado em freqüências até $1000 \mathrm{~Hz}$.

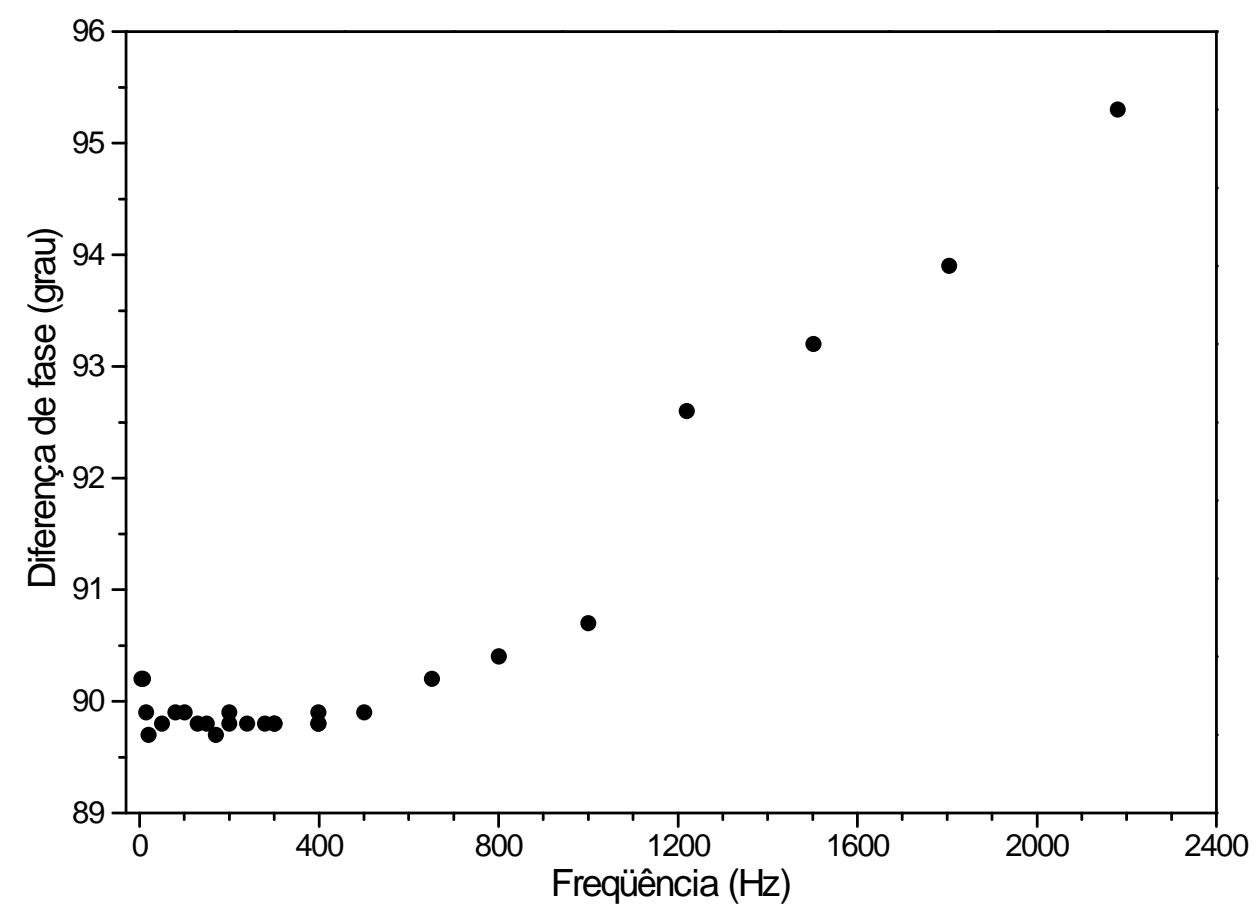

Figura 37 - Diferença de fase entre a voltagem induzida na bobina secundária e a corrente aplicada na bobina primária em função freqüência. 


\subsection{3 - Estabilidade térmica}

A estabilidade térmica do conjunto de bobinas é também um fator muito importante que pode influenciar na sensibilidade do susceptômetro. Entretanto se as flutuações térmicas forem muito lentas, elas não afetarão a medida da susceptibilidade magnética, devido ao fato da medida ser diferencial. Ou seja a cada aquisição é medido o sinal induzido em cada uma das seções da bobina secundária e calculado suas diferenças.

Com a finalidade de verificar possíveis influencias das flutuações térmicas, do "probe", nos resultados das medidas, realizou-se a aquisição de um sinal, em temperatura ambiente, por um longo tempo. Para isto utilizou-se uma amostra, de 111,3 mg de $\mathrm{CuSO}_{4}-5 \mathrm{H}_{2} \mathrm{O}$, posicionada relativa ao centro de cada uma das bobinas secundárias. A Figura 38 mostra que há uma pequena flutuação térmica, de longo período, no sinal. Entretanto esta flutuação não compromete a performance do equipamento, uma vez que o tempo necessário para a realização de cada aquisição, da ordem de 20 segundos, é muito menor que o período das flutuações.

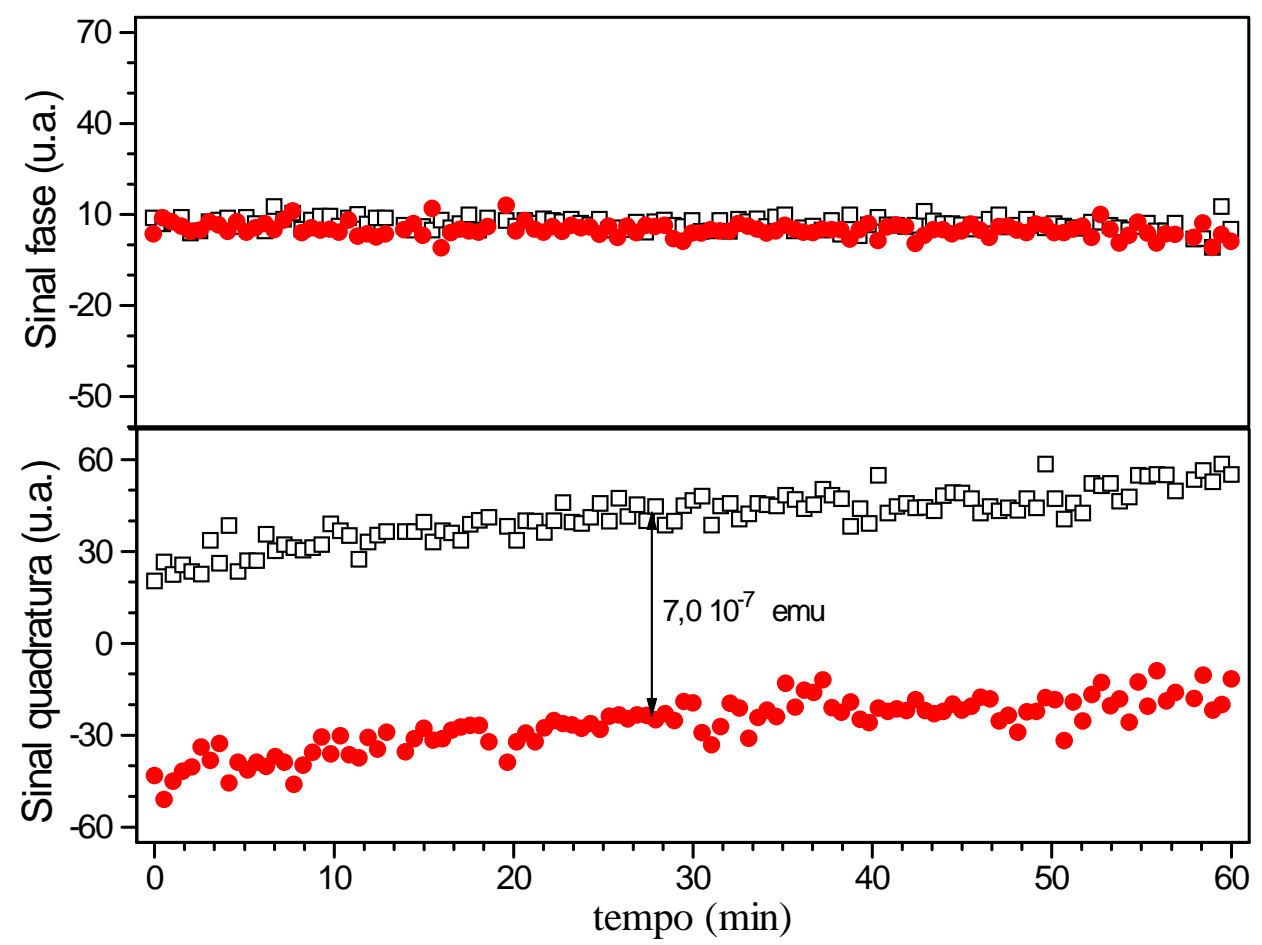

Figura 38 - Sinal de balanceamento (em fase e quadratura), necessário para a amostra de $\mathrm{CuSO}_{4}-5 \mathrm{H}_{2} \mathrm{O}$, em função do tempo. 


\subsection{4 - Tempo de medida}

Em nosso susceptômetro, o tempo necessário para a realização de uma seqüência completa de medida de susceptibilidade magnética em função da temperatura, é basicamente determinado pelo tempo requerido para elevar a temperatura desde $4 \mathrm{~K}$ até a temperatura ambiente. Este tempo varia em torno de 2 a 3 horas.

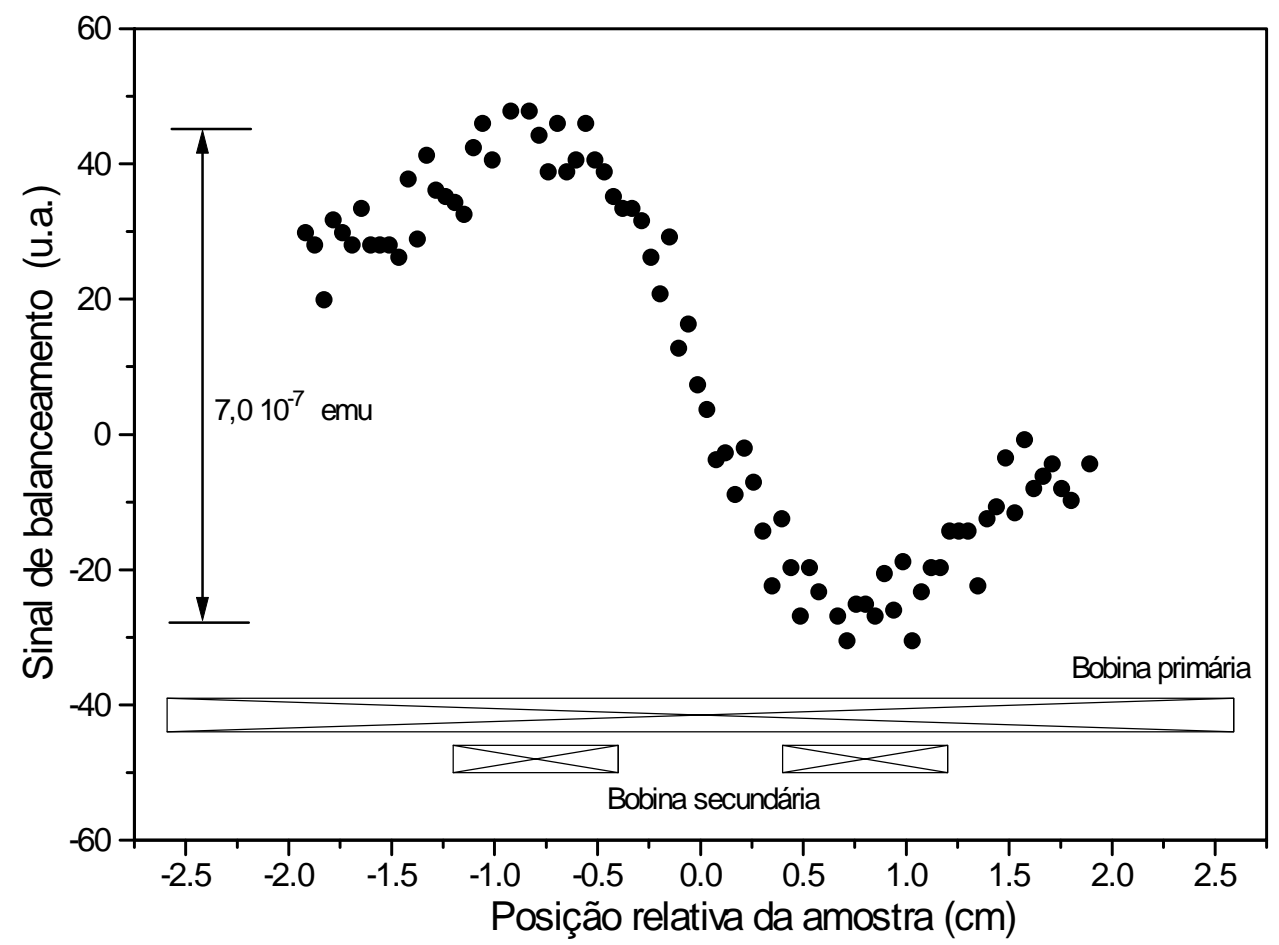

Figura 39 - Sinal de balanceamento (em quadratura) em função da posição da amostra relativa ao "probe". Medida utilizada para a determinação, exata, da posição da amostra $\left(\mathrm{CuSO}_{4}-5 \mathrm{H}_{2} \mathrm{O}\right)$ em relação ao centro de cada uma das bobinas secundárias.

Na aquisição do sinal, pela ponte de indutâncias mútuas, são realizados dois procedimentos: um para a determinação do posicionamento do "probe" relativo a amostra; e outro para aquisição dos sinais induzido pela amostra posicionada no centro de cada uma das bobinas secundárias. A determinação do posicionamento da amostra, realizado automaticamente pelo computador após análise dos dados mostrados na Figura 39, necessita de um tempo de aproximadamente 5 min. Embora este tempo seja relativamente longo, ele não prejudica a performance do susceptômetro, pois este 
procedimento é realizado apenas uma vez. Na medida do valor absoluto da susceptibilidade magnética, em cada temperatura, é necessário um tempo da ordem de 20 segundos. Este tempo é suficiente para a realização de 5 aquisições (realizadas para melhorar a relação sinal-ruído) em cada uma das duas posições do “probe”, movimento do "probe", leitura da temperatura e gravação, da susceptibilidade e da temperatura, em um arquivo de dados.

\subsection{5 - Sensibilidade}

Nos resultados, em temperatura ambiente, para o Sulfato de Cobre penta hidratado (ver Figura 38 e Figura 39), observa-se um sinal já bem ruidoso. Assim, a partir destes resultados, pode-se estimar o limite da sensibilidade do equipamento. Ou seja, para um campo magnético de 8 gauss e freqüência de 98,8 Hz, pode-se estimar, para o susceptômetro, uma sensibilidade da ordem de $1 \times 10^{-7}$ emu. Nestas condições, o susceptômetro apresenta uma resolução (1 bit) da ordem de $1 \times 10^{-7}$ emu.

Essa sensibilidade é inferior a dos susceptômetros comerciais ${ }^{[47]}$ por cerca de uma ordem de grandeza. Entretanto, observando-se os custos, o know-how adquirido e o fato do não resfriamento das bobinas e movimento do "probe”, este resultado pode ser considerado surpreendente, superando, inclusive, nossas expectativas. 


\section{4 - COMPOSTOS INTERMETÁLICOS}

Durante o desenvolvimento do susceptômetro, foram realizadas medidas em vários tipos de amostras, que serviram para testar sua qualidade e também para mostrar sua versatilidade. Dentre estas amostras destacamos: os supercondutores de alto $T_{c}$, os compostos intermetálicos e os polímeros condutores eletrônicos. Os resultados de supercondutores de alto $\mathrm{T}_{\mathrm{c}}$ são apresentados no Apêndice e os de polímeros condutores eletrônicos nos capítulos 5 e 6. Neste capítulo são mostrados alguns resultados, de susceptibilidade magnética AC, obtidos em certos tipos de compostos intermetálicos.

Os resultados apresentados neste capítulo, fazem parte de um projeto de pesquisa conjunto com o Departamento de Física da UFSCar, envolvendo os pesquisadores Maristela Olzon-Dyonisio e Sylvio Dyonisio de Souza. O trabalho encontra-se em fase de análise de dados, e por isso, por serem ainda preliminares, serão aqui omitidas as discussões mais profundas a respeito da interpretação dos resultados. No que diz respeito a esta tese, a importância das medidas efetuadas reside, principalmente, no fato delas representarem o primeiro teste real do susceptômetro construído. Estas medidas serviram para testar a qualidade do susceptômetro, ressaltando as suas principais características, tais como: reprodutibilidade, sensibilidade, precisão e automatização. Neste aspecto, as comparações dos nossos resultados, com os de outros trabalhos, serviram para dar confiabilidade ao equipamento.

O objetivo do projeto, é caracterizar as propriedades magnéticas de compostos intermetálicos ${ }^{[48-50]}$ do tipo $T b_{x} I n_{y}$ (Térbio-Índio) e $R e A l_{2}$, onde $x-y=1-1,2-$ 1 e 3-5, e Re = Gd, Tb, Ho e Dy (Gadolínio, Térbio, Hólmio e Disprósio). Separaremos os resultados obtidos em duas seções: na seção 4.1 serão mostrados os resultados para as amostras do tipo $\mathrm{Tb}_{\mathrm{x}} \mathrm{In}_{\mathrm{y}}$; e na seção 4.2 os resultados para as amostras do tipo $\operatorname{ReAl}_{2}{ }^{[51]}$. 
A preparação destes compostos é mais convenientemente realizada fundindo as porções estequiométricas dos metais componentes do composto, em um forno de arco ou em um forno de levitação. A combinação de metais por aquecimento em um cadinho é menos apropriado devido a rápida reação da terra rara com o material do cadinho em altas temperaturas. Em nosso caso, utilizou-se um forno de arco para a preparação das amostras.

Os compostos intermetálicos, aqui estudados, são constituidos pela composição de uma terra rara, com outros metais (In e Al). Sabe-se, da literatura, que a quantidade de compostos intermetálicos que pode ser produzido a partir de um elemento terra rara, é da ordem de milhares. Isto se dá devido a dois motivos. Em primeiro lugar tem-se o fato do grupo terras raras ser composto de 15 elementos, ou 16 se incluirmos o Ítrio (Y). Em segundo lugar, cada um desses 16 elementos, quando combinados com um parceiro não terra rara, pode, em geral, dar origem a mais de um composto. São conhecidos, por exemplo, sistemas binários que contêm mais de 10 diferentes compostos intermetálicos, cada um deles sendo caracterizado por composição e estrutura cristalina diferentes.

As terras raras formam um grupo de elementos químicos similares, que possuem em comum a camada eletrônica $4 f$ incompleta. Dos 13 elementos da série lantanídeos do grupo das terras raras (Ce a $\mathrm{Yb}$ ), 4 deles fazem parte dos compostos estudados neste trabalho (Gd, Tb, Dy e Ho). Eles são encontrados, normalmente, no estado de oxidação (+3), são fortemente paramagnéticos e, em alguns casos, se ordenam ferromagneticamente ou antiferromagneticamente em baixas temperaturas.

A configuração eletrônica de alguns íons de terras raras estão listadas na Tabela 2. Os valores de $L, S$ e $J$ foram calculados seguindo a regra de Hund.

Tabela 2 - Alguns íons terras raras trivalentes.

\begin{tabular}{||c|c|c|c|c|c|c|c|c||}
\hline \hline Terra rara & Conf. & Termo & $\mathbf{S}$ & $\mathbf{L}$ & $\mathbf{J}$ & $\mathbf{g}$ & $\mathbf{p}$ (calc) & $\mathbf{p}$ (exp) \\
\hline $\mathrm{Gd}^{3+}$ & $4 \mathrm{f}^{7} 5 \mathrm{~s}^{2} \mathrm{p}^{6}$ & ${ }^{8} \mathrm{~S}_{7 / 2}$ & $7 / 2$ & 0 & $7 / 2$ & 2 & 7,94 & 8,0 \\
\hline $\mathrm{Tb}^{3+}$ & $4 \mathrm{f}^{8} 5 \mathrm{~s}^{2} \mathrm{p}^{6}$ & ${ }^{7} \mathrm{~F}_{6}$ & 3 & 3 & 6 & $3 / 2$ & 9,72 & 9,5 \\
\hline $\mathrm{Dy}^{3+}$ & $4 \mathrm{f}^{9} 5 \mathrm{~s}^{2} \mathrm{p}^{6}$ & ${ }^{6} \mathrm{H}_{15 / 2}$ & $5 / 2$ & 5 & $15 / 2$ & $4 / 3$ & 10,63 & 10,6 \\
\hline $\mathrm{Ho}^{3+}$ & $4 \mathrm{f}^{10} 5 \mathrm{~s}^{2} \mathrm{p}^{6}$ & ${ }^{5} \mathrm{I}_{8}$ & 2 & 6 & 8 & $5 / 4$ & 10,60 & 10,4 \\
\hline
\end{tabular}


Em geral, a susceptibilidade magnética de cristais isolantes, contendo terras raras como impurezas, obedece, com bastante rigor, a lei de Curie, que é freqüentemente escrita na forma:

$$
\chi_{V}=\frac{N J(J+1) g^{2} \mu_{B}^{2}}{3 K_{B} T}=\frac{N p^{2} \mu_{B}^{2}}{3 K_{B} T}=\frac{C}{T}
$$

onde $T$ é a temperatura, $C=N p^{2} \mu_{B}^{2} / 3 K_{B}$ é a constante de Curie por unidade de volume, $p=g[J(J+1)]^{1 / 2}$ é o número efetivo de magnetons de Bohr, $\mu_{B}=e \hbar / 2 m c=$ $9,2710^{-21} \mathrm{erg} / \mathrm{G}$ é o magneton de Bohr, $K_{B}=1,38 \cdot 10^{-16} \mathrm{erg} / \mathrm{K}$ é a constante de Boltzman, $g$ é o "fator g" de Landé (ou simplesmente "fator-g”), $N$ é o número de átomos por unidade de volume e $J=L \pm S$ é o momento magnético total, calculado a partir das regras de Hund. Nesta expressão $\chi_{V}$ simboliza a susceptibilidade magnética por unidade de volume.

Utilizando o modelo de acoplamento de momentos angulares, $L-S$, o fator-g, dado por

$$
g=1+\frac{J(J+1)+S(S+1)-L(L+1)}{2 J(J+1)}
$$

pode ser usado, em conjunto com a Eq. (34), para o cálculo do número efetivo de magnetons de Bohr, $p($ calc), tabelados na Tabela 2. A última coluna desta tabela mostra os valores $p(\exp )$ determinados experimentalmente ${ }^{[52,53]}$, onde pode-se notar a excelente concordância com os valores calculados, o que demonstra o sucesso da regra de Hund e do modelo de acoplamento $L$-S. Isto se deve, principalmente, ao fato de os elétrons da camada $4 f$ estarem blindados pelas camadas 5 s e $5 p$, e por isso, não são muito afetados pelo campo cristalino.

Em geral, os materiais compostos de terras raras apresentam um comportamento magnético bastante complexo. Normalmente, em altas temperaturas observa-se, através das medidas de susceptibilidade magnética, um comportamento paramagnético que, de acordo com as teorias de campo médio, leva a uma dependência da susceptibilidade com a temperatura do tipo Curie-Weiss: 


$$
\chi_{V}=\frac{C}{T-\theta}=\frac{N \mu_{B}^{2} g^{2} J(J+1)}{3 K_{B}(T-\theta)}
$$

onde $C$ é uma constante e $\theta$ uma temperatura crítica que reflete o acoplamento entre os íons magnéticos. Quando $\theta$ é positivo, o acoplamento entre os íons é ferromagnético em altas temperaturas, por outro lado, se $\theta$ é negativo este acoplamento é antiferromagnético. No caso particular em que $\theta$ é nulo, espera-se que não deva existir acoplamento

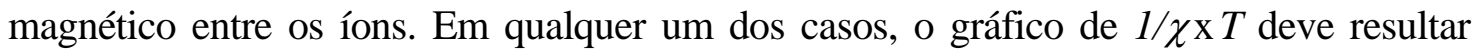
numa relação linear, onde, a partir do coeficiente angular pode-se determinar a constante $C$, e a partir do intercepto com o eixo $T$ pode-se determinar $\theta$. Utilizando a Eq. (36) e o valor estimado para $C$, a partir dos resultados experimentais, pode-se calcular o momento magnético efetivo do íon.

Em baixas temperaturas, a diminuição da agitação térmica permite que o acoplamento entre os spins promova o ordenamento magnético. Em muitos casos, o ordenamento, que se observa em baixas temperaturas, corresponde ao mesmo previsto pelo comportamento em altas temperaturas. Em outros casos, o comportamento magnético observado em baixas temperaturas é bastante complexo, envolvendo diversas transições de fase, tanto magnéticas como estruturais. Isto faz com que a análise dos resultados obtidos na medida da susceptibilidade AC requeira conhecimentos adicionais, adquiridos através de outras técnicas, tais como espalhamento de nêutrons, difração de raios-X e susceptibilidade DC.

\section{1- Compostos intermetálicos do tipo $\operatorname{Tb}_{\mathrm{x}} \mathrm{In}_{\mathrm{y}}$}

As amostras de $T b I n, ~ T b_{2} I n$ e $T b_{3} I_{5}$ foram encapsuladas, em tubos de pirex, sob atmosfera de Argônio, a fim de evitar-se a oxidação. A susceptibilidade magnética AC dessas amostras foi medida na ausência de campo DC e com um campo AC de freqüência de 98,9 Hz e intensidade de 2 G.

Os resultados das medidas de susceptibilidade AC em TbIn e $\mathrm{Tb}_{2} \mathrm{In}$ foram comparados com resultados de susceptibilidade magnética DC existentes na literatura $^{[54-58]}$ (ver Figura 41, Figura 43 e Figura 44). Para a amostra de $\mathrm{Tb}_{3} \mathrm{In}_{5}$ foram realizadas medidas de susceptibilidade magnética AC e DC (ver Figura 46). As medidas 
de susceptibilidade DC, para a amostra de $\mathrm{Tb}_{3} \mathrm{In}_{5}$, foram realizadas, no laboratório do Prof. Gaston Barberis, no Instituto de Física da Unicamp (Campinas - SP), utilizando um magnetômetro de SQUID.

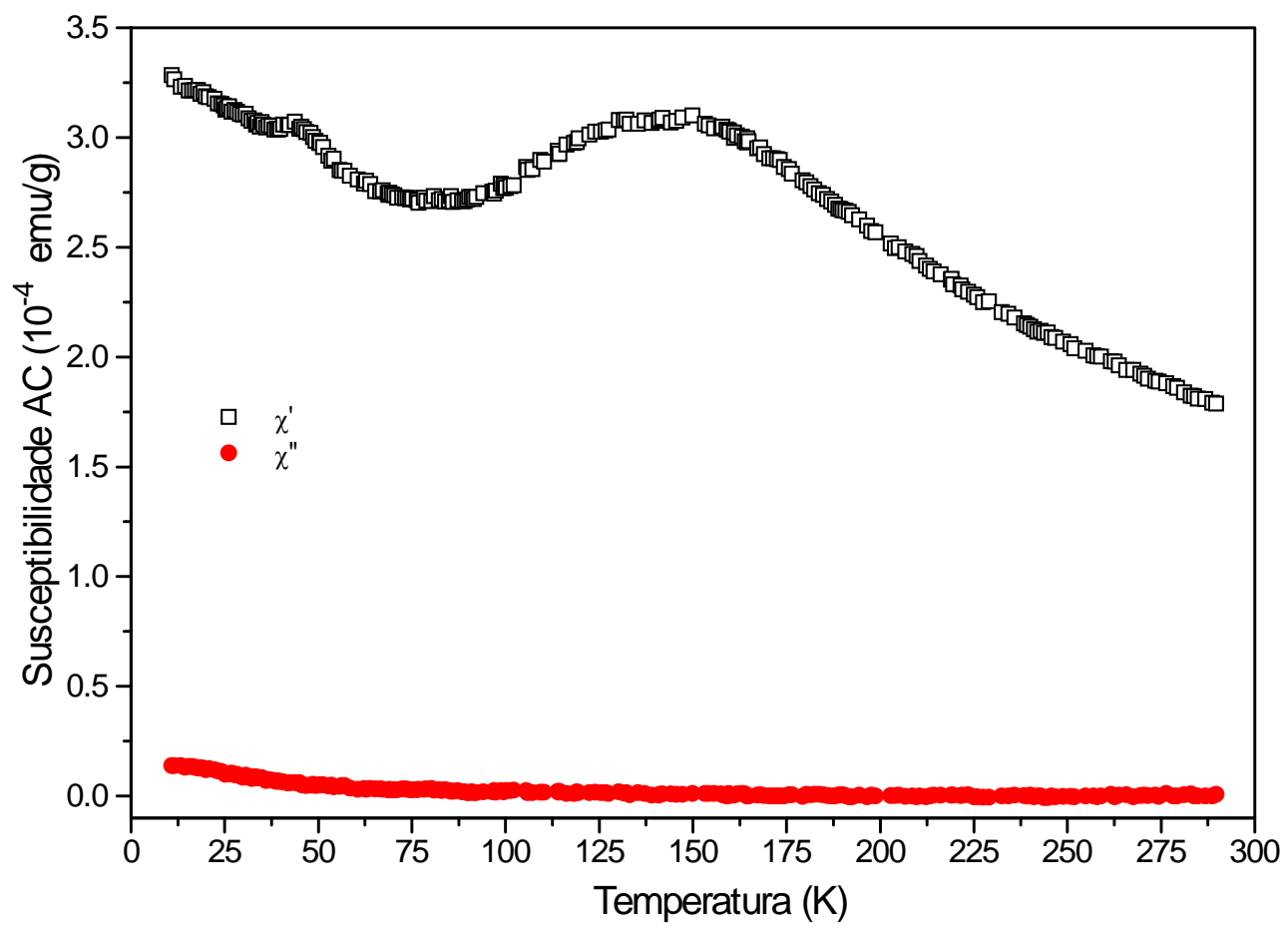

Figura 40 - Susceptibilidade magnética AC em função da temperatura da amostra de TbIn. Campo magnético DC nulo e campo magnético AC de 2 gauss de intensidade e freqüência de 98,9 Hz.

Na Figura 40 são mostrados as componentes, real e imaginária, da susceptibilidade magnética AC para a amostra de TbIn. A componente imaginária mostra uma fraca dependência com a temperatura, aumentando monotonicamente com o decréscimo da temperatura. Talik et $\mathrm{al}^{[55]}$ realizaram medidas, neste tipo de composto, em uma faixa de temperaturas mais abrangente, na qual foi possível observar um comportamento paramagnético acima de $200 \mathrm{~K}$. Os resultados de Talik, mostrados na Figura 41, foram obtidos utilizando a técnica de amostra vibrante, em uma faixa de temperaturas entre 77 e 1000 K. Em seu artigo são apresentados resultados de medidas em várias amostras de terras raras com In, nas quais foram utilizados campo DC entre 500 e 2000 G. Entretanto não fica claro qual foi o campo DC aplicado na amostra de TbIn. Embora nossos resultados e de Talik tenham sido obtidos por técnicas diferentes (AC e 
DC), observa-se, a partir da comparação, uma grande concordância dos valores das susceptibilidades na região entre 77 e $290 \mathrm{~K}$.

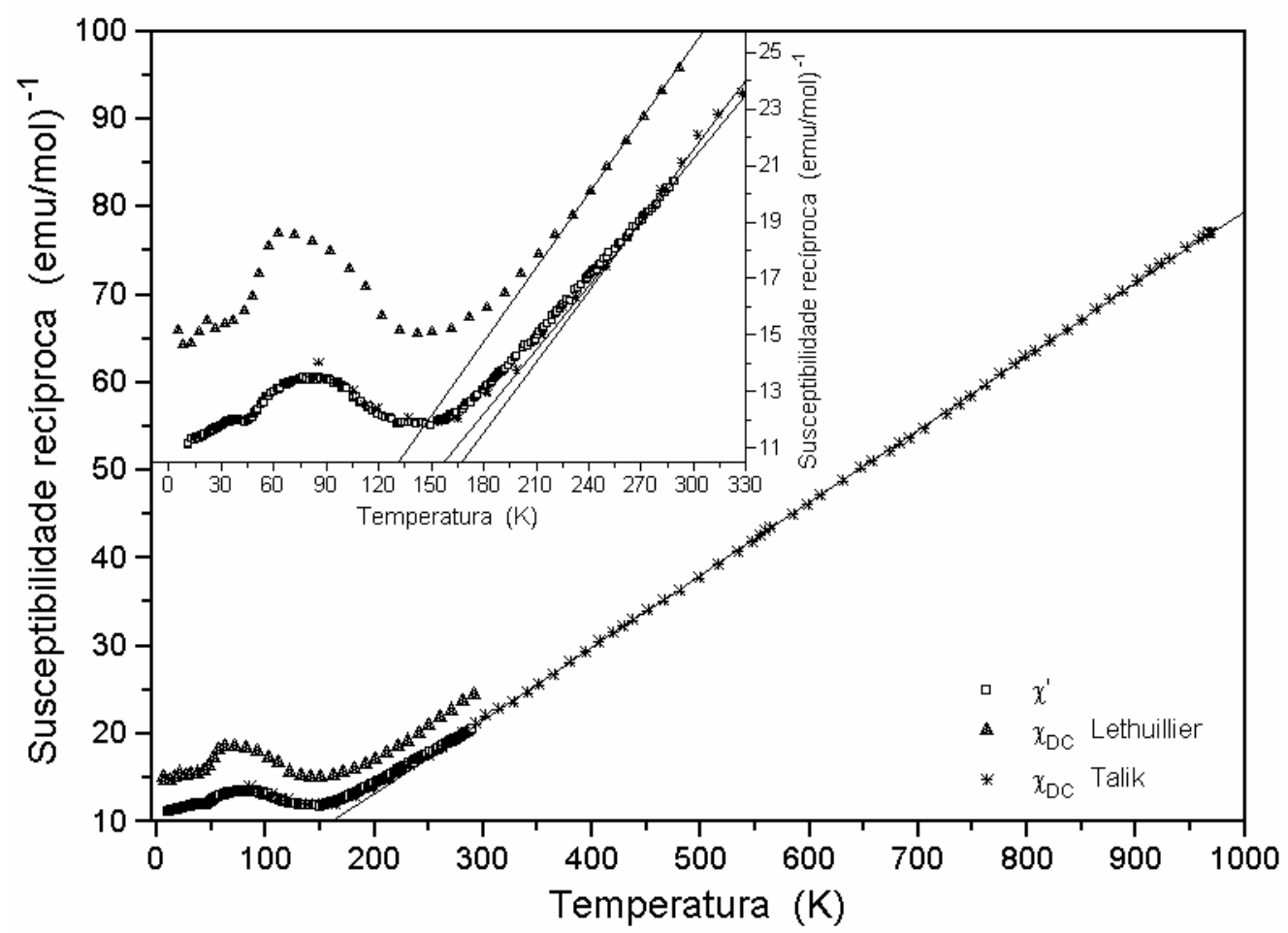

Figura 41 - Dependência com a temperatura da susceptibilidade molar recíproca do composto intermetálico de TbIn: $\square$ componente real da susceptibilidade AC medida sem campo DC e com campo AC de 2 G de intensidade e 98,9 Hz de freqüência; - suscetibilidade DC, obtida por Lethuillier; Percheron-Guegan ${ }^{[54]}$, medida utilizando uma balança de Faraday com um campo magnético DC de 1600 G; \$ suscetibilidade DC, obtida por Talik et $\mathrm{al}^{[55]}$, medida utilizando a técnica de amostra vibrante.

Na Figura 41 está mostrado também a comparação entre nossos resultados e os resultados obtidos por Lethuillier; Percheron-Guegan ${ }^{[54]}$. Estas medidas de susceptibilidade DC, foram realizadas, na mesma faixa de temperatura que a nossa, utilizando a técnica de balança de Faraday, com um campo magnético DC de 1600 G. Observamos, nesta figura, que os comportamentos da susceptibilidade recíproca em função da temperatura, para as duas medidas, são bastante semelhantes, entretanto, as amplitudes são diferentes.

A partir dos nossos resultados é possível estimar o valor da Temperatura de Curie-Weiss. A extrapolação de uma reta na região de temperaturas entre $240 \mathrm{~K} \mathrm{e}$ $300 \mathrm{~K}$ resulta em $\theta=15 \mathrm{~K}$, o que é consistente com o valor obtido por Lethuillier 
$(\theta=16 \mathrm{~K})$ na mesma faixa de temperaturas. Entretanto, este resultado difere daquele obtido por Talik: $\theta=40 \mathrm{~K}$. É provável que o resultado mais correto seja o de Talik, visto que ele efetuou medidas até mais altas temperaturas, onde o comportamento paramagnético está melhor definido. O valor positivo obtido para $\theta$ fornece indícios de que o comportamento magnético deste sistema, em baixas temperaturas deve ser ferromagnético. Isto foi confirmado por Lethuillier; Percheron-Guegan ${ }^{[54]}$, através da técnica de Difração de Nêutrons.

Uma outra informação que se pode obter do gráfico da Figura 41 é o valor do momento magnético efetivo do Tb, expresso através do número de magnetons de Bohr (p). Utilizando nossos resultados, este valor é obtido a partir do ajuste linear na região de altas temperaturas ( $240 \mathrm{~K}$ a $300 \mathrm{~K})$, de onde obtemos, $p=10,35$. Este valor está um pouco acima daquele obtido por Talik ( $p=9,87$ ), e também, daquele obtido por cálculos teóricos para o íon livre de $\mathrm{Tb}^{3+}(p=9,72)$.

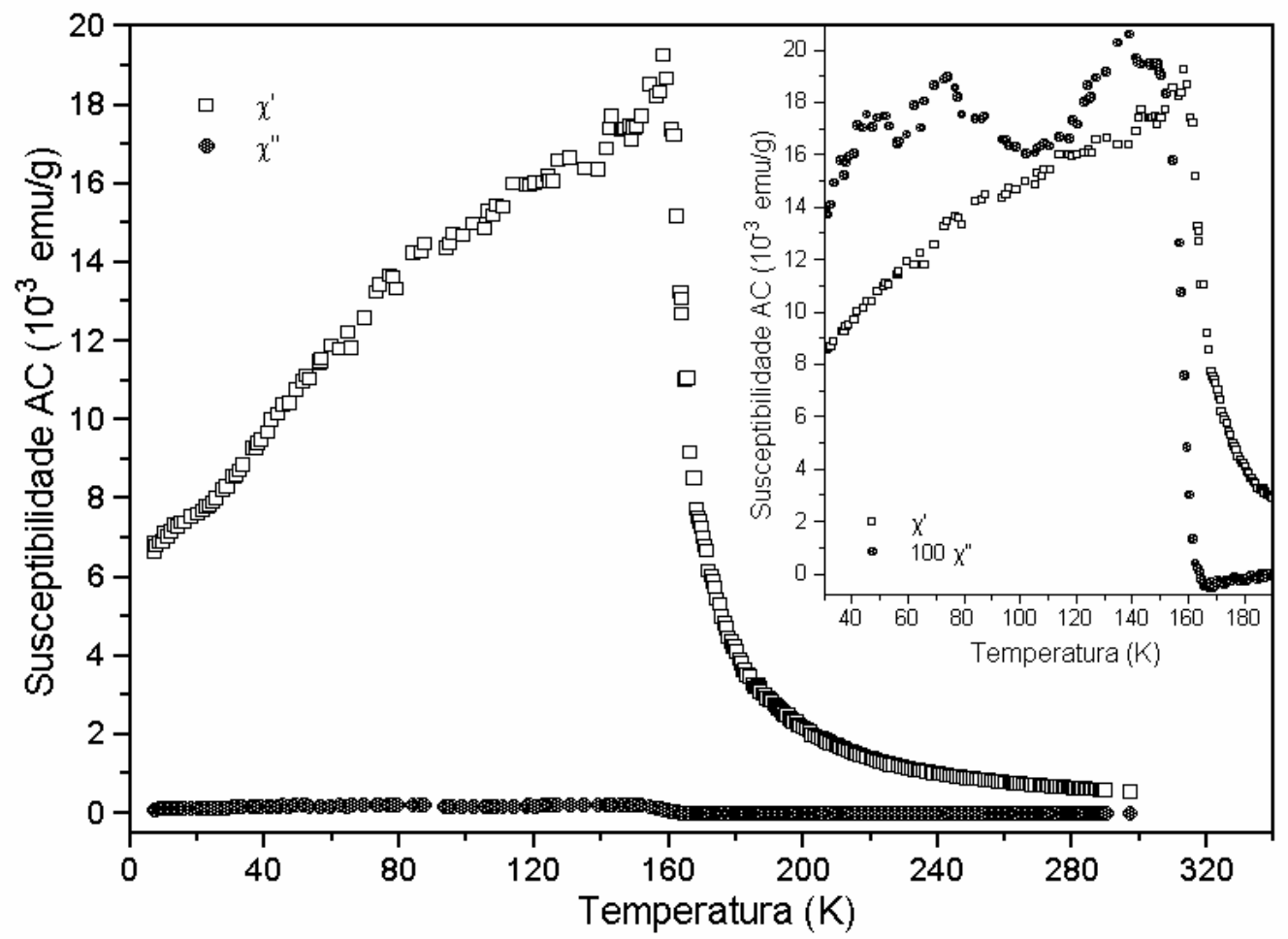

Figura 42 - Susceptibilidade magnética AC em função da temperatura da amostra de $\mathrm{Tb}_{2}$ In. Campo magnético DC nulo e campo magnético AC de 2 gauss de intensidade e freqüência de $98,9 \mathrm{~Hz}$. O gráfico interno mostra a componente real e uma ampliação (por um fator 100) da componente imaginária da susceptibilidade AC. 
A medida da susceptibilidade magnética $A C$ para a amostra de $T_{2} I n$, mostrada na Figura 42, foi realizada entre $7 \mathrm{~K}$ e $297 \mathrm{~K}$, utilizando uma quantidade de 73,5 mg de amostra. No gráfico interno, desta figura, podemos notar que a componente imaginária da susceptibilidade é nula em altas temperaturas e, abruptamente, cresce abaixo de $160 \mathrm{~K}$.

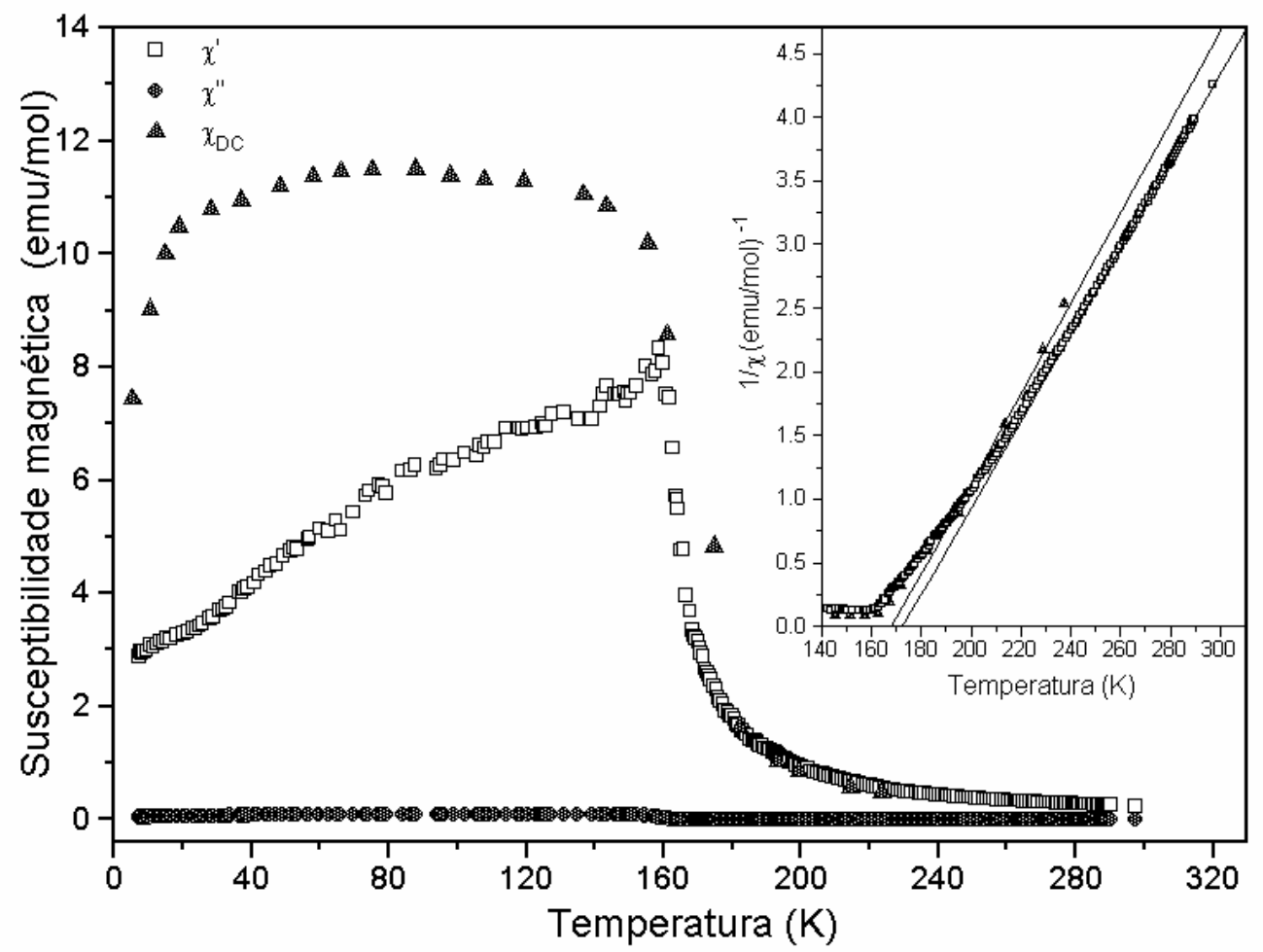

Figura 43 - Susceptibilidade molar em função da temperatura da amostra de $\mathrm{Tb}_{2} \mathrm{In}$. $\square$ componente real, e • componente imaginária da susceptibilidade AC, medida sem campo DC e com campo AC de $2 \mathrm{G}$ de intensidade e $98,9 \mathrm{~Hz}$ de freqüência; - suscetibilidade DC, obtida por Gamari-Seale et $\mathrm{al}^{[57]}$, medida utilizando um magnetômetro de amostra vibrante com um campo magnético DC de 1000 G. O gráfico interno mostra o inverso da componente real da susceptibilidade $\mathrm{AC}$ e da susceptibilidade DC em função da temperatura. Neste gráfico são mostrados também os ajustes, em altas temperaturas, para o comportamento de Curie-Weiss (linhas cheias).

Ao fazer um ajuste para o comportamento de Curie-Weiss na região de altas temperaturas (ver gráfico interno da Figura 43), obteve-se $\theta=171 \mathrm{~K}$, o que é consistente com os valores encontrados na literatura ${ }^{[56-58]}$ (entre $160 \mathrm{~K}$ e $\left.183 \mathrm{~K}\right)^{\star}$. Este

Para maiores detalhes, veja os valores na Tabela 3. 
valor positivo, da constante de Curie-Weiss, fornece indícios de transição ferromagnética. Esse comportamento ferromagnético, e m baixas temperaturas, foi confirmado por Kawano et $\mathrm{al}^{[56]}$ por meio de medidas de magnetização DC, em função do campo aplicado, em temperaturas abaixo e acima da temperatura de ordenamento ferromagnético. O campo magnético DC utilizado na medida de Kawano foi de até 16 kG. GamariSeale et $\mathrm{al}^{[57]}$ observaram, também através de magnetização DC, que além desta transição ferromagnética há uma outra transição em temperaturas ainda mais baixas. Suas medidas de magnetização mostraram um comportamento antiferromanético em 4,2 K.

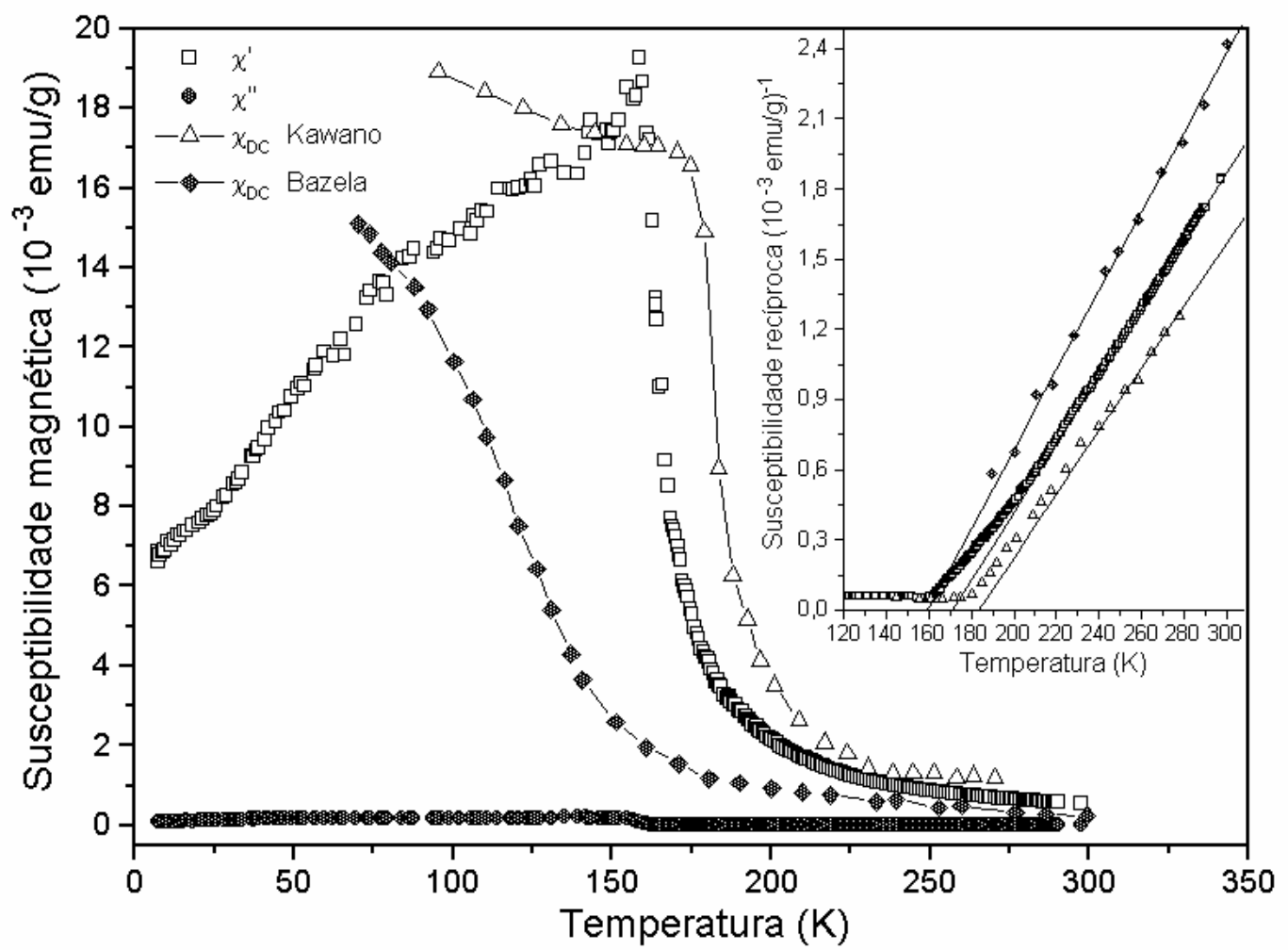

Figura 44 - Susceptibilidade mássica em função da temperatura da amostra de $\mathrm{Tb}_{2} \mathrm{In}$. $\square$ componente real, e • componente imaginária da susceptibilidade AC, medida sem campo DC e com campo AC de $2 \mathrm{G}$ de intensidade e $98,9 \mathrm{~Hz}$ de freqüência; $\Delta$ suscetibilidade DC, obtida por Kawano et al, medida utilizando um magnetômetro de amostra vibrante com um campo magnético DC de $500 \mathrm{G}$; - suscetibilidade DC, obtida por Bazela; Szytula, medida utilizando uma balança de Faraday com um campo magnético DC de 10000 G. O gráfico interno mostra o inverso da componente real da susceptibilidade AC e da susceptibilidade DC em função da temperatura. Neste gráfico são mostrados também os ajustes, em altas temperaturas, para o comportamento de Curie-Weiss (linhas cheias). 
Na Figura 43 e Figura 44 são comparados nossos resultados com outros obtidos da literatura $^{[56-58]}$. O resultado de susceptibilidade DC apresentado por GamariSeale et $\mathrm{al}^{[57]}$ foi obtido utilizando um magnetômetro de amostra vibrante com campo DC de 1000 G (ver Figura 43). Kawano et $\mathrm{al}^{[56]}$ utilizou em suas medidas um magnetômetro de amostra vibrante com campo DC de 500 G, e Bazela; Szytula ${ }^{[58]}$ utilizou uma balança de Faraday com campo DC de 10 kG (ver Figura 44).

Os valores do número de magneton de Bohr obtidos por Kawano et al ${ }^{[56]}$ $(p=9,80)$ e Bazela; Szytula ${ }^{[58]}(p=9,83)$, são próximos do valor teórico esperado para o íon livre $(p=9,72)$. Entretanto, tanto o nosso valor $(p=10,84)$ quanto aquele obtido por Gamari-Seale et $\mathrm{al}^{[57]}(p=10,40)$, estão acima do esperado para o íon livre.

A outra amostra desta série é a $\mathrm{Tb}_{3} \mathrm{In}_{5}$. Para esta medida foi utilizado 81,8 mg de amostra. A literatura não fornece resultados experimentais de susceptibilidade magnética para este composto. Os resultados que obtivemos para as componentes real e imaginária da susceptibilidade AC são mostrados na Figura 45. Em baixas temperaturas observa-se picos em ambas componentes da susceptibilidade.

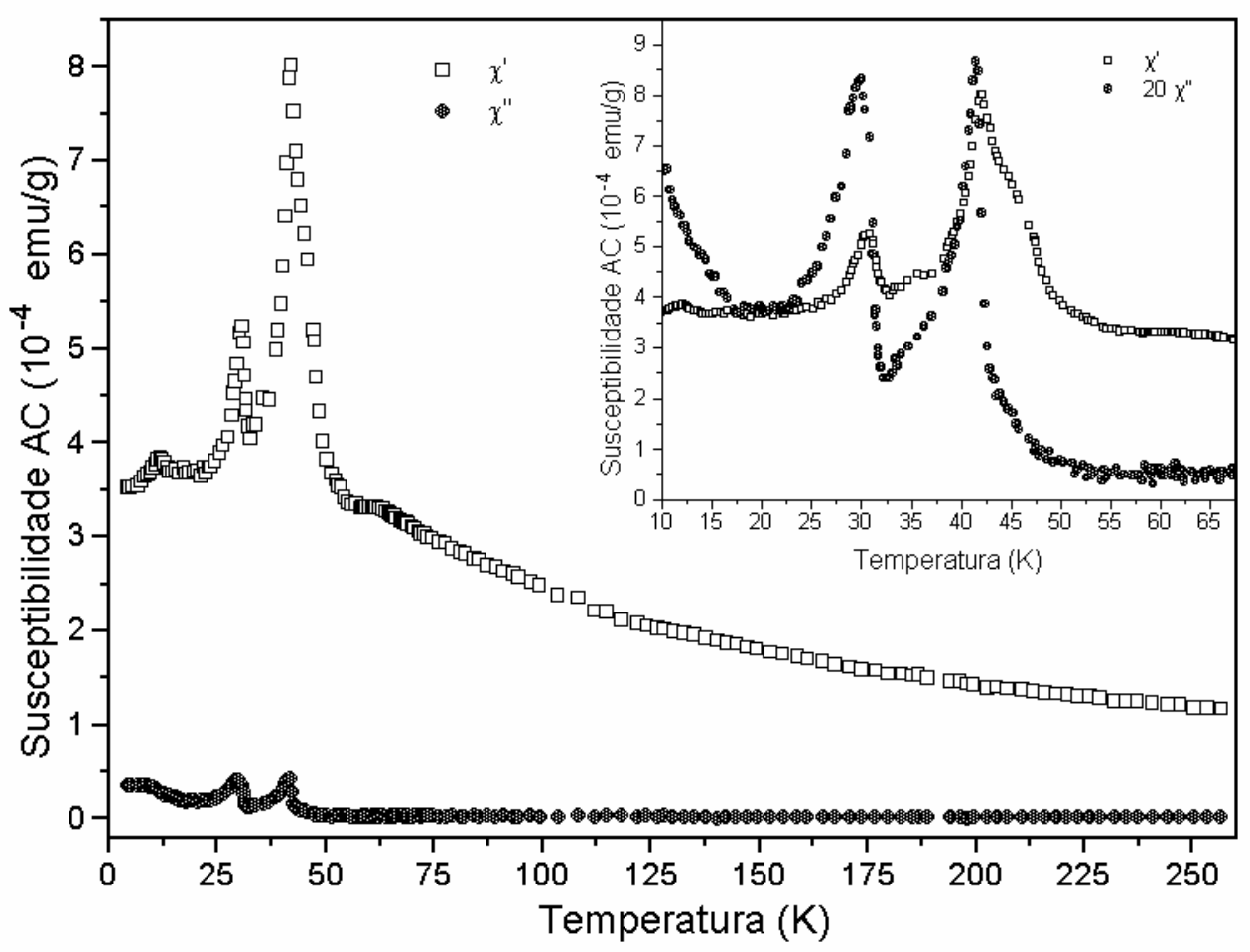

Figura 45 - Susceptibilidade magnética AC em função da temperatura da amostra de $\mathrm{Tb}_{3} \mathrm{In}_{5}$. Campo magnético DC nulo e campo magnético AC de 2 gauss de intensidade e freqüência de $98,9 \mathrm{~Hz}$. O gráfico interno mostra a componente real e uma ampliação (por um fator 20) da componente imaginária da susceptibilidade AC. 
Os resultados da medida de susceptibilidade magnética AC e DC ${ }^{\sqrt{a}}$, no composto $\mathrm{Tb}_{3} \mathrm{In}_{5}$, estão mostrados na Figura 46. Para a medida DC foi utilizado uma parte, contendo $9 \mathrm{mg}$ de massa, da mesma amostra utilizada na medida AC. Observamos que ambos resultados têm um comportamento semelhante em altas temperaturas, e que em baixas temperaturas a medida AC é muito mais rica em detalhes que a DC.

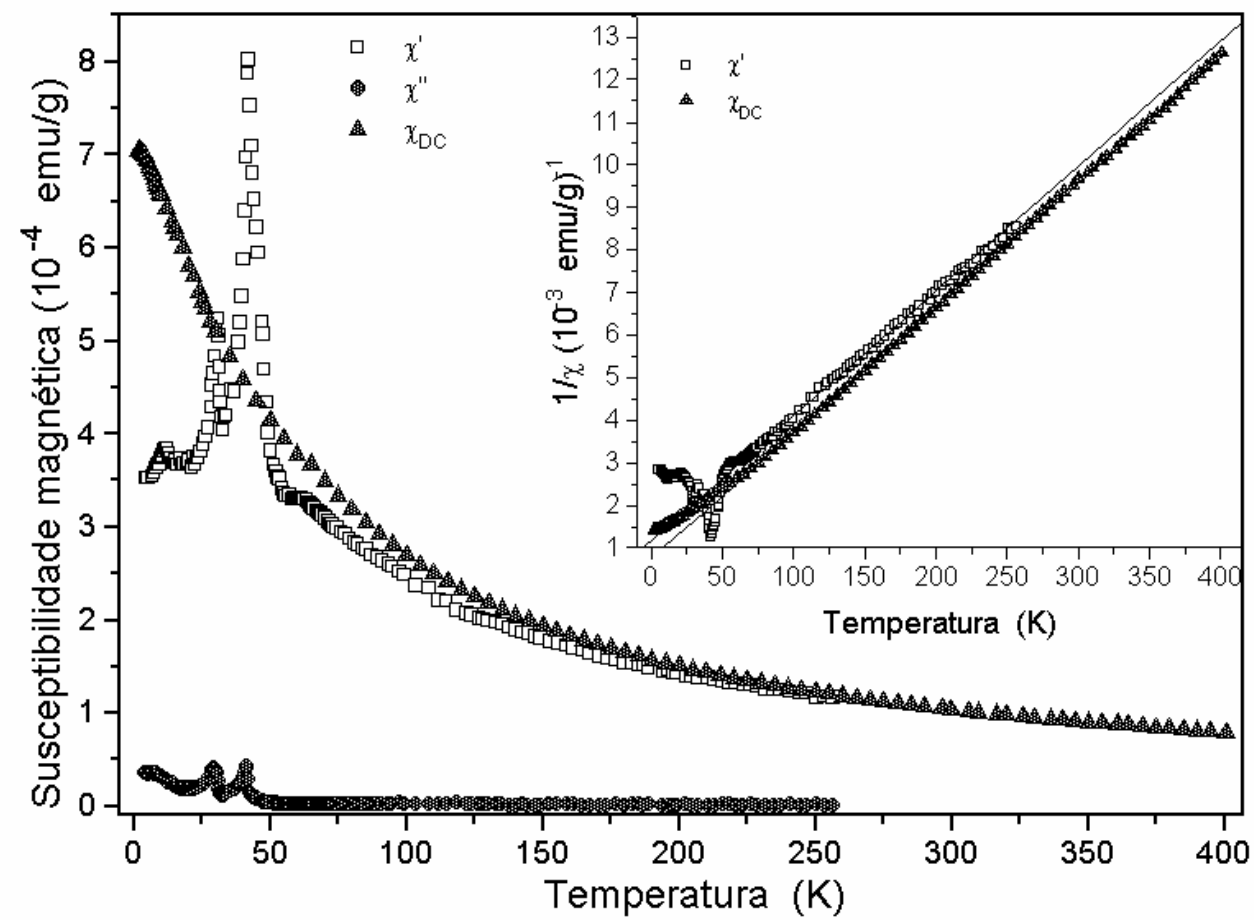

Figura 46 - Susceptibilidade mássica em função da temperatura da amostra de $\mathrm{Tb}_{3} \mathrm{In}_{5}$. $\square$ componente real, e • componente imaginária da susceptibilidade AC, medida sem campo DC e com campo AC de $2 \mathrm{G}$ de intensidade e 98,9 Hz de freqüência; • suscetibilidade DC obtida utilizando um magnetômetro SQUID com um campo magnético DC de $50 \mathrm{kG}$. O gráfico interno mostra o inverso da componente real da susceptibilidade AC e da susceptibilidade DC em função da temperatura, neste gráfico é mostrado também o ajuste, em altas temperaturas, para o comportamento de Curie-Weiss (linhas cheias).

As duas medidas resultaram em um mesmo valor para o número de magnéton de Bohr $(p=9,77)$. Este valor foi obtido através do ajuste mostrado no gráfico interno da Figura 46. A partir deste gráfico foi obtido também o valor da Temperatura de Curie-Weiss: $\theta=-39 \mathrm{~K}$ para a medida AC e $\theta=-26 \mathrm{~K}$ para a medida DC.

\footnotetext{
${ }^{\Xi}$ Esta medida foi realizada no Laboratório do Prof. Gaston Barberis, no Instituto de Física da UNICAMP.
} 
Embora haja uma pequena discrepância entre os valores da Temperatura de Curie-Weiss, obtida a partir das duas técnicas, ambas são negativas, o que é uma indicação de ordenamento antiferromagnético em baixas temperaturas. Porém o valor negativo dessa constante não é um fator conclusivo. Para podermos afirmar com certeza o tipo (ou tipos) de ordenamento magnético em baixas temperaturas, será necessário a realização da medida da curva de magnetização em algumas temperaturas abaixo da região paramagnética, uma vez que pode haver mais de uma transição magnética. Esta medida poderá ser realizada, futuramente, utilizando o magnetômetro SQUID.

Tabela 3 - Temperatura de Curie-Weiss $(\theta)$, temperatura de transição de fase magnética $\left(T_{N}\right)$ e momento efetivo $(p)$ dos compostos intermetálicos do tipo $\mathrm{Tb}_{\mathrm{x}} \mathrm{In}_{\mathrm{y}}$.

\begin{tabular}{|c|c|c|c|c|c|c|c|}
\hline \multirow[t]{2}{*}{ Amostra } & \multicolumn{2}{|c|}{$\theta(\mathbf{K})$} & \multicolumn{2}{|c|}{$\mathbf{T}_{\mathrm{N}}(\mathrm{K})^{\phi}$} & \multicolumn{3}{|c|}{ p } \\
\hline & medido & liter. & medido & liter. & medido & liter. & teórico \\
\hline TbIn & 15 & $\begin{array}{c}16^{d} \\
40^{\circ}\end{array}$ & 145 & $\begin{array}{c}145^{d} \\
145^{\circ}\end{array}$ & 10,35 & $9,87^{\circ}$ & 9,72 \\
\hline $\mathrm{Tb}_{2} \mathrm{In}$ & 171 & $\begin{array}{l}183^{\circ} \\
170^{\natural} \\
160^{\square}\end{array}$ & - & $\begin{array}{l}185^{\circ} \\
175^{\square}\end{array}$ & 10,84 & $\begin{array}{r}9,80^{\circ} \\
10,40^{\circ} \\
9,83^{\square}\end{array}$ & 9,72 \\
\hline $\mathrm{Tb}_{3} \mathrm{In}_{5}$ & -39 & $-26^{\odot}$ & - & - & 9,77 & $9,77^{\odot}$ & 9,72 \\
\hline
\end{tabular}

^a temperatura $T_{N}$ é obtida verificando o ponto de máxima susceptibilidade magnética.

resultados obtidos por Lethuillier; Percheron-Guegan ${ }^{[54]}$, utilizando balança de Faraday (1600 G).

Oresultados obtidos por Talik et al ${ }^{[55]}$, utilizando o método de Faraday.

resultados obtidos por Kawano et al ${ }^{[56]}$, utilizando um magnetômetro de amostra vibrante (500 G).

resultados obtidos por Gamari-Seale et al ${ }^{[57]}$, utilizando um magnetômetro de amostra vibrante (1000 G).

${ }_{\text {resultados obtidos por Bazela; Szytula }}^{[58]}$, utilizando uma balança de Faraday (10 kG).

resultados obtidos da medida, na mesma amostra, utilizando um magnetômetro SQUID (50 kG).

Na Tabela 3 estão listados as temperaturas de Curie-Weiss $(\theta)$, as temperaturas de transição de fase magnética $\left(T_{N}\right)$ e os números de magneton de $\operatorname{Bohr}(p)$ para as amostras de $\operatorname{Tb}_{\mathrm{x}} \mathrm{In}_{\mathrm{y}}$, obtidos a partir dos resultados mostrados na Figura 40 até a Figura 46 e dos resultados encontrados na literatura. A temperatura $T_{N}$ foi obtida, na região onde há a transição de fase magnética, verificando o ponto de máxima susceptibilidade magnética.

Comparando os diversos valores listados na Tabela 3 verificamos que os valores obtidos de nossas medidas estão consistentes com aqueles obtidos da literatura. As diferenças existentes entre estes valores podem ser atribuídas às diferenças entre as amostras ou entre as técnicas utilizadas. 


\section{2 - Compostos intermetálicos do tipo $\operatorname{ReAl}_{2}$}

As propriedades magnéticas de compostos intermetálicos do tipo $\mathrm{ReAl}_{2}$ (onde $\mathrm{Re}=$ terras raras) foram extensivamente estudadas durante os últimos anos. Medidas de magnetização ${ }^{[59-64]}$ e difração de nêutrons ${ }^{[62,65]}$ verificaram que, abaixo de uma temperatura de transição, estes compostos ordenam-se magneticamente. Na maioria das vezes este ordenamento é ferromagnético.

Nesta seção mostraremos nossos resultados das medidas de susceptibilidade magnética AC para amostras, de $\mathrm{ReAl}_{2}$, com $\mathrm{Re}=\mathrm{Gd}$, Tb, Dy e Ho. Estas medidas foram realizadas, em função da temperatura (entre 4,2 e $300 \mathrm{~K}$ ), na ausência de campo DC e com um campo AC de freqüência de 98,9 Hz e intensidade variando entre 1 e $3 \mathrm{G}$.

Na Tabela 4 são listados os valores das quantidades de massas de cada amostra utilizadas na medida da susceptibilidade magnética $\mathrm{AC}$, bem como a intensidade do campo magnético AC aplicado a estas amostras.

Tabela 4 - Intensidade do campo AC aplicado e massa, de $\operatorname{ReAl}_{2}$, utilizada na medida da susceptibilidade magnética.

\begin{tabular}{||c|c|c||}
\hline Amostra & massa (mg) & campo AC (G) \\
\hline $\mathrm{GdAl}_{2}$ & 22,4 & 2 \\
\hline $\mathrm{TbAl}_{2}$ & 62,5 & 2 \\
\hline $\mathrm{DyAl}_{2}$ & 77,4 & 1 \\
\hline $\mathrm{HoAl}_{2}$ & 29,5 & 3 \\
\hline
\end{tabular}

Assim como na literatura ${ }^{[59-67]}$, todas essas amostras apresentaram um comportamento paramagnético de Curie-Weiss em altas temperaturas, passando a se ordenar ferromagneticamente em baixas temperaturas. Com exceção da amostra de $\mathrm{GdAl}_{2}$ (ver Figura 47) todas elas apresentaram um comportamento semelhante da susceptibilidade em função da temperatura (ver Figura 48 à Figura 49). Em torno da temperatura de transição, as amostras de $\mathrm{TbAl}_{2}, \mathrm{HoAl}_{2}$ e $\mathrm{DyAl} \mathrm{A}_{2}$ apresentaram um valor máximo para a componente real da susceptibilidade magnética, e a componente imaginária passou a ter um valor não nulo (cerca de uma ordem de grandeza menor que o da componente real). 


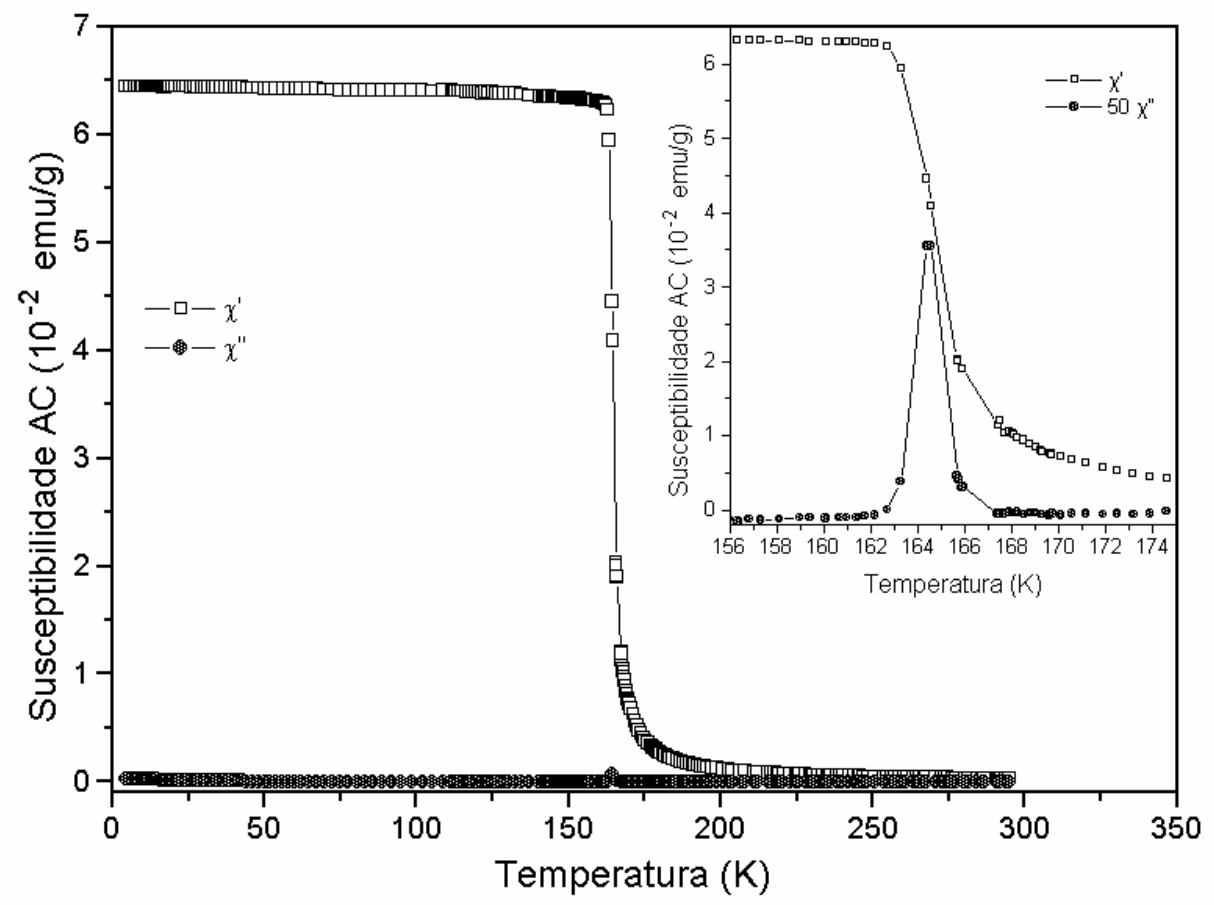

Figura 47 - Susceptibilidade magnética AC em função da temperatura da amostra de $\mathrm{GdAl}_{2}$. Campo magnético DC nulo e campo magnético AC de 2 gauss de intensidade e freqüência de $98,9 \mathrm{~Hz}$. O gráfico interno mostra a componente real e uma ampliação (por um fator 50) da componente imaginária da susceptibilidade AC.

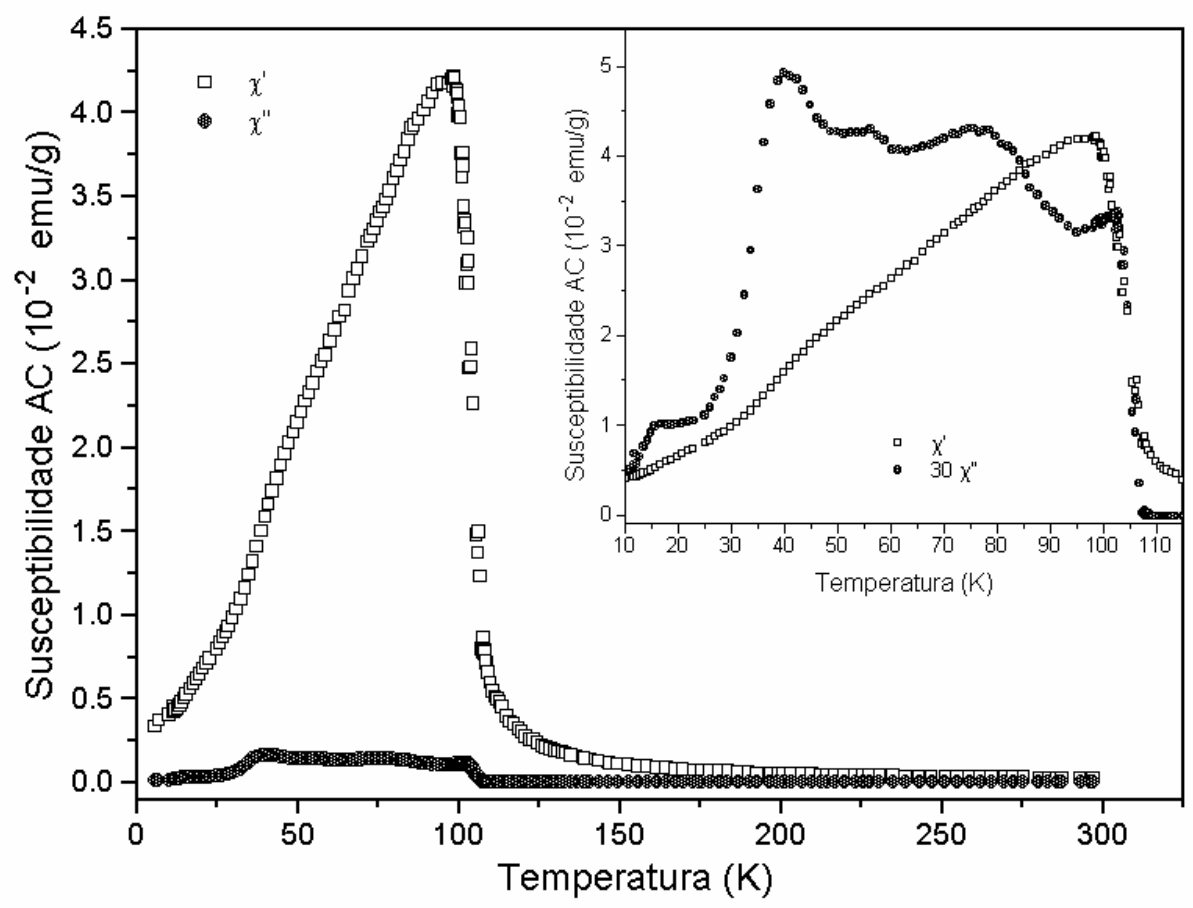

Figura 48 - Susceptibilidade magnética AC em função da temperatura da amostra de $\mathrm{TbAl}_{2}$. Campo magnético DC nulo e campo magnético AC de 2 gauss de intensidade e freqüência de 98,9 Hz. O gráfico interno mostra a componente real e uma ampliação (por um fator 30) da componente imaginária da susceptibilidade AC. 


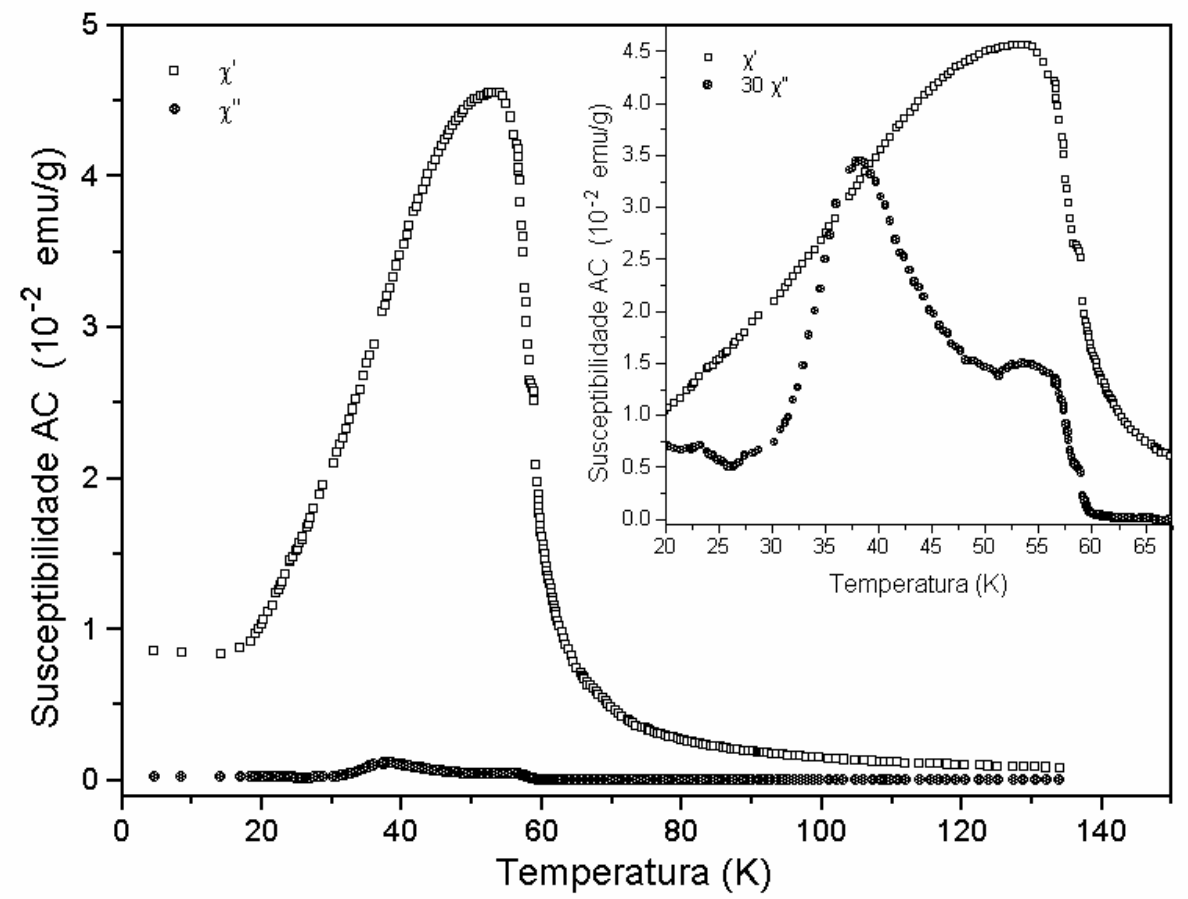

Figura 49 - Susceptibilidade magnética AC em função da temperatura da amostra de $\mathrm{DyAl}_{2}$. Campo magnético DC nulo e campo magnético AC de 1 gauss de intensidade e freqüência de 98,9 Hz.O gráfico interno mostra a componente real e uma ampliação (por um fator 30) da componente imaginária da susceptibilidade AC.

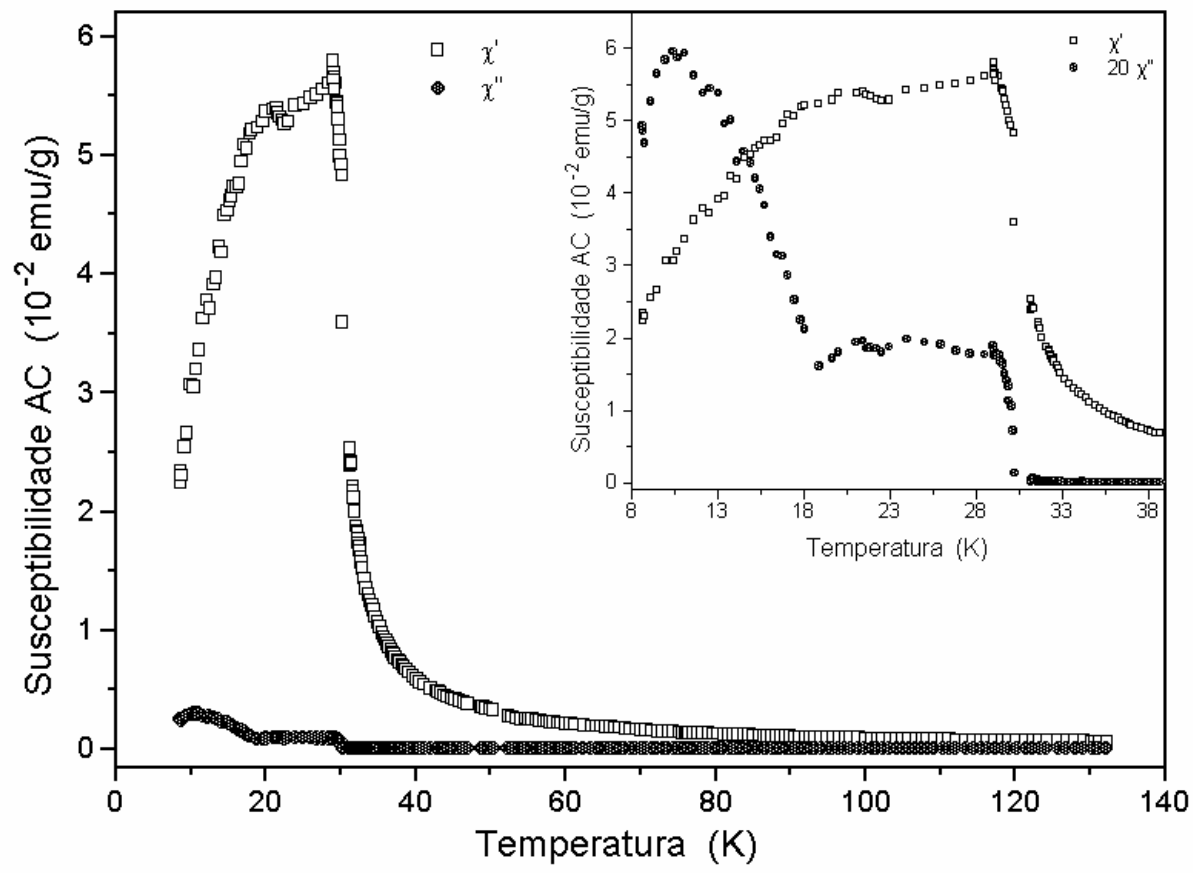

Figura 50 - Susceptibilidade magnética AC em função da temperatura da amostra de $\mathrm{HoAl}_{2}$. Campo magnético DC nulo e campo magnético AC de 3 gauss de intensidade e freqüência de 98,9 Hz.O gráfico interno mostra a componente real e uma ampliação (por um fator 20) da componente imaginária da susceptibilidade AC. 
O GdAl 2 , como mostra a Figura 47, apresentou transição abrupta em torno de $160 \mathrm{~K}^{\mathrm{a}}$, onde verifica-se a existência de um pico estreito na componente imaginária. Abaixo desta temperatura, a componente real é praticamente constante.

Com a finalidade de obter-se os valores das temperaturas de CurieWeiss $(\theta)$ e dos números de magnetons de Bohr $(p)$, foi feito um gráfico da susceptibilidade mássica recíproca, de cada um dos compostos, em função da temperatura (ver Figura 51). Os valores das temperaturas de Curie-Weiss foram obtidos através da extrapolação do comportamento paramagnético de Curie-Weiss em altas temperaturas. Esses valores estão listados na Tabela 5, bem como alguns valores obtidos da literatura, utilizando o método de Faraday ${ }^{[59-61]}$, de Gouy ${ }^{[62]}$ e de indutância mútua $^{[63,64]}$, e medidas de resistividade ${ }^{[66]}$ e de $\mathrm{NMR}^{[63,67]}$.

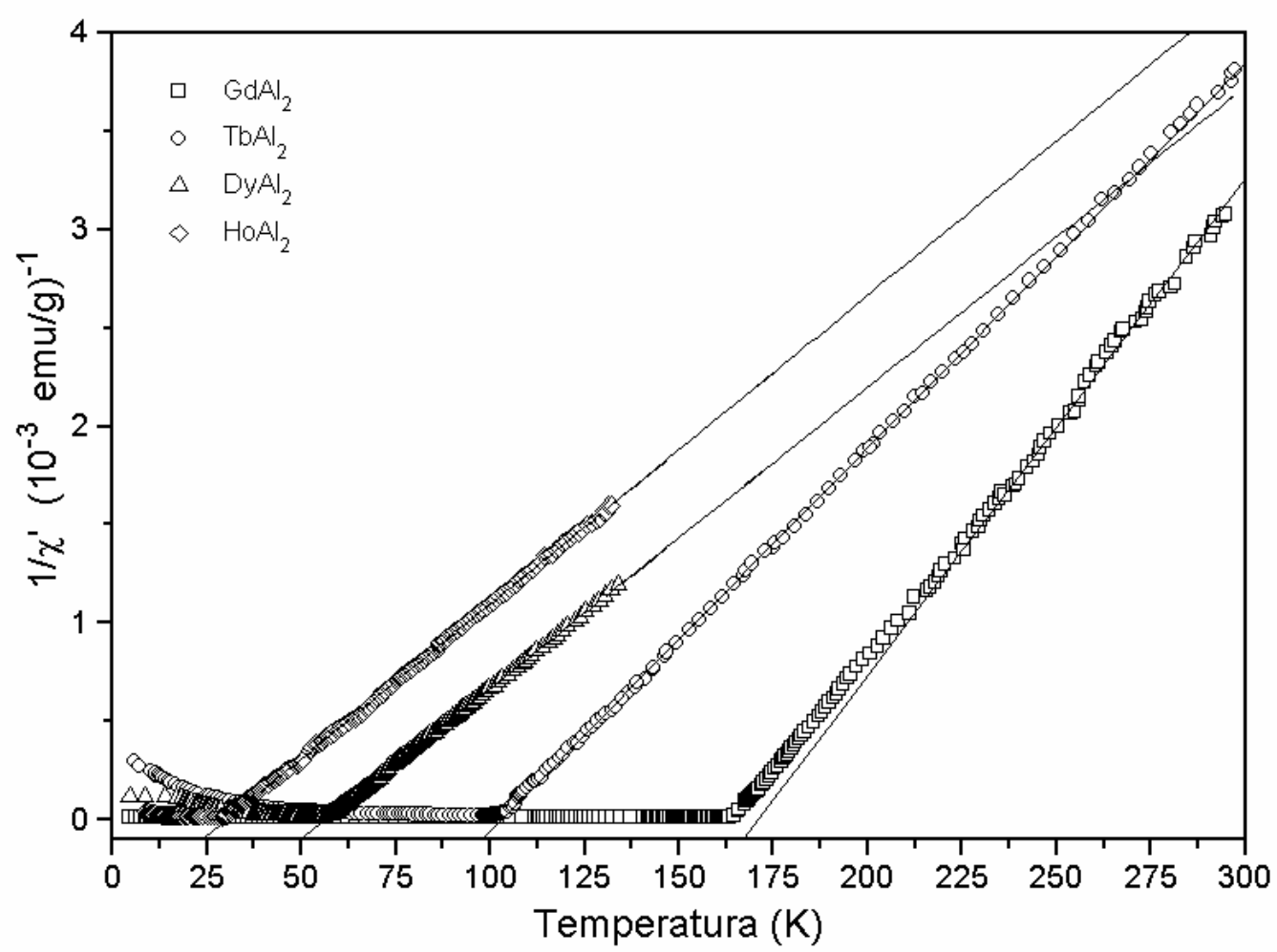

Figura 51 - Inverso da componente real da susceptibilidade magnética AC em função da temperatura, dos compostos intermetálicos do tipo $\operatorname{ReAl}_{2}$. Campo magnético DC nulo e campo magnético AC de freqüência de 98,9 Hz e intensidade 2 gauss para Gd e Tb, 1 gauss para Dy e 3 gauss para Ho.

\footnotetext{
(⿴囗十) Segundo Buchow et al ${ }^{[60]}$ esta transição fica menos acentuada a medida que o campo magnético DC é aumentado.
} 
Observando os valores dos números de magnetons de Bohr $(p)$ na Tabela 5, notamos que, com exceção da amostra de $\mathrm{TbAl}_{2}$ (que tem um valor um pouco abaixo do teórico), os valores experimentais estão bem próximo daqueles, teóricos, obtidos para o íon livre e coerentes também com aqueles otidos da literatura. As temperaturas de Curie-Weiss $(\theta)$ apresentaram uma discrepância relativamente alta entre nossos valores e os valores encontrados na literatura, e até mesmo entre os próprios valores da literatura.

Tabela 5 - Temperatura de Curie-Weiss $(\theta)$, temperatura de transição de fase magnética $\left(T_{N}\right)$ e número de magneton de Bohr $(p)$ dos compostos intermetálicos do tipo $\operatorname{ReAl}_{2}$.

\begin{tabular}{|c|c|c|c|c|c|c|c|}
\hline \multirow{2}{*}{ Amostra } & \multicolumn{2}{|c|}{$\theta(\mathbf{K})$} & \multicolumn{2}{|c|}{$\mathbf{T}_{\mathbf{N}}(\mathbf{K})^{\phi}$} & \multicolumn{3}{|c|}{$\mathbf{p}$} \\
\hline & medido & liter. & medido & liter. & medido & liter. & teórico \\
\hline $\mathrm{GdAl}_{2}$ & 171 & $\begin{array}{r}171,5^{\circ} \\
180^{8} \\
182^{8} \\
173^{-} \\
170 \pm 5^{\circ}\end{array}$ & 166 & $\begin{array}{c}171^{\circledR} \\
168^{8}\end{array}$ & 8,17 & $\begin{array}{c}7,88^{\circ} \\
7,92^{\circledR} \\
7,96^{\varnothing}\end{array}$ & 7,94 \\
\hline $\mathrm{TbAl}_{2}$ & 102,8 & $\begin{array}{r}108^{8} \\
121^{8} \\
111^{\text {ه }} \\
\end{array}$ & 113 & $110^{8}$ & 9,35 & $\begin{array}{l}9,82^{y} \\
9,81^{8}\end{array}$ & 9,72 \\
\hline $\mathrm{DyAl}_{2}$ & 56,2 & $\begin{array}{r}70^{8} \\
68 \pm 1^{\square} \\
62^{\odot} \\
62^{\square} \\
68 \pm 2^{\circ}\end{array}$ & 61 & $64^{3}$ & 10,64 & $\begin{array}{r}10,7^{d} \\
9,7 \pm 0,1^{\square}\end{array}$ & 10,60 \\
\hline $\mathrm{HoAl}_{2}$ & 30,2 & $\begin{array}{c}42^{\delta} \\
36^{\circ} \\
29^{\oplus}\end{array}$ & 36 & $\begin{array}{r}30^{8} \\
33 \pm 1^{\circ}\end{array}$ & 10,56 & $\begin{array}{r}10,7^{\circ} \\
9,18^{\circ}\end{array}$ & 10,60 \\
\hline
\end{tabular}

† a temperatura $T_{N}$ é obtida verificando o ponto de máxima susceptibilidade magnética.

${ }^{6}$ resultados obtidos por Stalínski; Pokrzywnicki ${ }^{[59]}$, utilizando o método de Faraday (9280 G).

resultados obtidos por Buschow et al ${ }^{[60]}$, utilizando o método de Faraday (30 kG).

resultados obtidos por Swift; Wallace ${ }^{[61]}$, utilizando o método de Faraday (19 kG).

${ }^{\square}$ resultados obtidos por Nereson et al ${ }^{[62]}$, utilizando o método de Gouy (1580 G).

${ }^{-}$resultados obtidos por Berthier; Devine ${ }^{[63]}$, utilizando o método de indutância mútua.

Oresultados obtidos por Barbara et al ${ }^{[64]}$, utilizando o método de indutância mútua.

resultados obtidos por Van Daal; Buschow ${ }^{[66]}$, utilizando medidas de resistividade.

'resultados obtidos por Barash et al ${ }^{[67]}$, utilizando medidas de NMR na região paramagnética. 


\section{5 - POLIPARAFENILENO}

\section{1 - Polímeros condutores eletrônicos}

No início do século XX, surgiu um fato importante na história da humanidade. Verificou-se que alguns materiais, produzidos no final do século XIX e que até então eram considerados como colóides (uma categoria intermediária entre mistura heterogênea e homogênea), consistiam na verdade de moléculas gigantescas, que podiam resultar do encadeamento de grande quantidade de átomos de carbono (10.000 ou mais). Esses produtos de síntese apresentavam repetições de pequenas unidades estruturais em sua longa cadeia principal, e assim foram denominados polímeros (que em grego significa "muitas partes") ${ }^{[68]}$.

Em resumo, um polímero é uma molécula muito grande que pode ser constituída de muitas moléculas pequenas e idênticas, chamadas de monômeros, ligadas entre si por meio de ligações covalentes. Como existem muitos tipos de monômeros, estes materiais possuem uma grande diversidade de propriedades físicoquímicas, o que torna possível a sua aplicação em um grande número de sistemas. Assim, o uso de materiais poliméricos está aumentando a cada ano e em muitas aplicações eles vêm substituindo materiais convencionais. Atualmente, grande quantidade de materiais poliméricos sintéticos são indispensáveis em nossa vida moderna, como plásticos, borrachas, fibras e adesivos, entre outros.

As vantagens dos polímeros orgânicos, como por exemplo, custo e processabilidade, estavam limitadas quando o assunto era boa condutividade elétrica. O surgimento de polímeros condutores como uma nova classe de materiais têm atraído muita atenção, por isso, o estudo destes sistemas tem gerado conceitos científicos novos e perspectivas para novas tecnologias. 
Por muito tempo esses compostos orgânicos foram considerados exemplos típicos de materiais isolantes, embora isto seja verdade para compostos saturados, ou seja, para compostos em que todos os quatro elétrons de valência do átomo de carbono estão participando nas ligações covalentes. Nos compostos orgânicos ditos não saturados, os elétrons de maior energia de cada átomo formam um tipo especial de ligação chamada ligação pi (esta ligação ocorre quando a maior densidade eletrônica ocupa duas regiões em lados opostos ao eixo da ligação, veja Figura 52). A nuvem eletrônica correspondente distribui-se paralelamente ao plano que une átomos consecutivos e pode ser compartilhada por grupos de átomos ${ }^{[69]}$.

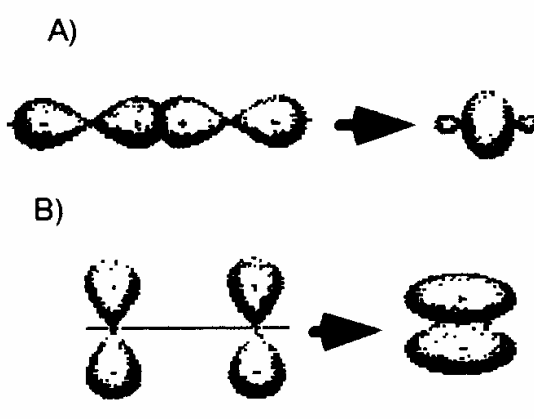

C)

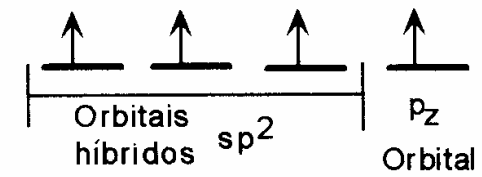

Não-hibridizado

Figura 52 - Representação A) da ligação sigma $(\sigma)$, B) da ligação pi $(\pi)$ e C) do orbital hibridizado $s p^{2} p_{z}$ para o átomo de carbono.

Em polímeros conjugados, a hibridização $s p^{2} p_{z}$ (Figura 52C) leva formalmente a um elétron desemparelhado por carbono. Dessa forma a estrutura eletrônica é determinada pela simetria da cadeia, o que resulta na possibilidade de tais polímeros exibirem propriedades semicondutoras ou ainda metálicas.

A condutividade elétrica de polímeros condutores é resultado de portadores de carga móveis introduzidos através do processo de dopagem. A descoberta que o poliacetileno $(\mathrm{PA})^{\circ}$ pode ser dopado após síntese, em temperatura ambiente, e com uma grande variedade de dopantes, abriu o campo para o estudo de polímeros condutores.

\footnotetext{
${ }^{\circ} \mathrm{O}$ poliacetileno [-CH- $]_{n}$ é o mais simples entre os polímeros conjugados e o primeiro a ser estudado. Para se ter uma idéia, durante a década passada mais de dois mil trabalhos foram publicados sobre este polímero.
} 
Além da concentração de portadores, outro fator limitante para a condutividade elétrica é a mobilidade dos portadores. A mobilidade efetiva dos portadores é determinada, como mostra a Figura 53, por três elementos, que são: transporte intracadeia, transporte intercadeias e transporte por contato interpartículas.

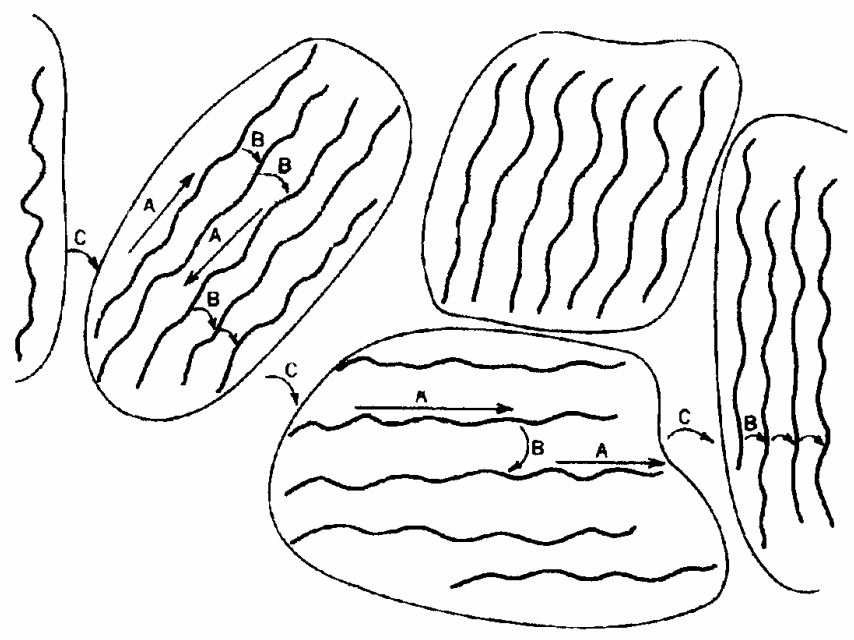

Figura 53 - Condutividade em um polímero condutor, com $A$ indicando transporte de carga intracadeia, $B$ intercadeias e $C$ interpartículas. As setas mostram o caminho de uma carga migrando através do material.

Separaremos os resultados obtidos para os polímeros condutores eletrônicos em dois capítulos: neste capítulo serão mostrados os resultados para o poliparafenileno; e no capítulo seguinte os resultados para a poli(o-metoxianilina).

O objetivo do presente trabalho foi investigar as possíveis alterações no comportamento da magnetização em função da temperatura e da concentração de dopagem com cloreto de ferro $\left(\mathrm{FeCl}_{3}\right)$. Para isso, utilizou-se os resultados obtidos através de duas técnicas: Susceptibilidade Magnética AC (SMAC); e Ressonância Paramagnética Eletrônica (RPE). Este material foi estudado, também, por outras técnicas espectroscópicas tais como: Espectroscopia de Alta Resolução por RMN; absorção atômica; e condutividade DC. Entretanto estes resultados não serão discutidos aqui por ser objeto de estudo de um outro trabalho de Doutorado, que está sendo desenvolvido neste departamento ${ }^{[70]}$. 


\section{2 - Poliparafenileno}

Até o final da década de 70, apenas o PoliAcetileno (PA) era conhecido como polímero condutor eletrônico. Em 1979, descobriu-se que o poliparafenileno (do inglês "PolyParaPhenylene" - PPP) poderia fornecer uma alta condutividade ao ser dopado. Na Figura 54 são comparados os valores de condutividade de alguns polímeros condutores com de alguns materiais convencionais. Vê-se, desta figura, que o PPP possui uma condutividade que pode variar desde $10^{-15} \mathrm{~S} / \mathrm{cm}$ (quando não dopado) até $10^{3} \mathrm{~S} / \mathrm{cm}$ (quando dopado com $\mathrm{AsF}_{5}$ ), que é da ordem de grandeza da condutividade de metais.

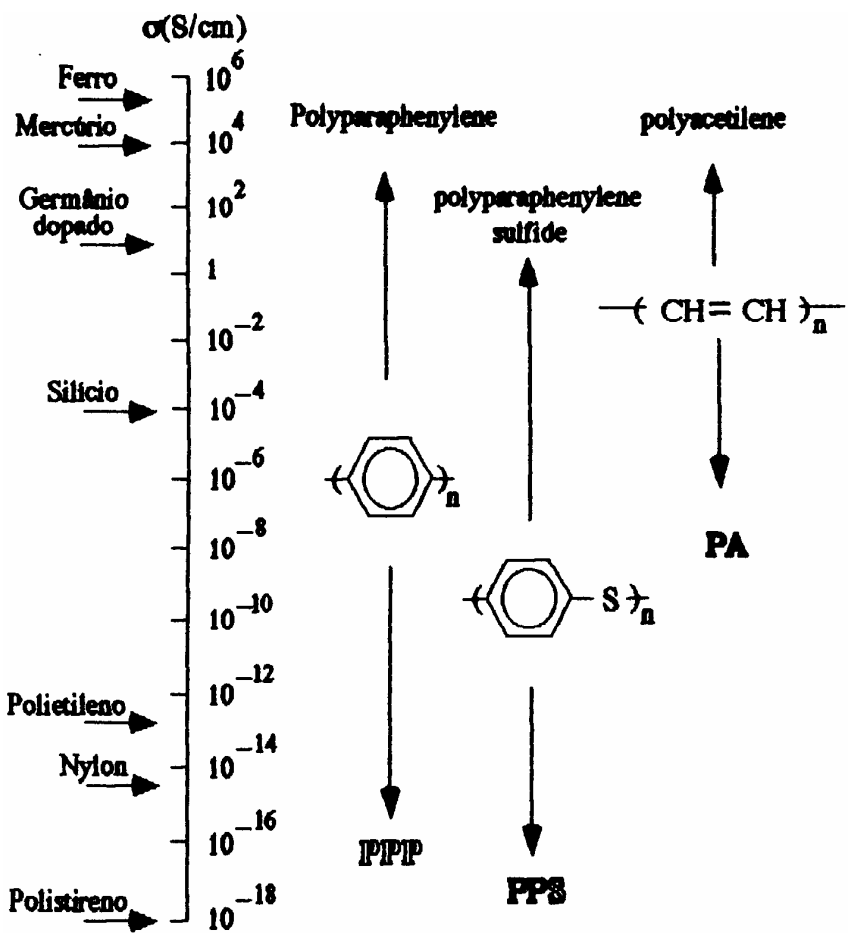

Figura 54 - Escala de condutividade do poliparafenileno (PPP), poliparafenileno sulfide (PPS) e poliacetileno (PA) dopados com AsF $F_{5}$ comparada com a condutividade de alguns materiais convencionais.

O PPP consiste de uma seqüência de anéis benzeno ligados na posição $p$ (posição “para”), com comprimento de ligações carbono-carbono ${ }^{[71]}$ dentro dos anéis de $1,4 \AA$ e entre os anéis de $1,5 \AA$. Uma forma ressonante pode ser derivada do anel benzenóide (Figura 55A) que corresponde a uma estrutura quinóide. Contudo, as formas benzenóides e quinóides não são energeticamentes equivalentes, sendo que a 
estrutura quinóide possui maior energia. Outra importante característica deste material é que, devido a sua não degenerescência do estado fundamental, ele não permite a acomodação de solitons. Assim os defeitos, no PPP, estão fortemente interagindo e correlacionados em pares. A literatura ${ }^{[72]}$ traz um tamanho médio para estes defeitos da ordem de 5 anéis, enquanto a cadeia polimérica tem em média o tamanho de 20 anéis benzenos (Figura 55B).
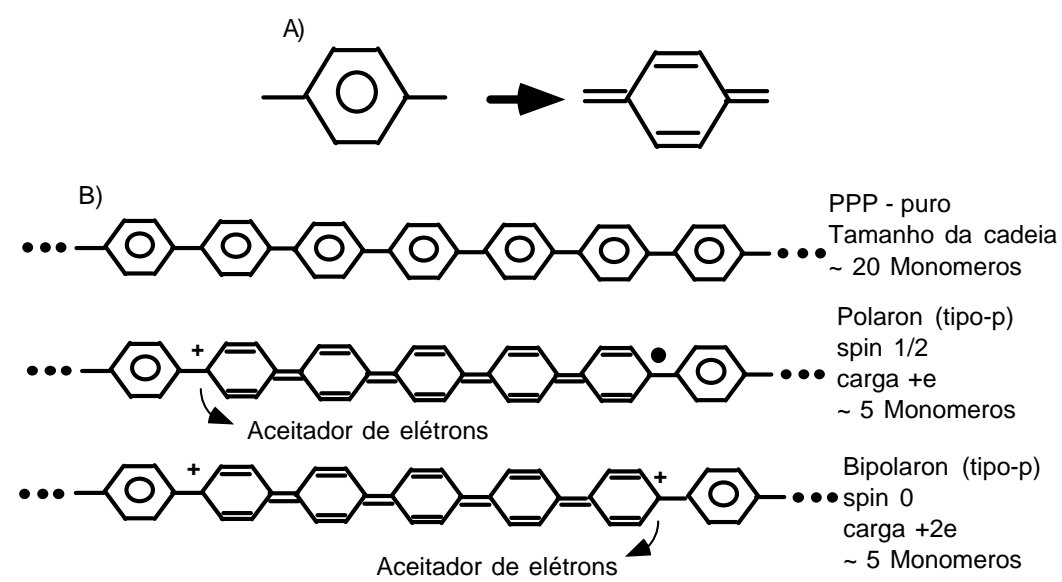

C)
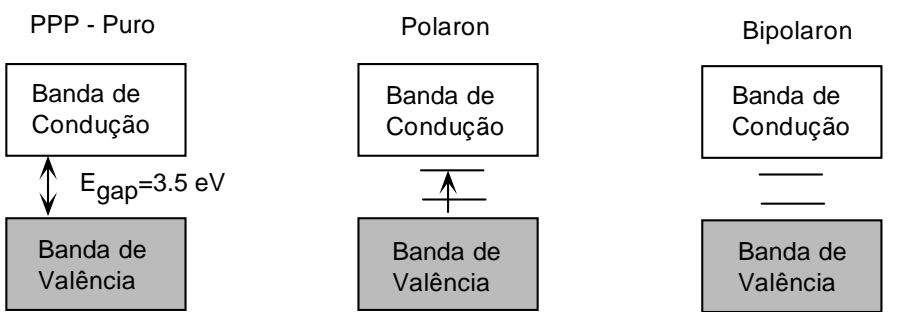

Figura 55 - A) forma benzenóide e quinóide encontrada no poliparafenileno; B) cadeia polimérica do poliparafenileno ( 20 anéis) e os defeitos produzidos devido a introdução do dopante no polímero ( 5 anéis); e C) estrutura de banda do PPP puro, do polaron e do bipolaron.

O defeito polarônico, como mostra a Figura 55B, é formado a partir da interação entre um defeito carregado com um defeito neutro. Este defeito se estende sobre 5 anéis, produzindo uma deformação, na cadeia polimérica, de aproximadamente 13 anéis. Na representação de estrutura de bandas a presença do polaron induz dois estados, ligante e antiligante, no “gap” da banda (Figura 55C).

É previsto também, no PPP, a formação de um defeito, chamado bipolaron, devido a interação de dois defeitos carregados (Figura 55B). Sua extensão é da ordem de 5 anéis, como no polaron, mas sua deformação é aproximadamente duas vezes 
a do polaron, e possui energia de formação favorecida em relação a dois polarons. Os bipolarons possuem spin nulo e também induzem estados ligante e antiligante no "gap" entre as bandas de valência e condução. Em alta dopagem é esperado interações entre os defeitos bipolarônicos levando a formação de bandas no "gap",[72].

É importante ressaltar que nem solitons carregados, nem bipolarons, possuem spin não nulo. Isto é consistente com observações experimentais, descritas na literatura, tais como a ausência de significante suscetibilidade de Pauli para sistemas poliacetileno (PA) e popiparafenileno (PPP) em níveis de dopagem acima da transição de alta condutividade.

\subsection{1 - Preparação das amostras}

As amostras de PPP foram sintetizadas no laboratório de Química Analítica do IQSC, pelo técnico José Fernando do Nascimento, utilizando o método descrito por Kovacic et $\mathrm{al}^{[73]}$. Este método envolve uma polimerização catiônica oxidativa do benzeno na presença dos agentes catalíticos $\mathrm{CuCl}_{2}$ (cloreto de cobre) e $\mathrm{AlCl}_{3}$ (cloreto de alumínio). Alguns aspectos importantes, deste processo ${ }^{[74]}$, devem ser destacados:

1. a máxima eficiência na reação ocorre quando a relação molar entre $\mathrm{AlCl}_{3} \mathrm{e}$ $\mathrm{CuCl}_{2}$ é 2:1;

2. a presença de água e/ou oxigênio durante o processo de polimerização influi na quantidade de produto obtida na proporção inversa.

A reação de polimerização completa do benzeno em PPP pode ser descrita na seguinte fórmula:

$$
n \mathrm{C}_{6} \mathrm{H}_{6}+2 n \mathrm{CuCl}_{2} \stackrel{\mathrm{AlCl}_{3}}{\longrightarrow}\left(\mathrm{C}_{6} \mathrm{H}_{4}\right)_{n}+2 \mathrm{nCuCl}+2 n \mathrm{HCl}
$$

No processo de polimerização descrito por Kovacic et $\mathrm{al}^{[73]}$ são observados radicais que poderiam estar associados com defeitos estruturais, devido à imperfeições no processo de polimerização, também chamados macrociclos. Estes macrociclos possuem um elétron desemparelhado que se estende sobre alguns átomos de carbono, sendo observado nos espectros de $\mathrm{RPE}^{[75,76]}$. 
O processo de dopagem, utilizando o cloreto de ferro $\left(\mathrm{FeCl}_{3}\right)$, é o mesmo descrito por Prón et $\mathrm{al}^{[77]}$, e pode ser expresso a partir da seguinte reação:

$$
\left(\mathrm{C}_{6} \mathrm{H}_{4}\right)_{x}+2 y x\left(\mathrm{FeCl}_{3}\right) \rightarrow\left[\left(\mathrm{C}_{6} \mathrm{H}_{4}\right) \cdot\left(\mathrm{FeCl}_{4}\right)_{y}\right]_{x}+x y\left(\mathrm{FeCl}_{2}\right)
$$

Esta dopagem se faz misturando o PPP numa solução saturada de $\mathrm{FeCl}_{3}$ em nitrometano, agitando continuamente, por 4 horas em atmosfera de $\mathrm{N}_{2}$. Após este tempo, o excesso de $\mathrm{FeCl}_{3}$ é lavado com nitrometano puro e o pó secado em estufa à $150{ }^{\circ} \mathrm{C}$ por 2 horas.

\section{3 - Susceptibilidade Magnética AC}

As medidas de susceptibilidade magnética AC foram realizadas, utilizando o Susceptômetro descrito no capítulo 3, em temperaturas variando entre $4,2 \mathrm{~K}$ e $120 \mathrm{~K}$ e com um campo AC de 10 gauss de intensidade e freqüência de 98,9 Hz. Para estas medidas utilizou-se pastilhas cilíndricas de 4 mm de diâmetro por $4 \mathrm{~mm}$ de espessura. Estas pastilhas são provenientes da prensagem, sob 4 ton/ $\mathrm{cm}^{2}$, de aproximadamente $45 \mathrm{mg}$ de amostra em pó (com várias concentrações de Fe).

Estas amostras, em todas as concentrações de Fe, não apresentaram sinal da componente imaginária da susceptibilidade magnética AC $\left(\chi^{\prime \prime}\right)$, elas apresentaram apenas a componente real $\left(\chi^{\prime}\right)$. Desta forma pode-se referir a esta componente, real, como sendo a susceptibilidade total $(\chi)$.

Para melhor visualização do comportamento da susceptibilidade em função da temperatura, os resultados, obtidos para as diversas concentrações de dopante, foram separados em três gráficos: o primeiro, mostrado na Figura 56, com dopagens de Fe de 0 a 0,005; o segundo, mostrado na Figura 57, com dopagens de 0,02 a 0,8; e o terceiro, mostrado na Figura 58, com dopagens de 1,1 a 1,8. A partir destes resultados observa-se que, para uma dada temperatura, o valor da susceptibilidade magnética aumenta a medida que há um aumento da concentração de Fe, sendo que quando a concentração de Fe é nula (ver Figura 56) a susceptibilidade é praticamente igual a zero. 


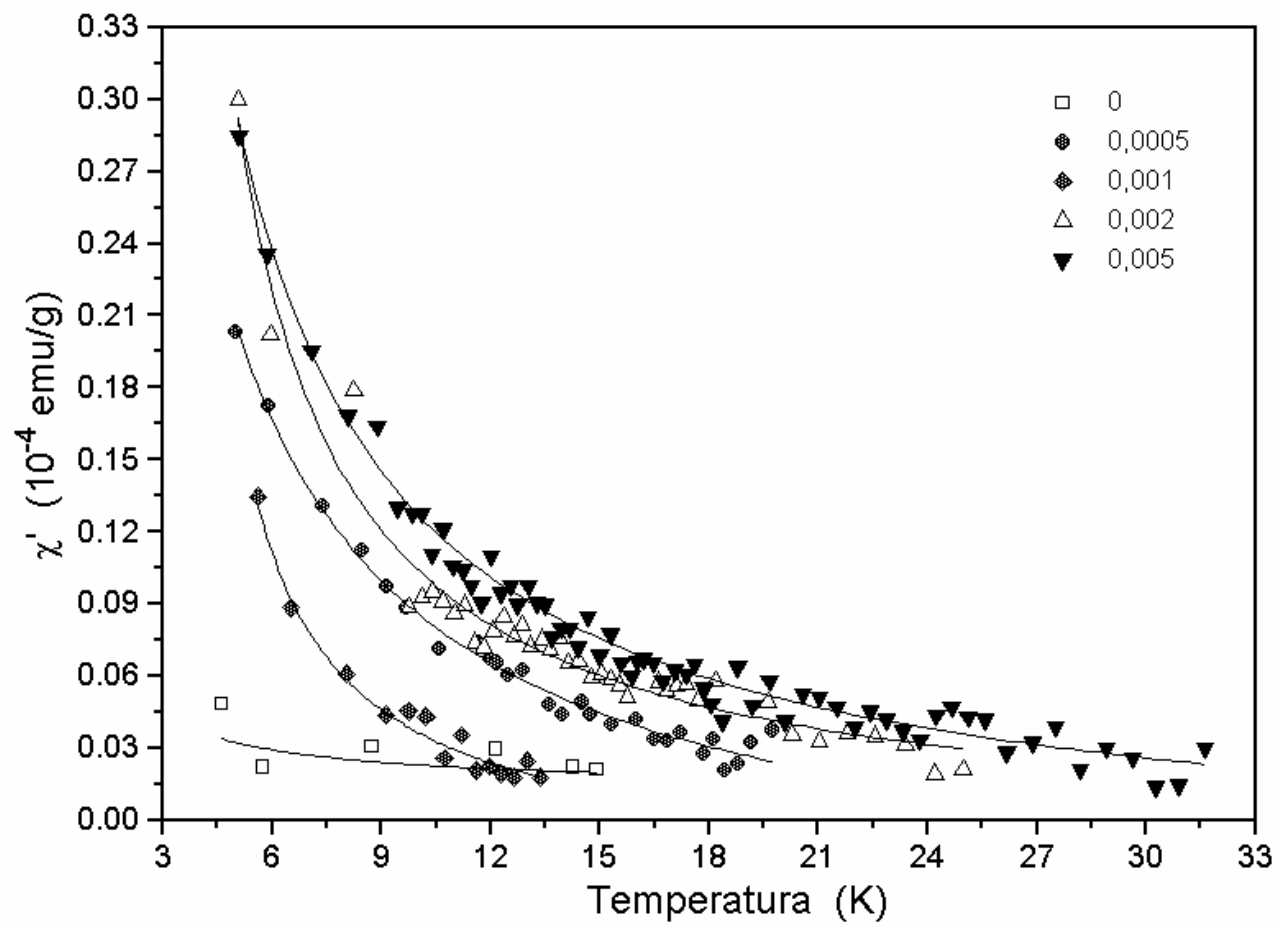

Figura 56 - Gráfico da componente real da susceptibilidade magnética AC em função da temperatura para as amostras de PPP xFe, com x entre 0 e 0,005.

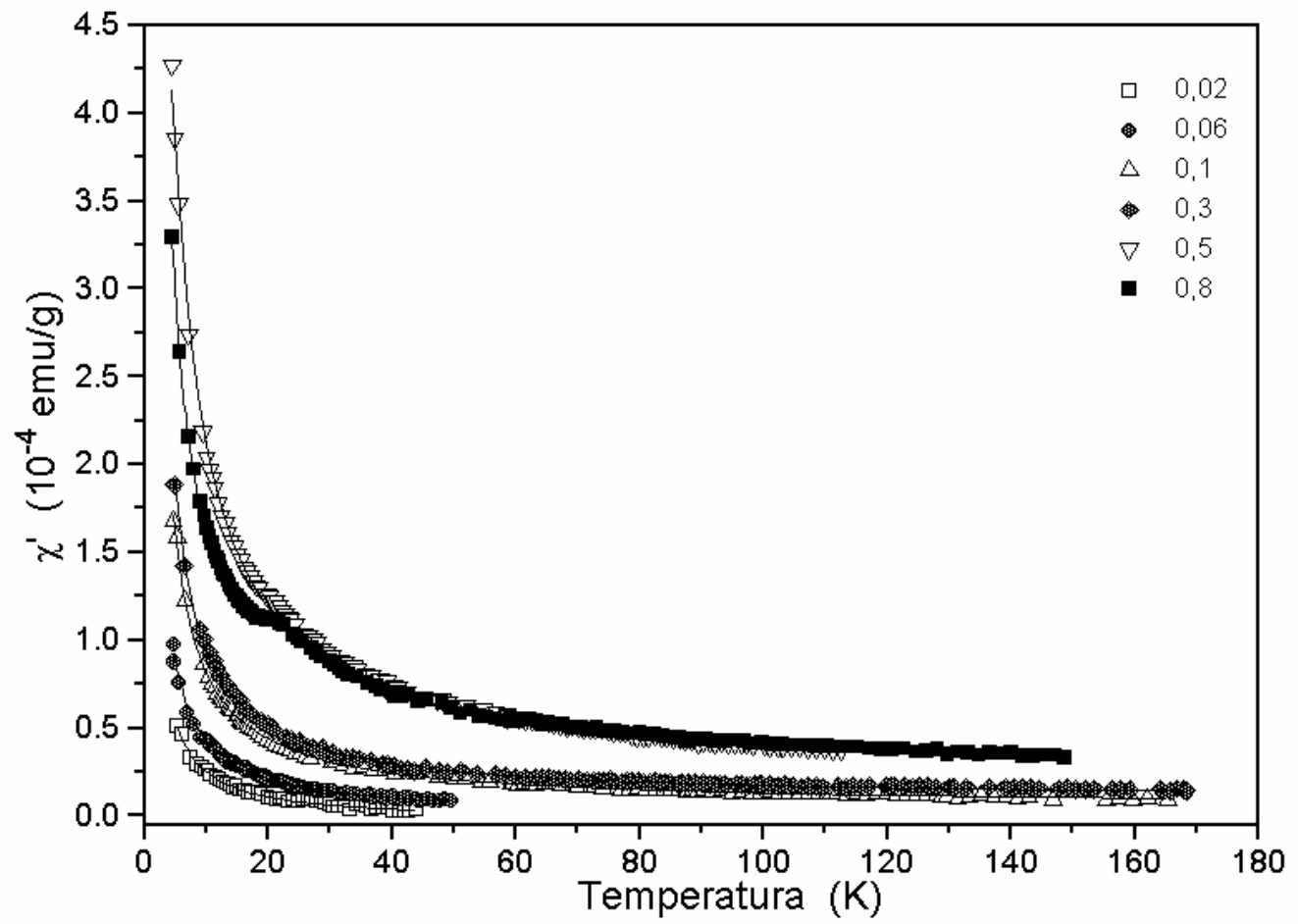

Figura 57 - Gráfico da componente real da susceptibilidade magnética AC em função da temperatura para as amostras de PPP xFe, com x entre 0,02 e 0,8. 


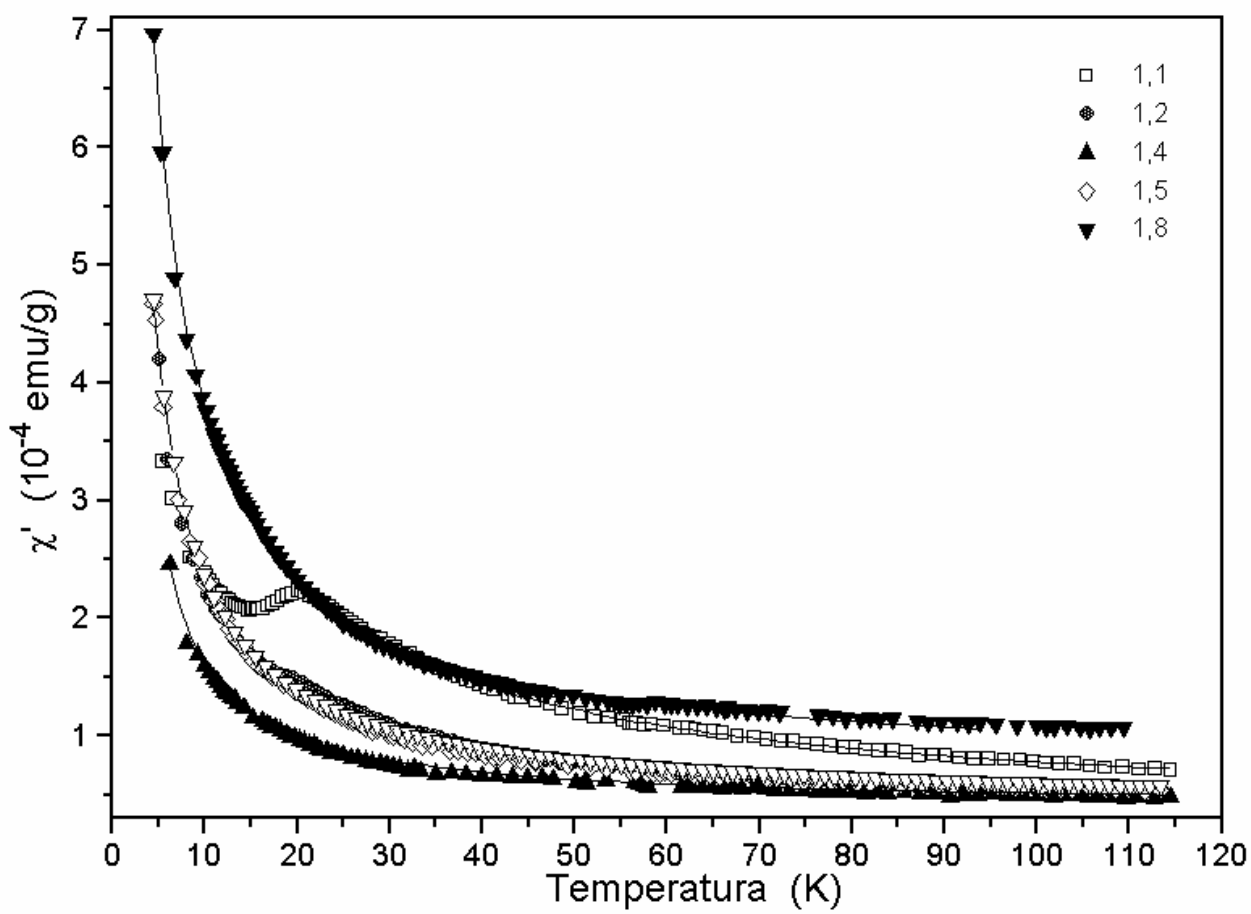

Figura 58 - Gráfico da componente real da susceptibilidade magnética AC em função da temperatura para as amostras de PPP xFe, com x entre 1,1 e 1,8.

Para concentrações, de Fe, a partir de 0,8 (ver Figura 57 e Figura 58) nota-se a ocorrência de um pico (mais nitidamente observado na concentração de 1,1), em torno de $20 \mathrm{~K}$, o qual fornece um indício de uma mudança de comportamento magnético. O comportamento da susceptibilidade magnética deixa de ser inversamente proporcional à temperatura.

Para melhor visualizar o comportamento anômalo (pico) da susceptibilidade magnética para as amostras a partir da concentração de 0,8, fez-se um gráfico (mostrado na Figura 59) do produto da susceptibilidade pela temperatura em função da temperatura $(\chi T \times T)^{\text {m }}$. Neste gráfico verifica-se, nitidamente, a existência do pico (em torno de $20 \mathrm{~K}$ ) para as amostras nas concentrações entre 0,8 e 1,2, e que acima desta concentração não há mais a existência deste pico. Entretanto, para estas amostras o sinal não é completamente linear como aquelas de menor concentração, e observa-se que na região abaixo de $25 \mathrm{~K}$ (ver Figura 59) há um certo desvio no comportamento linear da susceptibilidade.

\footnotetext{
m Observa-se, neste gráfico, que, devido a inclinação da curva, há uma outra contribuição independente da temperatura, além daquela inversamente proporcional a temperatura, para a susceptibilidade magnética $(\chi=A+B / T)$
} 


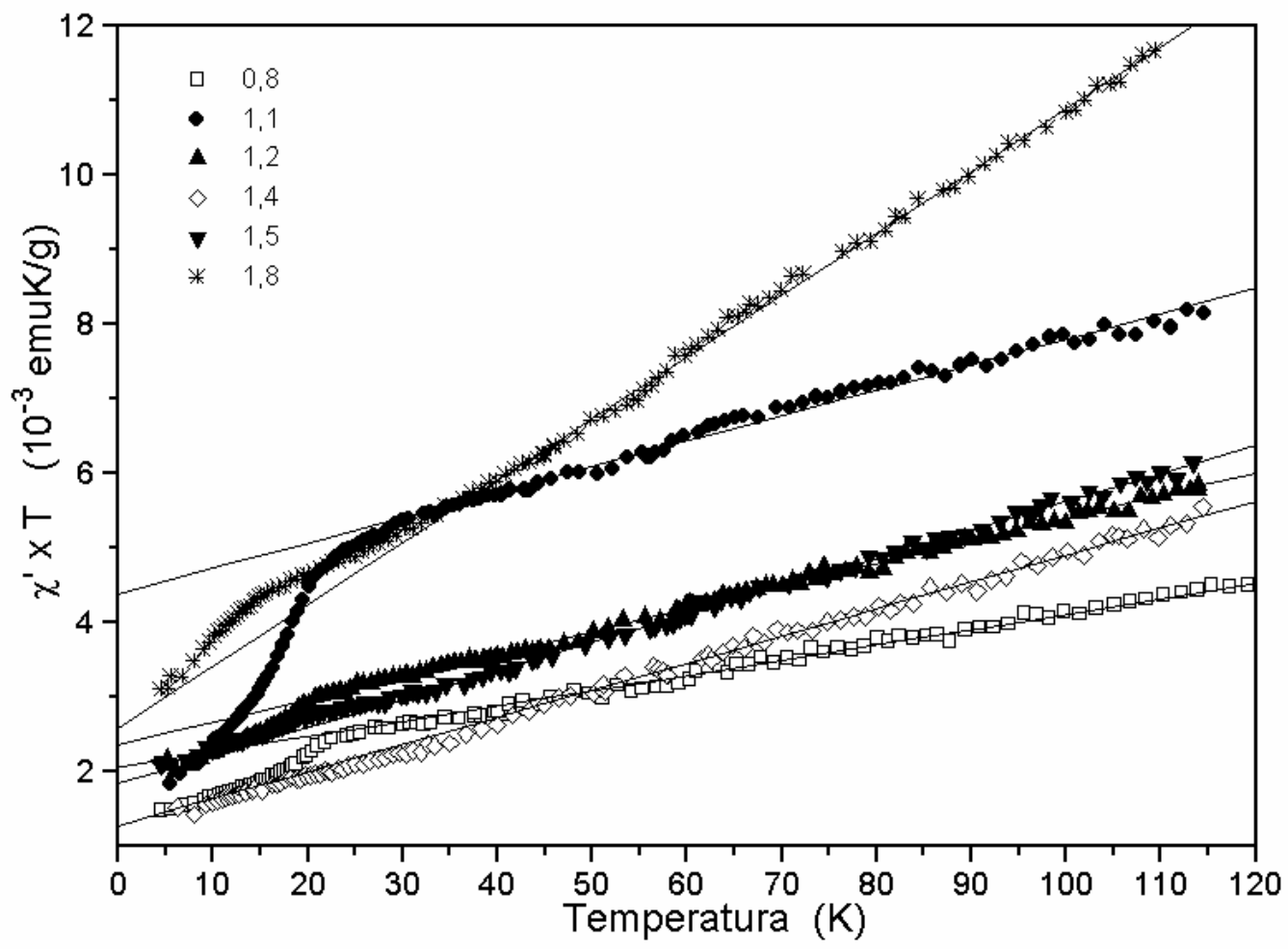

Figura 59 - Gráfico do produto da componente real da susceptibilidade magnética AC pela temperatura em função da temperatura $(\chi T \times T)$, para as amostras de PPP xFe, com x entre 0,8 e 1,8 .

Assim como no caso dos resultados obtidos por Peo et $\mathrm{al}^{[78]}$, para a susceptibilidade $\mathrm{DC}^{\odot}$ do PPP dopado com $\mathrm{SbF}_{5}$, acredita-se que a susceptibilidade magnética, do PPP dopado com $\mathrm{FeCl}_{3}$, seja composta por uma componente que é independente da temperatura, e uma dependente da temperatura. A componente independente da temperatura, $\chi 0$, tem sido identificada em vários compostos como sendo devido à contribuição conjunta do paramagnetismo de Pauli, associado aos elétrons de condução, e do diamagnetismo da cadeia polimérica. A contribuição dependente da temperatura para o paramagnetismo do polímero é, em muitos casos, descrita por uma dependência do tipo Curie-Weiss ( $\chi$ Curie-Weiss), de tal forma a obedecer a seguinte equação:

$$
\chi=\chi_{0}+\chi_{\text {Curie-Weiss }}=\chi_{\text {Dia }}+\chi_{\text {Pauli }}+\frac{C}{T-\theta}
$$

\footnotetext{
(․) Resultados obtidos com a utilização do método da balança de Faraday.
} 
Utilizando a equação (39) para ajustar as curvas da susceptibilidade em função da temperatura, contidas na Figura 56 até Figura 58, obtém-se os valores, da Constante de Curie $(C)$, da Temperatura de Curie-Weiss $(\theta)$ e da susceptibilidade independente da temperatura $\left(\chi_{0}\right)$, listados na Tabela 6. Para isto, o ajuste das curvas que possuem um pico (entre 0,8 e 1,2) foi realizado somente com os pontos da região de altas temperaturas (acima da temperatura do pico).

Tabela 6 - Constante de Curie $(C)$, susceptibilidade independente da temperatura $\left(\chi_{0}\right)$ e

Temperatura de Curie-Weiss $(\theta)$ para as amostras de poliparafenileno dopado com Ferro em diversas concentrações, onde $x$ é a concentração nominal de Ferro e $p$ é a concentração (em porcentagem de massa) medida por Absorção Atômica.

\begin{tabular}{|c|c|c|c|c|}
\hline \multicolumn{2}{|c|}{ Concentração de Fe } & \multirow{2}{*}{$\begin{array}{c}\mathrm{C} \\
\left(10^{-5} \mathrm{emuK} / \mathrm{g}\right)\end{array}$} & \multirow{2}{*}{$\begin{array}{c}\chi_{0} \\
\left(10^{-7} \text { emu/g) }\right.\end{array}$} & \multirow{2}{*}{$\begin{array}{c}\theta \\
(\mathbf{K})\end{array}$} \\
\hline nominal (x) & Abs. Atôm. (p) & & & \\
\hline 0 & 0 & $*$ & $*$ & $*$ \\
\hline 0,0005 & 0,27 & $10 \pm 2,0$ & $-29 \pm 11$ & $1,1 \pm 1,1$ \\
\hline 0,001 & 0,11 & $4 \pm 1,0$ & $-20 \pm 10$ & $3,0 \pm 0,6$ \\
\hline 0,002 & 0,42 & $11 \pm 2,0$ & $-18 \pm 10$ & $1,1 \pm 0,8$ \\
\hline 0,005 & 0,46 & $14 \pm 0,8$ & $-22 \pm 3,8$ & $0,6 \pm 0,3$ \\
\hline 0,02 & 1,13 & $27 \pm 1,0$ & $-28 \pm 4,4$ & $0,3 \pm 0,3$ \\
\hline 0,06 & 1,48 & $42 \pm 0,9$ & $-1 \pm 3,0$ & $0,3 \pm 0,1$ \\
\hline 0,1 & 1,77 & $75 \pm 0,6$ & $56 \pm 1,5$ & $0,2 \pm 0,1$ \\
\hline 0,3 & 2,05 & $84 \pm 0,8$ & $90 \pm 1,6$ & $0,2 \pm 0,1$ \\
\hline 0,5 & 2,48 & $259 \pm 6,0$ & $200 \pm 15$ & $-3,4 \pm 0,6$ \\
\hline 0,8 & 2,32 & $209 \pm 7,0$ & $200 \pm 5,2$ & $-1,5 \pm 0,9$ \\
\hline 1,1 & 2,88 & $481 \pm 12$ & $300 \pm 10$ & $-2,9 \pm 0,6$ \\
\hline 1,2 & 3,98 & $220 \pm 7,0$ & $300 \pm 6,0$ & $1,6 \pm 0,8$ \\
\hline 1,4 & 3,33 & $123 \pm 2,0$ & $400 \pm 4,0$ & $-0,2 \pm 0,1$ \\
\hline 1,5 & 4,11 & $200 \pm 2,0$ & $400 \pm 4,5$ & $-0,2 \pm 0,1$ \\
\hline 1,8 & 6,07 & $318 \pm 6,0$ & $700 \pm 10$ & $-0,2 \pm 0,1$ \\
\hline
\end{tabular}

"devido a péssima relação sinal-ruído, não foi possível o ajuste da curva para a amostra não dopada.

Na Tabela 6 estão listados dois valores para as concentrações de Ferro no polímero. A primeira concentração (nominal - x) é determinada na dopagem do polímero a partir da expressão dada na Eq. (40). Entretanto, esta concentração não tem muita utilidade, uma vez que nem todo $\mathrm{FeCl}_{3}$ reage com o polímero, sendo então extraído no processo de lavagem do composto. Porem, utilizaremos esta concentração, x, para identificação das amostras. A outra concentração $(p)$, listada nessa tabela, foi 
determinada utilizando a técnica de Absorção Atômica, a qual, após uma calibração inicial, fornece a massa de Ferro contida em uma determinada massa de composto. A partir desta massa de Ferro obtêm-se o valor de $p$, em porcentagem de massa total, através da Eq. (41):

$$
\begin{gathered}
\frac{\operatorname{massa}(\mathrm{PPP})}{\operatorname{massa}\left(\mathrm{FeCl}_{3}\right)}=\frac{\mathrm{mol}(\mathrm{PPP})}{x \mathrm{~mol}\left(\mathrm{FeCl}_{3}\right)} \\
p=\frac{\text { massa } \mathrm{Fe}}{\text { massa total }} 100
\end{gathered}
$$

Observando a Tabela 6, nota-se que as amostras com baixas concentrações de dopagem (menor que 0,06) possuem um valor negativo para a susceptibilidade independente da temperatura $\left(\chi_{0}\right)$, indicando, como mostra a Eq (39), a existência de uma susceptibilidade diamagnética ( $\left.\chi_{\text {Dia }}\right)$ somada à susceptibilidade paramagnética de Pauli ( $\chi_{\text {Pauli }}$ ). Assim sendo, será de grande interesse a determinação de quanto, desta susceptibilidade total $\left(\chi_{0}\right)$, é devido a contribuição diamagnética e quanto é devido a contribuição de Pauli.

O diamagnetismo é associado com a tendência de cargas elétricas blindarem o interior de um corpo de um campo magnético aplicado. Estudos anteriores têm mostrados que, em algumas situações, a contribuição diamagnética é mais intensa que a paramagnética do tipo Pauli. De fato, Peo et $\mathrm{al}^{[78]}$ observaram uma aparente ausência do paramagnetismo de Pauli em PPP dopado com $\mathrm{SbF}_{5}$. Neste composto, a susceptibilidade é resultado da superposição de uma contribuição paramagnética do tipo Curie-Weiss com uma diamagnética independente da temperatura. Como resultado, a susceptibilidade total se torna negativa em temperaturas acima de $20 \mathrm{~K}$. O cálculo teórico dessa componente diamagnética é uma tarefa muito árdua, que envolve aplicação ou de teoria de perturbação ou de técnicas variacionais. A fim de quantificar a contribuição diamagnética foi utilizado o procedimento empírico de Pascal ${ }^{[25,79]}$, que permite o cálculo de $\chi_{\text {Dia }}$ baseado na adição de incrementos atômicos. O resultado obtido por Peo mostrou que o valor experimental da susceptibilidade independente da temperatura é devido, exclusivamente, a contribuição diamagnética. 
Como uma tentativa de justificar os valores negativos de susceptibilidade, observados em nossos experimentos em baixas concentrações de dopagem (ver Tabela 6), calculamos a contribuição diamagnética para as nossas amostras, seguindo o procedimento descrito na referência [78]. Este procedimento foi também utilizado, com sucesso, por vários autores ${ }^{[80-82]}$, para o cálculo da contribuição da susceptibilidade diamagnética para o poliacetileno. Para isto utilizou-se a seguinte fórmula aditiva:

$$
\chi_{\text {Dia }}=\sum_{A} n_{A} \chi_{A}+\lambda
$$

onde $n_{A}$ é o número de átomos, na molécula, com susceptibilidade atômica $\chi_{A}$, e $\lambda$ é uma constante que é determinada pelas ligações químicas dos átomos da molécula. Os valores destes incrementos atômicos $\left(\chi_{A}\right.$ e $\left.\lambda\right)$ estão reproduzidos na Tabela 7.

Tabela 7 - Valores de Pascal.

\begin{tabular}{||llll|ll||}
\hline \multicolumn{3}{|c|}{$\chi_{\mathbf{A}}\left(\mathbf{1 0}^{-\mathbf{6}} \mathbf{e m u} / \mathbf{m o l}\right)$} & & \multicolumn{1}{||}{$\boldsymbol{\lambda}\left(\mathbf{1 0}^{-6} \mathbf{e m u} / \mathbf{m o l}\right)$} \\
\hline $\mathrm{H}$ & $-2,95$ & & & \\
$\mathrm{Li}$ & $-4,2$ & & & \\
$\mathrm{C}$ & $-6,0$ & $\mathrm{NO}_{3}$ & $-14,2$ & Benzeno & $-1,5$ \\
$\mathrm{~N}$ & $-5,55$ & $\mathrm{SO}_{4}$ & $-33,6$ & Naftaleno & $-6,1$ \\
$\mathrm{O}$ & $-4,61$ & $\mathrm{NH}_{3}$ & $-14,4$ & Etileno & $+5,5$ \\
$\mathrm{~F}$ & $-6,3$ & $\mathrm{H}_{2} \mathrm{O}$ & $-13,0$ & Acetileno & $+0,8$ \\
$\mathrm{Na}$ & $-9,2$ & & & & \\
$\mathrm{~S}$ & $-15,0$ & & & & \\
$\mathrm{Cl}$ & $-20,0$ & & & & \\
$\mathrm{Br}$ & $-30,5$ & & & & \\
$\mathrm{~K}$ & $-18,5$ & & & & \\
\hline
\end{tabular}

* valores retirados da referência [25].

A teoria mostra que a susceptibilidade diamagnética de íons possui sinal negativo e não depende, por exemplo, do sinal da carga eletrônica ${ }^{[83]}$. Fundamentalmente, o sinal negativo surge devido à lei de Lenz. Quando o campo magnético é aplicado, a mudança de fluxo magnético através da órbita dos elétrons induz uma força eletromotriz, causando uma mudança na órbita dos elétrons. Esta mudança induz um momento magnético no átomo em oposição à mudança do fluxo através da órbita. O cálculo detalhado ${ }^{[83]}$ mostra que a susceptibilidade diamagnética é 
proporcional ao valor médio quadrático do raio da órbita do elétron, $\left\langle\mathrm{r}^{2}\right\rangle$, desde que 0 campo magnético aplicado não seja muito intenso (o que corresponde à situação experimental comum). Em primeira aproximação $\left\langle\mathrm{r}^{2}\right\rangle$ é constante para um tipo particular de átomo e não é fortemente afetado pela sua vizinhança. Por isso, diversas substâncias obedecem razoavelmente bem ao princípio de adição descrito na Eq. (42). Quando aplicado a íons dissolvidos em uma solução, este princípio é conhecido como lei da adição de Wiedemann.

A estimativa do valor da contribuição diamagnética será feita referindo-se a susceptibilidade molar para uma molécula reduzida, contendo apenas um átomo de carbono. Ou seja, esta estimativa será feita para a seguinte fórmula reduzida do PPP:

$$
\frac{1}{6}\left(\mathrm{C}_{6} \mathrm{H}_{4} \cdot y \mathrm{FeCl}_{4}\right)
$$

onde $y$ é a concentração molar de $\mathrm{FeCl}_{4}{ }^{-}$. Este valor de $y$ (listado na Tabela 8) foi determinado a partir das concentrações (p) obtidas por Absorção Atômica (listadas na Tabela 6) e utilizando a expressão a seguir:

$$
y=\frac{76 p}{5585-197,65 p}
$$

onde 76 é o peso molecular do $\mathrm{C}_{6} \mathrm{H}_{4}, 5585$ é o peso molecular do Ferro multiplicado por 100 e 197,65 é o peso molecular do $\mathrm{FeCl}_{4}{ }^{-}$.

Utilizando a Eq. (42) e os valores da Tabela 7 (com o valor de $\lambda$ para o benzeno), obtém-se a seguinte equação para a susceptibilidade diamagnética em função da concentração de dopante $(y)$ :

$$
\chi_{\text {Dia }}=-(8,22+13,33 \mathrm{y}) \cdot 10^{-6} \mathrm{emu} / \mathrm{mol}-\mathrm{C}
$$

A partir desta equação obtêm-se os valores da susceptibilidade diamagnética listados na Tabela 8. Nesta tabela estão listados também a susceptibilidade de Pauli (obtida da Eq.(39)) e a constante de Curie. Todos estes valores estão em unidade molar para a fórmula reduzida contendo apenas um Carbono (ver Eq. (43)). Observa-se que os valores calculados para a contribuição de Pauli em baixas concentrações (abaixo de 
$y=0,0160$ ), resultaram em valores negativos. Isto nos leva a concluir que a contribuição diamagnética calculada pelo modelo de Pascal está subestimada, o que poderia implicar numa falha do modelo ou na existência de outras fontes diamagnéticas além da cadeia do polímero.

Tabela 8 - Contribuições diamagnética e paramagnética de Curie-Weiss e Pauli para a susceptibilidade magnética AC do poliparafenileno dopado com Ferro, onde $\mathrm{x}$ a concentração nominal e y a concentração determinada por absorção atômica.

\begin{tabular}{|c|c|c|c|c|c|}
\hline \multicolumn{2}{|c|}{ "Concentração de Fe } & \multirow{2}{*}{$\begin{array}{c}\mathrm{C}\left(\mathrm{x10} 0^{-4}\right) \\
(\mathrm{emuK} / \mathrm{mol}-\mathrm{C})\end{array}$} & \multirow{2}{*}{$\begin{array}{c}\chi_{0}\left(\times 10^{-6}\right) \\
(\mathrm{emu} / \mathrm{mol}-\mathrm{C})\end{array}$} & \multirow{2}{*}{$\begin{array}{c}\chi_{\text {Dia }}\left(x 10^{-6}\right) \\
(\mathrm{emu} / \mathrm{mol}-\mathrm{C})\end{array}$} & \multirow{2}{*}{$\begin{array}{l}\chi_{\text {Pauli }}\left(x^{-6}\right) \\
(\text { emu/mol-C) }\end{array}$} \\
\hline nominal (x) & Abs. Atôm. (y) & & & & \\
\hline 0 & 0 & - & - & $-8,22$ & - \\
\hline 0,0005 & 0,0037 & $13 \pm 2,5$ & $-37 \pm 14$ & $-8,27$ & -28 \\
\hline 0,001 & 0,0015 & $5,1 \pm 0,9$ & $-25 \pm 13$ & $-8,24$ & -17 \\
\hline 0,002 & 0,0058 & $13,9 \pm 0,8$ & $-23 \pm 13$ & $-8,30$ & -15 \\
\hline 0,005 & 0,0064 & $17,7 \pm 0,6$ & $-28 \pm 4,8$ & $-8,30$ & -20 \\
\hline 0,02 & 0,0160 & $34,2 \pm 1,0$ & $-35 \pm 5,6$ & $-8,43$ & -27 \\
\hline 0,06 & 0,0214 & $53,2 \pm 1,1$ & $-1 \pm 3,8$ & $-8,51$ & 7,2 \\
\hline 0,1 & 0,0257 & $95 \pm 0,8$ & $71 \pm 1,9$ & $-8,56$ & 80 \\
\hline 0,3 & 0,0301 & $106 \pm 1,0$ & $114 \pm 2,0$ & $-8,62$ & 123 \\
\hline 0,5 & 0,0370 & $328 \pm 7,6$ & $253 \pm 19$ & $-8,71$ & 262 \\
\hline 0,8 & 0,0344 & $265 \pm 8,9$ & $253 \pm 6,6$ & $-8,68$ & 262 \\
\hline 1,1 & 0,0436 & $609 \pm 15$ & $380 \pm 13$ & $-8,80$ & 389 \\
\hline 1,2 & 0,0630 & $279 \pm 2,5$ & $380 \pm 7,6$ & $-9,06$ & 389 \\
\hline 1,4 & 0,0514 & $156 \pm 2,5$ & $507 \pm 5,1$ & $-8,90$ & 516 \\
\hline 1,5 & 0,0655 & $253 \pm 7,6$ & $507 \pm 5,7$ & $-9,09$ & 516 \\
\hline 1,8 & 0,1052 & $403 \pm 3,0$ & $887 \pm 13$ & $-9,62$ & 897 \\
\hline
\end{tabular}

O gráfico da Constante de Curie e da Susceptibilidade de Pauli (em unidades molar), em função da concentração molar de Fe, estão mostrados, respectivamente, na Figura 60 e na Figura 61. Por motivos didáticos, os resultados foram separados em duas regiões (I e II), delimitadas em $\mathrm{y} \cong 0,047$. $\mathrm{O}$ motivo deste procedimento será melhor esclarecido adiante e deve-se ao fato de que na região II a susceptibilidade foi medida numa faixa de temperaturas abaixo do limite de altas temperaturas, onde acredita-se valer a lei de Curie-Weiss. Na região I, observa-se que o comportamento de ambas susceptibilidades (Curie-Weiss e Pauli) são semelhantes, ou seja, a medida que se aumenta a concentração de Fe, aumenta também os valores das susceptibilidades. 


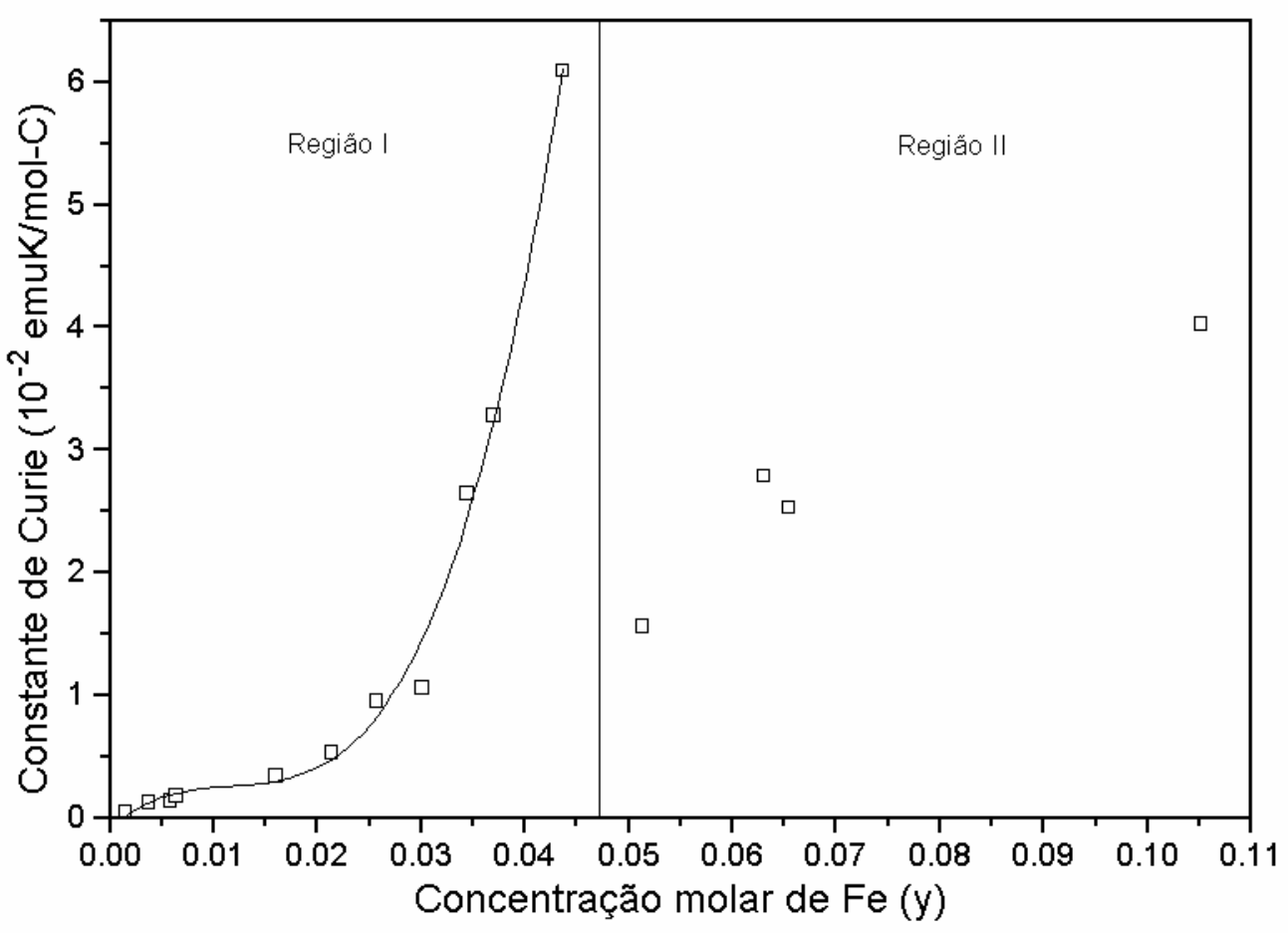

Figura 60 - Gráfico da Constante de Curie em função da concentração molar de Ferro na amostra de PPP. Linha cheia utilizada apenas como guia para os olhos.

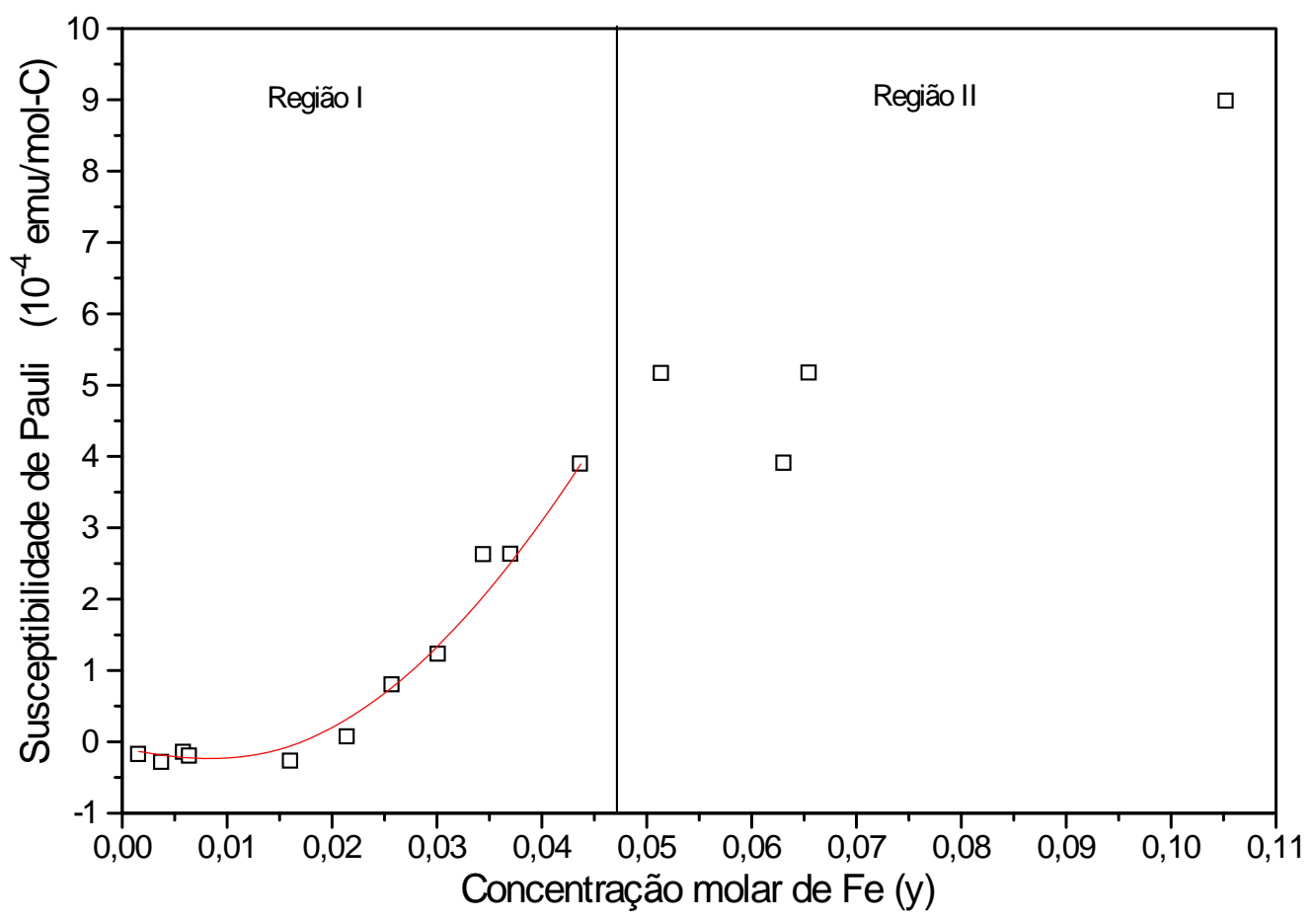

Figura 61 - Gráfico da susceptibilidade de Pauli em função da concentração molar de Ferro na amostra de PPP. Linha cheia utilizada apenas como guia para os olhos. 


\section{4 - Ressonância Paramagnética Eletrônica}

Com a finalidade de melhor entender a origem do comportamento magnético das amostras, realizou-se medidas de RPE, em função da temperatura, para as amostras de PPP dopadas com Fe, nas concentrações 1,1 e 1,8 (y = 0,0436 e 0,1052).

Na Figura 62 e Figura 63 estão mostrados alguns dos espectros de RPE adquiridos para essas amostras. Estas medidas foram realizadas entre 4,2 K e temperatura ambiente, em freqüência 9,25 GHz (Banda X). Para modulação de campo utilizou-se um sinal de 1,15 G de amplitude e $86 \mathrm{kHz}$ de freqüência. Nestes espectros há duas linhas intensas e estreitas, uma em 1860 gauss ( $g=3,51$ ) e outra em 5250 gauss ( $g=1,25$ ), que são devidas ao cristal de $\mathrm{Al}_{2} \mathrm{O}_{3}: \mathrm{Cr}^{3+}$ (rubi) utilizado como padrão para normalização da intensidade do sinal da amostra.

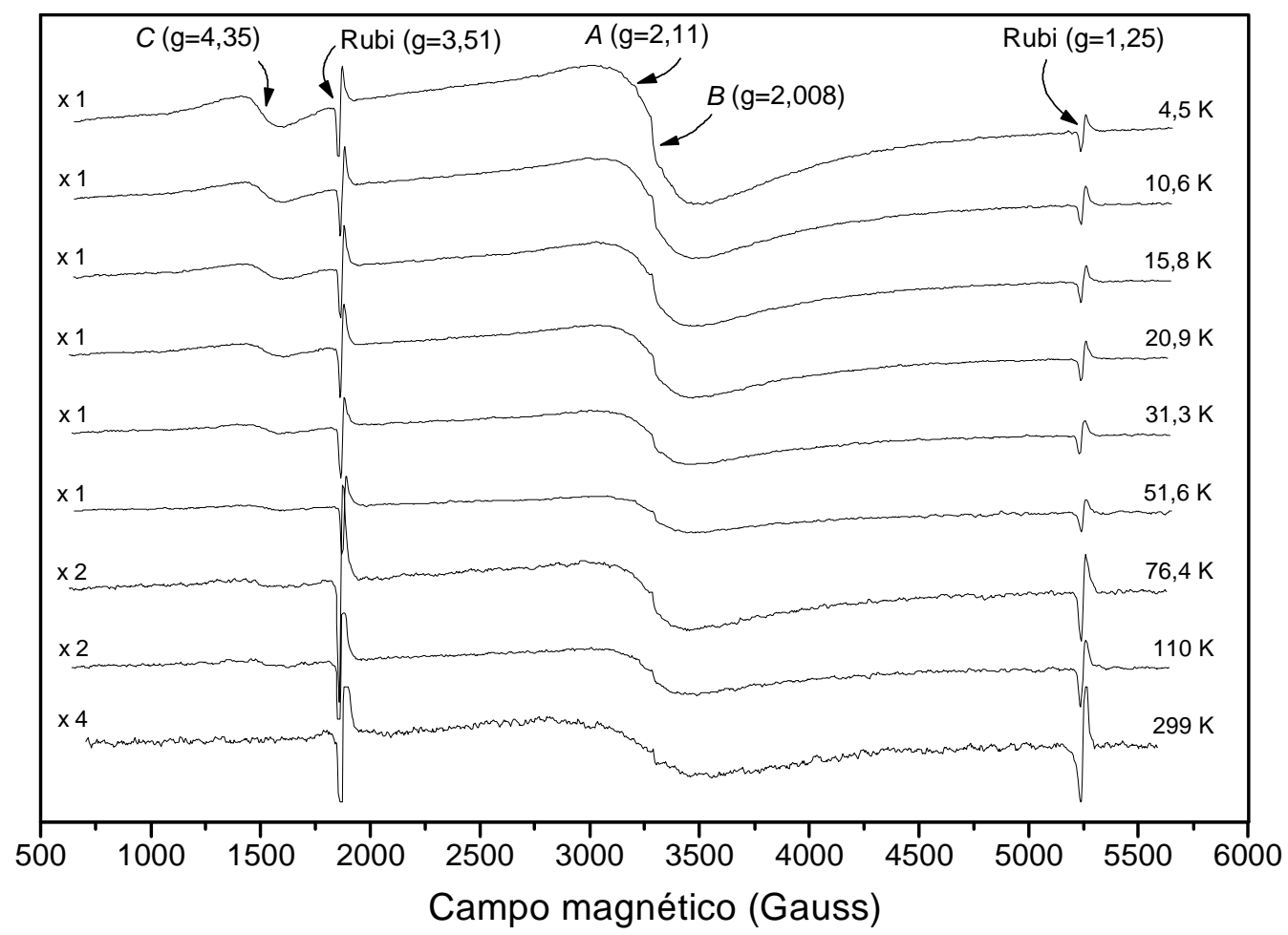

Figura 62 - Evolução do espectro de RPE, da amostra de PPP dopada com 1,1 de Fe, em função da temperatura. 


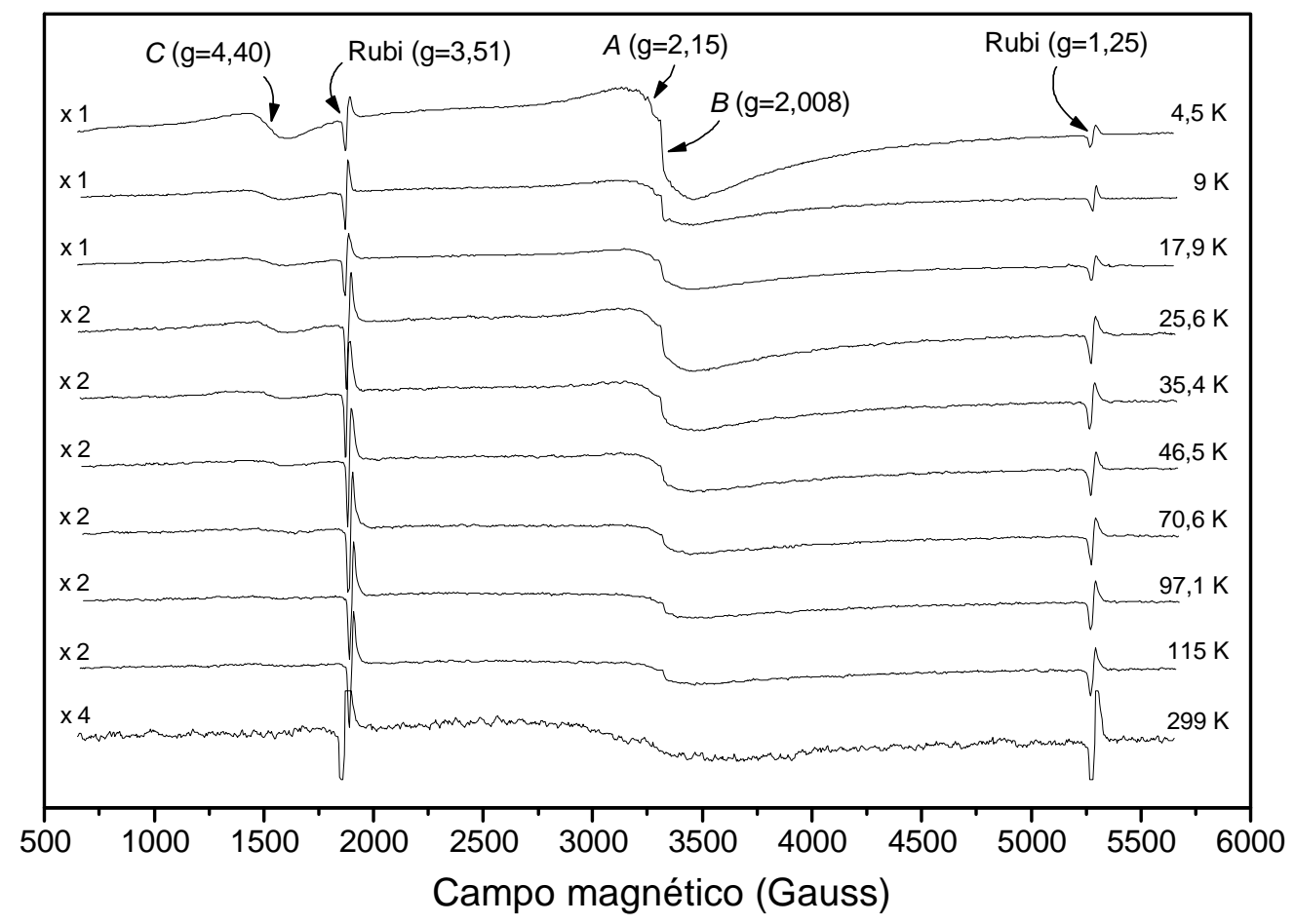

Figura 63 - Evolução do espectro de RPE, da amostra de PPP dopada com 1,8 de Fe, em função da temperatura.

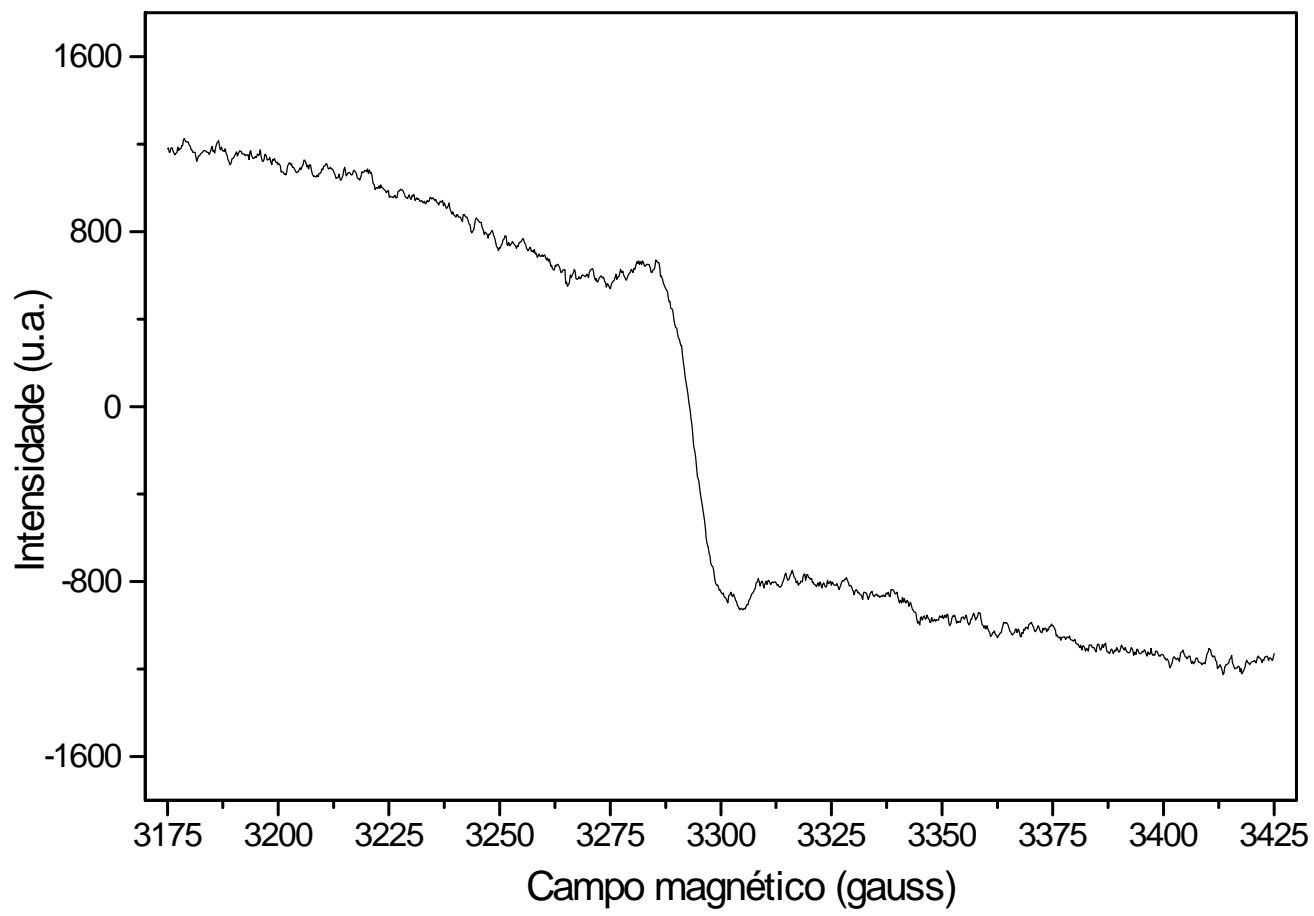

Figura 64 - Ampliação da linha $C$ que se encontra sobreposta à linha $A$, vista nos espectros da Figura 62 e da Figura 63. 
Os espectros das duas amostras $(1,1$ e 1,8$)$ são bem parecidos. Neles observa-se, além das linhas do $\mathrm{Cr}^{3+}$ (rubi), outras três linhas, daqui por diante, designadas por $A, B$ e $C$. A linha $A$ é uma linha muito larga (da ordem de 500 gauss) centrada em torno de 3300 gauss. Sobreposta à esta linha, observa-se uma linha estreita, de aproximadamente 17 gauss, que designamos por $B$. Na Figura 64 tem-se um espectro em que é mostrada uma ampliação da região onde se encontra a sobreposição destas duas linhas. Em baixas temperaturas observou-se também o aparecimento de uma terceira linha, designada por $C$, que é relativamente larga (da ordem de 200 gauss), centrada em 1520 gauss.

O ajuste desses espectros pode ser realizado a partir da soma de funções lorentzianas. As linhas $B$ e $C$ são, cada uma, bem ajustadas por uma única função lorentziana, enquanto que a linha larga, $A$, é melhor ajustada pela soma de duas lorentzianas $\left(A_{1}\right.$ e $\left.A_{2}\right)$. Portanto, no total, são utilizadas 4 funções lorentzianas para reproduzir todo o espectro, em qualquer temperatura. A partir do ajuste, por quadrados mínimos, obtém-se os resultados que estão mostrados na Tabela 9 .

Tabela 9 - Parâmetros encontrados pelo ajuste do espectro de RPE.

\begin{tabular}{||c|c|c||}
\hline Linha & fator $\mathbf{g}$ & Largura pico-pico (gauss) \\
\hline$A_{1}$ & $\cong 2$ & $1000-1300$ \\
\hline$A_{2}$ & $\cong 2$ & $\cong 400$ \\
\hline$B$ & 2,008 & $10-15$ \\
\hline$C$ & 4,40 & 200 \\
\hline
\end{tabular}

A Figura 65 mostra a dependência com a temperatura das larguras de linha do espectro de RPE. Nota-se que a largura da linha $A$ está dividida de acordo com as contribuições individuais, $A_{1}$ e $A_{2}$, de cada uma duas lorentzianas utilizadas para o ajuste do espectro. As larguras das linhas $A_{1}$ e $B$ são dependentes da temperatura. De fato, a Figura 66 e Figura 67 mostram, de forma expandida, os resultados obtidos para a linha $A_{1}$. Para a amostra 1,8, a largura da linha $A_{1}$ aumenta com a temperatura até cerca de $70 \mathrm{~K}$, e a partir daí ela se estreita da mesma forma que a amostra 1,1.

Não foi observada alterações significativas dos fatores g das linhas em função da temperatura. 


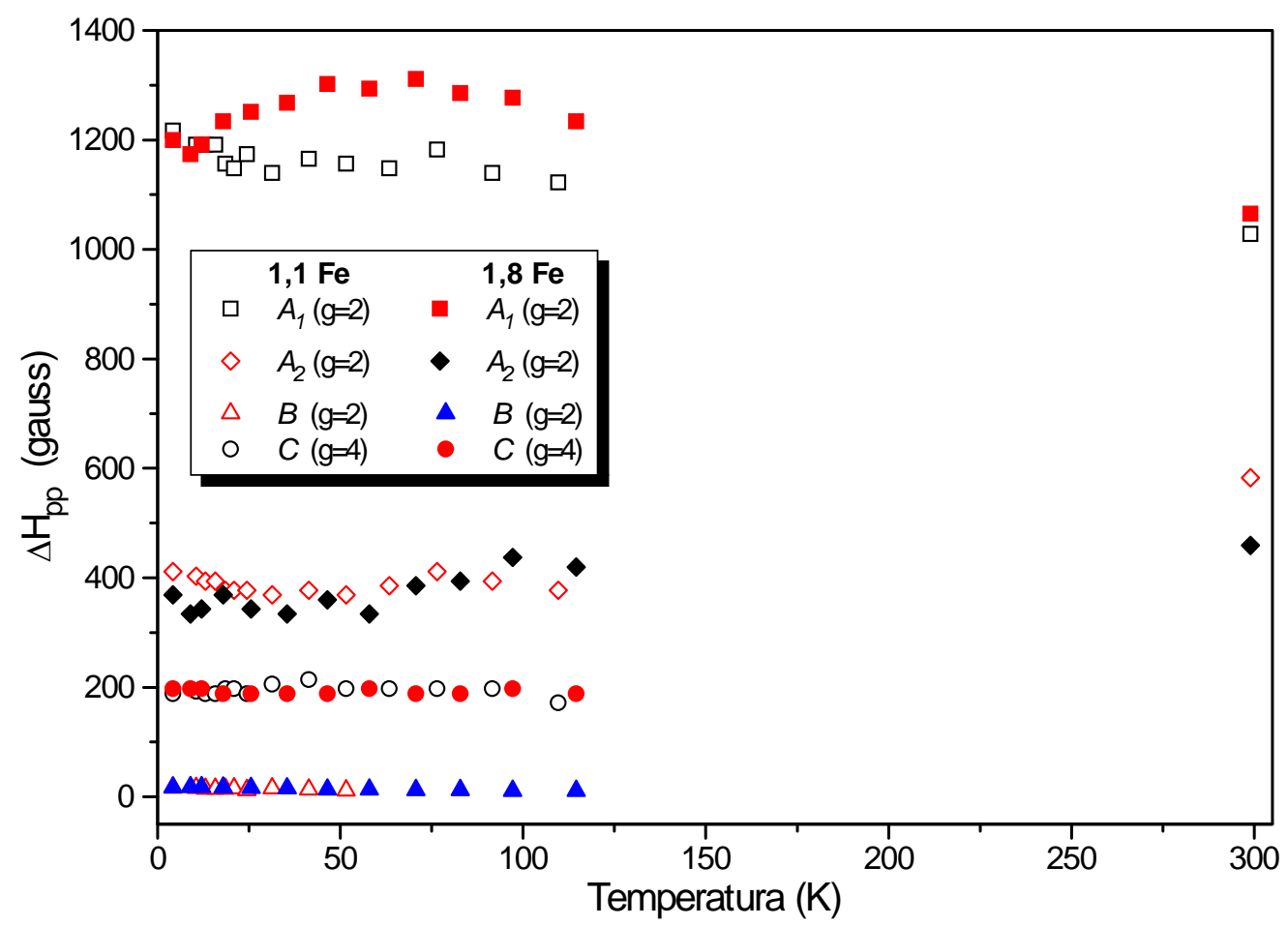

Figura 65 - Gráfico das larguras de linhas pico a pico, em função da temperatura, para os sinais de RPE do PPP dopado com $\mathrm{FeCl}_{3}$. Medidas realizadas nas amostras de PPP $x F e$, onde $x=1,1$ e 1,8 .

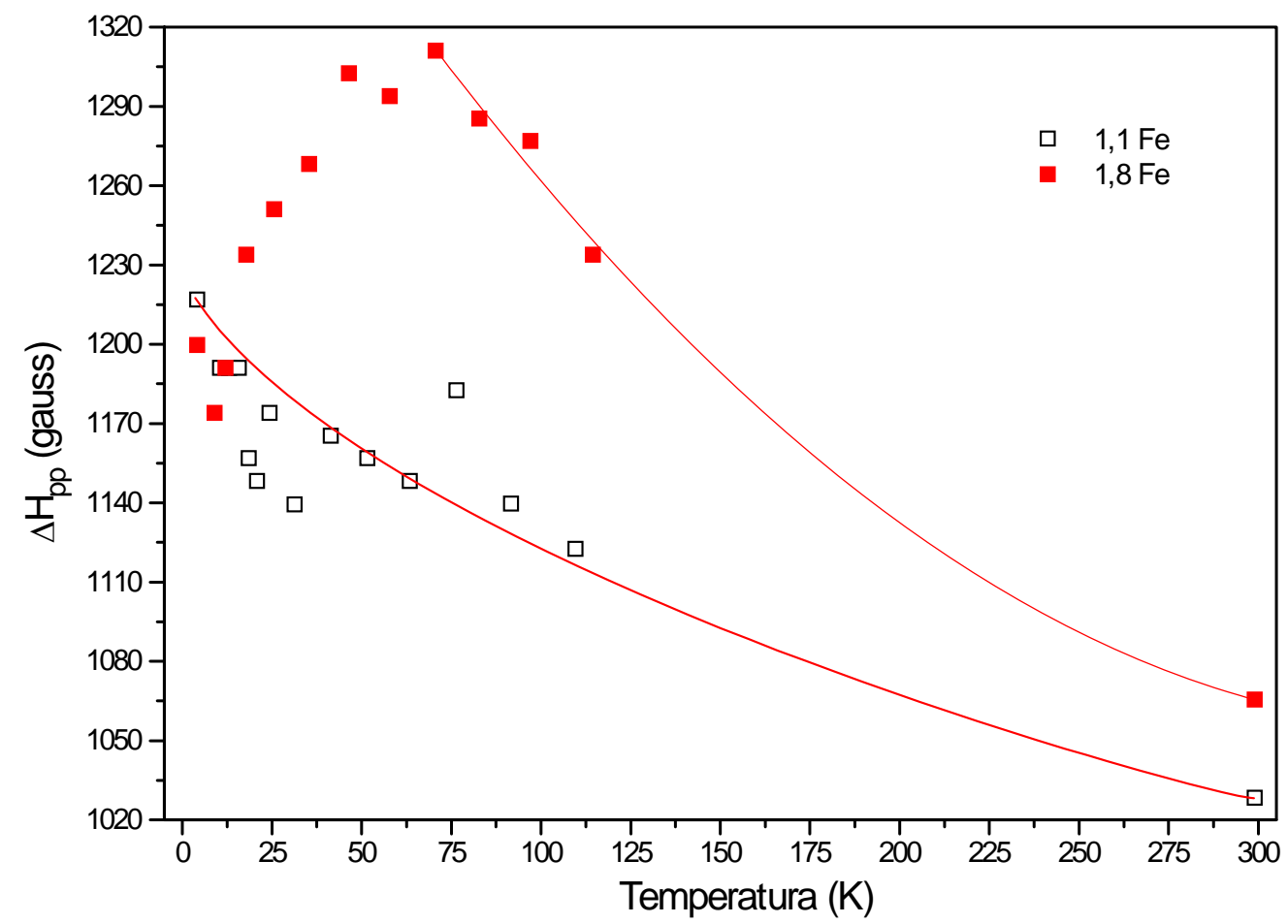

Figura 66 - Gráfico da largura de linha pico a pico, em função da temperatura, para a linha $A_{1}$. Medidas realizadas nas amostras de PPP xFe, onde $\mathrm{x}=1,1$ e 1,8. Linhas cheias utilizadas apenas como guia para os olhos. 


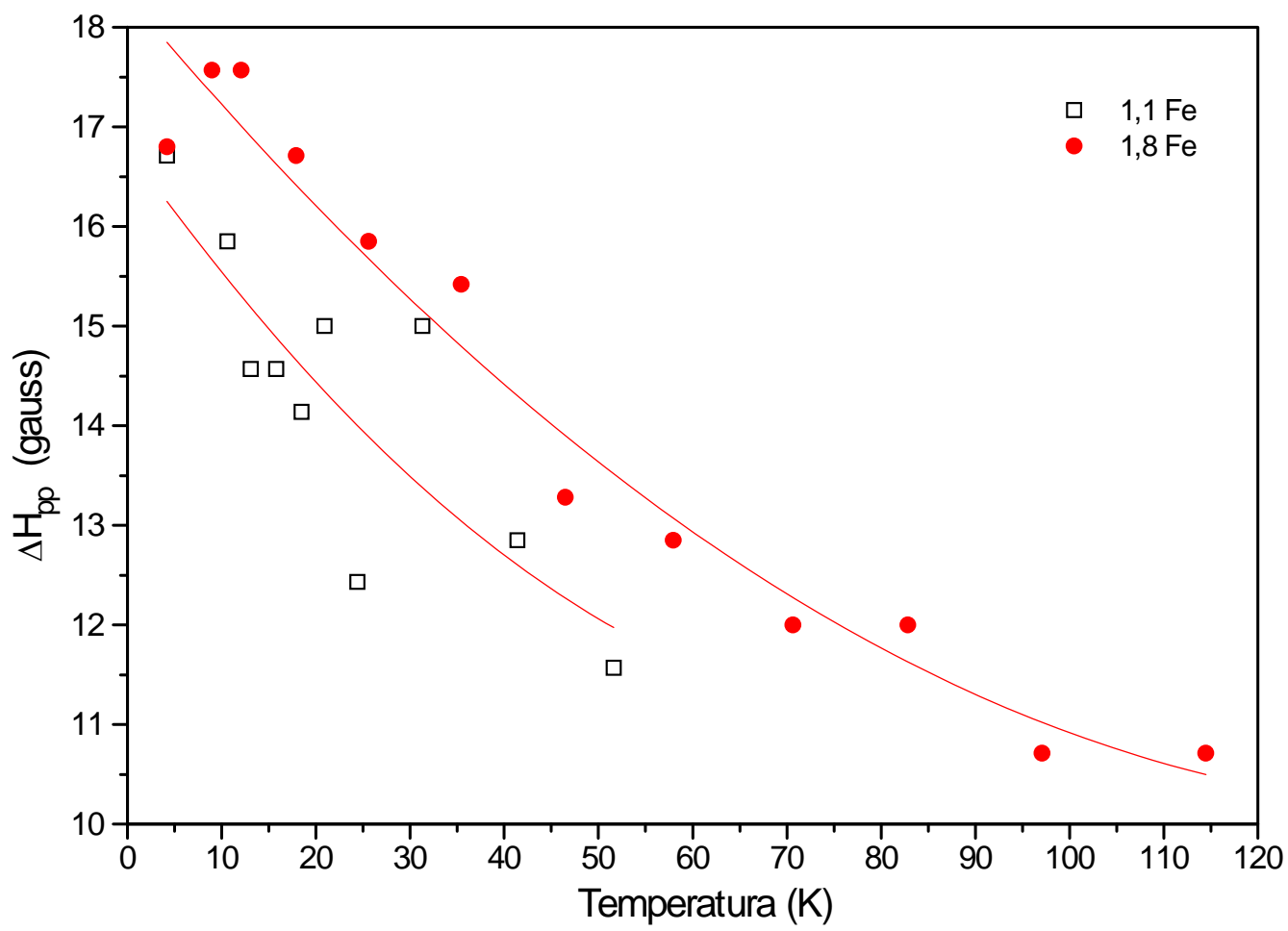

Figura 67 - Gráfico da largura de linha pico a pico, em função da temperatura, para o sinal, de RPE, da linha $B$. Medidas realizadas nas amostras de PPP $x F e$, onde $x=1,1$ e 1,8. Linhas cheias utilizadas apenas como guia para os olhos.

Como visto no Capítulo 2, a dupla integração do sinal de RPE fornece um resultado que é proporcional à susceptibilidade magnética estática. Esta dupla integração pode ser calculada a partir dos parâmetros de uma função que ajusta o espectro de RPE, ou por integração numérica do espectro (indicado principalmente quando não é possível o ajuste com uma função conhecida). No caso destas duas amostras de PPP, adotou-se o cálculo da intensidade integrada a partir dos parâmetros determinados pelo ajuste das linhas, de acordo com a composição descrita anteriormente. O sinal do rubi, ajustado com uma gaussiana, foi utilizado para a normalização das intensidades integradas dos espectros do PPP. Para isto dividiu-se as intensidades integradas, para cada um dos sinais $\left(I_{1}\right)$ mencionados anteriormente, pela intensidade integrada do rubi $\left(I_{0}\right)$ e pela massa do polímero $\left(m_{s}\right)$ :

$$
I=\frac{I_{1}}{m_{s} I_{0}}
$$




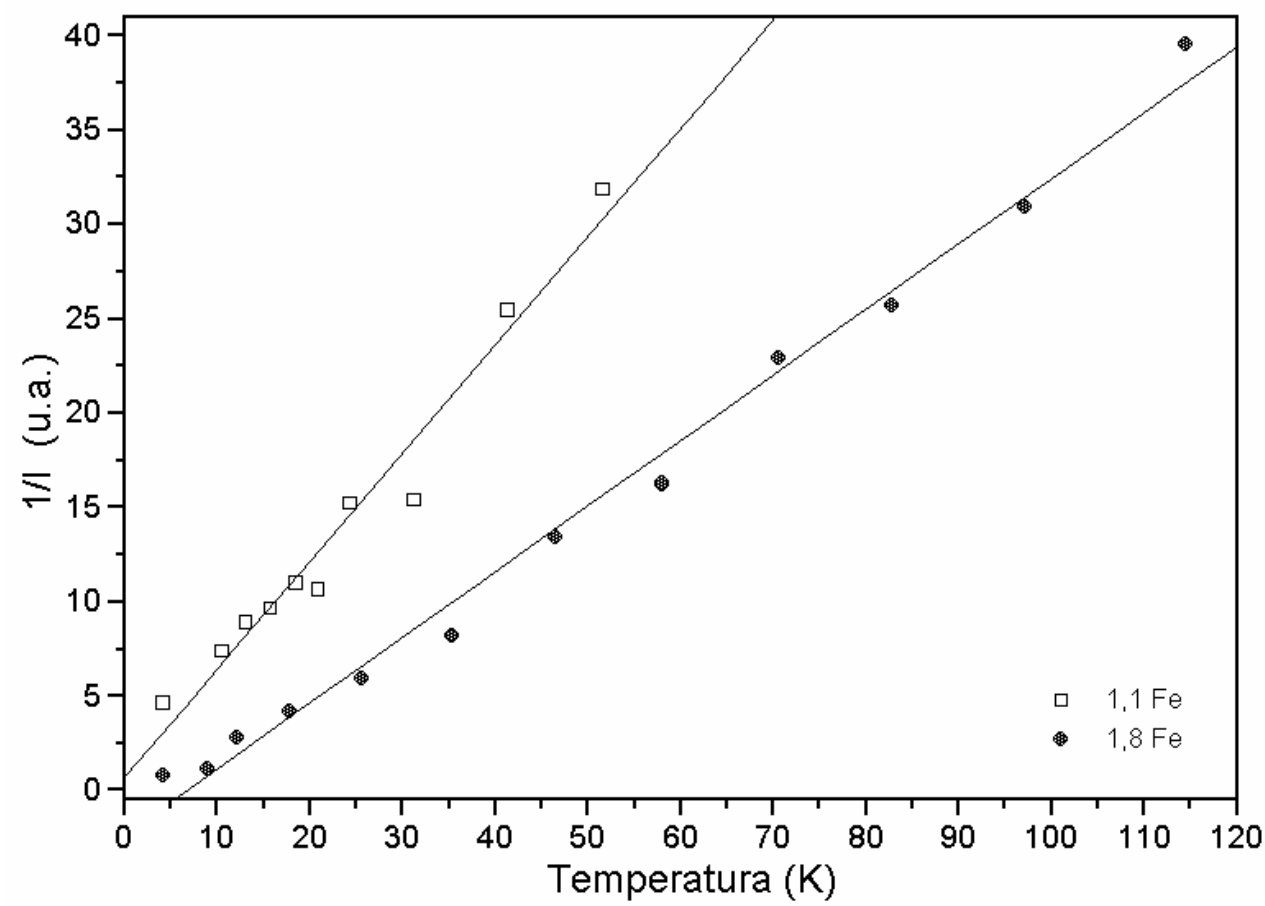

Figura 68 - Gráfico do inverso da intensidade integrada da linha $B$, em função da temperatura.

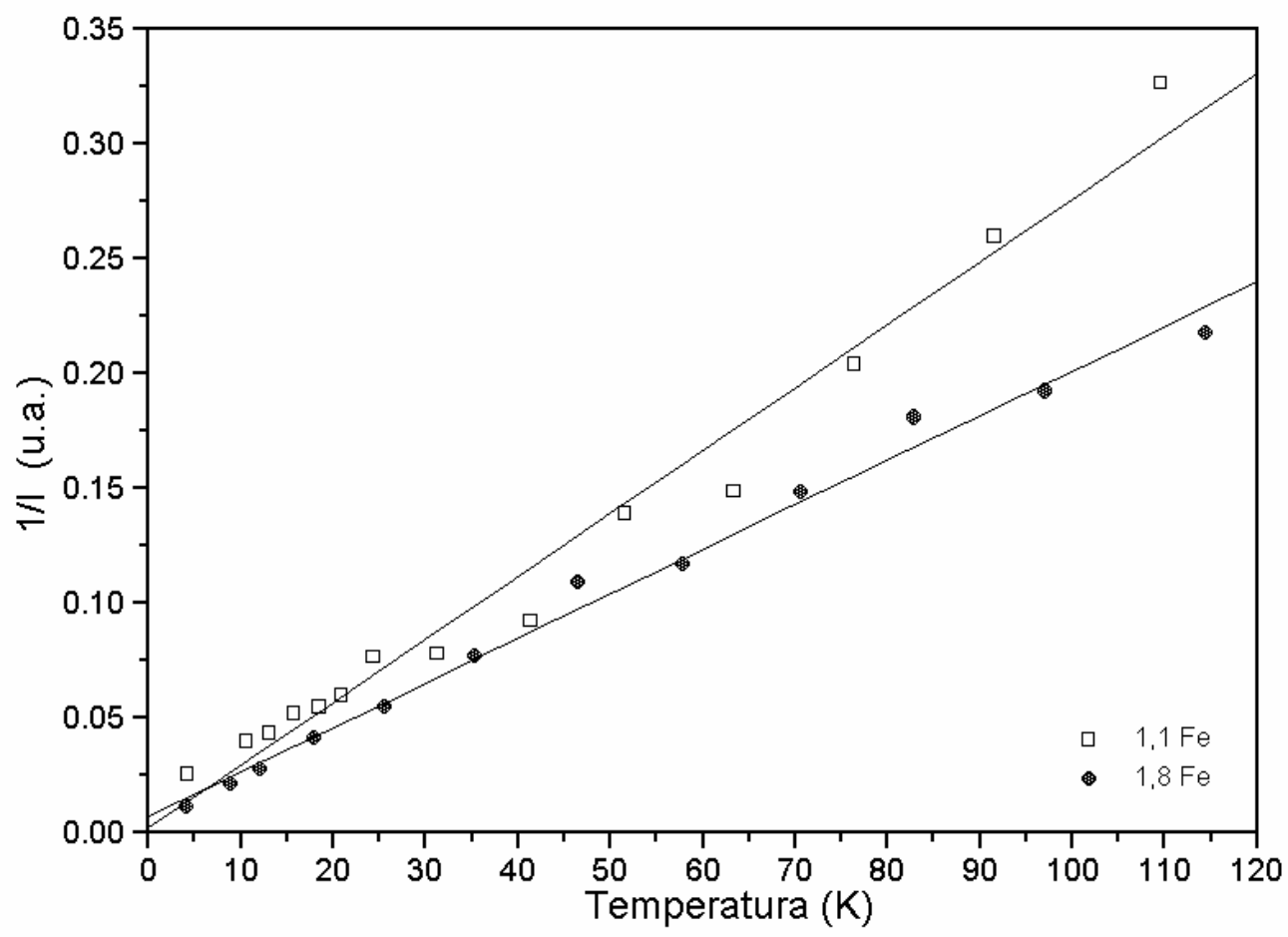

Figura 69 - Gráfico do inverso da intensidade integrada da linha $C$, em função da temperatura. 


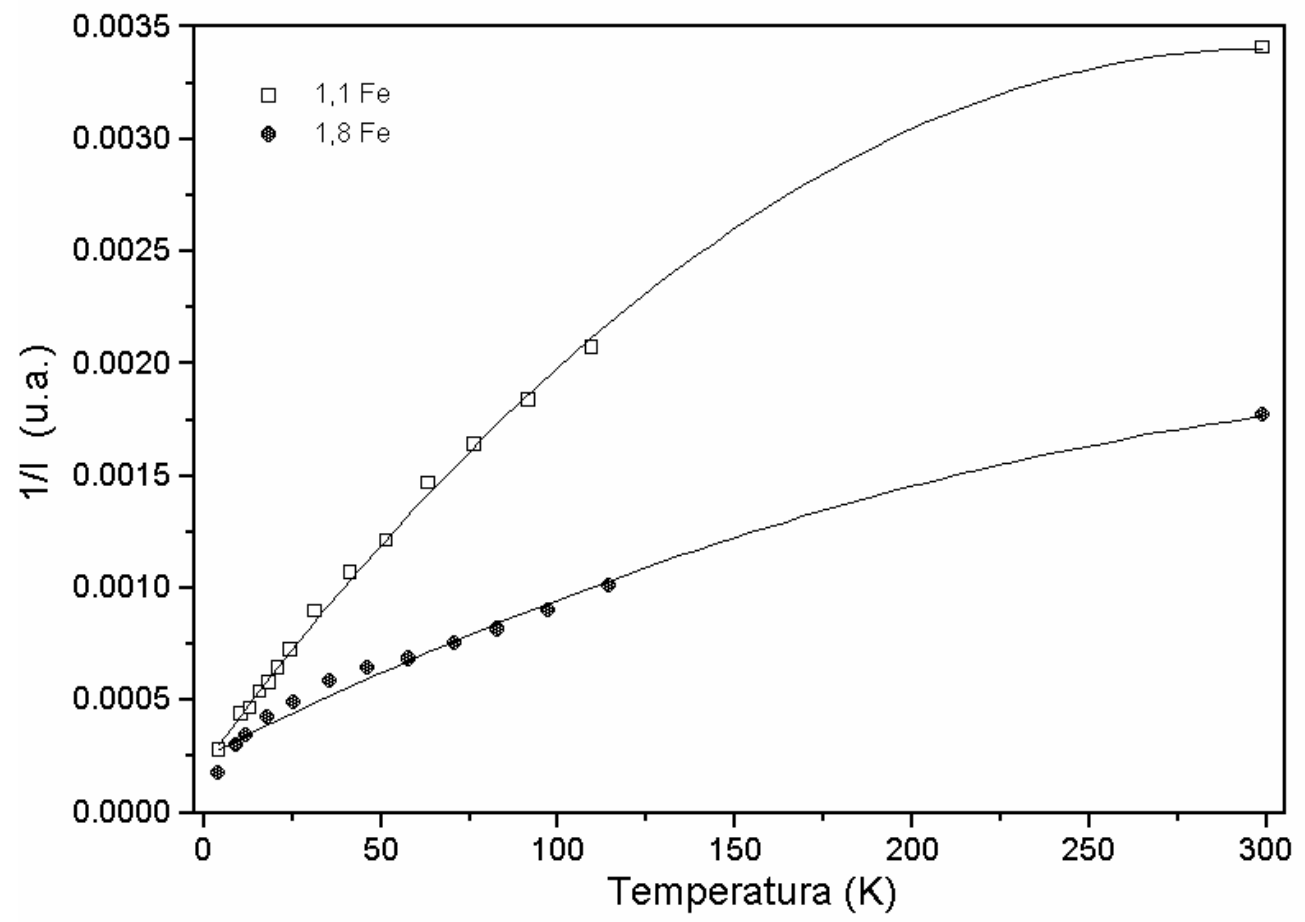

Figura 70 - Gráfico do inverso da intensidade integrada da linha $A$, correspondente a soma de duas lorentzianas $\left(A_{1}+A_{2}\right)$, em função da temperatura. Linhas cheias utilizadas apenas como guia para os olhos.

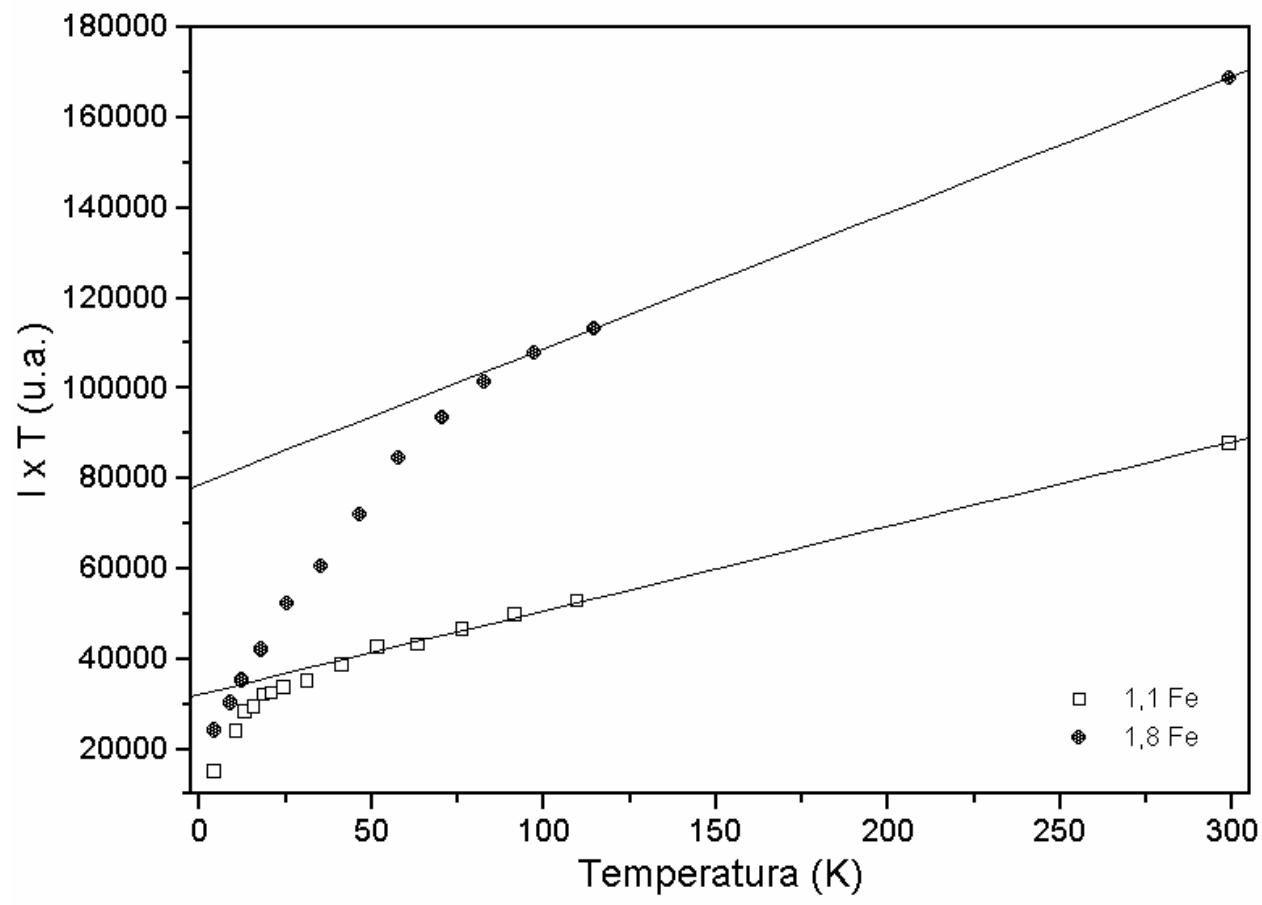

Figura 71 - Gráfico do produto da temperatura pela intensidade integrada da linha $A$, correspondente a soma de duas lorentzianas $\left(A_{1}+A_{2}\right)$, em função da temperatura. 
Na Figura 68 e na Figura 69 mostramos a dependência com a temperatura do inverso da intensidade integrada das linhas $B$ e $C$, para as duas amostras estudadas. O comportamento observado pode ser explicado supondo que estas linhas são provenientes de centros paramagnéticos localizados, cuja dependência com a temperatura é do tipo Curie-Weiss. De fato, observa-se nestas figuras um comportamento linear de $1 / / \times T$, abaixo de $120 \mathrm{~K}$.

Por outro lado, a dependência com a temperatura do inverso da intensidade integrada da linha $A$, mostrada na Figura 70, apresenta um comportamento não linear. Este mesmo resultado está mostrado no gráfico da Figura 71, onde é aparente que, somente em altas temperaturas, a dependência de $I T \times T$ é linear ${ }^{\beta}$. Observa-se em baixas temperaturas um desvio deste comportamento linear. A temperatura, a partir da qual este desvio acontece, depende da concentração de Fe, sendo em torno de $20 \mathrm{~K}$ e $125 \mathrm{~K}$ para as amostras 1,1 e 1,8, respectivamente. Curiosamente, foi também observado, em torno de $20 \mathrm{~K}$, um máximo no valor da susceptibilidade AC da amostra 1,1, conforme pode-se observar na Figura 58 e na Figura 59. Na Figura 59 nota-se claramente que o comportamento de $\chi T \times T$, para a amostra 1,1, é linear acima de $20 \mathrm{~K}$, portanto, parece que o efeito observado por RPE, nesta amostra, está correlacionado com aquele observado por SMAC. Se for possível extrapolar este mesmo raciocínio para os resultados obtidos com a amostra 1,8, chegaremos à conclusão de que, as medidas de SMAC nesta amostra, foram obtidas numa faixa de temperaturas em que o comportamento de $\chi T \times T$ pode não ser linear. Em outras palavras, com relação aos dados da amostra 1,8 mostrados na Figura 59, é possível que a inclinação da reta ajustada numericamente, assim como o seu intercepto em $T=0$, se alterem acima de $120 \mathrm{~K}$.

\section{5 - Discussão}

Wan et $\mathrm{al}^{[84]}$ realizou experimentos de RPE em amostras de polianilina dopada com $\mathrm{HCl}$ (PANI-Cl$\left.{ }^{-}\right)$e com $\mathrm{FeCl}_{4}^{-}\left(\mathrm{PANI}^{-} \mathrm{FeCl}_{4}{ }^{-}\right)$. O espectro medido para a PANI-Cl' ${ }^{-}$mostra uma única linha estreita $(1,5$ gauss, $\mathrm{g} \cong 2)$ que foi atribuída à presença de

\footnotetext{
• A ausência de pontos experimentais na faixa 120 K a $300 \mathrm{~K}$ não nos permite ser conclusivos a este respeito.
} 
polarons. O espectro da $\mathrm{PANI}-\mathrm{FeCl}_{4}{ }^{-}$, está mostrado na Figura 72 e é semelhante ao aqui obtido para o PPP xFe. Nele, observa-se uma linha larga (600 gauss, $g \cong 2$ ), que foi também atribuída a polarons. A largura de linha observada no composto PANI$\mathrm{FeCl}_{4}{ }^{-}$é bem maior que a da $\mathrm{PANI}-\mathrm{Cl}^{-}$. Segundo os autores, isto é devido ao alto grau de localização dos elétrons no composto PANI-FeCl ${ }_{4}^{-}$, o que é consistente com a sua baixa condutividade elétrica e baixa susceptibilidade magnética. Os autores não comentam se uma pequena oscilação que se observa no espectro de RPE da PANI$\mathrm{FeCl}_{4}{ }^{-}$, em torno de 1600 gauss, $\mathrm{g} \cong 4$ (ver Figura 72 ), é apenas ruído ou se corresponde de fato a uma linha de ressonância. Utilizando as técnicas Mössbauer e espalhamento de raios-X, os autores puderam identificar o estado de oxidação do íon Fe e concluiram que se trata de $\mathrm{Fe}^{3+}$. Entretanto, eles não comentam, porque o íon $\mathrm{Fe}^{3+}$, não contribui ao espectro de RPE observado.

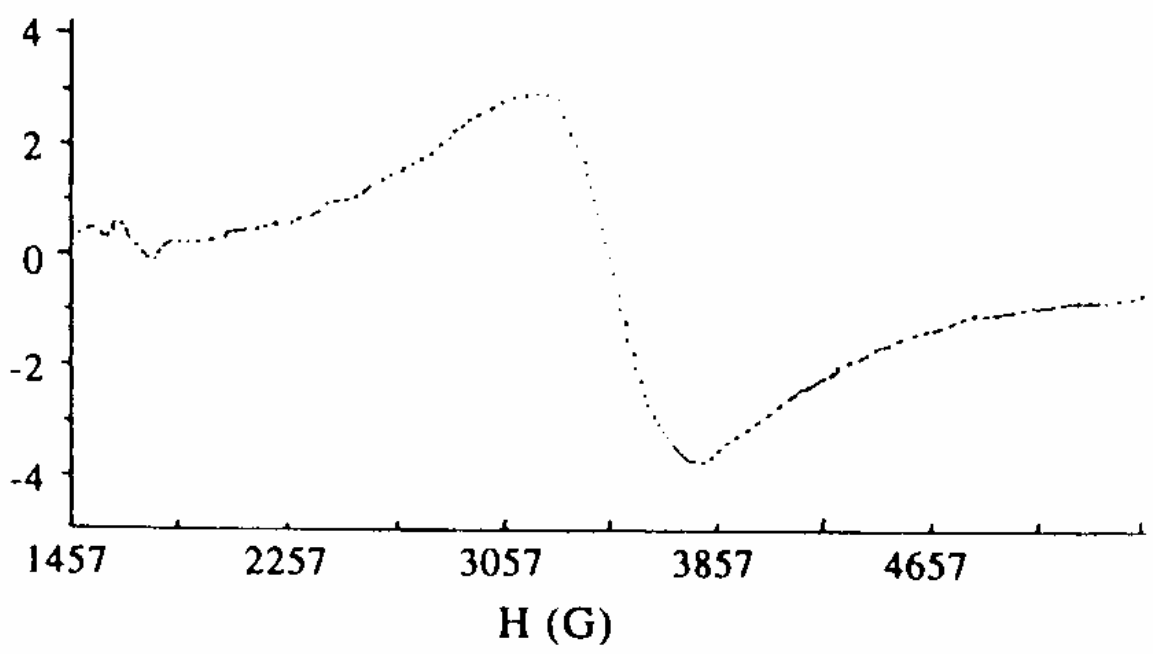

Figura 72 - Espectro de RPE da polianilina (PANI) dopada com $\mathrm{FeCl}_{4}$, obtido por Wan et $\mathrm{al}^{[84]}$.

Por outro lado, Kuivalainen et $\mathrm{al}^{[85]}$, em seus estudos de RPE em PPP fortemente dopado com $\mathrm{FeCl}_{3}$, observaram uma absorção intensa, $\Delta \mathrm{H}_{\mathrm{pp}}(300 \mathrm{~K}) \cong 500-900$ gauss, com $\mathrm{g} \cong 2,04$, que foi atribuída aos íons $\mathrm{Fe}^{3+}$ nas moléculas do dopante. Sobreposta a esta linha larga, foi observada também uma linha estreita, $\Delta \mathrm{H}_{\mathrm{pp}}(300 \mathrm{~K}) \cong 5$ gauss, com $\mathrm{g} \cong 2,00$, que foi atribuída a defeitos estruturais da rede polimérica, criados no processo de polimerização e dopagem. A principal fonte de alargamento desta linha é a interação 
hiperfina, não resolvida, com prótons vizinhos. No PPP não dopado, a largura desta linha é independente da temperatura, enquanto que nas amostras dopadas ela aumenta com o decréscimo da temperatura. A linha larga observada é ligeiramente assimetrica porém, em contraste com a forma Dysoniana, a relação $A / B$ é menor que 1. A largura desta linha varia com a concentração do dopante Fe, de uma forma não monotônica: as amostras pouco dopadas e as muito dopadas possuem largura menor ( $\cong 500$ gauss) enquanto que as intermediárias possuem largura maior ( $\cong 900$ gauss).

Castner et $\mathrm{al}^{[86]}$ estudaram impurezas de Fe em amostras de vidros, com o objetivo de determinar a estrutura cristalina em torno dos íons $\mathrm{Fe}^{2+}$ e $\mathrm{Fe}^{3+}$, cujas concentrações foram determinadas por métodos químicos. Utilizando RPE eles observaram um espectro (banda X) consistindo de linhas largas, estendendo-se desde campos altos $(\mathrm{g} \cong 1$ ) até campos baixos ( $\mathrm{g} \cong 10)$, e de uma linha de ressonância muito intensa, quando comparada com o restante do espectro, com g =4,27 e largura de aproximadamente 60 gauss. A correlação entre a intensidade integrada desta linha com as concentrações de $\mathrm{Fe}^{2+}$ e $\mathrm{Fe}^{3+}$ indicaram que esta ressonância é devida ao $\mathrm{Fe}^{3+}$. Este resultado, foi explicado teoricamente, em termos de um Hamiltoniano altamente anisotrópico, no qual o íon $\mathrm{Fe}^{3+}(\mathrm{S}=5 / 2)$ está sujeito a um termo de estrutura fina da forma $\mathrm{E}\left(\mathrm{S}_{\mathrm{x}}{ }^{2}-\mathrm{S}_{\mathrm{y}}{ }^{2}\right)$ que, a campo magnético nulo, levanta a degenerescência do nível $\mathrm{S}=5 / 2$ em 3 dubletos igualmente espaçados. Normalmente, a separação entre os dubletos é muito maior que a energia do fóton da microonda e, em campos baixos, isto leva a um fator g isotrópico igual a 4,28, em concordância com os resultados experimentais.

Wickman et $\mathrm{al}^{[87]}$ generalizaram o modelo de Castner introduzindo o termo axial no Hamiltoniano de spin, como forma de explicar a grande largura de linha observada em g $\approx 4$ (400 gauss em vez de 60 gauss, como observado por Castner). Assim, até segunda ordem nas componentes de spin, o Hamiltoniano mais geral é dado por:

$$
\aleph=D\left[S_{z}^{2}-(1 / 3) S(S+1)\right]+E\left(S_{x}^{2}-S_{y}^{2}\right)+g \beta \vec{H} \bullet \vec{S}
$$

Os termos de campo cristalino, D e E, são considerados grandes comparados com o termo Zeeman. Diagonalizando o Hamiltoniano para valores positivos de $\lambda=E / D$, obtêm-se os valores do g efetivo, no conjunto de estados $\mathrm{J}=5 / 2$, que estão mostrados na Figura 73 . A faixa de valores de $\lambda$ que possui significado físico está restrito à $\lambda \leq 1 / 3$. Pode-se mostrar 
que a situação estudada por Castner $(\mathrm{D}=0)$ é equivalente ao caso particular em que $\lambda=1 / 3$ no modelo de Wickman. Nesta situação, de extrema distorção rômbica, observa-se somente uma linha isotrópica, com $g \cong 4,3$. Se $\lambda<1 / 3$, os valores de $g_{x, y}$ diferem de $g_{z}$ causando um alargamento da linha. A partir da largura observada (400 gauss) foi determinado o valor $\lambda=0,25$. É importante notar que foi observado que esta largura de linha é independente da temperatura na faixa de $1 \mathrm{~K}$ a $300 \mathrm{~K}$. Como pode-se observar na Figura 73, para $\lambda=0,25$ espera-se também observar ressonâncias com g =9,45, 1,32 e 0,86, o que só foi observado experimentalmente em temperaturas muito baixas, da ordem de $1 \mathrm{~K}$. Além disso, a anisotropia do espectro em $\mathrm{g} \cong 4,3$, evidenciando os valores de $\mathrm{g}_{\perp} \mathrm{e}$ go, também só é observada em baixas temperaturas.
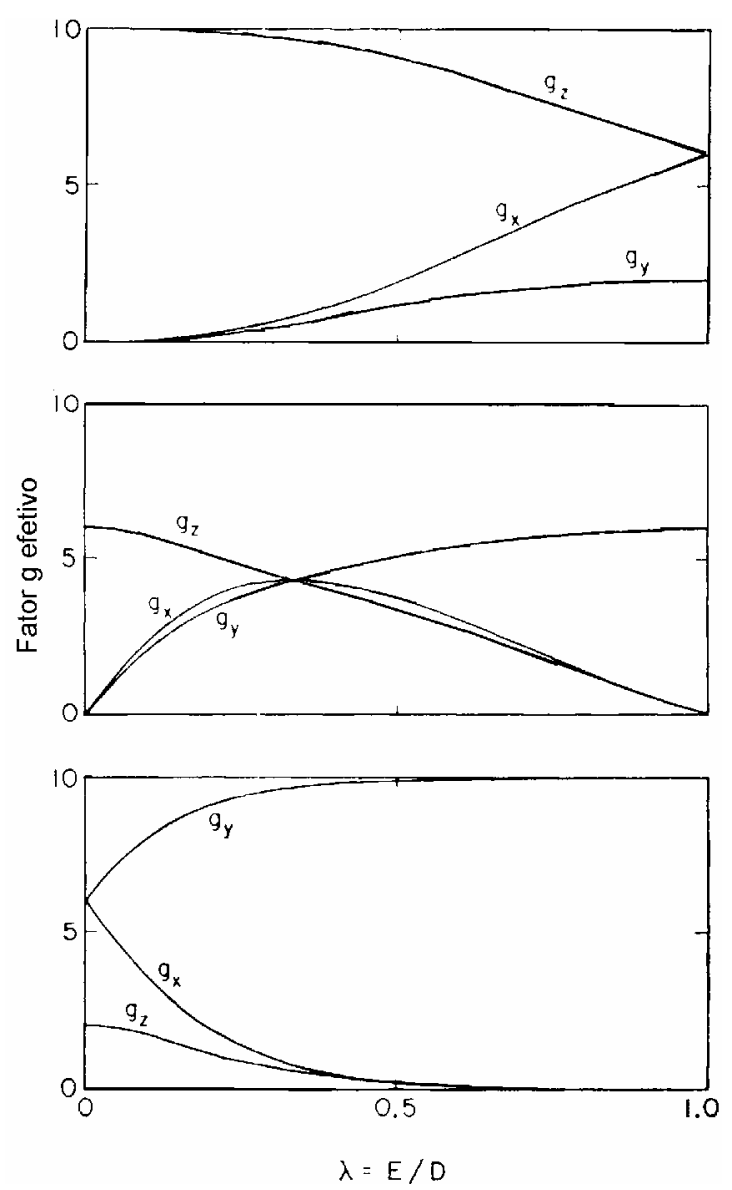

Figura 73 - Valores de g efetivo para o Hamiltoniano de spin dado pela Eq. (47),

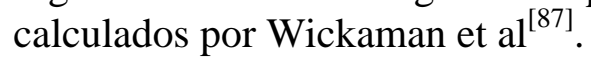

Baseados nos nossos resultados e nas conclusões de Wan e Kuivalainen (trabalhos citados anteriormente) podemos admitir que o íon Ferro se liga ao polímero, no 
estado de oxidação (+3). Isto é compatível com a nossa observação da linha $C$, em campo baixo $(g=4,4)$, que segundo Castner (citado anteriormente), é característica do íon $\mathrm{Fe}^{3+}$ em simetria rômbica. Esta linha não foi observada por Wan e Kuivalainen. No caso do espectro obtido por Wan (Figura 72), já mencionamos anteriormente que ele apresenta indícios de ressonância em $g \approx 4$. Entretanto, é difícil concluir algo a este respeito, por se tratar do mesmo íon $\mathrm{Fe}^{3+}$, porém em uma matriz diferente. No caso de Kuivalainen, a matriz é a mesma, porém, eles não mencionam em que faixa de temperaturas foi medido o espectro de RPE. É possível que eles não tenham realizado medidas em temperaturas suficientemente baixas para observar esta linha.

De acordo com o nosso modelo, a linha $C$ fica atribuída aos íons $\mathrm{Fe}^{3+}$ situado na molécula do dopante. Isto é consistente com o comportamento da intensidade integrada da linha $C$ em função da temperatura, mostrada na Figura 69. Utilizando o modelo de Wickman, podemos estimar, a partir da largura de linha observada (200 gauss, de acordo com a Figura 65) que $\lambda \cong 0,29$. Isto indica que o íon $\mathrm{Fe}^{3+}$ encontra-se ligado à rede polimérica em um sítio com alta distorção rômbica. Infelizmente não foi possível realizar medidas em temperaturas abaixo de $4 \mathrm{~K}$, o que permitiria a observação das outras ressonâncias, particularmente aquela em $g \approx 9$.

No modelo de Castner, o espectro de RPE do $\mathrm{Fe}^{3+}$ apresenta uma única linha intensa com $g \cong 4,27$. Portanto, a linha larga, $A$, observada nos nossos espectros em $\mathrm{g} \cong 2$, não pode ser atribuída à este mesmo íon, em sítios de mesma simetria. Não temos conhecimento, através da literatura existente, de outras possíveis coordenações de mais alta simetria do íon $\mathrm{Fe}^{3+}$ neste tipo de materiais. Da mesma forma, a literatura não menciona a presença de íons Fe em outros estados de oxidação. Por isso, acreditamos que a linha $A$ deva ser atribuída a íons $\mathrm{Fe}^{3+}$ que, por estarem próximos entre si, podem interagir fortemente, formando pequenos grupos ou, até mesmo, aglomerados. Kuivalainen também observa uma linha similar a essa mas, apesar de atribuí-la a íons $\mathrm{Fe}^{3+}$ nas moléculas do dopante, não menciona a possibilidade deles interagirem entre si. Por outro lado, eles observaram uma forte dependência da largura dessa linha com a concentração de dopante. Acreditamos que este fato é incompatível com a hipótese de íons isolados, a menos que a introdução de dopantes, mesmo em baixas concentrações, provoque fortes deformações estruturais na cadeia polimérica, o que, a nosso ver, é bastante improvável. 
Acreditamos que a linha estreita, $B$, com $g \cong 2$, deva ser atribuída à formação de polarons, a partir da introdução do dopante. Esta afirmação concorda com os resultados e conclusões de Kuivalainen, porém não é compatível com o modelo proposto por Wan. A linha observada por Wan no composto PANI-FeCl ${ }_{4}^{-}$(600 gauss) é bem mais larga que a observada em PANI-Cl- (1,5 gauss), entretanto, ambas foram associadas ao polaron. Observamos que a largura da primeira é da mesma ordem que a observada por nós em $\mathrm{PPP}_{-} \mathrm{FeCl}_{4}^{-}$(linha $A$ ). A justificativa utilizada para expicar esta diferença na largura de linha entre os dois compostos é contrastante com os nossos resultados, conforme explicaremos adiante.

A Figura 68 mostra a dependência com a temperatura do inverso da intensidade integrada da linha $B$, aqui atribuída ao polaron. Observa-se uma dependência do tipo Curie-Weiss, o que indica um alto grau de localização do polaron na faixa de temperaturas entre 4-120 K. Observa-se também que o valor da intensidade integrada aumenta com o aumento da concentração (entre 1,1 e 1,8), indicando um aumento na população de polarons com a concentração do dopante. A Figura 67 mostra que a largura da linha $B$ decresce com o aumento da temperatura, valendo cerca de 17 gauss em $4 \mathrm{~K}$ e 10 gauss em $120 \mathrm{~K}$. Na temperatura ambiente a largura decresce para cerca de 6 gauss (não mostrado na figura). A origem deste alargamento é atribuída à interação hiperfina do polaron com o spin nuclear dos íons da cadeia polimérica. Acreditamos que, na medida em que a temperatura aumenta, o grau de localização do polaron diminue, diminuindo também o seu tempo de residência na proximidade dos núcleos. Isto faz com que a largura de linha do polaron diminua com o decréscimo do seu grau de localização, o que certamente deverá ocorrer com o aumento da temperatura. Este fato não é evidente na Figura 69 porque, na faixa de temperaturas em que o experimento foi realizado, a contribuição de Curie-Weiss para a susceptibilidade magnética do polaron é dominante.

De acordo com este modelo, é possível que esteja correto o argumento utilizado por Wan, para explicar o aumento da largura de linha do polaron observada no composto PANI-FeCl ${ }_{4}^{-}$(600 gauss), relativamente à PANI-Cl- (1,5 gauss). Entretanto, é bastante contrastante o fato de termos observado uma linha relativamente estreita (6 - 17 gauss) para o polaron no composto $\mathrm{PPP}-\mathrm{FeCl}_{4}{ }^{-}$. Por isso, suspeitamos que a linha larga observada por Wan deve ser atribuída aos íons $\mathrm{Fe}^{3+}$ acoplados, que formaram aglomerados no processo de dopagem da PANI, e não ao polaron. É possível que a linha associada ao 
polaron esteja, no caso de Wang, não resolvida. Entretanto, é difícil concluir algo a este respeito, por se tratar do mesmo dopante, porém em uma matriz diferente.

A possível existência de aglomerados de íons Ferro nos compostos estudados pode explicar porque a susceptibilidade magnética medida através da linha $A$ não exibe um comportamento do tipo Curie-Weiss. Da mesma forma, acreditamos que este mesmo fato também exerça uma influência grande nos resultados obtidos pela técnica de susceptibilidade AC. Esta última, representa uma medida macroscópica da magnetização do material, que leva em conta as contribuições conjuntas do polaron e íons $\mathrm{Fe}^{3+}$. É provável que a contribuição maior seja aquela devida aos aglomerados de Ferro pois, como indicam os espectros de RPE, são eles quem possuem a maior intensidade integrada. Esta idéia é reforçada pelo fato de que, da normalização dos dados da susceptibilidade AC com a concentração do dopante (medida por absorção atômica), resulta numa relação não linear entre os parâmetros magnéticos encontrados, com a concentração, conforme pode-se observar na Figura 60 e Figura 61. A elaboração de um modelo teórico capaz de simular os resultados obtidos por SMAC não é uma tarefa simples. Pouco conhecemos a respeito da estrutura destes aglomerados, especialmente tamanho e distância média entre os íons. Além disso, não temos ainda um modelo para a interação Fe-Fe nestes materiais, a fim de estimar a temperatura abaixo da qual ocorreria um possível ordenamento magnético. Considerando o forte empacotamento das cadeias poliméricas, é bem possível que, tanto o acoplamento entre íons pertencentes a uma mesma cadeia (intracadeia) como o intercadeias, contribuam para definir a estrutura magnética destes aglomerados.

Para concluir, podemos dizer que as medidas feitas por RPE permitiram separar as contribuições dos diferentes centros magnéticos que podem contribuir para a susceptibilidade deste material: polarons $(B)$ e íons Ferro ( $A$ e $C$ ). Por outro lado, as medidas de SMAC parecem vir a confirmar a hipótese de que elas refletem primordialmente a estrutura e comportamento dinâmico dos aglomerados magnéticos formados com a introdução de dopantes. 


\section{6 - POLI(O-METOXIANILINA)}

Nas últimas décadas as polianilinas têm tido um grande destaque no campo dos polímeros condutores, devido a facilidade de síntese e dopagem, estabilidade química no estado dopado e alta condutividade elétrica ${ }^{[88]}$. Neste período, vários estudos foram realizados acerca de sua estrutura, do mecanismo de condução e de transição metal-isolante ${ }^{[89-}{ }^{100]}$.

Embora tenham sido obtidos valores relativamente altos de condutividade, através da dopagem da polianilina com ácidos protônicos convencionais, esta condutividade tem um comportamento, com a temperatura, contrário àquele esperado para um metal. Seu valor diminui por várias ordens de grandeza quando a temperatura é diminuída. Esta forte dependência com a temperatura sugere uma composição de ilhas metálicas ${ }^{[101]}$ separadas por barreiras isolantes.

A Poli(O-MetoxiAnilina), denominada POMA, é um polímero derivado da polianilina, que contém um grupo metoxi $\left(\mathrm{OCH}_{3}\right)$ em substituição a um hidrogênio (H), da posição orto, do anel benzeno. Outros polímeros, derivados da polianilina, podem ser obtidos através da substituição dos átomos de hidrogênio, do anel ou nos átomos de nitrogênio amina, por algum radical. Na Tabela 10 são listados outros polímeros provenientes da substituição do $\mathrm{H}$, da posição orto do anel benzeno, por um outro grupo radical.

A grande vantagem da POMA, consiste no fato de, na forma base esmeraldina, ser solúvel em uma variedade de solventes orgânicos tais como: Dimetilformamida (DMF), N-N, Dimetilacetamida (DMA), N-Metilpirrolidona (NMP), m-cresol, etc. Além disto, a sua protonação pode ser realizada com uma variedade de ácidos tais como HCl, TFA, CSA e outros. 
Tabela 10 - Denominação dada à derivados da polianilina devido a substituição do $H$, da posição orto do anel benzeno, por um dos radicais $(R)$ listados abaixo.

\begin{tabular}{||l|l|l||}
\hline \multicolumn{1}{|c|}{$\mathbf{R}$} & \multicolumn{1}{|c|}{ NOME } & SIGLA \\
\hline $\mathrm{H}$ & polianilina & PANI \\
\hline $\mathrm{CH}_{3}$ & poli(o-toluidina) & POT \\
\hline $\mathrm{OCH}_{3}$ & poli(o-metoxianilina) & POMA \\
\hline $\mathrm{OC}_{2} \mathrm{H}_{5}$ & poli(o-etoxianilina) & POEA \\
\hline
\end{tabular}

A estrutura básica da polianilina é mostrada na Figura 74, onde y e (1-y) correspondem, respectivamente, a fração das unidades repetidas das espécies reduzidas e oxidadas. $\mathrm{O}$ valor de y pode variar continuamente de 0 a 1 . O estado mais estável e que apresenta maior condutividade elétrica depois de protonado é quando y é igual 0,5, que é conhecido como base esmeraldina (EB).

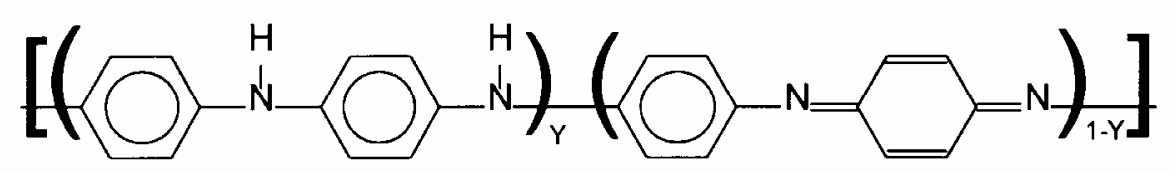

Figura 74 - Estrutura básica da polianilina.

Para os polímeros derivados da PANI, mencionados anteriormente (ver Tabela 10), a estrutura básica é semelhante àquela esquematizada na Figura 74, com a diferença, como mostra a Figura 75, do radical $(R)$ na posição orto do anel benzeno $(R$ é um dos grupos listados na Tabela 10).

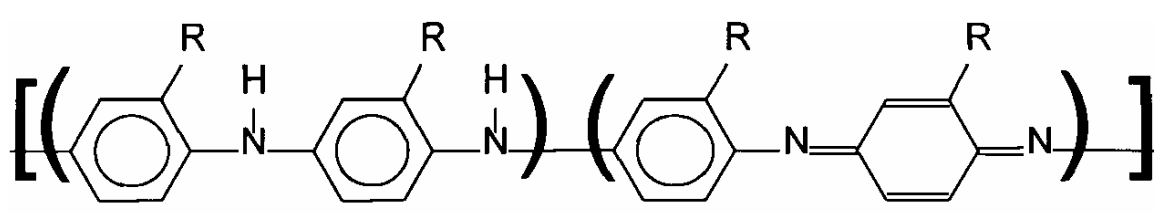

Figura 75 - Estrutura básica da derivada da polianilina devido a substituição do $H$, da posição orto do anel benzeno, por um dos radicais $(R)$ listados na Tabela 10. 


\section{1- Preparação das amostras}

A polianilina e suas derivadas podem ser processadas tanto na forma isolante (Base Esmeraldina - EB) ${ }^{[102]}$ quanto na forma condutora (Sal de Esmeraldina ES) ${ }^{[103]}$. A síntese destes polímeros ${ }^{[104,105]}$ podem ser realizadas via processo químico ou eletroquímico. Com a síntese eletroquímica, é possível obter-se filmes finos, diretamente sobre um substrato inerte, sem a presença de agente oxidante e catalisador. Entretanto, esse método tem a desvantagem de apresentar dificuldades em produzir filmes autosustentáveis, sem prejudicar as propriedades físicas dos polímeros. A síntese química tem a vantagem de produzir polímeros com alto peso molecular e pureza, na forma de pó (dopado) e em quantidades razoavelmente grandes.

A polianilina e a poli(o-metoxianilina), utilizadas neste trabalho, foram sintetizadas quimicamente de maneira análoga ao método usado por MacDiarmid et al ${ }^{[106]}$. O processo químico utilizado está esquematizado na Figura 76.

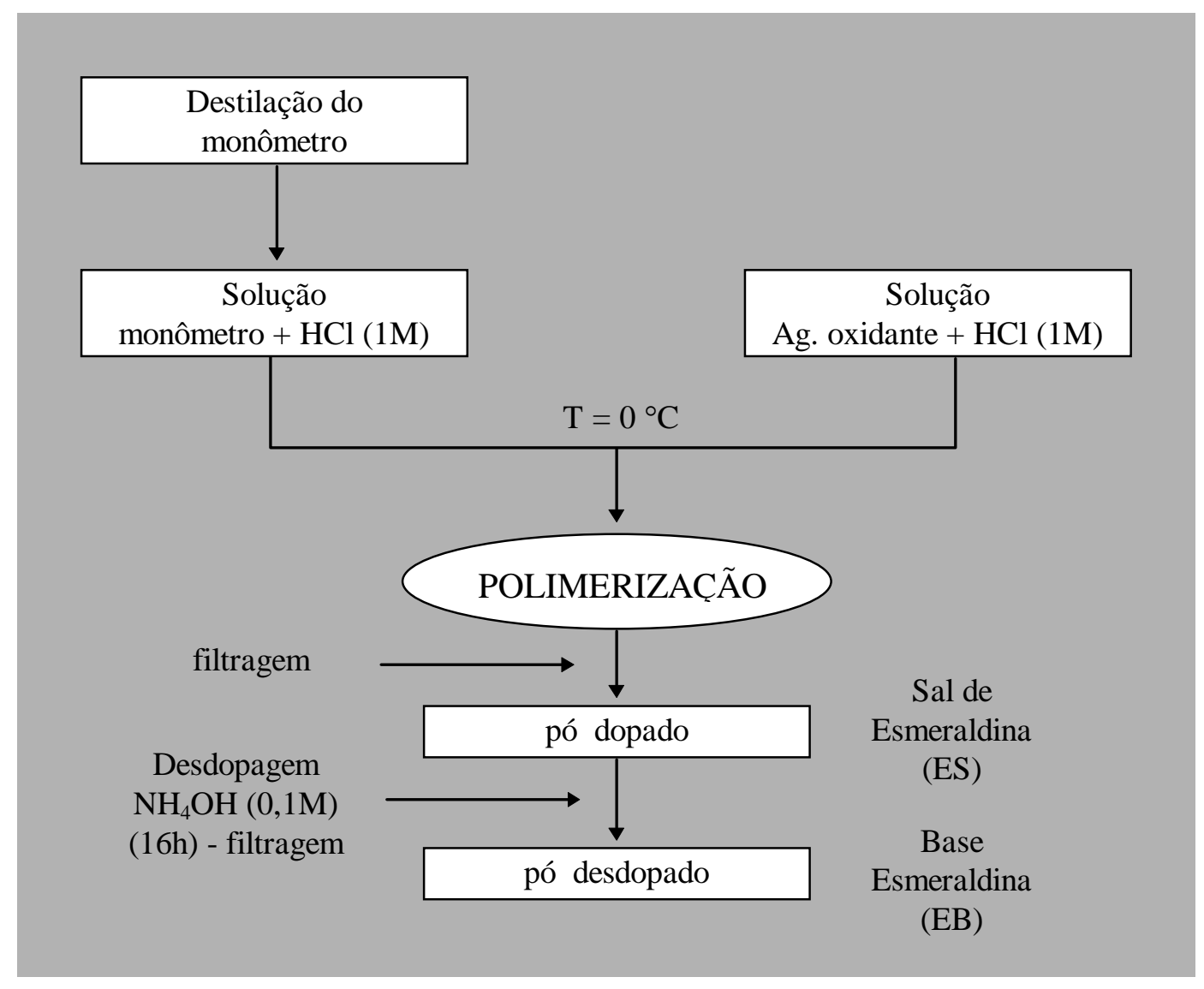

Figura 76 - Diagrama esquemático do processo químico utilizado na síntese da PANI e POMA (ver referências [104] e [105]). 
Os produtos utilizados na síntese química da PANI e POMA (ácidos, bases e agente oxidante) foram adquiridos da MERCK e Aldrich e foram usados conforme recebidos. Os monômeros anilina $\left(\mathrm{C}_{6} \mathrm{H}_{5} \mathrm{NH}_{2}\right)$ e anisidina $\left(\mathrm{C}_{6} \mathrm{H}_{4} \mathrm{~N}-\mathrm{OCH}_{3}\right)$ foram adquiridos da Aldrisch e Riedel, respectivamente e destilados, sob vácuo, para purificação.

A síntese química da PANI e POMA foi realizada usando monômero em excesso ${ }^{[107,108]}$ com razão molar monômero/oxidante de 4:1. Primeiro, em $300 \mathrm{~mL}$ de solução aquosa de $\mathrm{HCl}$ 1,0 M, dissolveu-se $20 \mathrm{~mL}$ do monômero de anilina (ou $28 \mathrm{~mL}$ do monômero de anisidina para a POMA) e a solução foi resfriada a $0{ }^{\circ} \mathrm{C}$. Em outro béquer, contendo $200 \mathrm{~mL}$ de solução aquosa de $\mathrm{HCl}$ 1,0 M, dissolveu-se 11,5 g do agente oxidante persulfato de amônio $\left(\mathrm{NH}_{4}\right)_{2} \mathrm{~S}_{2} \mathrm{O}_{8}$ e a solução foi também resfriada a $0{ }^{\circ} \mathrm{C}$. Após resfriadas as soluções, adicionou-se, lentamente, a solução contendo agente oxidante à solução contendo o monômero, mantendo sempre sob agitação constante à temperatura entre 0 e $2^{\circ} \mathrm{C}$. Após 2 horas (ou 4 horas para o derivado) de reação, a solução foi filtrada em um funil de Buchner e lavada com solução aquosa de $\mathrm{HCl}$ 1,0 M (acetona para a POMA) até que o resíduo da lavagem se tornasse incolor. Para isso, foi utilizado aproximadamente 2 litros da solução aquosa. O produto assim obtido, apresenta-se na forma de pó de cor verde escura, característico do estado condutor (sal de esmeraldina). Para a desdopagem, misturou-se o sal de esmeraldina numa solução básica de hidróxido de amônio $\left(\mathrm{NH}_{4} \mathrm{OH}\right)$ 0,1 M que foi deixada sob agitação constante à temperatura ambiente por 16 horas. Em seguida, a solução foi filtrada e lavada com $\mathrm{NH}_{4} \mathrm{OH}$ 0,1 M (acetona para a POMA) até que o resíduo ficasse incolor. Nesse estágio, o pó apresenta uma cor azul escuro, característica do polímero no estado não dopado (base esmeraldina). O pó desdopado foi então secado num dessecador, sob vácuo, por aproximadamente 24 horas. A PANI obtida por este caminho apresentou um peso molecular médio $\left(P_{M}\right)$ de aproximadamente $53.000 \mathrm{~g} / \mathrm{mol}$ e a POMA de $30.000 \mathrm{~g} / \mathrm{mol}$, concordando com valores apresentados na literatura $^{[109,110]}$.

A dopagem da polianilina e seus derivados é um processo reversível, que ocorre por meio de protonação quando na presença de ácidos (TFA 1M e HCl 1M). A protonação dos nitrogênios imina da base esmeraldina (EB) resulta na formação de

\footnotetext{
* A protonação da base esmeraldina, com ácido, leva a formação do sal de esmeraldina (ES), que é uma forma condutora da PANI.
} 
defeitos na cadeia (polarons). Na Figura 77 tem-se o esquema do processo de dopagem da polianilina, usando como ácido dopante o $\mathrm{HCl}$. Com a dopagem, a condutividade da PANI, na forma de pastilha, pode variar de $10^{-10}$ até $5 \mathrm{~S} / \mathrm{cm}$, dependendo do $\mathrm{pH}$ da solução dopante ${ }^{[111]}$. As amostras estudadas no presente trabalho foram a POMA não dopada (EB) e dopada com: HCl (1M) por 24 h; e TFA (1M) por 1 h (TFA-1) e por $24 \mathrm{~h}$ (TFA-24). Para este estudo, utilizou-se as técnicas de susceptibilidade magnética AC (SMAC) e ressonância magnética eletrônica (RPE) e nuclear (RMN).

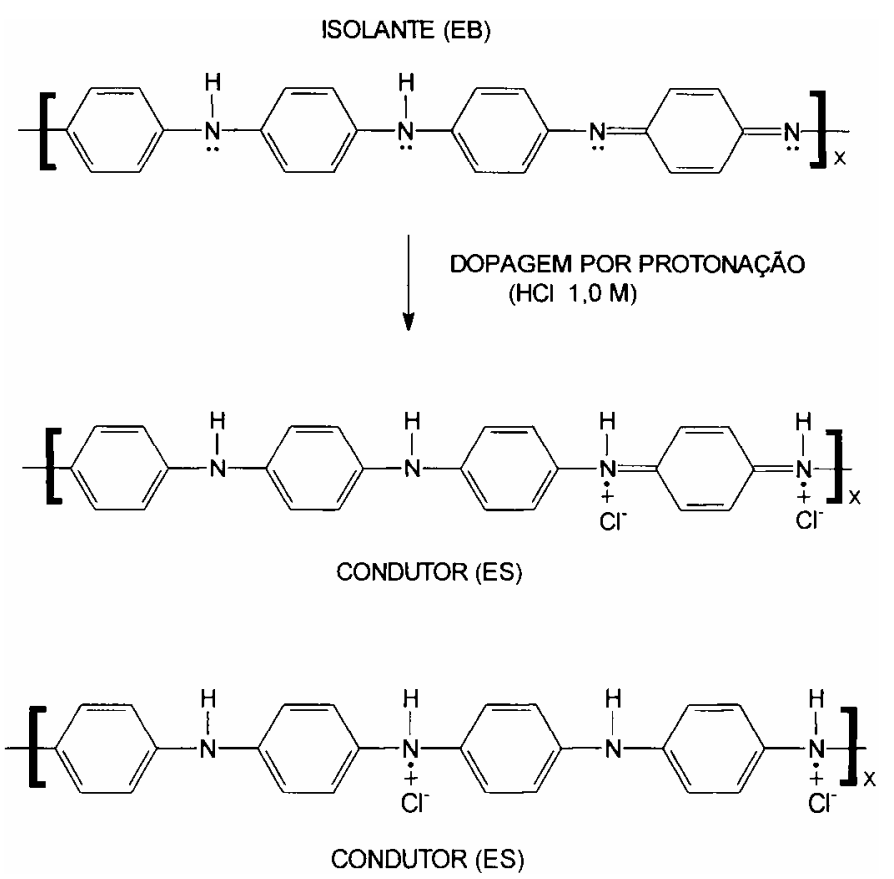

Figura 77 - Esquema da protonação da polianilina em meio ácido de $\mathrm{HCl}$ 1M.

\section{2 - Susceptibilidade Magnética AC}

Na Figura 78 estão mostrados os resultados das medidas de susceptibilidade magnética AC, para as amostras POMA, realizadas entre 4,2 K e $24 \mathrm{~K}^{\circledR}$ e com um campo magnético AC de intensidade $8 \mathrm{G}$ e freqüência 98,9 Hz. Para estas medidas foram utilizadas amostras na forma de pastilha de $4 \mathrm{~mm}$ de espessura por 4 mm de diâmetro. Estas pastilhas foram prensadas sob uma pressão de 4 ton/cm².

\footnotetext{
${ }^{\otimes}$ Não foi possível a realização de medidas de susceptibilidade AC, em temperaturas mais elevadas devido a pequena relação sinal-ruído para estas amostras. A intensidade do sinal para estas amostras é da ordem da sensibilidade do susceptômetro $\left(\sim 10^{-7} \mathrm{emu}\right)$.
} 


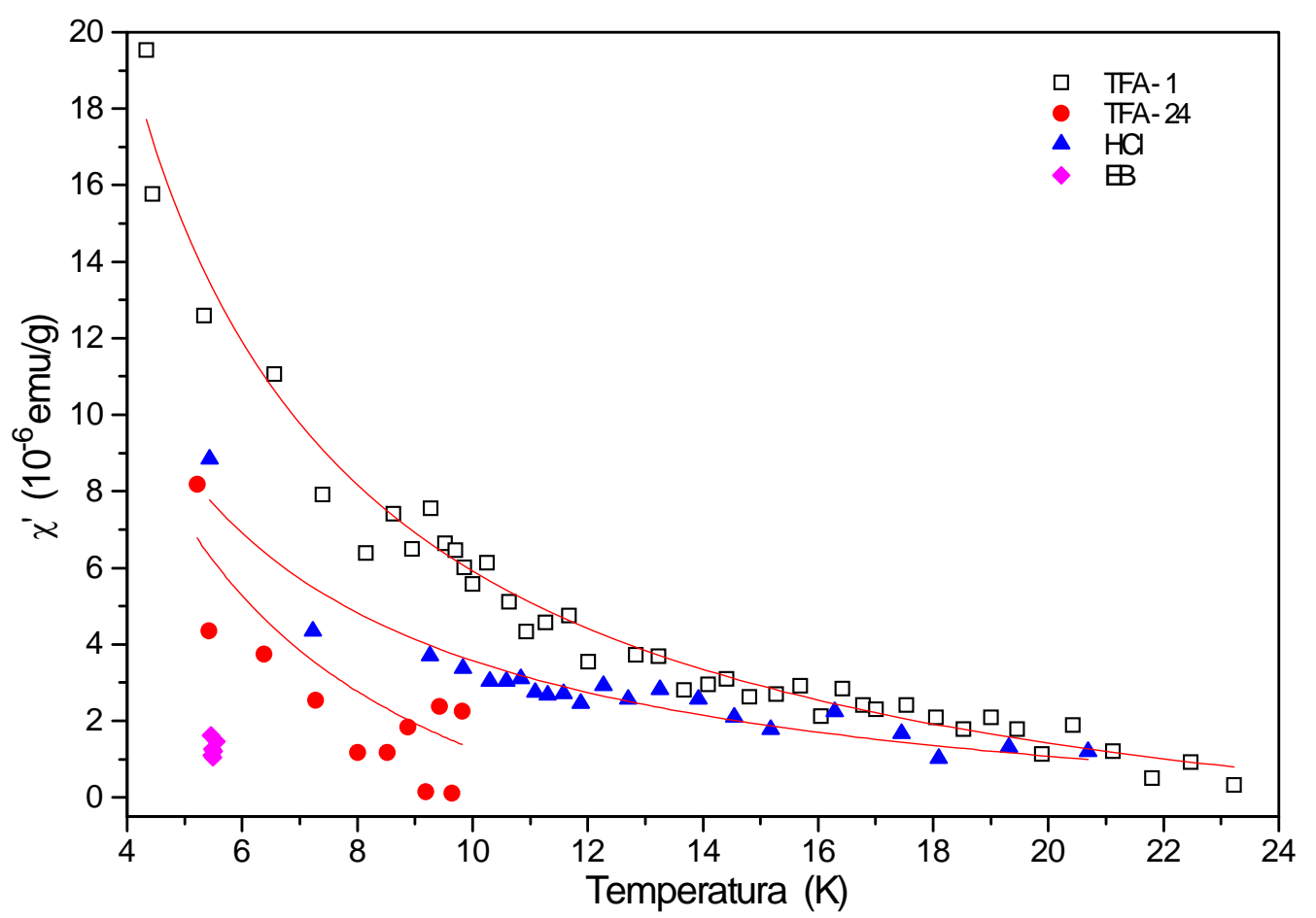

Figura 78 - Dependência com a temperatura, da componente real, da susceptibilidade magnética AC das amostras POMA EB ( $\diamond)$ e POMA dopada com TFA (• e •) e $\mathrm{HCl}(\bullet)$. Medidas realizadas nas amostras na forma de pastilhas e com um campo AC de 8 gauss de intensidade e $98,9 \mathrm{~Hz}$ de freqüência. Nestas medidas $\chi^{\prime \prime} \approx 0$.

Estudos de susceptibilidade magnética DC realizados em polianilinas e derivados $^{[112-118]}$ mostraram que a susceptibilidade pode ser descrita a partir de duas contribuições: uma independente da temperatura, proveniente do paramagnetismo de Pauli e do diamagnetismo da cadeia polimérica; e outra dependente da temperatura devido ao paramagnetismo de Curie. A Figura 79 apresenta o gráfico de $\chi T \times T$ onde verifica-se que a função linear, utilizada para ajustar os resultados, possui uma inclinação negativa. Esta inclinação indica a existência de um termo independente da temperatura $(\chi T=C+$ $\chi_{0} T$ ). O fato dela ser negativa, indica que a contribuição diamagnética (negativa) é maior que a de Pauli (positiva). Os parâmetros desse ajuste, embora muito impreciso, forneceram os valores da constante de Curie $(C)$ e da susceptibilidade independente da temperatura ( $\chi_{0}$, mostrados na Tabela 11. O sinal da amostra não dopada é muito pequeno, e acima de $5 \mathrm{~K}$ está abaixo da sensibilidade do equipamento utilizado. 


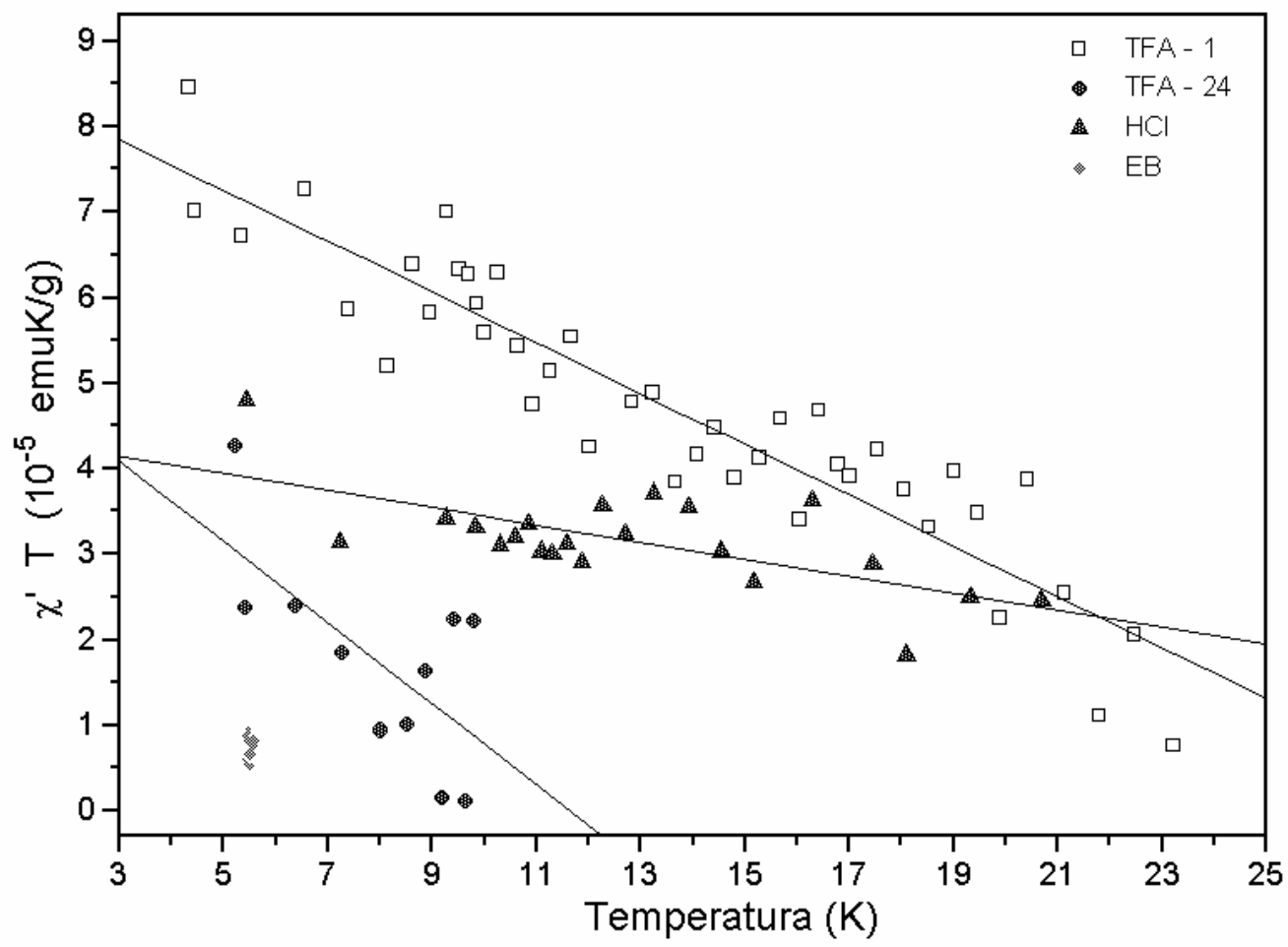

Figura 79 - Dependência com a temperatura do produto da componente real da susceptibilidade magnética AC, das amostras POMA EB ( $\diamond$ ) e POMA dopada com TFA (• e •) e $\mathrm{HCl}(\bullet)$, pela temperatura. Medidas realizadas nas amostras na forma de pastilha e com um campo AC de 8 gauss de intensidade e 98,9 Hz de freqüência.

Tabela 11 - Constante de Curie $(C)$ e susceptibilidade independente da temperatura $\left(\chi_{0}\right)$ para as amostras de poli(o-metoxianilina)

\begin{tabular}{||c|c|c||}
\hline Polímero + dopante & $\mathbf{C ~}\left(\mathbf{1 0}^{-\mathbf{5}} \mathbf{e m u K / g}\right)$ & $\chi_{\mathbf{0}}\left(\mathbf{1 0}^{-\mathbf{7}} \mathbf{e m u} / \mathbf{g}\right)$ \\
\hline POMA - EB & $\sim 0,1$ & $*$ \\
\hline POMA + HCl & 4 & -1 \\
\hline POMA + TFA-1 & 9 & -3 \\
\hline POMA + TFA-24 & 6 & -5 \\
\hline
\end{tabular}

O sinal da amostra não dopada é muito pequeno, com isto não foi possível medir sua susceptibilidade em temperaturas acima de $5 \mathrm{~K}$, impossibilitando assim a determinação de $\chi_{0}$.

Assim, como no caso do poliparafenileno (Capítulo 5), é interessante calcular a contribuição diamagnética da cadeia polimérica, utilizando a regra de adição de Pascal, exemplificada na Eq. (42). A fim de possibilitar comparações com resultados apresentados na literatura ${ }^{[112]}$, o cálculo foi realizado referindo-se à susceptibilidade molar para uma molécula reduzida contendo 4 anéis benzenos. Supõe-se também que o 
polímero dopado com $\mathrm{HCl}$ ou TFA $\left(\mathrm{CF}_{3} \mathrm{COOH}\right)$ esteja completamente protonado (um dopante a cada dois anéis como mostra Figura 77). Os valores calculados para $\chi_{\text {Dia }}$ (em unidades molares) estão mostrados na Tabela 12. O valor de $\chi$ Pauli é estimado subtraindo a contribuição diamagnética do valor de $\chi_{0}$ medido experimentalmente.

Tabela 12 - Contribuição diamagnética e de Pauli para a susceptibilidade da POMA.

\begin{tabular}{||c|c|c|c||}
\hline \hline Polímero + dopante & $\chi_{\mathbf{0}}\left(\mathbf{1 0}^{-\mathbf{6}} \mathbf{e m u} / \mathbf{m o l}\right)$ & $\chi_{\text {Dia }}\left(\mathbf{1 0}^{-\mathbf{6}} \mathbf{e m u} / \mathbf{m o l}\right)$ & $\chi_{\text {Pauli }}\left(\mathbf{1 0}^{-\mathbf{6}} \mathbf{e m u} / \mathbf{m o l}\right)$ \\
\hline POMA - EB & - & $-291,34$ & - \\
\hline POMA + HCl & $-55,5$ & $-337,24$ & 281,74 \\
\hline POMA + TFA-1 & -213 & $-377,48$ & 164,48 \\
\hline POMA + TFA-24 & -355 & $-377,48$ & 22,48 \\
\hline
\end{tabular}

Este resultado indica que a comportamento diamagnético observado pode ser explicado através da contribuição dos íons que compõem a cadeia do polímero. Entretanto, o cálculo é apenas aproximado, visto que não é conhecido o grau de protonação dos polímeros tratados com ácidos. Embora não tenha sido possível confirmar estes resultados através de outras técnicas, lembramos que o valor da susceptibilidade de Pauli, mostrado na Tabela 12, é da mesma ordem de grandeza da susceptibilidade magnética, obtida por Ginder et $\mathrm{al}^{[112]}$, para a polianilina dopada com $\mathrm{HCl}$ e para polímeros derivados da polianilina ${ }^{[117,118]}$.

\section{3 - Ressonância Paramagnética Eletrônica (RPE)}

Estudos de Ressonância Paramagnética Eletrônica em polianilina (filme e pastilha), dopada por vários ácidos, vem sido largamente explorados nos últimos anos. Alguns autores ${ }^{[112,114,119-124]}$ associam a susceptibilidade estática medida por RPE como sendo devido a uma contribuição de Curie e outra de Pauli. Já outros autores ${ }^{[125]}$ apresentam modelos diferentes para explicar o comportamento magnético destes materiais. Encontra-se também na literatura ${ }^{[126]}$ trabalhos onde o comportamento magnético da polianilina é interpretado em termos da existência de ilhas metálicas dispersas no material.

As medidas de RPE, onda contínua, foram realizadas entre $5 \mathrm{~K}$ e temperatura ambiente, em freqüências em torno de 9,26 GHz (Banda X). Para 
modulação de campo magnético utilizou-se um sinal de $0,57 \mathrm{G}$ de amplitude e $85 \mathrm{kHz}$ de freqüência.

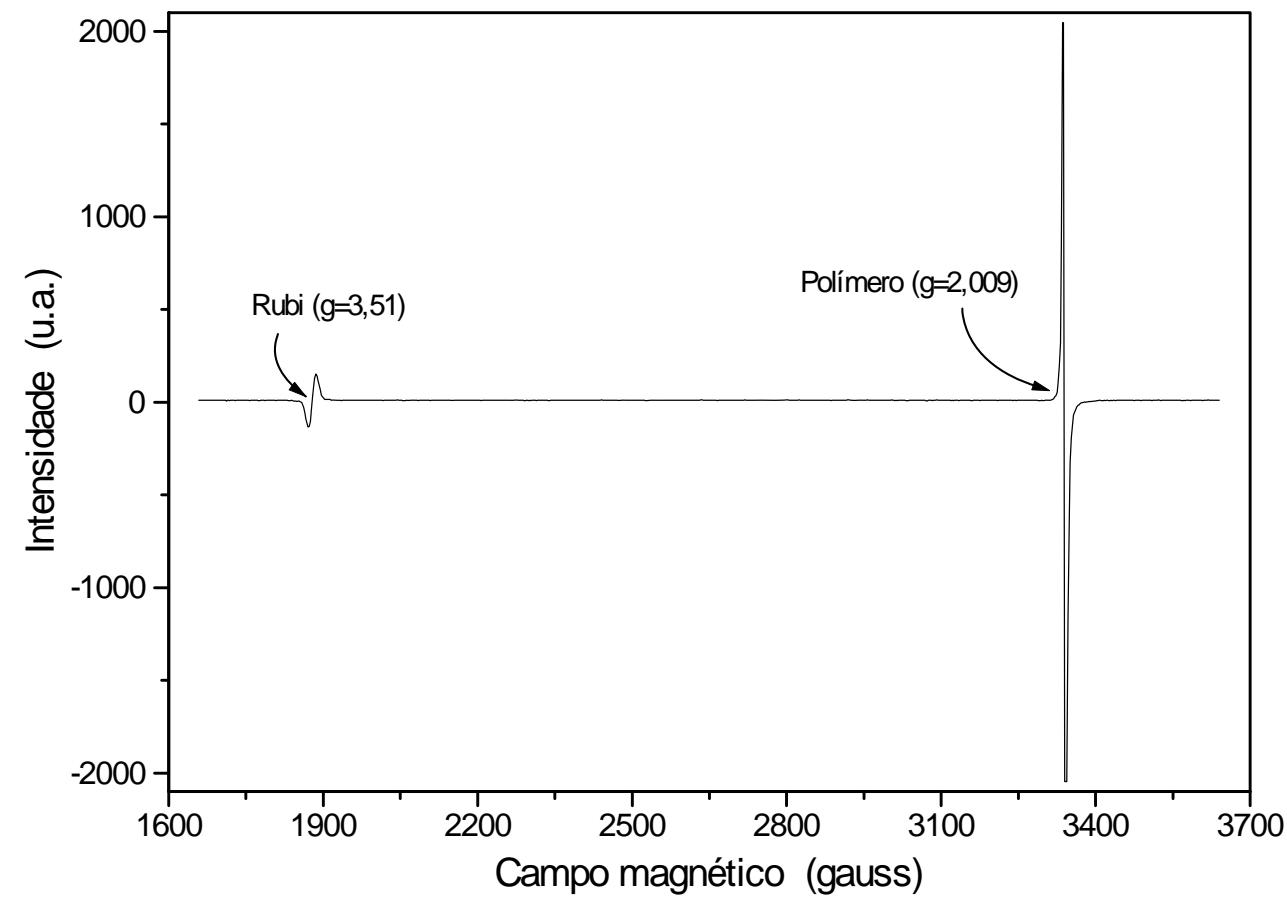

Figura 80 - Sinal de RPE, em temperatura ambiente, da amostra POMA dopada com TFA por $1 \mathrm{~h}$. Neste espectro são mostrados os sinais do polímero $(\mathrm{g} \cong 2,009)$ e do rubi, em baixo campo ( $\mathrm{g}=3,51)$, utilizado como padrão.

Foi utilizado um cristal de $\mathrm{Al}_{2} \mathrm{O}_{3}: \mathrm{Cr}^{3+}$ (rubi), colocado no interior da cavidade ressonante e mantido em temperatura ambiente, para normalização do sinal da amostra. Na Figura 80 tem-se um espectro de RPE onde é mostrado o sinal devido ao polímero $(g \approx 2,009)$ e o sinal do rubi em baixo campo $(g=3,51)$. As amostras foram prensadas (sob uma pressão de $4 \mathrm{ton} / \mathrm{cm}^{2}$ ) na forma de uma pastilha fina. $\mathrm{Na}$ Tabela 13 são mostradas as espessuras das amostras e as freqüências de microondas utilizadas. Para a amostra não dopada, na qual o sinal de RPE é muito pouco intenso, foi necessário a utilização de uma pastilha de maior espessura, a fim de melhorar a relação sinal/ruído. No caso das amostras dopadas, o sinal de RPE é muito intenso e por isso utilizou-se um pequeno pedaço, de aproximadamente um quarto, destas pastilhas. O fator $\mathrm{g}$, medido no centro da linha de ressonância, permaneceu em torno de 2,009 \pm 0,005 em toda a faixa de temperaturas em que o experimento foi realizado. 
Tabela 13 - Especificações das pastilhas de poli(o-metoxianilina) utilizadas nas medidas de RPE.

\begin{tabular}{||l|c|c|c|c||}
\hline \multicolumn{1}{|c|}{ Amostra } & espessura $(\boldsymbol{\mu m})$ & diâmetro $(\mathbf{m m})$ & massa $(\mathbf{m g})$ & $\mathbf{f}(\mathbf{G H z})$ \\
\hline POMA-EB & 1500 & 4 & 21,2 & 9,25 \\
\hline POMA-TFA-1 & 500 & $\sim 1,5$ & 1,3 & 9,26 \\
\hline POMA-TFA-24 & 650 & $\sim 1,5$ & 2,3 & 9,26 \\
\hline POMA-HCl & 650 & $\sim 1,5$ & 1,6 & 9,26 \\
\hline
\end{tabular}

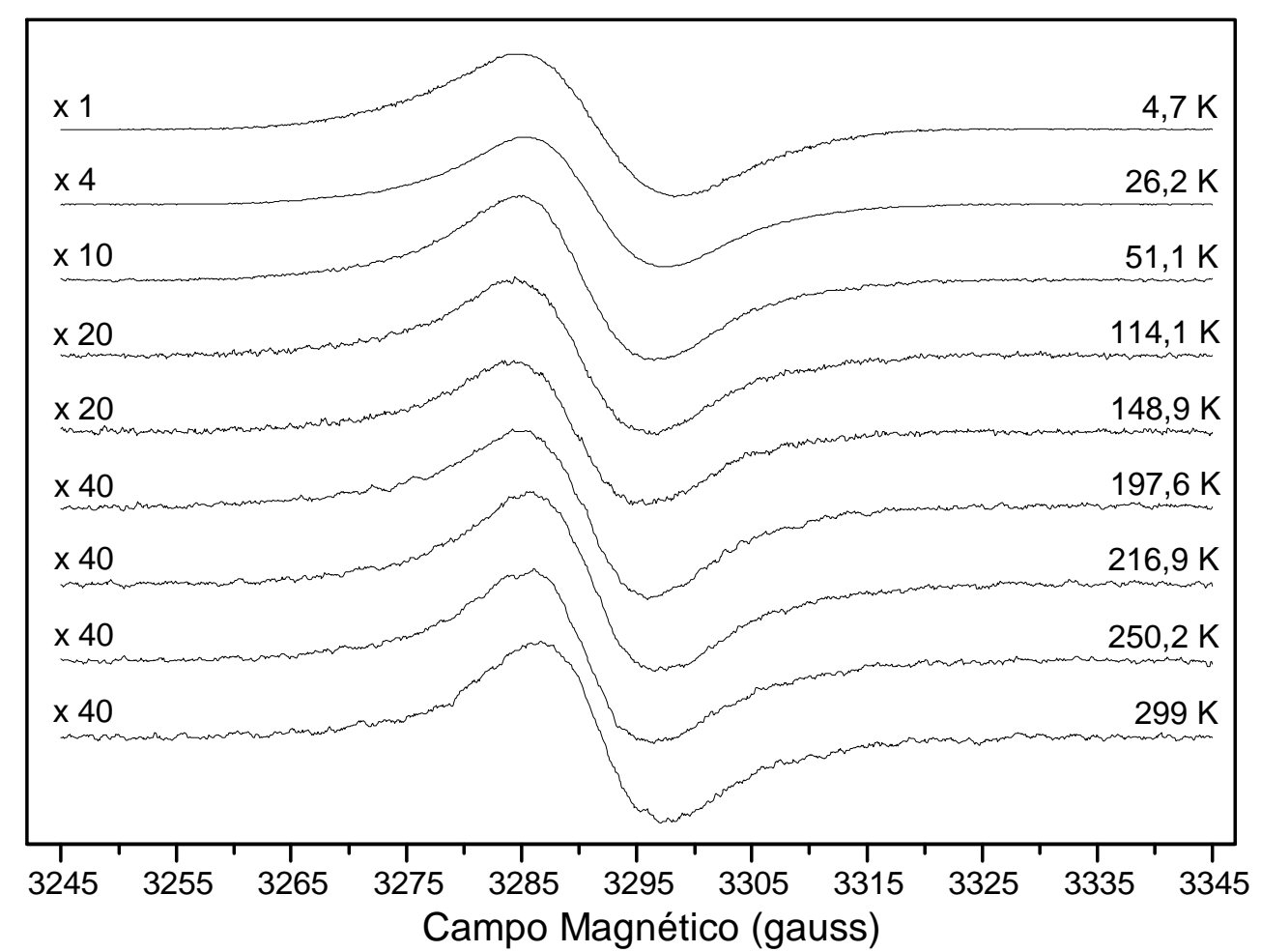

Figura 81 - Evolução do espectro de RPE, da amostra POMA EB (pastilha), em função da temperatura.

Na realização das medidas de RPE seguiu-se sempre o mesmo procedimento, no que diz respeito a variação da temperatura da amostra. A temperatura é rapidamente abaixada até 4,2 K e os espectros de RPE são registrados conforme a amostra é lentamente aquecida até temperatura ambiente. Alguns dos espectros obtidos para a amostra POMA-EB estão mostrados na Figura 81. Os espectros podem ser ajustados, em toda faixa de temperatura, pela superposição de duas linhas gaussianas, cujas intensidades estão na razão 2:1. 


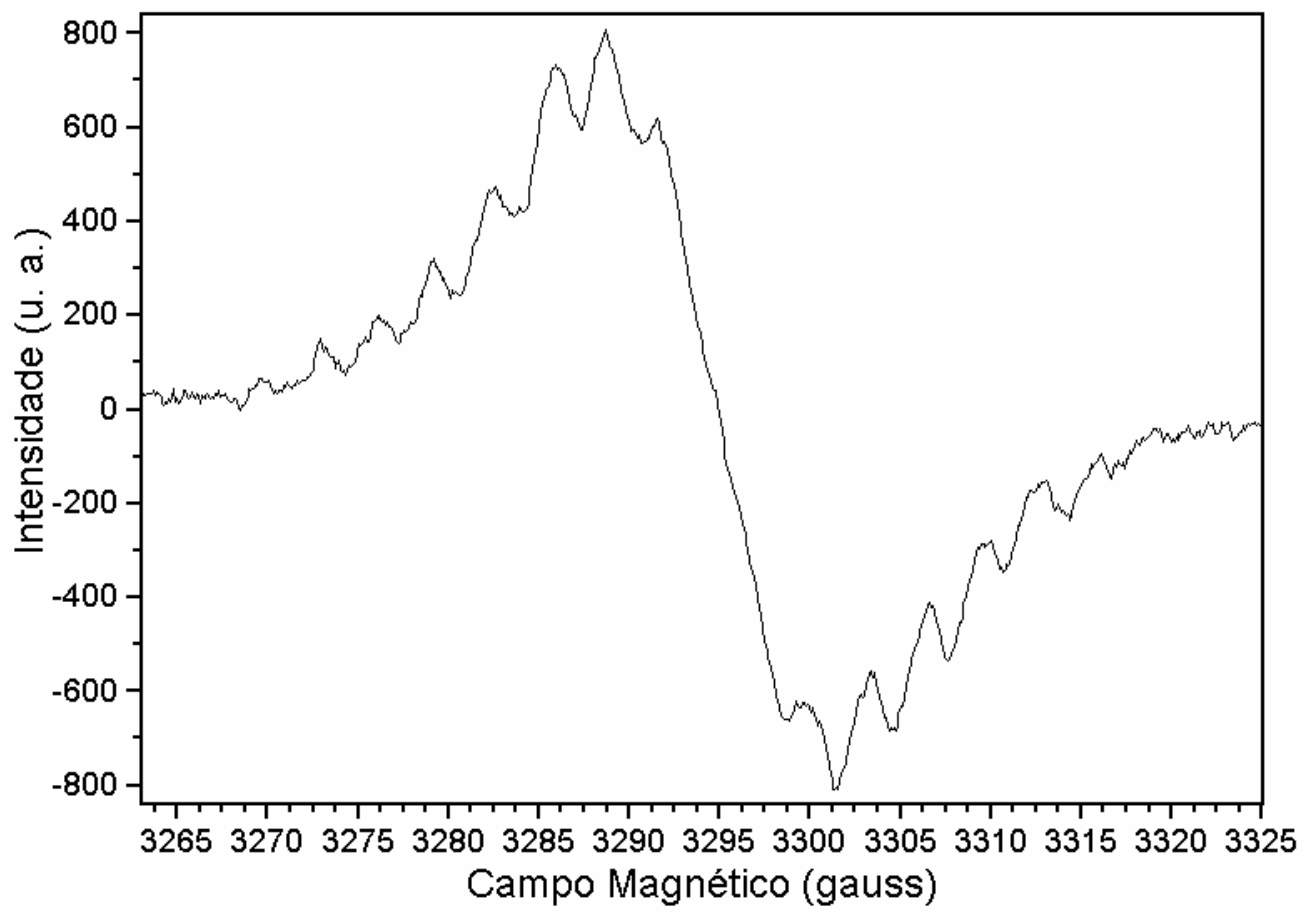

Figura 82 - Linhas hiperfinas resolvidas para o sinal de RPE da POMA-EB na forma de pastilha e em temperatura de $12 \mathrm{~K}$.

Em uma particular amostra de poli(o-metoxianilina) não dopada (POMA-EB), obteve-se o espectro com linhas hiperfinas resolvidas, mostrado na Figura 82. Esta medida foi observada em uma pastilha de $300 \mu \mathrm{m}$ de espessura, prensada a 4 ton $/ \mathrm{cm}^{2}$. Este espectro, com linhas hiperfinas, foi observado ao se elevar a temperatura no intervalo entre $9 \mathrm{~K}$ e $15 \mathrm{~K}$. Em $12 \mathrm{~K}$, observou-se que o espectro apresentava uma maior resolução e tanto acima de $15 \mathrm{~K}$ como abaixo de $9 \mathrm{~K}$ as hiperfinas desapareciam. O aparecimento e desaparecimento da estrutura hiperfina, com a variação da temperatura, era reprodutível dentro do intervalo 4-25 K. Entretanto, após a realização de um ciclo térmico até temperatura ambiente, a estrutura hiperfina do espectro não mais foi observada nos próximos experimentos, realizados alguns dias depois. Estas linhas hiperfinas também não foram observadas em outras amostras sintetizadas posteriormente. Infelizmente, sendo que este experimento não pôde ser reproduzido, não foi possível determinar quais fatores importantes, sejam na fabricação da amostra ou no tratamento térmico, que viabilizaram o aparecimento desta estrutura hiperfina resolvida. Observa-se, na Figura 82, aproximadamente de 15 a 17 linhas hiperfinas parcialmente resolvidas. 


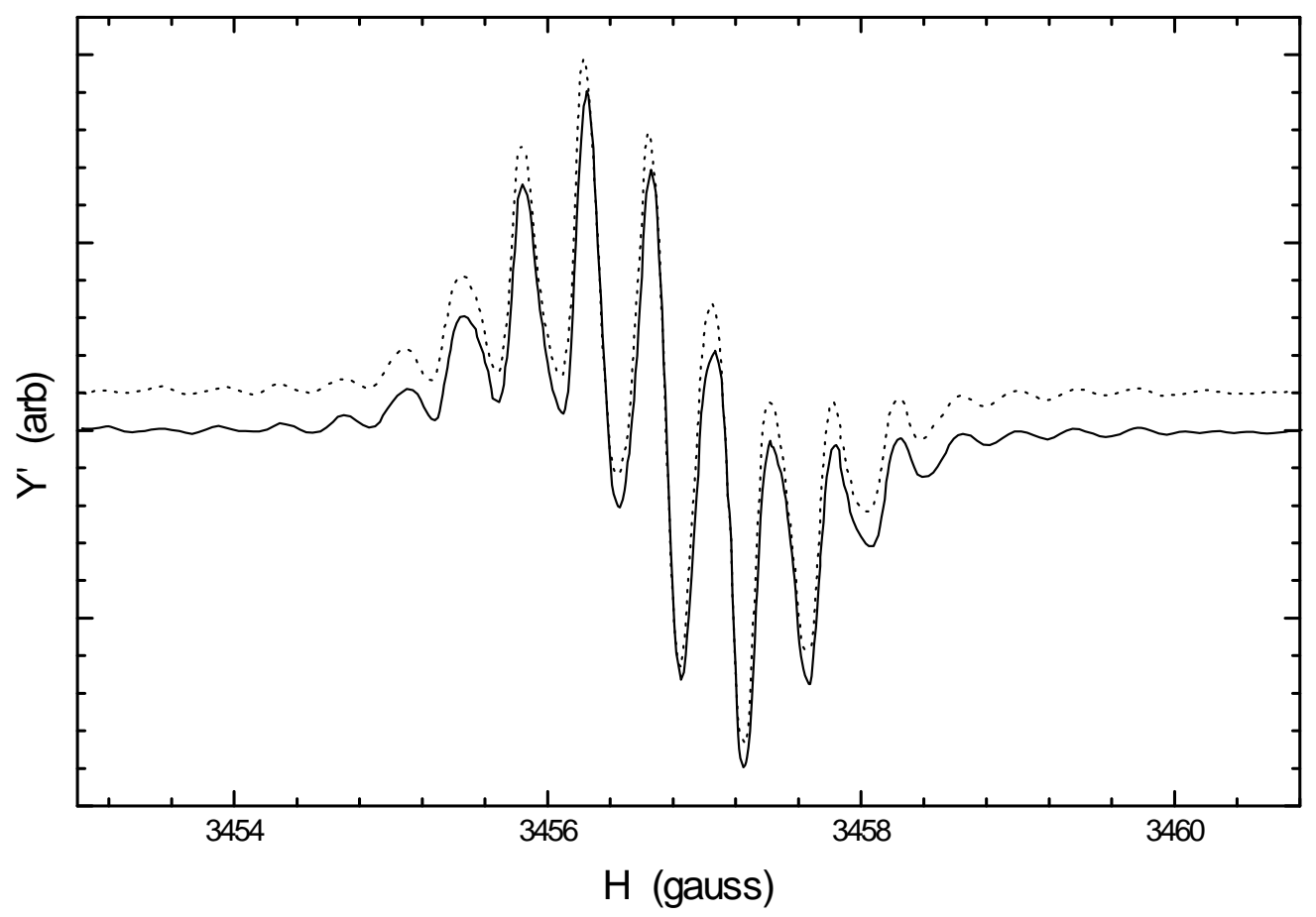

Figura 83 - Estrutura hiperfina resolvida para o sinal de RPE de polianilina, na forma PNB (linha cheia) e EB (linha pontilhada), diluída em dioxane. Espectro em solução obtido, em temperatura ambiente, por Long et $\mathrm{al}^{[127]}$.

Recentemente, Long et al $^{[127]}$ obteve espectros de RPE, com estruturas hiperfinas resolvidas, para as amostras de polianilina dissolvida em dioxane. Estas amostras encontravam-se na forma de base pernigranilina (PNB) e base esmeraldina (EB). Para ilustrar o efeito, reproduzimos o espectro que eles obtiveram na Figura 83. Ele é bem semelhante àquele da Figura 82 e as suas 17 linhas, igualmente espaçadas, foram interpretadas pelos autores como sendo devidas a interação hiperfina do polaron (ver Figura 84) com os 8 núcleos de hidrogênios dos anéis adjacentes $(I=1 / 2)$ e com os 2 núcleos de nitrogênios $(I=1)$ mais próximos. Embora seja aparente que as separações das hiperfinas que observamos seja maior que aquela observada por Long, acreditamos que a interpretação do nosso espectro pode ser análoga. Entretanto, dada a baixa relação sinal/ruído do nosso espectro, as tentativas efetuadas para o ajuste teórico, resultam em uma imprecisão muito grande no valor estimado para as amplitudes da interação hiperfina isotrópica. Isto dificulta o estabelecimento de um modelo preciso para definir a localização do defeito no nosso caso. 


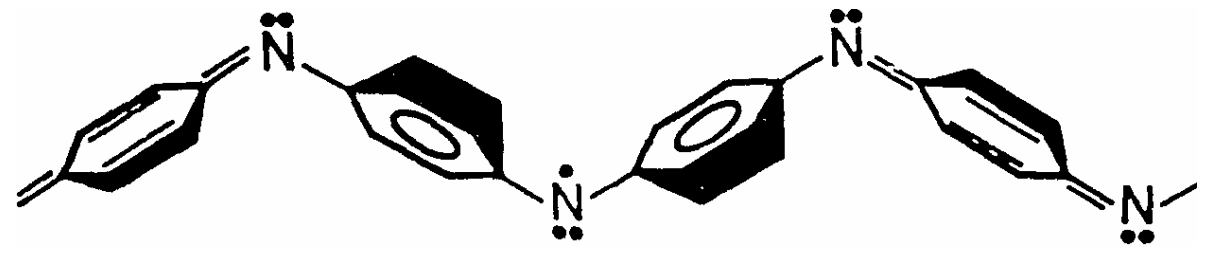

Figura 84 - Ilustração esquemática de um soliton neutro BNB (Benzenóide Nitrogênio Benzenóide) na base pernigranilina (PNB).

Embora seja difícil extrair resultados quantitativos a partir do espectro da Figura 82, ele possui importância vital para entendermos a origem do alargamento da linha de RPE associada ao polaron na amostra POMA-EB, mostradas na Figura 81. Acreditamos que o alargamento é primordialmente devido à interação hiperfina isotrópica não resolvida. Esta conclusão se apoia também em outros fatos observados experimentalmente. Em primeiro lugar, observou-se que a forma da linha de RPE é muito próxima da forma gaussiana e a sua largura varia muito pouco com a temperatura. De fato, a largura de linha, medida pela distância pico a pico do sinal de $\mathrm{RPE}$, diminuiu monotonicamente de $13,5 \mathrm{G}$ em 4,7 K para 10,5 G em temperatura ambiente (ver Figura 92). Isto é compatível com o modelo, sendo que não esperamos que a amplitude da interação hiperfina varie com a temperatura. Resultados similares foram obtidos por Wang et al ${ }^{[114]}$ para a amostra POT-EB, onde a largura de linha pico a pico variou de $14 \mathrm{G}$ em $4 \mathrm{~K}$ para $10 \mathrm{G}$ em $295 \mathrm{~K}$ (ver Figura 93). Segundo Wang esta largura de linha está de acordo com a estimativa feita para a interação hiperfina entre um elétron e um próton, a qual resulta em:

$$
\Delta H=\frac{\mu_{p}}{r^{3}} \approx 10 G
$$

onde $\mu_{p}=1,4 \cdot 10^{-23} \mathrm{erg} / \mathrm{G}$ é o momento do próton e $r \sim 1 \AA$.

Por outro lado, se faz necessário determinar o grau de localização do polaron no nosso caso. Certamente, é possível que ele não esteja completamente localizado visto que a largura de linha decresce ligeiramente com a temperatura, indicando a tendência do polaron deixar de ser localizado com o aumento da temperatura. Entretanto, acreditamos que este efeito é muito pequeno visto que a dependência da intensidade integrada dos espectros com a temperatura, conforme está 
mostrado na Figura 89, segue a lei de Curie $(\chi \propto 1 / T)$, característica de centros paramagnéticos localizados. Portanto, podemos concluir que o polaron na amostra POMA-EB está preferencialmente localizado, conforme parecem indicar os resultados experimentais. $\mathrm{O}$ fato da estrutura hiperfina se apresentar resolvida em apenas uma das amostras estudadas, segue, até o momento, sem uma explicação plausível.

Passaremos agora a estudar o efeito da dopagem sobre os espectros de RPE. Alguns dos espectros obtidos nas amostras POMA dopadas com TFA (1h e 24h) e $\mathrm{HCl}$ (24h) estão mostrados na Figura 85 até a Figura 87. A fim de possibilitar comparações entre as intensidades relativas entre os espectros obtidos em amostras diferentes, eles foram cuidadosamente normalizados pela massa da amostra e pelo sinal do rubi, conforme já descrevemos anteriormente no Capítulo 5. Com relação ao efeito da dopagem sobre os espectros de RPE, chamamos a atenção para dois fatos importantes. Em primeiro lugar, a intensidade do espectro das amostras dopadas é cerca de 100 vezes maior que a da amostra não dopada, o que pode-se notar mais facilmente através da Figura 88. Em segundo lugar, a dopagem produz um estreitamento da linha de RPE, para cerca de alguns gauss.

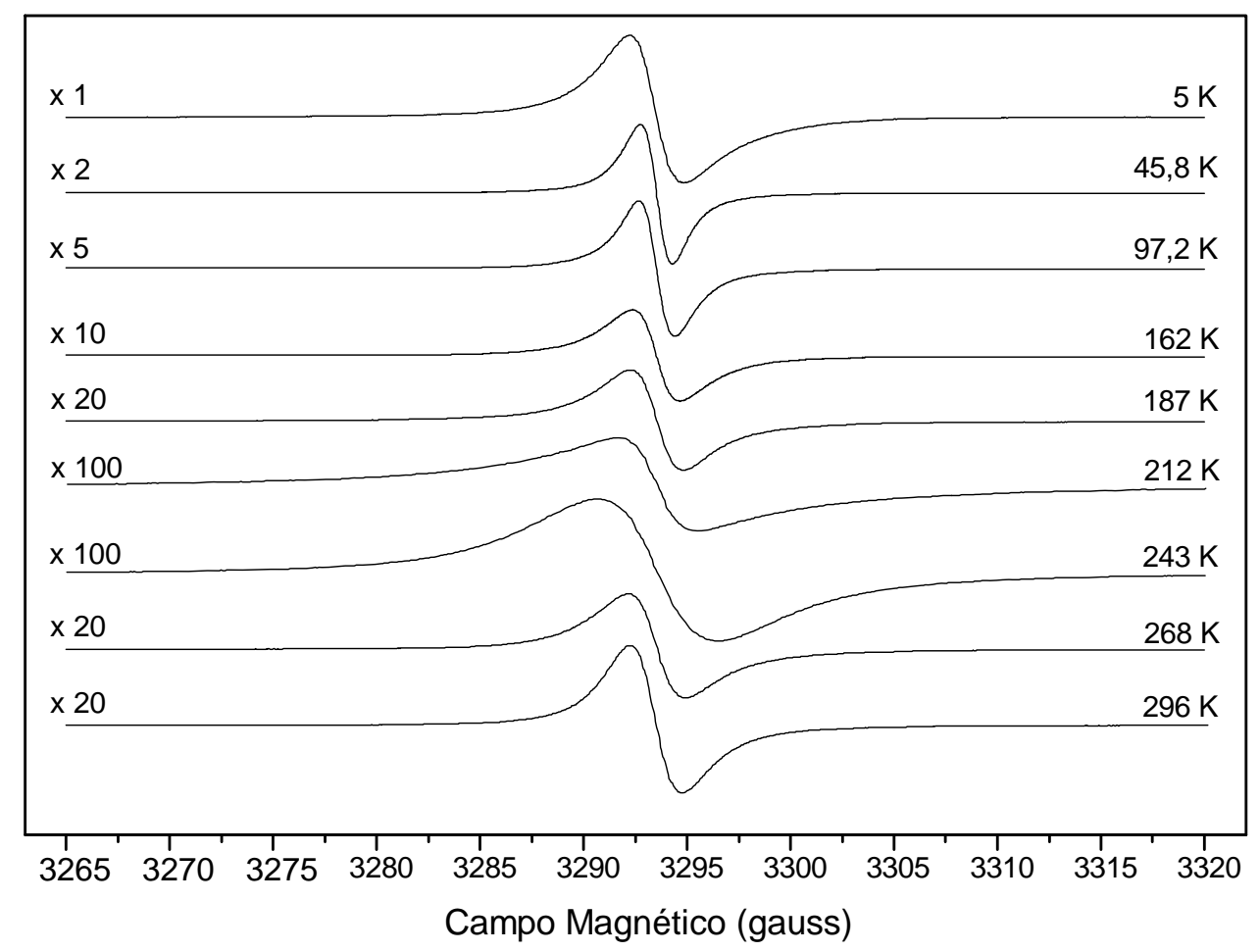

Figura 85 - Evolução do espectro de RPE, da amostra POMA dopada com TFA por 1h (pastilha), em função da temperatura. 


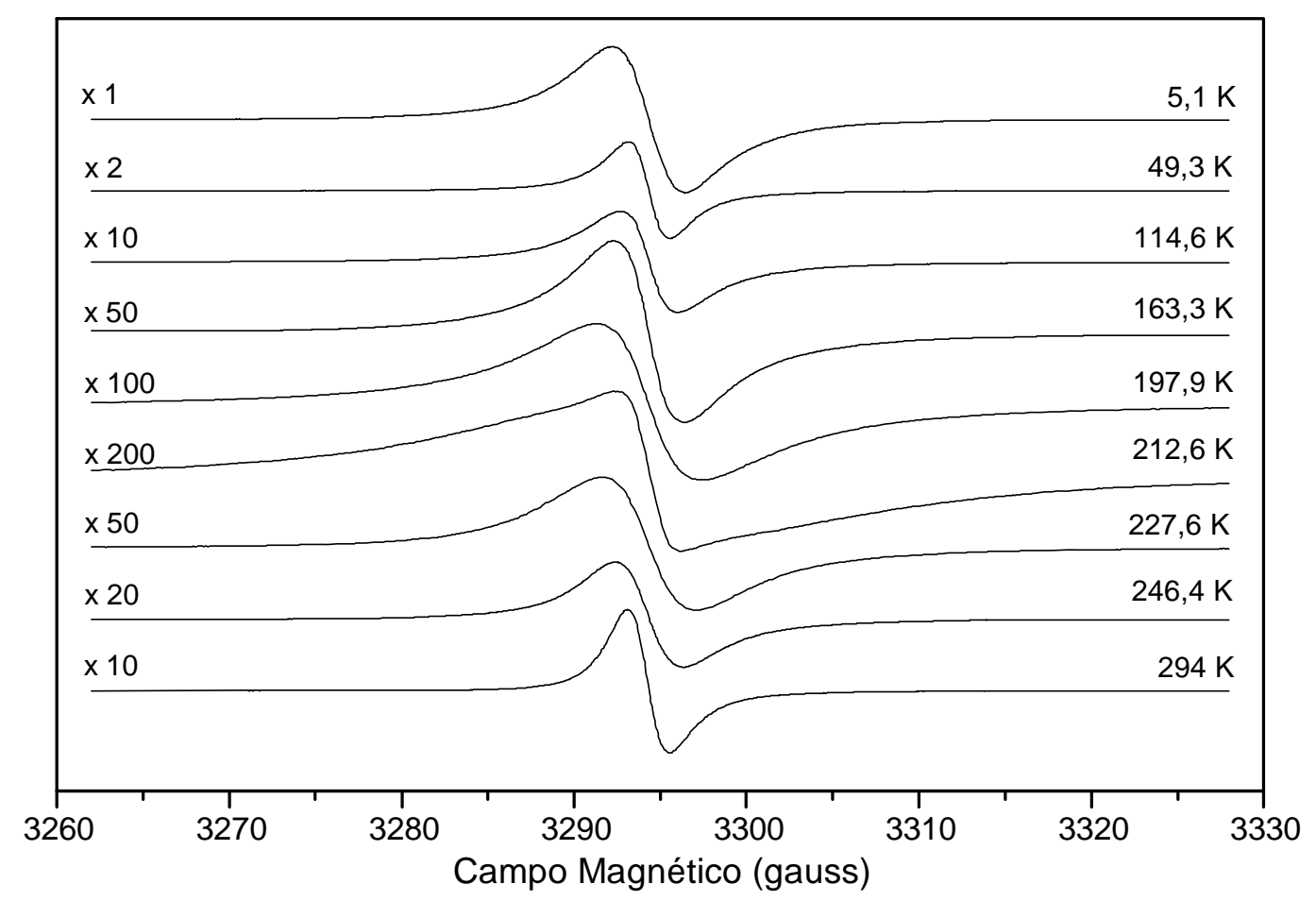

Figura 86 - Evolução do espectro de RPE, da amostra POMA dopada com TFA por 24h (pastilha), em função da temperatura.

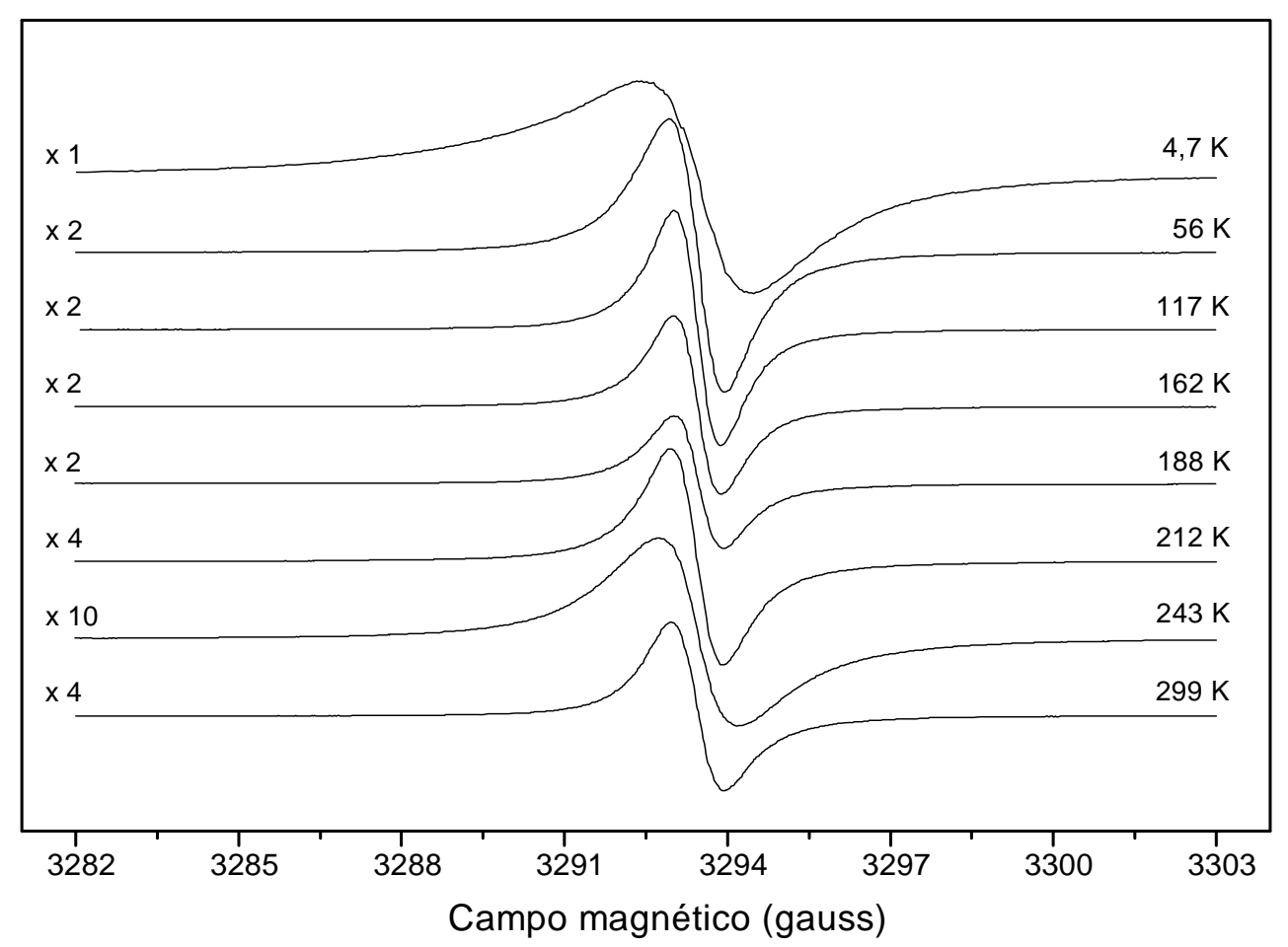

Figura 87 - Evolução do espectro de RPE, da amostra POMA dopada com $\mathrm{HCl}$ por 24h (pastilha), em função da temperatura. 
Para as amostras dopadas podemos dividir a faixa de temperatura estudada em duas regiões: uma de altas temperaturas (acima de $220 \mathrm{~K}$ ) e outra de baixas (abaixo de 220 K). Na região de altas temperaturas os espectros de RPE destas amostras podem ser ajustados por uma única linha dysoniana. Na região de baixas temperaturas os espectros parecem ser melhor ajustados por superposição de linhas. Em temperaturas muito baixas (abaixo de $30 \mathrm{~K}$ ) estes espectros podem ser facilmente ajustados por uma combinação de duas linhas lorentzianas, com intensidades na razão de 2:1. As duas apresentam larguras de linhas diferentes, mas possuem, aproximadamente, o mesmo campo central e o mesmo comportamento com a temperatura. Em temperaturas intermediárias (entre 30 e 220 K), mais de duas linhas são necessárias para reproduzir o espectro observado. Embora seja matematicamente possível ajustar estes espectros através da superposição de linhas lorentzianas e/ou gaussianas, o procedimento carece de significado físico, sendo que, até o momento, não possuímos um modelo apropriado para descrever a forma de linha no polímero dopado.

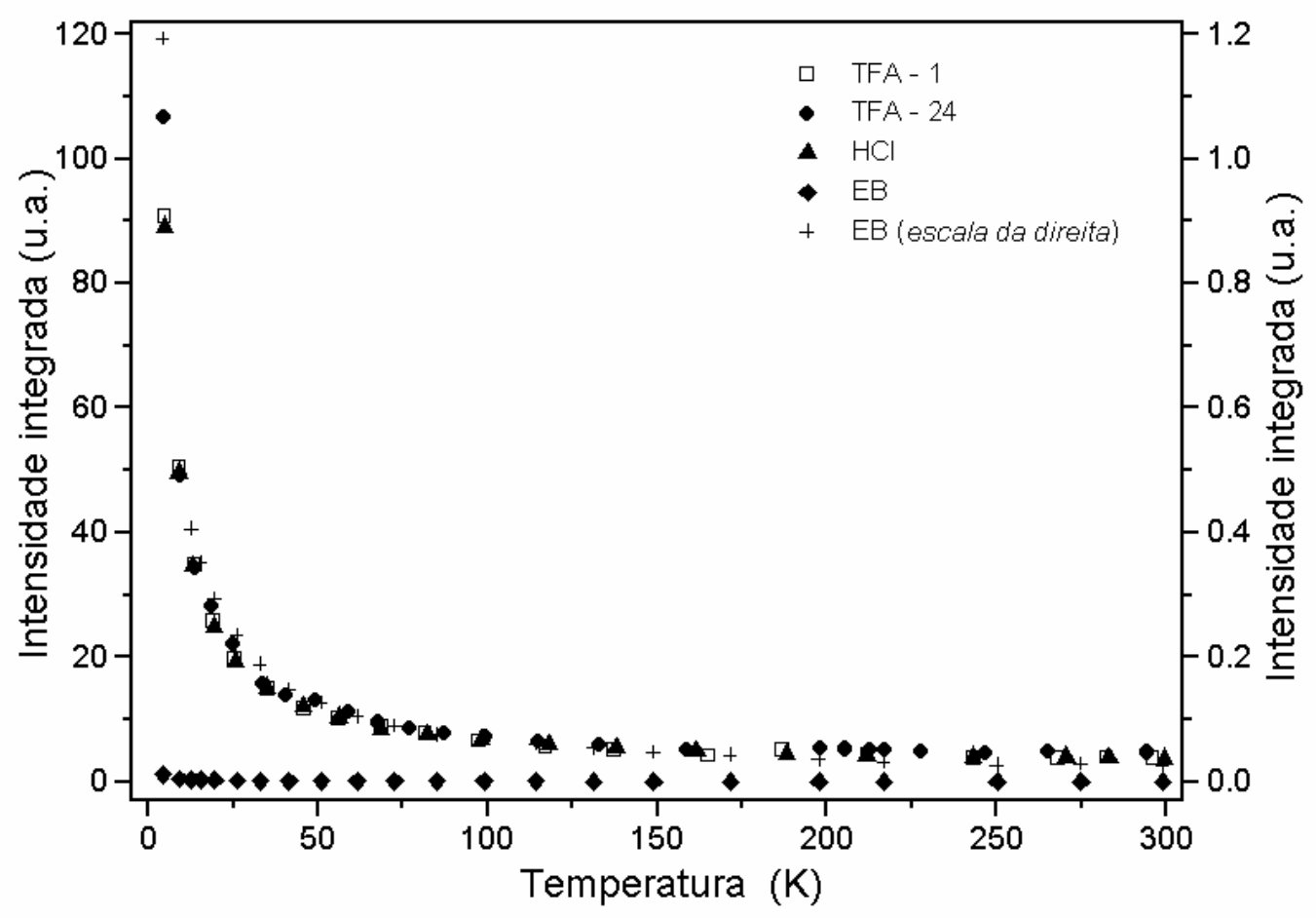

Figura 88 - Intensidade integrada $(I)$ do sinal de RPE, da POMA EB $(\diamond)$ e da POMA dopada com TFA $(\bullet$ e •) e $\mathrm{HCl}(\bullet)$, em função da temperatura. Na escala da esquerda tem-se a intensidade integrada do sinal de RPE para a amostra POMA-EB $\left(^{+}\right.$) em escala ampliada. Resultados obtidos com as amostras na forma de pastilha, e normalizado pelo sinal do rubi e pela massa da amostra. 
Devido a impossibilidade de estabelecermos um critério para o ajuste do espectro de RPE em toda a faixa de temperaturas, por funções conhecidas, optamos por calcular a intensidade dos espectros através do processo de dupla integração numérica. Pelo mesmo motivo, as larguras de linha apresentadas neste capítulo foram determinadas pela distância pico a pico da derivada do espectro de absorção.

As intensidades integradas dos espectros de RPE para essas amostras estão apresentadas na Figura 88. Observa-se que as amostras dopadas possuem, aproximadamente, um mesmo valor para a intensidade integrada do sinal de RPE. Entretanto, a amostra não dopada possui uma intensidade integrada cerca de 100 vezes menor que as dopadas. Observamos mais uma vez que o espectro de RPE é bastante afetado pela dopagem do polímero. A Figura 89 mostra o inverso da intensidade integrada $(1 / l)$ em função da temperatura $(T)$ e a Figura 90 mostra o gráfico de $I T$ em função de $T$.

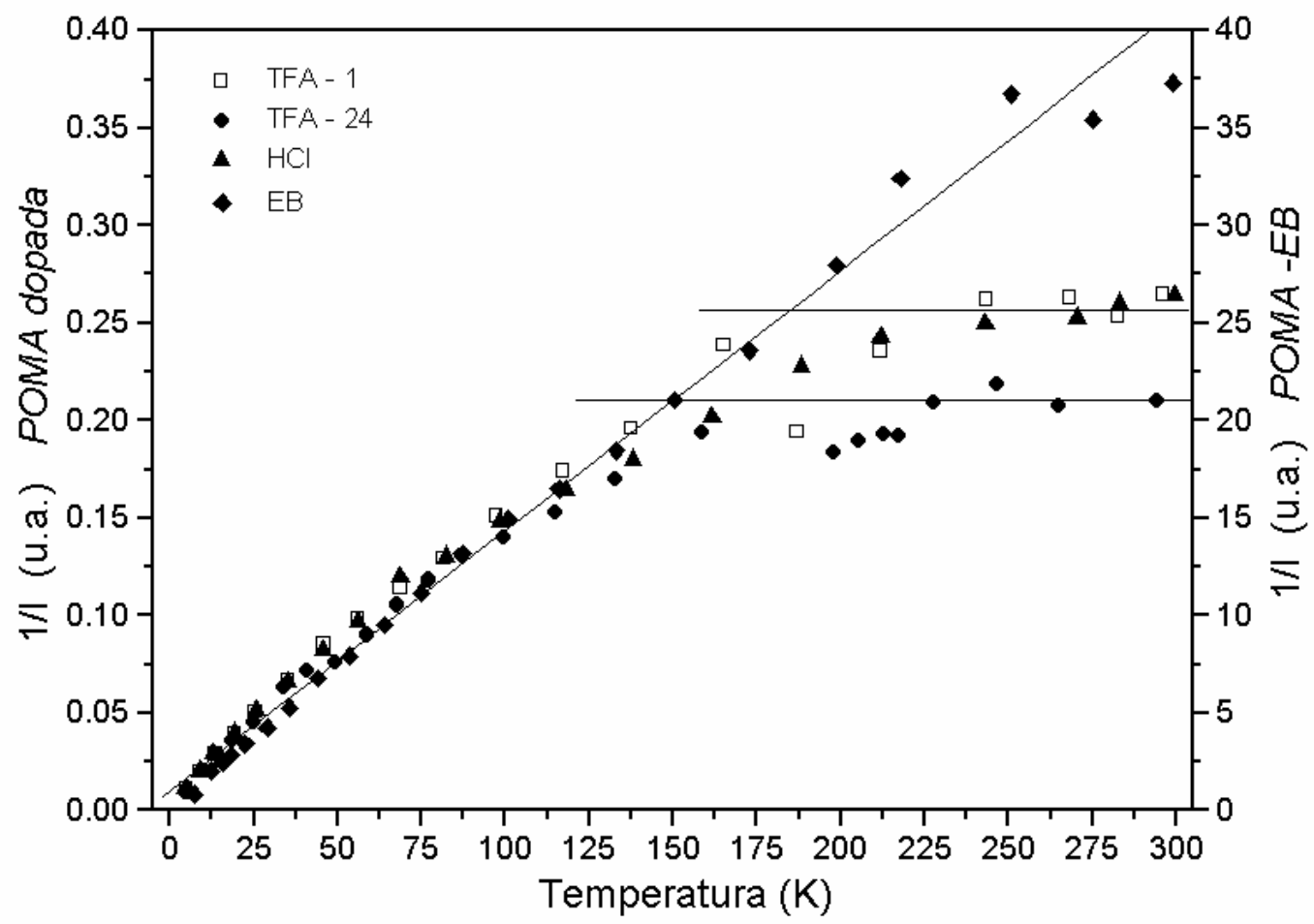

Figura 89 - Inverso da intensidade integrada $(1 / I)$ do sinal de RPE, da POMA EB $(\diamond)$ (escala da direita) e da POMA dopada com TFA (• e •) e $\mathrm{HCl}(\bullet)$ (escala da esquerda), em função da temperatura. Resultados obtidos com as amostras na forma de pastilha. Linhas cheias utilizadas apenas como guia para os olhos. 
A partir destes gráficos observa-se que, para a amostra não dopada (EB), o comportamento é essencialmente do tipo Curie em toda a faixa de temperatura estudada, com uma maior dispersão dos pontos em altas temperaturas, onde a relação sinal-ruído é menor. Para as amostras dopadas, o comportamento linear, em baixas temperaturas, tende assintoticamente a uma constante em altas temperaturas. Isto é típico de um sistema paramagnético descrito por contribuições do tipo Curie, característicos de centros paramagnéticos localizados, e Pauli, associados a elétrons não localizados:

$$
\chi=\chi_{\text {Pauli }}+\frac{C}{T} \quad \text { ou } \quad \chi T=\chi_{\text {Pauli }} T+C
$$

Em baixas temperaturas a componente de Curie é predominante, enquanto que em altas temperaturas predomina a componente de Pauli.

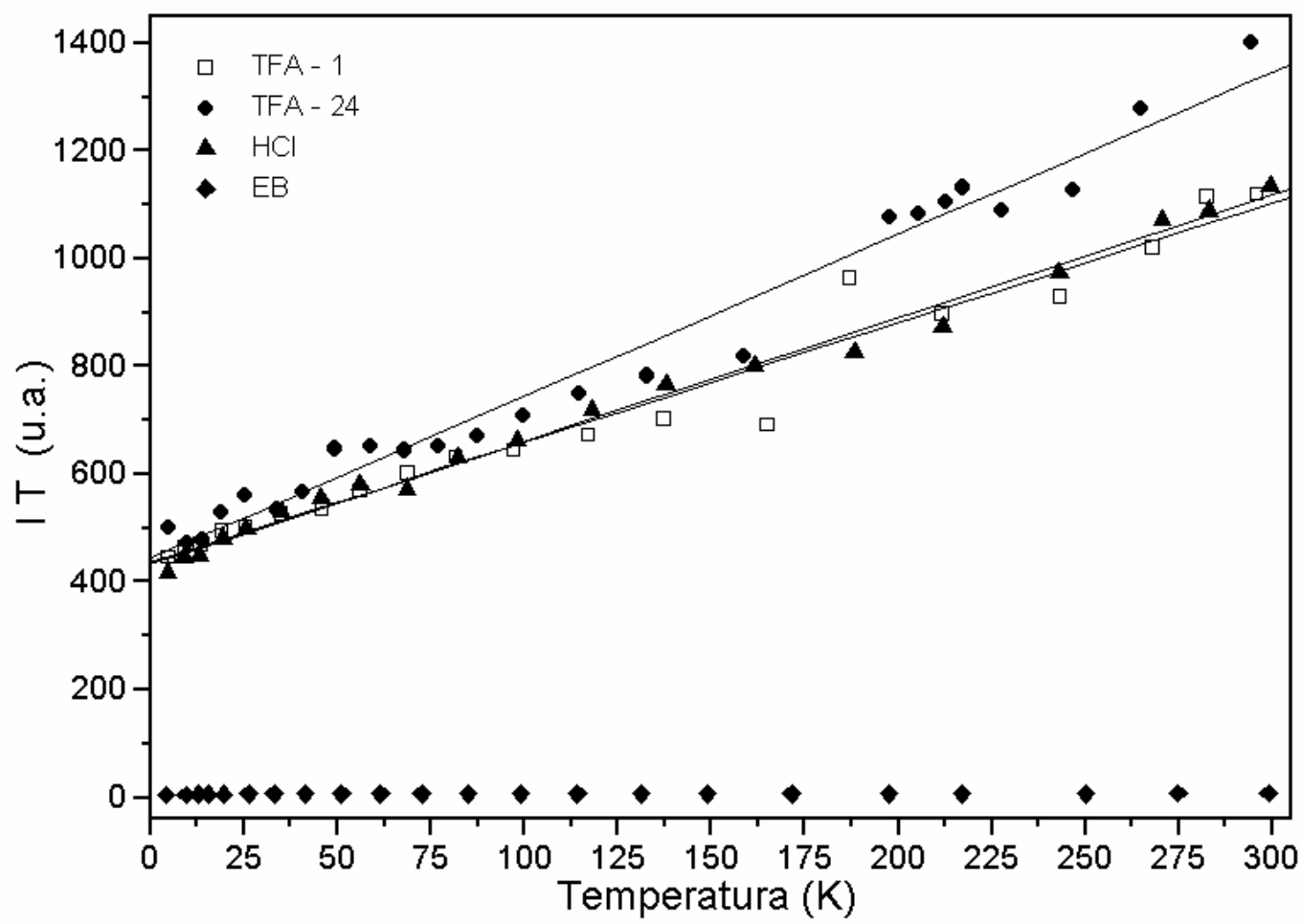

Figura 90 - Dependência com a temperatura do produto da intensidade integrada, do sinal de RPE da amostra POMA EB ( $\bullet$ e POMA dopada com TFA $(\bullet$ e •) e $\mathrm{HCl}(\bullet)$ pela temperatura. Resultados obtidos com as amostras na forma de pastilha. 
As contribuições de Curie e Pauli serão da mesma ordem em uma certa temperatura $T_{0}$, tal que $T_{0}=C / \chi_{\text {Pauli }}$. A partir dos dados experimentais verifica-se que as Constantes de Curie $(C)$ possuem aproximadamente o mesmo valor para as três amostras dopadas. Entretanto, $\chi_{\text {Pauli }}$ é maior para a amostra dopada com TFA por $24 \mathrm{~h}$. Os valores estimados são: $T_{0} \cong 150 \mathrm{~K}$ para TFA-24 e $T_{0} \cong 190 \mathrm{~K}$ para TFA-1 e HCl.

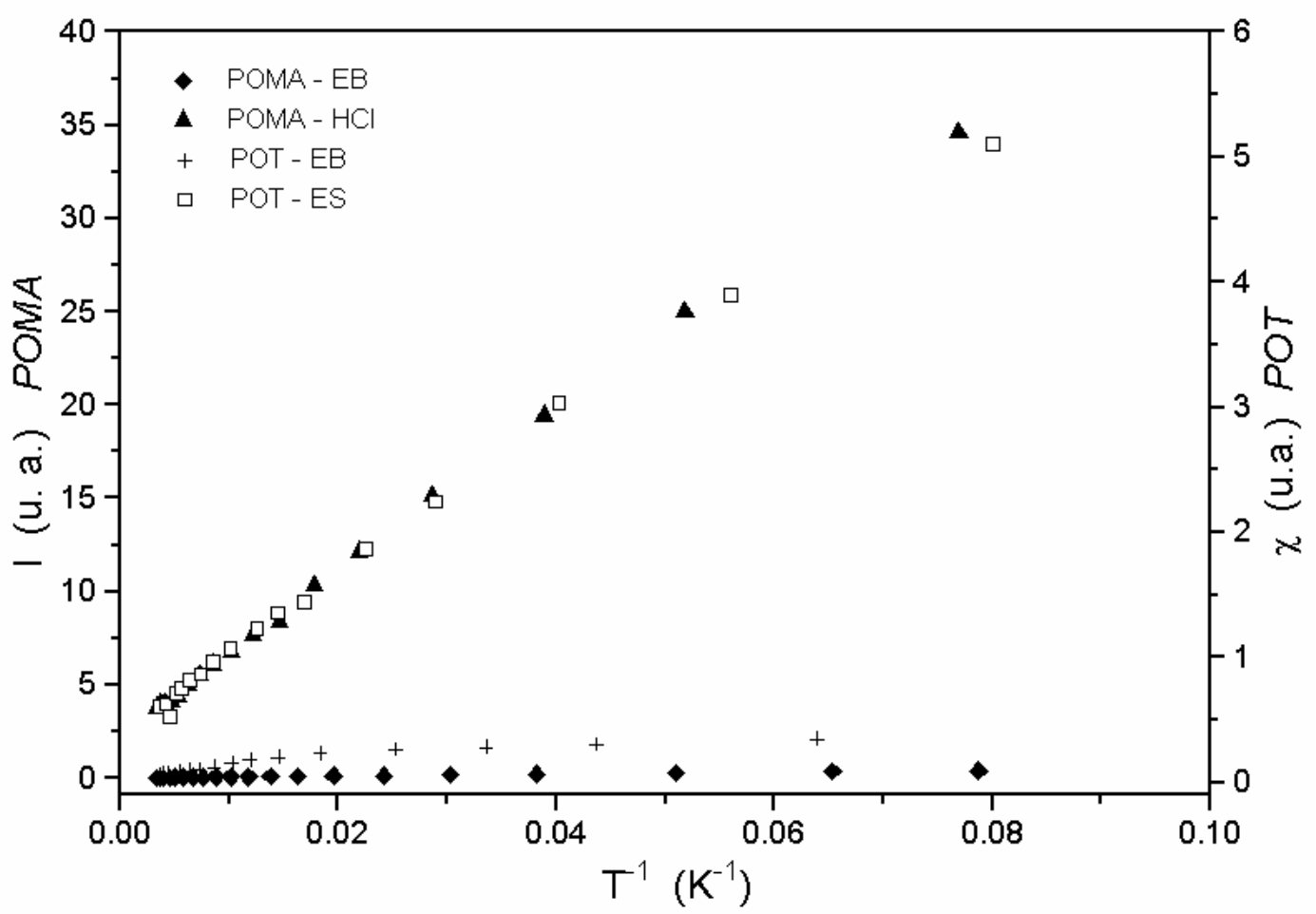

Figura 91 - Gráficos de $\chi$ (proporcional à dupla integração do sinal de RPE) em função do inverso da temperatura. Comparação entre os resultados da dupla integração do sinal de RPE para a amostra POMA-EB ( $\bullet$ e POMA dopada com HCl $(\bullet)$, com os resultados obtidos por Wang et $\mathrm{al}^{[114]}$ para a amostra POT-EB $(+)$ e POTES (3), ambas na forma de filme. Escala da esquerda para as amostras POMA e da direita para as amostras POT.

Wang et $\mathrm{al}^{[114]}$ em seu artigo sobre localização de elétrons e transporte de cargas em poli(o-toluidina) apresentou, entre outros, os resultados de medidas de RPE realizadas em amostras fílmicas de poli(o-toluidina) na forma de base esmeraldina (POTEB) e dopada com HCl (POT-ES). A amostra poli(o-toluidina) assim como a poli(ometoxianilina), como mencionado no início deste capítulo, é um derivado da polianilina, no qual o $H$, da posição orto do anel benzênico, foi substituído pelo grupo $\mathrm{CH}_{3}$ (ver 
Tabela 10). A comparação entre os resultados de Wang e aqueles aqui obtidos para a POMA, estão mostrados na Figura 91. Observa-se que, a menos de uma constante de normalização, nossos resultados coincidem, relativamente bem, com os de Wang, tanto para a amostra dopada com HCl (POMA-HCl / POT-ES) quanto para a não dopada (POMA-EB / POT-EB).

Na Figura 91 nota-se uma diferença mais acentuada entre os nossos resultados, quando comparamos as amostras POMA-EB com a POT-EB. Entretanto, conforme discute-se no trabalho de Wang, o comportamento da susceptibilidade medida na POT-EB se afasta do previsto pela lei de Curie, em temperaturas abaixo de 100 K. Isto foi explicado, pelos autores, como sendo devido à contribuição de oxigênio residual na amostra. Também, não foi observada variações significativas do fator-g nas amostras POT, acima de $100 \mathrm{~K}$. Neste trabalho, Wang e colaboradores também apresentam um modelo para a forma de linha de RPE nestes materiais. Comentaremos este assunto mais adiante neste trabalho.

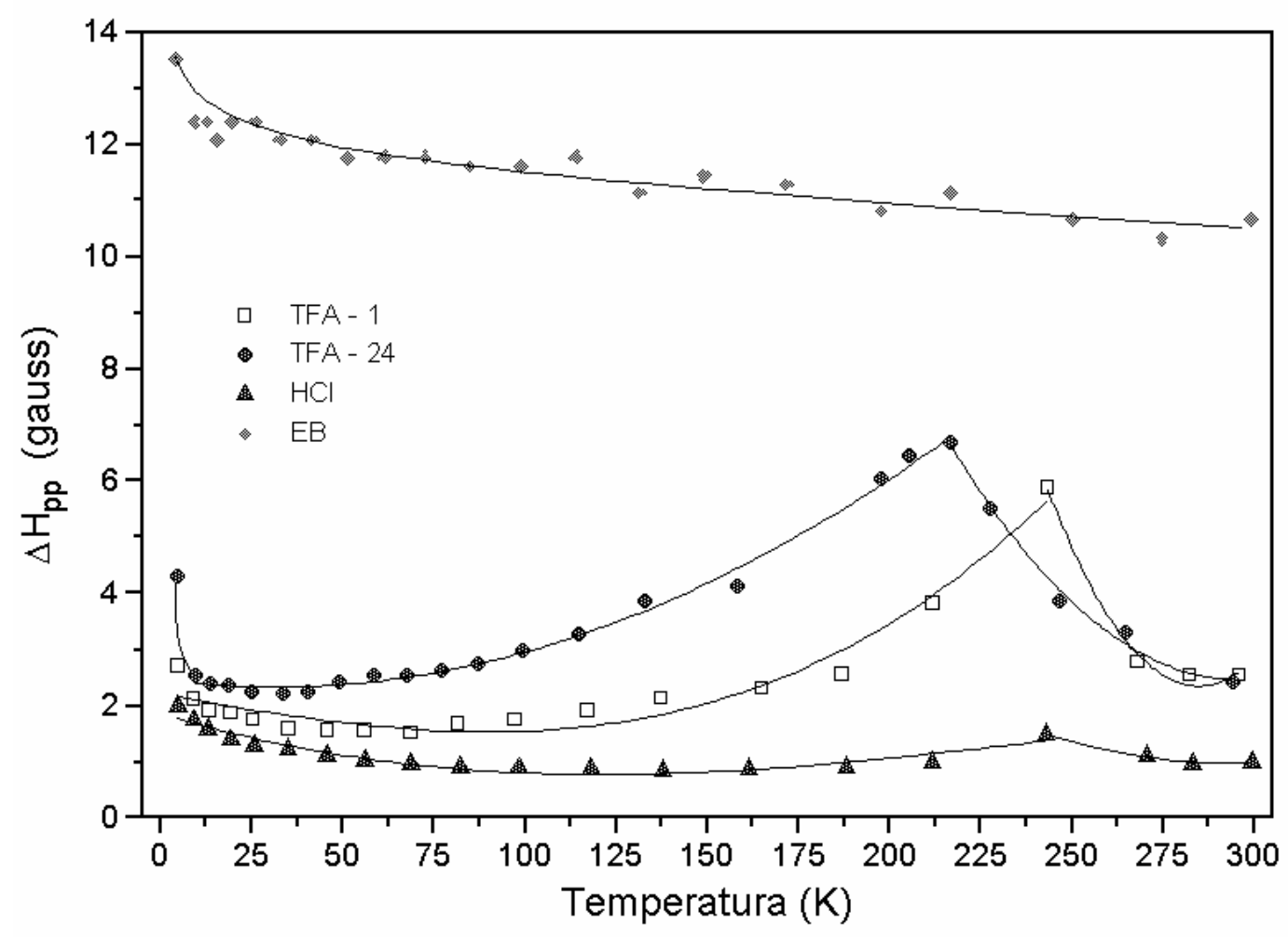

Figura 92 - Dependência com a temperatura das larguras de linha pico a pico do sinal de RPE da amostra POMA EB ( $\diamond$ ) e dopada com TFA (• e •) e $\mathrm{HCl}(\bullet)$. Todas estas amostras estão na forma de pastilha. Linhas cheias utilizadas apenas como guia para os olhos. 
Nas amostras POMA dopadas observa-se uma diminuição na largura de linha relativa à não dopada, como mostra a Figura 92. Nas amostras dopadas a largura de linha pico a pico é de aproximadamente $3 \mathrm{G}$ em 4,7 K, aumenta monotonicamente até temperaturas em torno de $220 \mathrm{~K}$ e, em tempetura ambiente, torna a diminuir, para larguras em torno de $2 \mathrm{G}$. Observa-se na figura que, em temperaturas em torno de $220 \mathrm{~K}$, ocorre um acentuado alargamento das linhas. No caso da amostra dopada com $\mathrm{HCl}$, a dependência da largura de linha com a temperatura é mais suave, mostrando um alargamento de linha menos acentuado em torno de $240 \mathrm{~K}$, fato este não observado por Wang, conforme mostra a Figura 93. Nesta figura comparamos as larguras de linha obtidas por Wang nas amostras POT com os nossos resultados da POMA. A concordância entre ambos resultados é marcante, indicando que os mecanismos de alargamento de linha podem ser similares nestes dois materiais, quando se trata do dopante $\mathrm{HCl}$.

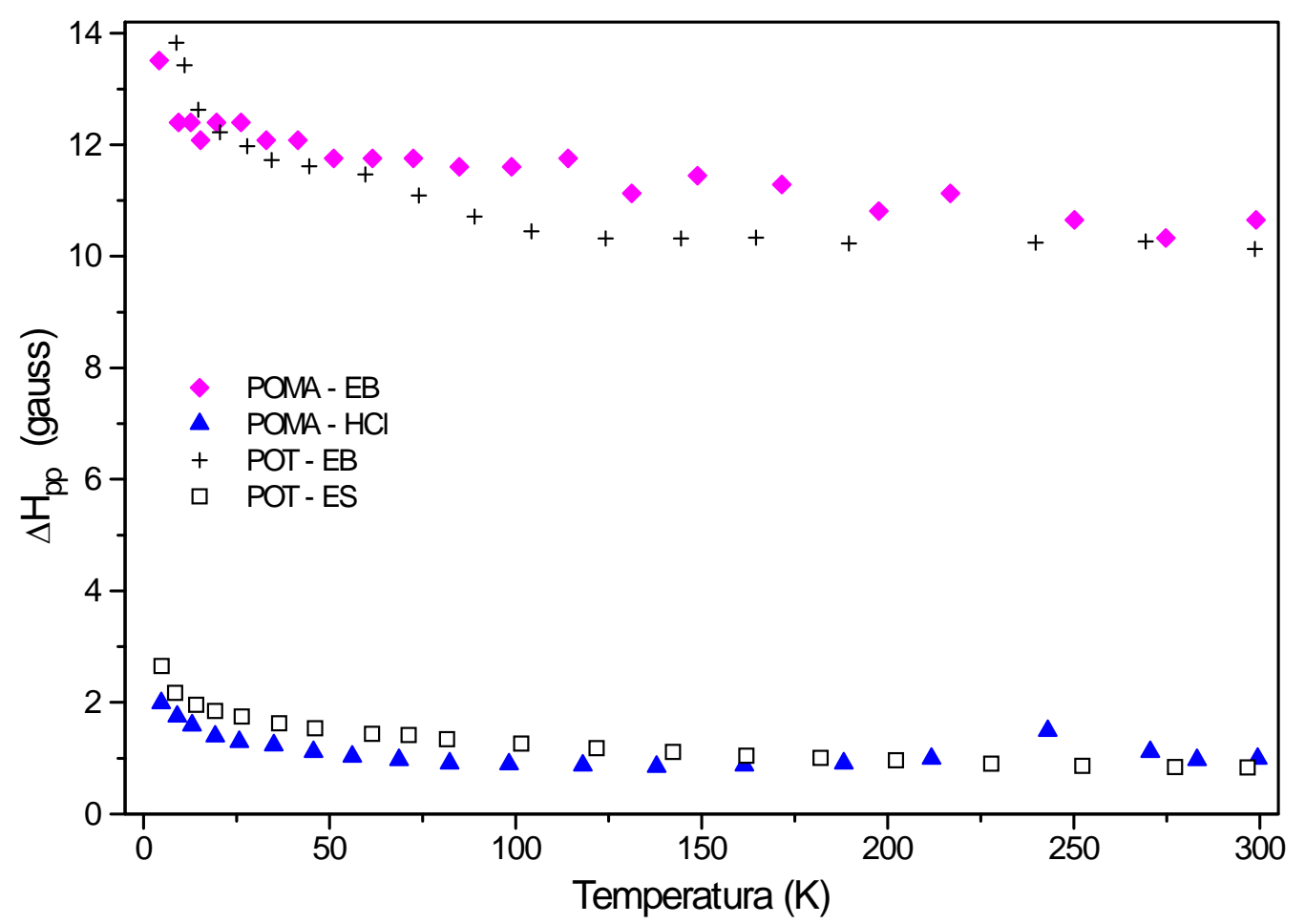

Figura 93 - Comparação entre as larguras de linha pico a pico do sinal de RPE da amostra POMA-EB ( $\diamond)$ e POMA dopada com $\mathrm{HCl}(\bullet)$ com os resultados obtidos por Wang et $\mathrm{al}^{[114]}$ para a amostra de POT-EB (+) e POT-ES (B), ambas na forma de filme. Medidas realizadas em temperaturas entre $5 \mathrm{~K}$ e temperatura ambiente. 


\subsection{1 - Condutividade elétrica}

As formas de linha, observadas experimentalmente, nas amostras dopadas alteram-se significantemente acima de $220 \mathrm{~K}$. Nas amostras em forma de pastilha fina, a forma de linha nesta faixa de temperaturas adquire um aspecto assimétrico, sendo a amplitude $(A)$ do pico em baixo campo maior que a de alto campo (B). Este comportamento tem sido observado constantemente nos estudos em polímeros condutores eletrônicos e é, em geral, explicado como resultado dos mecanismos de transporte de carga nestes materiais condutores.

Na Teoria de Dyson ${ }^{[128-130]}$ discute-se o efeito da condutividade elétrica na forma de linha ligada à ressonância paramagnética eletrônica de metais. O movimento de elétrons de condução em metais resulta em alta condutividade elétrica, “skin depth” superficial e distribuição não uniforme da microonda, o que pode, como mostra a teoria, produzir uma assimetria da forma de linha. A forma exata da linha depende de diversos parâmetros, estruturais e dinâmicos, da matriz condutora e não pode ser, em geral, descrita por uma única expressão matemática simples. A forma da linha é, por exemplo, fortemente dependente da forma da amostra (ou da espessura, no caso de amostras com o formato de pastilha). Nos trabalhos citados, onde explora-se a teoria, a forma de linha é extraida sempre em situações aproximadas, obedecendo a certas relações limites entre os parâmetros de interesse.

Uma situação particular, que acreditamos ser apropriada ao nosso caso, foi estudada por Walmsley ${ }^{[131]}$. Neste trabalho, é proposto um modelo válido para a situação em que a espessura da amostra $(d)$ é menor, ou da ordem, que o “skin depth” $(\delta)$. Neste limite, a forma da linha é unicamente determinada pela relação $\lambda=d / \delta$. Basicamente, a condutividade pode ser calculada a partir da relação $A / B$ do espectro de RPE e do valor da espessura da amostra. Normalmente, quanto maior for a espessura da amostra, ou a condutividade da mesma, maior será a assimetria do espectro. Recentemente, este modelo foi utilizado, com suscesso, no cálculo da condutividade elétrica AC, na freqüência de microondas, de amostras poliméricas, dopadas, de poli(3metiltiofeno) $^{[132-135]}$.

Conforme o modelo proposto, $\lambda$ pode ser estimado a partir da relação de intensidades $A / B$, e esta estimativa, feita por Walmsley, está reproduzida na Figura 94. 
Assim, a partir do conhecimento do valor de $\lambda$, pode-se determinar o valor da condutividade pode ser determinada utilizando a seguinte expressão:

$$
\sigma=\frac{\lambda^{2}}{d^{2} \pi v_{0} \mu_{0}}
$$

onde $\mu_{0}$ é a permeabilidade do vácuo, $v_{0}$ é a freqüência de microondas e $d$ a espessura da amostra.

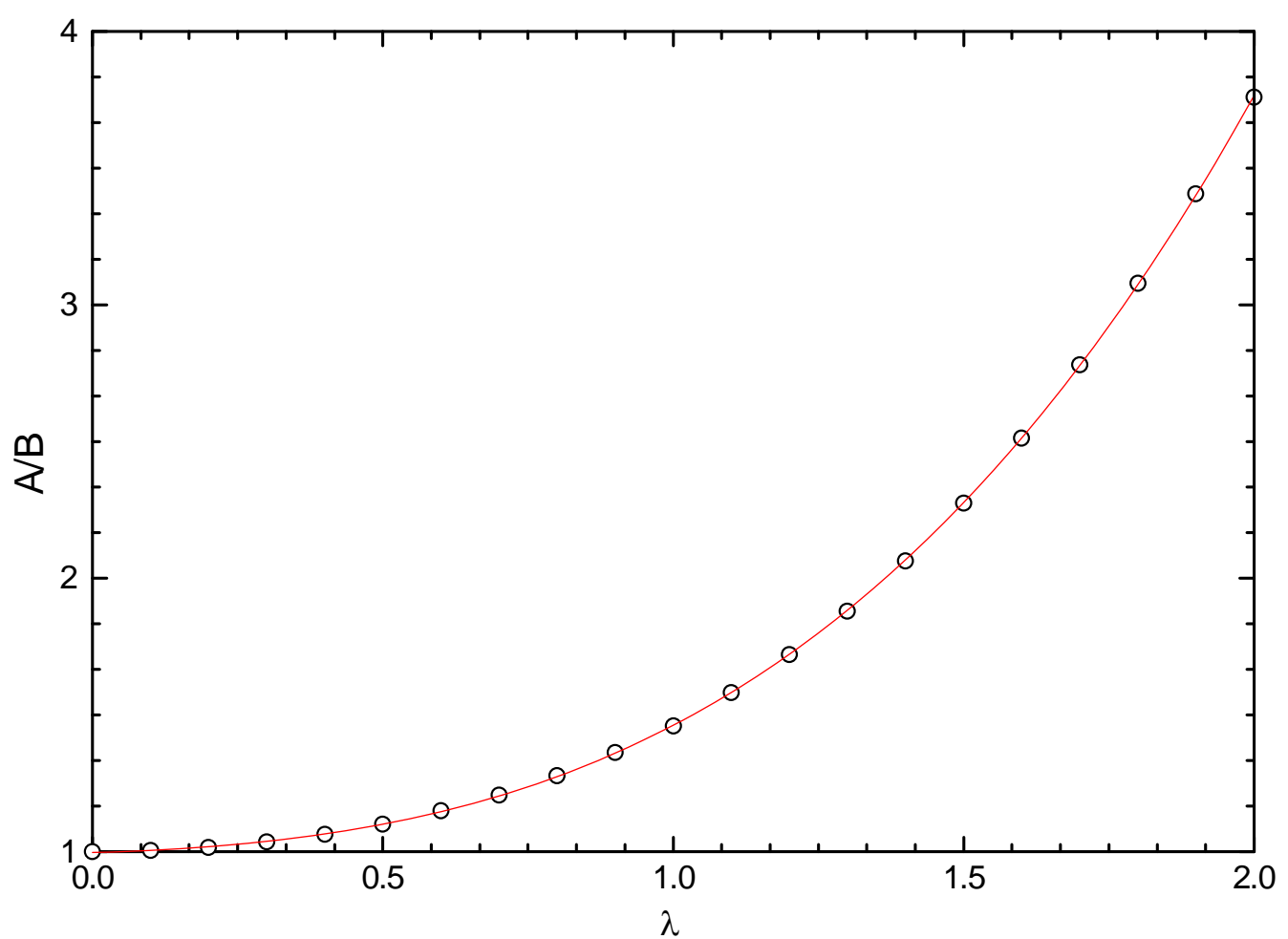

Figura 94 - Relação entre a razão $A / B$, do sinal de RPE, e o coeficiente $\lambda$ da teoria de Dyson. Gráfico extraído do artigo de Walmsley ${ }^{[131]}$.

A partir da relação $A / B$, dos espectros de RPE, obtidos nas amostras dopadas (na forma de pastilha) e utilizando-se da técnica proposta por Walmsley, obtivemos os valores da condutividade elétrica $\mathrm{AC}(\mathrm{em} \approx 9,26 \mathrm{GHz}$ ) mostrados na Figura 95. 


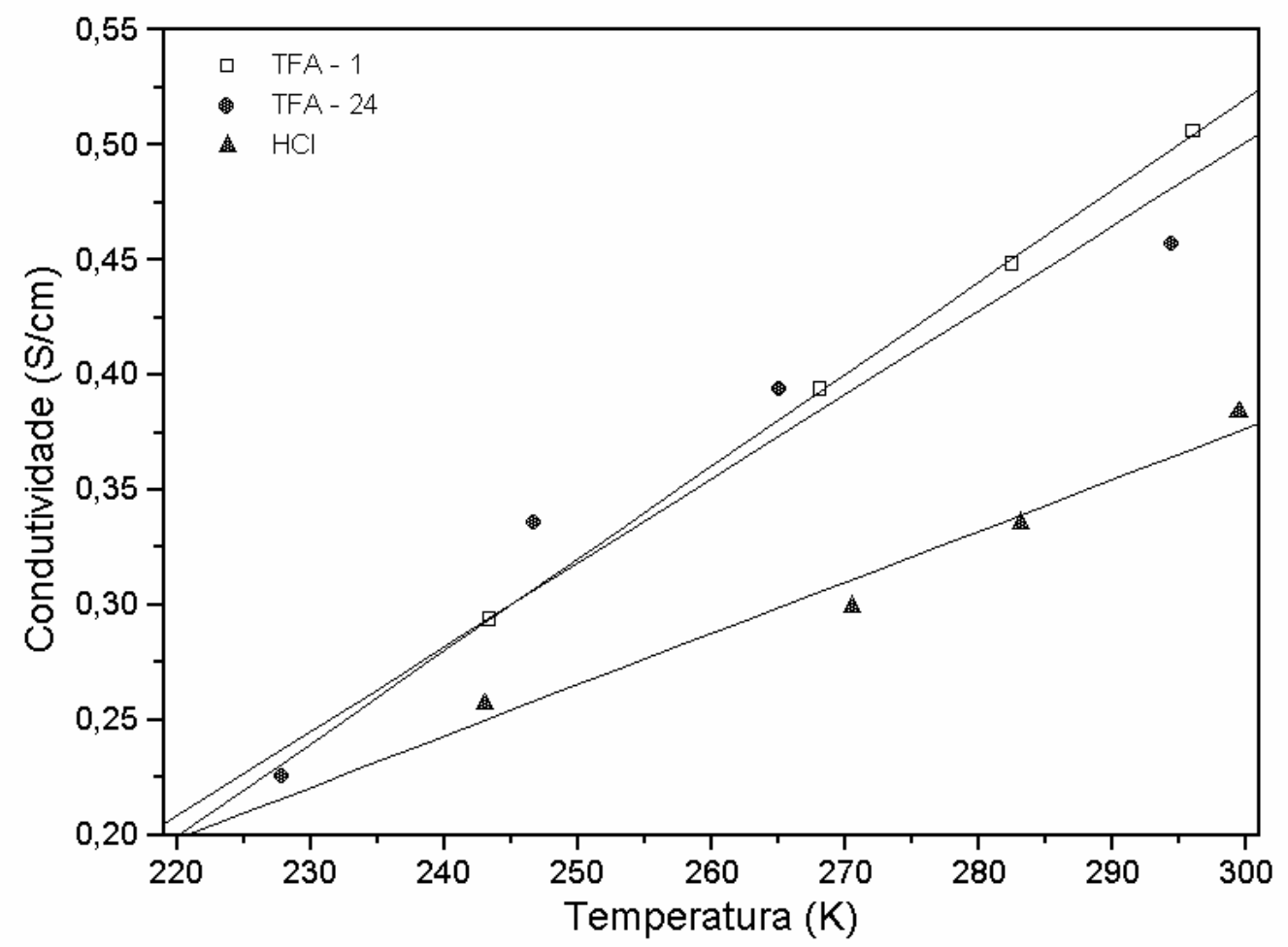

Figura 95 - Condutividade elétrica AC, medida a partir da assimetria do sinal de RPE (razão $A / B$ ), para as amostras POMA dopada com TFA (• e •) e $\mathrm{HCl}(\bullet)$. Amostras na forma de pastilha, com espessuras entre 350 e $650 \mu \mathrm{m}$. Freqüência: 9,26 GHz

O acréscimo da condutividade (em freqüências abaixo de $1 \mathrm{MHz}$ ) com a temperatura já foi observado por outros autores ${ }^{[136-139]}$ em materiais similares, processados na forma de filmes finos. Nestes trabalhos, a condutividade elétrica é independente da freqüência (nesta faixa de freqüências) e é da ordem de $10^{-3} \mathrm{~S} / \mathrm{cm}$ para as amostras fortemente dopadas. Nogueira ${ }^{[104]}$ realizou medidas de condutividade AC, nessa mesma faixa de freqüências, para amostras POMA dopada com TFA em várias concentrações. Ele obteve, para a amostra dopada com TFA 0,01 M, uma condutividade da ordem de $10^{-3} \mathrm{~S} / \mathrm{cm}$, o que corresponde a 2 ordens de grandeza abaixo dos valores aqui encontrados em $9 \mathrm{GHz}$.

Até o momento, não encontramos na literatura disponível, qualquer referência às medidas de condutividade em altas freqüências $(\mathrm{GHz})$ na POMA dopada. Por outro lado, Pereira et al ${ }^{[132]}$ mostram os resultados da condutividade elétrica DC e AC para a amostra Poli(3-metiltiofeno). O valor da condutividade AC, obtida em 9,4 GHz, foi da ordem de $10 \mathrm{~S} / \mathrm{cm}$, enquanto que a condutividade DC foi de $0,6 \mathrm{~S} / \mathrm{cm}$, 
o que corresponde a uma variação de 2 ordens de grandeza, em concordância com o que observamos neste trabalho, utilizando a POMA dopada. Um dos fatores responsáveis por essa diferença, entre a condutividade DC e a condutividade em GHz, é a desdopagem da amostra causada pelo contato necessário na medida DC.

Um outro fator, responsável pelo menor valor da condutividade DC em relação a AC, está relacionado à distância média percorrida pelos portadores de carga. Quanto maior a freqüência menor a distância média percorrida por estes portadores de carga. Em baixas freqüências, essa distância média é maior que o tamanho de uma cadeia polimérica, englobando, assim, várias cadeias poliméricas. Desta forma, a condutividade, em baixas freqüências, envolve transporte de cargas intercadeias e interpartículas (ver Figura 53), os quais são mais difíceis de serem ativados. A medida que a freqüência é aumentada este transporte de cargas passa a ser realizado apenas dentro das cadeias (intracadeia), aumentando assim a condutividade.

\subsection{2 - Comparação entre as amostras em pó e em pastilhas}

Para verificar possíveis alterações no sinal de RPE, devido à prensagem da amostra, realizou-se, como mostra a Figura 96, uma medida de RPE em função da temperatura, na amostra POMA dopada com TFA por 24 horas, na forma de pó. Para esta medida utilizou-se $1,5 \mathrm{mg}$ de amostra, e o mesmo procedimento experimental adotado para a amostra na forma de pastilha.

Nesta amostra, observou-se que o alargamento da linha de RPE, em torno de $220 \mathrm{~K}$, continua existindo e é mais acentuado e mais abrupto do que na amostra na forma de pastilha (Figura 97). Na região de altas temperaturas, os espectros de RPE da amostra na forma de pó, podem ser ajustados por uma única linha lorentziana. Este fato é compatível com a teoria de Dyson, visto que, na amostra em pó, a dimensão típica dos grãos é bem menor que o “skin depth” e, além disto, o contato elétrico entre eles é bastante ruim, o que faz com que a amostra se comporte macroscópicamente como um isolante. No limite em que $d \ll \delta$ a teoria de Dyson prevê que a forma de linha deva ser do tipo lorentziana. Na região de baixas temperaturas os espectros de RPE continuam necessitando de uma combinação de linhas para serem ajustados. 


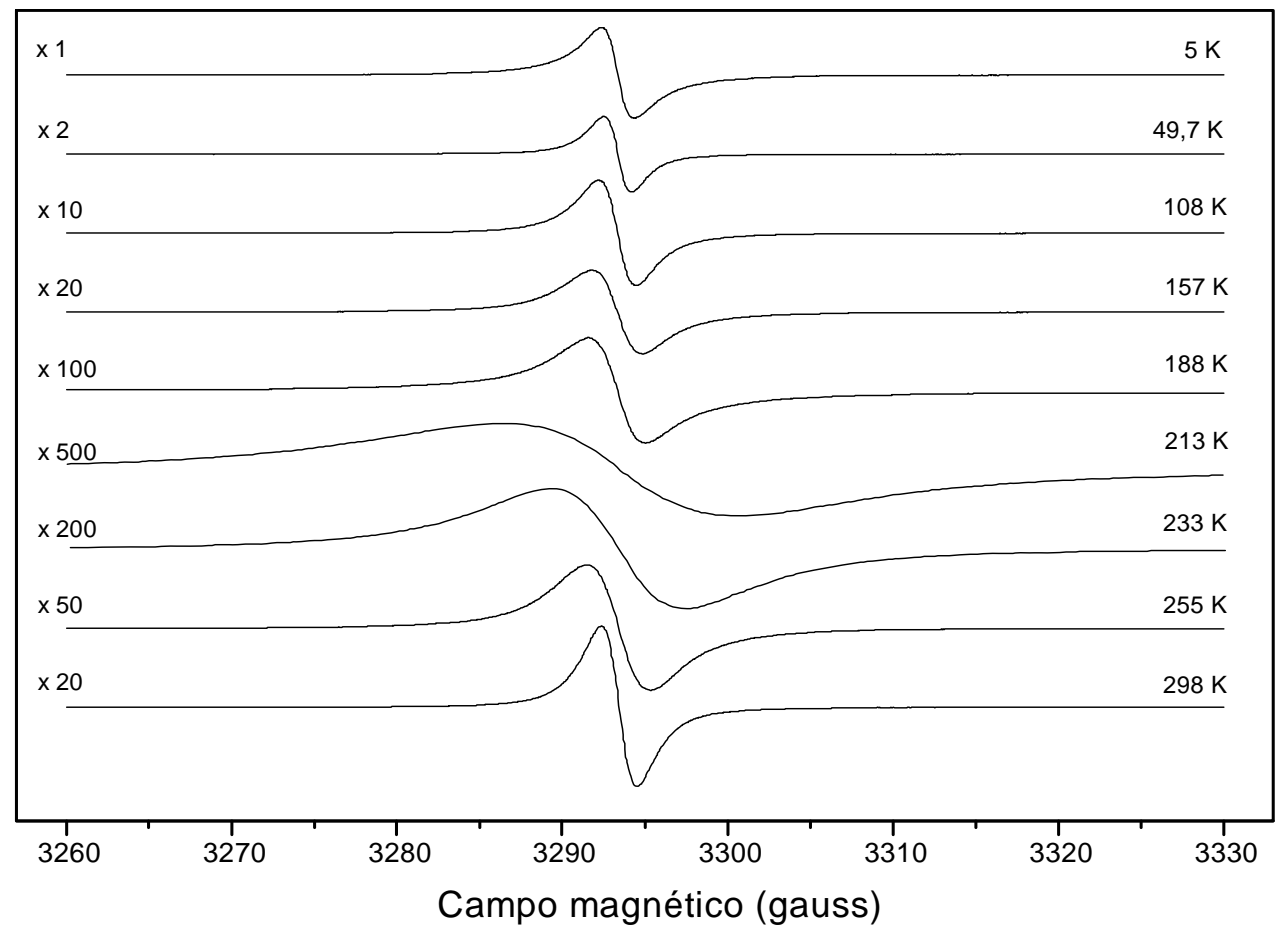

Figura 96 - Evolução do espectro de RPE, da amostra POMA dopada com TFA por 24h (em pó), em função da temperatura.

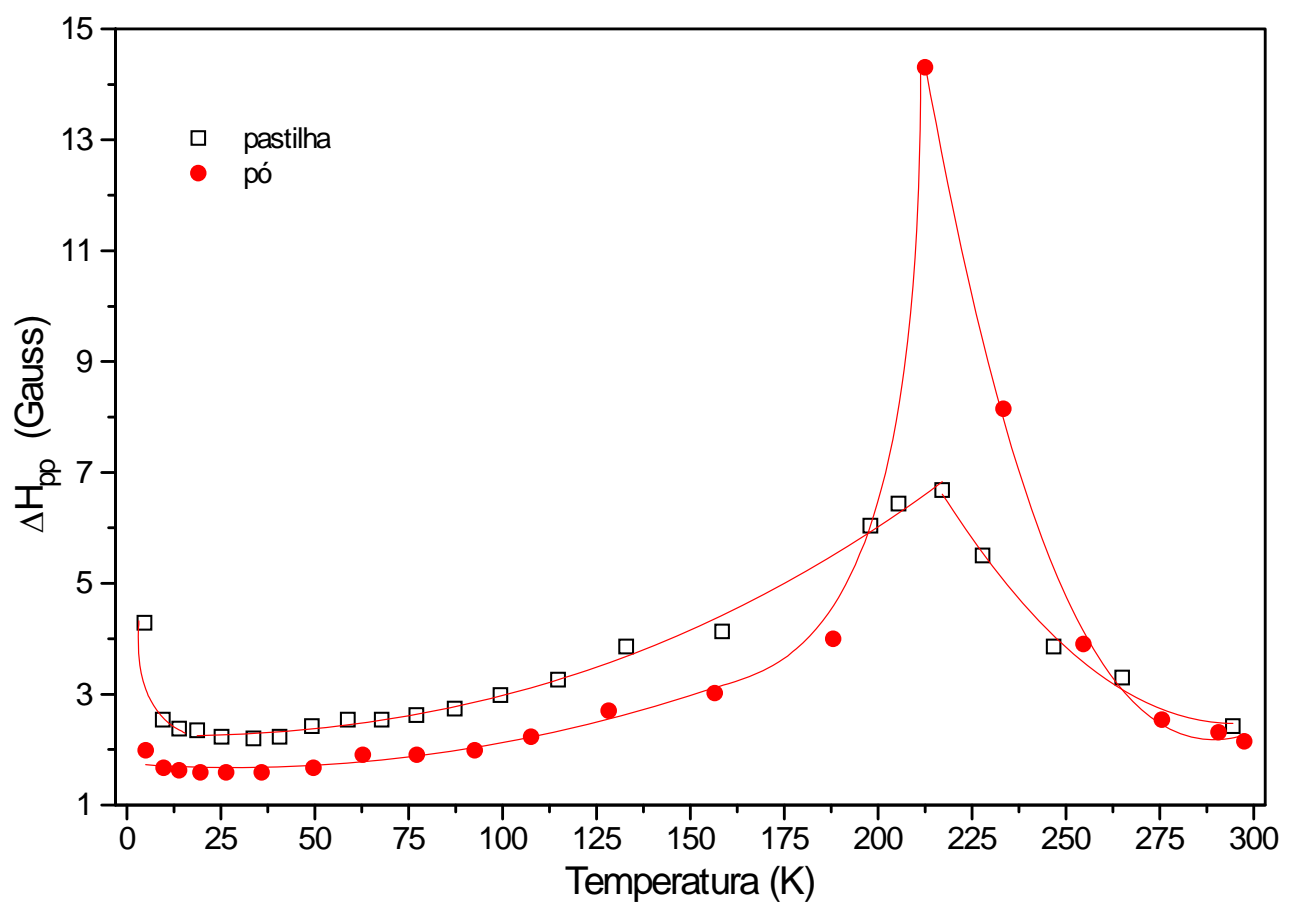

Figura 97 - Dependências com a temperatura das larguras de linha pico a pico do sinal de RPE da amostra, POMA dopada com TFA por 24 h, em pó (•) e em pastilha $(\bullet)$. Linhas cheias utilizadas apenas como guia para os olhos. 
Para melhor verificar se ocorrem alterações do comportamento magnético, fez-se o gráfico do inverso da intensidade integrada, do sinal de RPE, em função da temperatura, mostrado na Figura 98. As escalas verticais foram normalizadas, para as duas amostras, em função da massa da amostra e do sinal do rubi. Entretanto, observa-se neste gráfico que, embora as duas amostras exibam o mesmo comportamento da intensidade integrada em função da temperatura, a intensidade do sinal da amostra em pó é cerca de 3 vezes maior que a intensidade da amostra em pastilha.

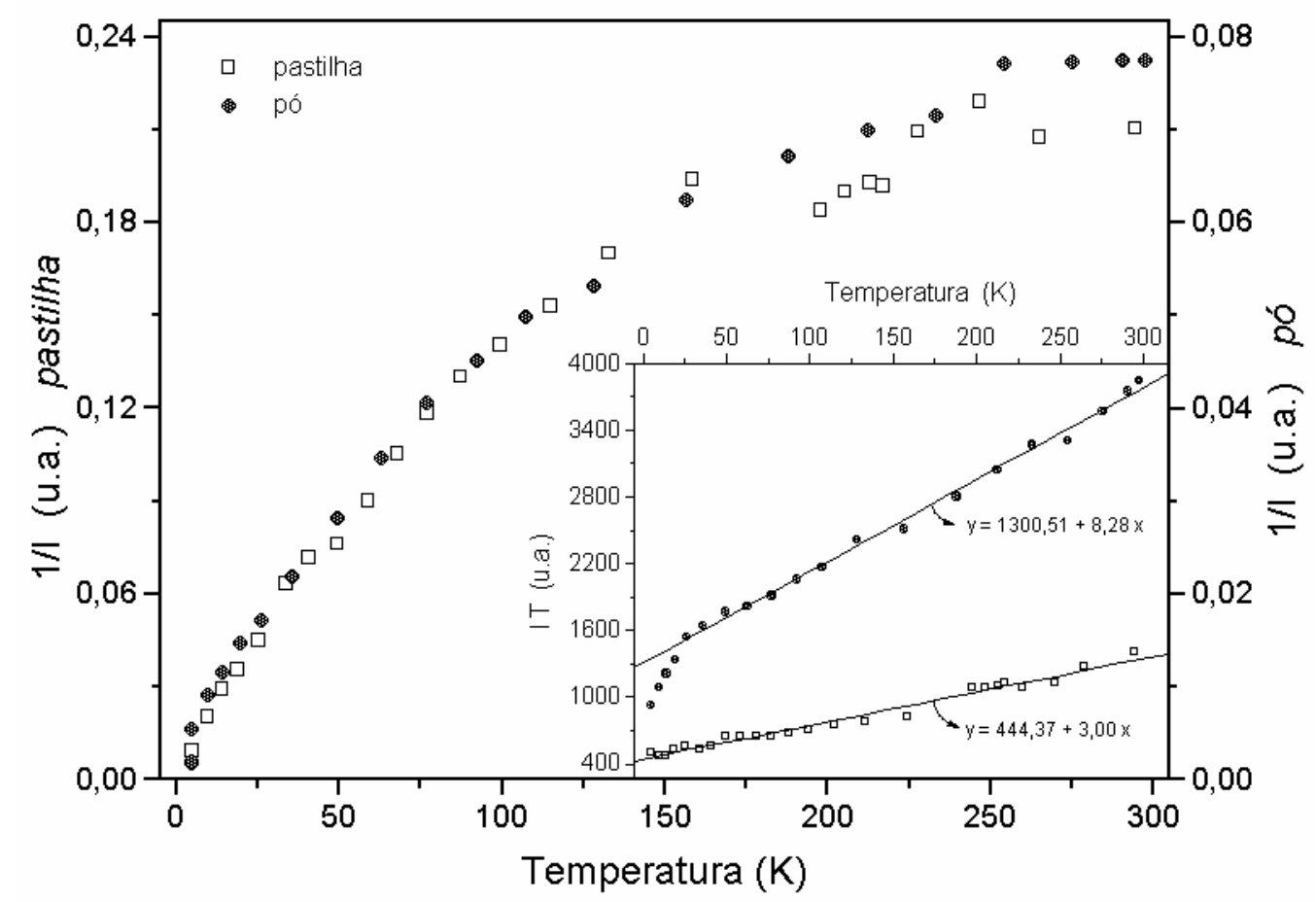

Figura 98 - Comparação entre a dependência com a temperatura do inverso da dupla integração do sinal de RPE da amostra, POMA dopada com TFA por 24 h, na forma de pó $(\bullet)$ e pastilha $(\bullet)$. Escala da direita para a amostra na forma de pó, e da esquerda para pastilha. No gráfico interno tem-se a dependência com a temperatura do produto da intensidade integrada pela temperatura para a amostra em pó e pastilha.

A perda de intensidade do sinal de RPE, por um fator 3, devido ao processo de prensagem da amostra, ainda não foi estudado com maiores detalhes. É possível que este fato ocorra devido a fatores puramente instrumentais, não relacionados à possíveis alterações físicas da amostra. Por exemplo, é possível que, no caso da amostra prensada, a sua alta condutividade elétrica induz maiores alterações na estrutura do campo eletromagnético da microonda na região onde se encontra a amostra, do que na 
região em que está situado o rubi. Isto poderia provocar um decréscimo de sensibilidade relativamente ao sinal da amostra, sem alterar significativamente o sinal do rubi. Um outro fator, que poderia ser responsável por essa diferença de intensidades, seria a atenuação da microonda no interior da amostra em pastilha, visto que a espessura desta pastilha é da ordem do “skin depth”. Entretanto, é pouco provável que esses fatores promovam uma diminuição tão acentuada do sinal de RPE. Desta forma, acreditamos que a possibilidade mais correta seja a transformação de polarons em bipolarons, promovida por uma diminuição da distância média entre os polarons, devido a prensagem da amostra. Como os bipolarons não possuem spins desemparelhados, isto explicaria a diminuição da intensidade do sinal de RPE para a amostra em pastilha.

Uma outra diferença apresentada, entre o sinal de RPE das duas amostras, é melhor visualizado no gráfico interno da Figura 98. Neste gráfico tem-se o comportamento do produto da intensidade integrada pela temperatura em função da temperatura. Para a amostra em pó, observa-se um desvio do comportamento linear em temperaturas inferiores a $25 \mathrm{~K}$. Um comportamento semelhante a este é observado, por Wang et $\mathrm{al}^{[114]}$, para a amostra POT dopada com $\mathrm{HCl}$. Segundo eles, este desvio pode ser devido a um fraco acoplamento antiferromagnético de interações dipolo-dipolo entre spins adjacentes, podendo também ser reflexo de uma transição polaron para bipolaron em baixas temperaturas.

\subsection{3 - Discussão}

RPE é uma técnica poderosa, que permite obter informações a respeito da localização dos estados eletrônicos e da dimensionalidade da transferência de carga nestes polímeros condutores. Estas informações são conseguidas através da medida da susceptibilidade, fator-g, largura de linha e forma de linha, em função de parâmetros de interesse, como por exemplo, concentração de dopantes, temperatura e campo magnético aplicado. Um dos propósitos mais importantes dos estudos de RPE, encontrados na literatura, reside na busca de uma relação entre as propriedades de transporte de carga e magnéticas dos polímeros condutores, como a polianilina. Por exemplo, caso exista uma correlação direta entre estas propriedades, pode-se estabelecer uma conecção entre o spin e os portadores de carga. Neste caso, o 
mecanismo de condução envolveria os polarons paramagnéticos. A ausência de tal correlação poderia levar à conclusão de que o transporte de carga não é devido, somente, ao movimento dos polarons ao longo da cadeia polimérica.

Wang et $\mathrm{al}^{[114,126]}$ e Anand et $\mathrm{al}^{[140]}$ propuseram um modelo que introduzia novos conceitos importantes para a interpretação das propriedades elétricas e magnéticas da polianilina, em especial PANI-ES e POT-ES. Eles propõem que estes polímeros representam uma classe de condutores desordenados quase-unidimensionais (1D-DS), consistindo de feixes de cadeias poliméricas, eficientemente bem acopladas entre si, tal que os estados eletrônicos podem se estender tridimensionalmente (3D).

Esta idéia difere do modelo unidimensional convencional, no qual as cadeias são essencialmente isoladas entre si. Estes feixes metálicos 3D, correspondem às regiões cristalinas (ou mais ordenadas) do polímero, separadas por regiões amorfas (ou menos ordenadas). Entretanto, nas regiões amorfas, onde as cadeias são essencialmente isoladas, a transferência de elétrons intercadeias é parcialmente suprimida, devido à desordem, de tal forma que nestas regiões os elétrons podem ser considerados como localizados unidimensionalmente. Tendo uma maior desordem na separação intercadeias

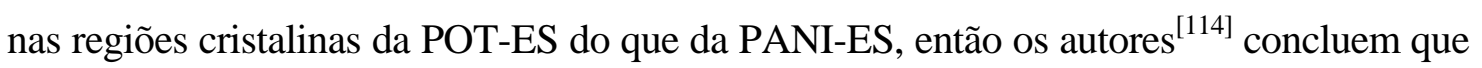
os estados eletrônicos na POT-ES devem ser mais localizados que os da PANI-ES.

Segundo Wang, a POT-ES e PANI-ES possuem o mesmo valor para a susceptibilidade magnética total $(\chi)$ em temperatura ambiente, entretanto a POT-ES possui

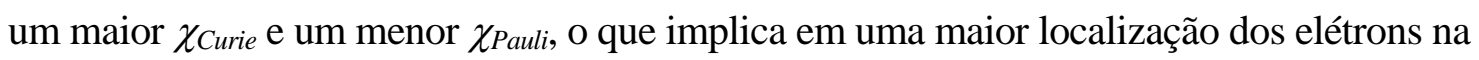
POT-ES. Além disso, a largura de linha do espectro de RPE da POT-ES é maior, o que também sugere uma maior localização dos elétrons na POT-ES.

Em geral, a largura de linha é determinada pelo tempo de relaxação spinspin $\left(T_{2}\right)$. Entretanto, existem vários processos que podem causar uma diminuição de $T_{2}$ e, como conseqüência, alargar a linha. Por exemplo, um destes processos é a relaxação spin-rede, que também diminui o tempo de vida do spin no estado excitado e contribue para o alargamento da linha. A relaxação spin-rede é caracterizada por um tempo $T_{1}$.

A meia largura de uma linha de absorção, $\Delta H_{1 / 2}$, definida como a metade da distância entre os pontos de meia intensidade, é dada por:

$$
\Delta H_{1 / 2}=\gamma^{-1} \frac{1}{T_{2}}=\gamma^{-1}\left(\frac{1}{T_{2}^{\prime}}+\frac{1}{2 T_{1}}\right)
$$


onde $T_{2}^{\prime}$ representa o tempo característico de todos os outros processos de relaxação spinspin que não envolvem a relaxação spin-rede. Os termos $1 / T_{2}^{\prime}$ e $1 /\left(2 T_{1}\right)$ correspondem, respectivamente, às contribuições secular e não-secular para a largura de linha.

Para um spin isolado, existem duas interações que podem contribuir para $T_{2}$, e que são importantes para o modelo que apresentaremos aqui. A primeira é a interação magnética dipolar, dada por uma freqüência característica, $\omega_{d}=\gamma H_{d}$, onde $\gamma$ é o fator giromagnético eletrônico, $\gamma \cong 1,7610^{7}(\mathrm{Gs})^{-1} \mathrm{e}$

$$
H_{d}^{2}=5,1\left(g \mu_{B} n\right)^{2} S(S+1)
$$

com, $n$ sendo a densidade de spins (spins $/ \mathrm{cm}^{3}$ ), $g$ o fator-g e $\mu_{B}$ o magneton de Bohr.

A segunda é a interação hiperfina isotrópica, entre o spin eletrônico $S$ e o spin nuclear $I$. Ela é caracterizada por uma freqüência característica $\omega_{h}=\gamma H_{h}$, onde

$$
H_{h}^{2}=\frac{1}{3} A^{2} I(I+1)
$$

e A é a constante de acoplamento hiperfino.

Considerando somente estas duas interações, espera-se que a forma da linha seja gaussiana. A inclusão, tanto do movimento do spin eletrônico como da interação de troca entre os spins, provoca uma forte alteração na forma de linha. Para um sistema magnético 3D, o aumento da interação de troca faz a forma da linha, alargada dipolarmente, mudar de gaussiana para lorentziana. Como resultado, ocorre uma diminuição na meia largura da linha de ressonância. Este fenômeno é conhecido como “exchange narrowing” e foi estudado teoricamente por Kubo; Tomita ${ }^{[141]}$. Em termos da freqüência de troca característica $\omega_{e}=\gamma H_{e}$, a meia largura da lorentziana passa a ser dada por

$$
\Delta H_{1 / 2}=\frac{1}{\gamma T_{2}^{\prime}}=\frac{\frac{10}{3} \omega_{d}^{2}+\omega_{h}^{2}}{\gamma \omega_{e}}
$$

desde que $\omega_{e} » \omega_{d}, \omega_{h}$.

Posteriormente aos trabalhos de Kubo; Tomita, surgiu o interesse experimental em sistemas de mais baixa dimensionalidade (1D e 2D) e descobriu-se que a dimensionalidade, das interações magnéticas ou do movimento dos spins, exerce profunda 
influência na forma do decaimento da magnetização transversal dos spins. Em outras palavras, a forma de linha de RPE é fortemente dependente da dimensionalidade.

Para sistemas onde o movimento ou a interação de troca é 3D, a forma da linha é aproximadamente lorentziana, correspondendo a um decaimento exponencial da magnetização transversal com o tempo $t$, já previsto pela teoria de Kubo; Tomita: $\Phi(t) \sim \exp (-\eta t)$, onde $\eta$ é uma constante. A interação de troca faz com que o estado dos spins se altere de tempos em tempos, através de "spin flips” simultâneos. O efeito destas flutuações em sistemas 3D densos e ordenados antiferromagneticamente foi estudado por Moriya $^{[142]}$. Em altas temperaturas, onde pode-se assumir uma distribuição gaussiana para essas flutuações, a freqüência de troca é independente da temperatura, e dada por:

$$
\omega_{e}=\frac{2}{3} \frac{J^{2}}{\hbar^{2}} z S(S+1)
$$

onde $J$ é o valor da integral de troca e $z$ o número de primeiros vizinhos coordenados ao spin S.

O composto $\left(\mathrm{CH}_{3}\right)_{4} \mathrm{NMnCl}_{3}$, abreviado como TMMC, é um sistema clássico onde os spins $\mathrm{Mn}^{2+}$ estão acoplados entre si através da interação de troca ao longo de cadeias unidimensionais. Estudos da ressonância magnética destes compostos ${ }^{[143]}$ mostram que a forma da linha é a transformada de Fourier de $\Phi(t) \sim \exp \left[(-\beta t)^{3 / 2}\right]^{[144]}$, onde $\beta$ é uma constante. Esta forma de linha corresponde a uma situção intermediária entre a gaussiana e a lorentziana.

No caso da amostra POMA-EB observamos que, em baixas temperaturas, os spins estão preferencialmente localizados, conforme evidenciam os dados de susceptibilidade, medida por RPE, e pela forma gaussiana da linha. Além disso, a estrutura hiperfina observada nos espectros, mostra que a função de onda do elétron localizado se estende, possivelmente, a grandes distâncias na cadeia polimérica, pelo menos através de dois anéis benzênicos.

Com a dopagem, o número de defeitos ao longo da cadeia aumenta de forma significativa, e podemos supor que a distância média entre eles diminue drasticamente, a ponto de promover interações elétricas e magnéticas entre eles. A interação entre os defeitos, tem sido objeto de estudo de diversos autores ${ }^{[88,112,120,145]}$ que, entre outros mecanismos, propõem que em certas polianilinas, um mecanismo de supertroca promove forte correlação antiferromagnética entre os defeitos. 
Isto pode ser explicado através do modelo em que o spin de um polaron, situado próximo a um átomo de nitrogênio carregado positivamente, induz uma polarização de spin em um elétron $\pi$ de um átomo de carbono adjacente. Esta polarização de spin é induzida sucessivamente através da cadeia até encontrar um outro elétron desemparelhado. Este efeito pode produzir o acoplamento antiferromagnético entre dois spins. É possível que este acoplamento antiferromagnético possa ocorrer através de um número grande de polarons existentes na cadeia polimérica.

Se uma perturbação provoca a mudança do estado de um spin, espera-se que esta perturbação se propague através de longas distâncias por intermediação da interação de troca. Após um tempo longo, este processo envolverá muitos spins e pode portanto ser considerado como um processo de difusão em um meio contínuo, descrito por um coeficiente de difusão proporcional a $\left(\omega_{\mathrm{e}}\right)^{-1}$. O cálculo detalhado mostra que a função de correlação, neste caso, passa a decair mais lentamente do que a forma gaussiana, produzindo drásticas alterações na forma da linha do espectro de RPE, conforme aqui observado experimentalmente.

Além da forma de linha, os resultados mostrados na Figura 98 indicam que na amostra em pó, abaixo de $25 \mathrm{~K}$, o comportamento da susceptibilidade desvia do previsto pela lei de Curie. Isto pode ser um indicativo de que, nestas baixas temperaturas, o acoplamento entre os centros paramagnéticos passa a influir no comportamento magnético do sistema, conforme já argumentado por Wang et al ${ }^{[114]}$.

Javadi et al $^{[120]}$ propõem uma forma de linha, para a polianilina protonada, composta pela superposição de uma componente gaussiana e outra lorentziana, respectivamente associadas aos spins localizados e móveis. Os autores argumentam que, a partir da dependência com a temperatura do espectro de RPE, é possível distinguir, através da deconvolução da forma de linha, as contribuições de cada tipo de spin. Entretanto, a forma de linha observada nos nossos espectros, já discutida anteriormente, não pôde ser ajustada de acordo com este modelo.

Trabalhos mais recentes ${ }^{[114,126]}$ analisam a forma de linha, baseados em um modelo quase-unidimensional, onde a interação de troca intracadeia $(J)$ e intercadeias $(J)$ possuem, ambas, influência importante. No caso em que $J$ 'é grande, o comportamento do sistema se aproxima da situação 3D, onde a forma de linha é lorentziana. No caso em que $J^{\prime}=0$, a forma de linha é intermediária entre gaussiana e lorentziana, como previsto pela 
teoria 1D. No caso da POMA dopada, estudada neste trabalho, a forma da linha em baixas temperaturas parece concordar com a previsão de Wang para o caso 1D. Nossos estudos, relativos à interpretação da forma de linha dos nossos espectros, à luz da teoria de Wang, são ainda preliminares.

Uma estimativa grosseira da freqüência de troca, $\omega_{\mathrm{e}}$, para a amostra POMA-TFA-24 em pó, pode ser feita através da Eq. (54). A partir da Eq. (52), assumindo $g \approx 2, S=1 / 2$ e estimando $n \approx 210^{20}$ spins $/ \mathrm{cm}^{3}$, obtemos $H_{d}^{2} \approx 60 \mathrm{G}^{2}$. A constante hiperfina do nitrogênio no $\mathrm{NH}^{+}$é $30 \mathrm{G}^{[146]}$ e considerando $I=1$, a Eq. (53) fornece $H_{h}^{2} \approx 600 \mathrm{G}^{2}$. Assumindo que a largura de linha $\Delta H_{1 / 2}$ em baixas temperaturas é da ordem de 1,73 G (correspondendo a $\Delta H_{\mathrm{pp}} \approx 2 \mathrm{G}$ - ver Figura 97), obtemos, através da Eq. (54), $\omega_{\mathrm{e}} \approx 810^{9} \mathrm{~s}^{-1}$. Esta freqüência de troca (ou difusiva) é muito menor que a taxa de espalhamento, $10^{15} \mathrm{~Hz}^{[126]}$, o que parece indicar que os elétrons estão localizados nas regiões amorfas e que processo de condução é por "hopping”.

Uma característica marcante dos nossos resultados pode ser observada na Figura 92 e na Figura 97. Nas amostras POMA-TFA, a largura de linha aumenta monotonicamente com a temperatura, na região 25-220 K. Além disso, este efeito não é observado na amostra dopada com $\mathrm{HCl}$.

Considerando que a largura de linha, determinada por $1 /\left(\gamma T_{2}^{\prime}\right)$, deve ser fracamente dependente da temperatura, a origem do alargamento da linha deve estar relacionado com outros mecanismos de relaxação. Uma hipótese que consideramos bastante provável é que a contribuição não secular, 1/( $\left.\gamma 2 T_{1}\right)$, definida na Eq. (51), contribua de forma relevante ao alargamento da linha. Considerando que, com o aumento da temperatura, $T_{1}$ deve diminuir, é razoável admitir que os mecanismos de relaxação spin-rede sejam eficientes nesta faixa intermediária de temperaturas.

Wang et $\mathrm{al}^{[126]}$ utilizou o mesmo argumento para explicar a dependência da largura de linha, em função da temperatura, na PANI-ES. O comportamento observado era que a largura de linha aumentava linearmente com o aumento da temperatura, na região 200-300 K. A dependência linear, $\Delta H_{1 / 2} \approx 1 / T_{1} \approx T$, sugeria que o processo de relaxação, envolvendo um único fônon (processo direto), era responsável pela relaxação spin-rede nesta faixa de temperatura. No nosso caso, acima de $220 \mathrm{~K}$, a largura da linha diminui, fato contrário ao observado por Wang. Observamos na POMA um alargamento similar da linha de ressonância somente em mais baixas temperaturas (25-220 K). 
Javadi et $\mathrm{al}^{[120]}$ argumentam que dois efeitos importantes podem produzir um alargamento da linha de ressonância. O primeiro é devido à exposição da amostra a uma atmosfera de vapor de água. Após os primeiros segundos de exposição a largura aumenta por um fator 2 e, a partir de então, decresce vagarosamente até estabilizar, após cerca de 5 minutos, em um valor 50\% maior do que a largura inicial. Após bombear a amostra em vácuo, a largura da linha retorna ao seu valor inicial. O segundo efeito é a exposição da amostra ao oxigênio, o qual produz um resultado mais acentuado. A largura da linha aumenta imediatamente por um fator maior que 100 , enquanto que a amplitude da linha fica multiplicada por 2, sem alterar significantemente a sua forma. Esta mudança do sinal também é reversível, após bombeio da amostra em vácuo. Os efeitos causados pela absorção de oxigênio foram observados em polipirrol ${ }^{[147]}$ e foi atribuído ao espalhamento do elétron seguido de um "spin-flip”, pelas moléculas de $\mathrm{O}_{2}(S=1)$. A competição entre “motional narrowing” e o alargamento da linha, que é produzido por uma relaxação spinrede rápida, foi observada em politiofeno ${ }^{[148]}$ e em poliacetileno ${ }^{[149]}$. Um efeito similar a este pode ocorrer com as polianilinas. De fato, o alargamento da linha de RPE em polianilinas, induzido pela presença de oxigênio molecular tem sido, recentemente, objeto de estudo de diversos autores ${ }^{[150]}$.

Os resultados obtidos para a largura de linha em função da temperatura, na POMA-TFA, são ainda insuficientes para podermos ser conclusivos a respeito da origem do alargamento observado. Entretanto, vamos propor aqui uma explicação deste efeito, onde moléculas de oxigênio presentes na cadeia polimérica, nas proximidades do polaron, representam um papel fundamental. Não discutiremos por enquanto se este oxigênio foi adsorvido do ar ambiente, se ele faz parte da composição da cadeia polimérica ou se foi introduzido no processo de dopagem.

Acreditamos que o acentuado alargamento de linha observado nas amostras POMA-TFA, representa uma evidência contundente de que deve existir uma forte interação magnética entre o polaron e as moleculas de $\mathrm{O}_{2}$, que poderia ser, em princípio, do tipo troca ou dipolo-dipolo. É também sugestivo o fato de que este alargamento ocorre com o aumento da temperatura, assim como aumenta a mobilidade dos polarons. Por isso, acreditamos que estes dois efeitos devem estar relacionados entre si.

Para que a interação polaron-oxigênio seja eficiente, eles devem estar relativamente próximos um do outro. É possível que esta interação favoreça a proximidade entre ambos, se o oxigênio tiver mobilidade suficiente para se localizar próximo de algum 
sítio ativo da polianilina. Desde que isso aconteça, e desde que a amplitude da interação seja adequada, os processos de espalhamento do polaron pelas moléculas de $\mathrm{O}_{2}$ podem alterar o estado de polarização do spin eletrônico, o que representa um processo que contribui para relaxação spin-rede do polaron. Isto requer, é claro, que o tempo de relaxação spin-rede do oxigênio seja mais curto que o $T_{1}$ do polaron. Espera-se que a taxa de relaxação do polaron seja proporcional à freqüência de colisão, $\omega_{c}$, entre o polaron e o oxigênio $^{[150]}$, de tal forma que a largura de linha passa a ser uma medida indireta de $\omega_{c}$, isto é: $\Delta H_{1 / 2} \propto \omega_{c}$. A freqüência de colisão deve ser proporcional à mobilidade do polaron e, no regime em que os portadores de carga são os polarons, o alargamento da linha deve acompanhar o aumento da condutividade: $\Delta H_{1 / 2} \propto \sigma$.

$\mathrm{O}$ valor de $\mathrm{T}_{1}$ em altas temperaturas $(\approx 220 \mathrm{~K})$ pode ser estimado a partir da diferença em larguras de linha entre 25 e $220 \mathrm{~K}$, que vale cerca de $12 \mathrm{G}$ (ver Figura 97), de onde obtém-se $T_{1} \approx 510^{-9} \mathrm{~s}$, que é cerca de 1 ordem de grandeza inferior ao tempo característico, $2 \pi / \omega_{e}$, associado ao "spin-flip”, do elétron, devido à interação de troca polaron-polaron.

Acima de $220 \mathrm{~K}$, acreditamos que o polaron adquiri mobilidade suficiente para que o processo de "motional narrowing" promova o estreitamento da linha. De fato, conforme havíamos concluído anteriormente, as medidas da intensidade integrada do espectro de RPE mostram que, nesta faixa de temperaturas, a contribuição de Pauli é dominante, sugerindo uma maior mobilidade para os elétrons.

O pequeno alargamento de linha, observado nas amostras dopadas, em baixas temperaturas (abaixo de $25 \mathrm{~K}$ ), pode ser explicado como sendo devido à interação hiperfina elétron-núcleo, que se torna mais eficiente nesta faixa de temperaturas, onde o grau de localização dos elétrons aumenta drasticamente.

É interessante ressaltar que a amostra POMA dopada com $\mathrm{HCl}$ não apresenta o alargamento de linha observado nas dopadas com TFA. Este alargamento também não foi observado na POT-ES (ver Figura 93). Os resultados são ainda preliminares para concluir algo a este respeito. Um fato bastante curioso é que tanto a POT-ES, como a POMA-HCl, apresentam larguras de linha semelhantes em toda a faixa de temperatura estudada, além disso, ambas não possuem $\mathrm{O}_{2}$ na molécula do dopante, enquanto que as dopadas com TFA possuem. 
Outros autores têm utilizado outros tipos de modelos para interpretar a dependência da largura de linha com a temperatura. Pereira et $\mathrm{al}^{[132]}$ observaram, em 240 K, um comportamento anômalo no espectro de RPE no poli(3-metiltiofeno) dopado com $\mathrm{ClO}_{4}$, associado a uma transição do tipo Peierls, indo de um comportamento metálico em altas temperaturas para um estado CDW produzido por ânions que se ordenam nesta temperatura. Tourillon et $\mathrm{al}^{[151]}$ observaram um máximo alargamento da linha de RPE em derivados de politiofeno dopado com $\mathrm{SO}_{3} \mathrm{CF}_{3}$, em torno de $180 \mathrm{~K}$. Eles concluem que este efeito é semelhante ao produzido por flutuações que precedem a transição metal-isolante em condutores unidimensionais porém, afirmam que os resultados são ainda inconclusivos. Os espectros de RPE de Anand et $\mathrm{al}^{[140,145]}$ foram analisados com base em um modelo de transição polarons-bipolarons, que é típico de sistemas não degenerados e os resultados obtidos em altas temperaturas (até $200{ }^{\circ} \mathrm{C}$ ) mostraram evidência da presença de paramagnetismo termicamente ativado.

\section{4 - Ressonância Magnética Nuclear}

Com o objetivo de investigar a dinâmica de spins nucleares, e a sua relação com os portadores de carga, das amostras de poli(o-metoxianilina), realizou-se medidas de RMN em função da temperatura, entre $77 \mathrm{~K}$ e $323 \mathrm{~K}\left(-196{ }^{\circ} \mathrm{C}\right.$ e $\left.+50{ }^{\circ} \mathrm{C}\right)$, e em freqüências de $24 \mathrm{MHz}$ e $36 \mathrm{MHz}$. Estas medidas consistiram na determinação do tempo de relaxação $T_{1}$ e das formas de linha, do hidrogênio $\left({ }^{1} H\right)$ e do flúor $\left({ }^{19} F\right)^{\odot}$, em função da temperatura. Para isso, a temperatura da amostra foi rapidamente abaixada até $77 \mathrm{~K}$ e, a seguir, realizadas as medidas elevando-se, lentamente, a temperatura até 323 K. O trabalho realizado até o momento esclarece, semi-quantitativamente, vários aspectos do problema, indica novos caminhos, mas ainda é insuficiente para demonstrar, de forma rigorosa, os modelos propostos.

Em vários polímeros condutores, apresentados na literatura, a condução se processa via difusão de íons (como $\mathrm{Li}^{+}$, por exemplo), e são por isso classificados como condutores iônicos. Os mecanismos responsáveis pela condutividade iônica ainda não são totalmente conhecidos, porém, acredita-se que a condutividade nestes

\footnotetext{
${ }^{\odot}$ As medidas de RMN para o núcleo de Flúor foram realizadas somente nas amostras dopadas com o ácido trifluoracético (TFA).
} 
materiais está principalmente localizada na região amorfa do polímero ${ }^{[162]}$. A razão para esta tendência está fundamentada no fato de que a mobilidade da cadeia polimérica na fase amorfa é bem maior que a da fase cristalina. Assim, a mobilidade da fase amorfa promove, com mais facilidade, o transporte de íons e, como conseqüência, também a condutividade.

Por outro lado, uma outra classe de polímeros condutores, que têm sido bastante estudada nas últimas décadas, são os polímeros condutores eletrônicos. Em certos polímeros desta classe, como por exemplo a polianilina, a condutividade tem sido interpretada em termos do polaron, que possui um elétron paramagnético. A relação entre o transporte de carga e a dinâmica deste spin tem sido objeto de muita controvérsia entre as interpretações de diversos autores ${ }^{[126]}$, porém, acredita-se que estes materiais desordenados se comportam como condutores quase unidimensionais. Em outras palavras, estes materiais são essencialmente compostos de cadeias metálicas, unidimensionais, por onde se processa quase todo o transporte de elétrons. Entretanto, está claro também que o transporte por "hopping” intercadeias, embora sendo um processo secundário, é essencial para explicar os resultados observados. Com base nestes modelos, tem-se concluído que, nas regiões amorfas do polímero, os elétrons estão essencialmente localizados e a condução se faz através do mecanismo de “hopping” intercadeias que, neste caso, é um processo de muito baixa probabilidade. Portanto, espera-se que o transporte de elétrons seja mais eficiente nas regiões cristalinas do polímero, facilitada pelo compactamento, acoplamento e coerência intercadeias.

Neste panorama, a RMN do ${ }^{1} \mathrm{H}$, e em alguns casos do ${ }^{19} \mathrm{~F}$, é de fundamental importância para o entendimento dos mecanismos de transporte nos polímeros. Isto se compreende considerando que a dinâmica do spin nuclear é fortemente afetada, não somente pela difusão dos spins eletrônicos, como também pelo grau de mobilidade das cadeias poliméricas. Sendo assim, através da RMN, é possível estudar seletivamente as diferentes fases de um sistema heterogêneo, como é o caso destes polímeros.

Entretanto, a heterogeneidade do material é um fator complicante na análise e interpretação dos resultados de RMN. Por exemplo, os dados de relaxação freqüentemente resultam em decaimentos (ou recuperações) não exponenciais, e as formas de linha são quase sempre representadas por combinações de diversas 
componentes espectrais. Em primeira análise, este comportamento complexo pode ser resultado do fato de que as conformações locais do material podem variar de uma região para outra, e de que estas regiões não são delimitadas espacialmente: elas podem intercambiar-se, formando-se e dissolvendo-se lentamente. $\mathrm{O}$ tratamento térmico, ao qual foi submetido o material, em geral, pode influir em suas propriedades estruturais, elétricas e magnéticas. Além disso, o comportamento não exponencial pode também advir de uma distribuição heterogênea de tempos de correlação e de movimentos anisotrópicos, o que pode ocorrer até mesmo em materiais morfologicamente homogêneos. Outro efeito que pode complicar a análise dos resultados é a transferência (ou difusão) de magnetização nuclear de uma região a outra do material, causada pela propagação de "spin-flips” mútuos (que conservam a energia) entre spins adjacentes. Quando este processo de difusão da magnetização é suficientemente rápido, o que é freqüentemente observado na relaxação do proton, o comportamento das diferentes regiões tendem a se igualar, e nem sempre as diferenças estruturais ou dinâmicas locais são observáveis na relaxação nuclear. Por estes motivos, a análise dos resultados de RMN está longe de ser uma tarefa simples.

Vários estudos ${ }^{[152-159]}$ foram realizados para entender o efeito da absorção da água na polianilina. Segundo Matveeva ${ }^{[158]}$ o efeito da hidratação da polianilina na forma base esmeraldina (PANI-EB) é comparável, no que diz respeito a condutividade do polímero, àquele obtido a partir da dopagem por ácido, embora em uma escala muito menor. A completa hidratação da amostra provoca um aumento na condutividade de cerca de 3 ordens de grandezas, enquanto que na protonação por ácido este aumento pode chegar a 10 ordens de grandezas. Este processo de hidratação da polianilina é, em parte ${ }^{\beta_{\text {}}}$, reversível, e, segundo Matveeva, o processo de remoção da água da PANI-EB é equivalente ao processo de desdopagem do polímero.

\subsection{1 - Forma de linha}

Além do estudo do comportamento do tempo de relaxação spin-rede $\left(T_{1}\right)$, realizou-se também um estudo do comportamento da forma da linha em função da

\footnotetext{
fu A hidratação torna-se irreversível quando a água liga-se ao anel benzenóide, ou quinóide.
} 
temperatura na POMA-EB e POMA dopada. A linha de RMN é obtida a partir da transformada de Fourier do sinal de decaimento da indução livre (FID).

A Figura 99 mostra alguns espectros típicos obtidos para a amostra POMA-EB. As larguras de linha, medidas pela distância entre os pontos de meia intensidade, estão mostradas no gráfico da Figura 100. Abaixo de $220 \mathrm{~K}$, a forma de linha é aproximadamente gaussiana e a sua largura, de aproximadamente $40 \mathrm{kHz}$, é independente da temperatura. Entretanto, a forma de linha observada em altas temperaturas (acima de $220 \mathrm{~K}$ ), pode ser bem ajustada pela superposição de duas componentes espectrais: uma absorção gaussiana larga $(\approx 40 \mathrm{kHz})$ e uma lorentziana estreita $(\approx 10 \mathrm{kHz})$.
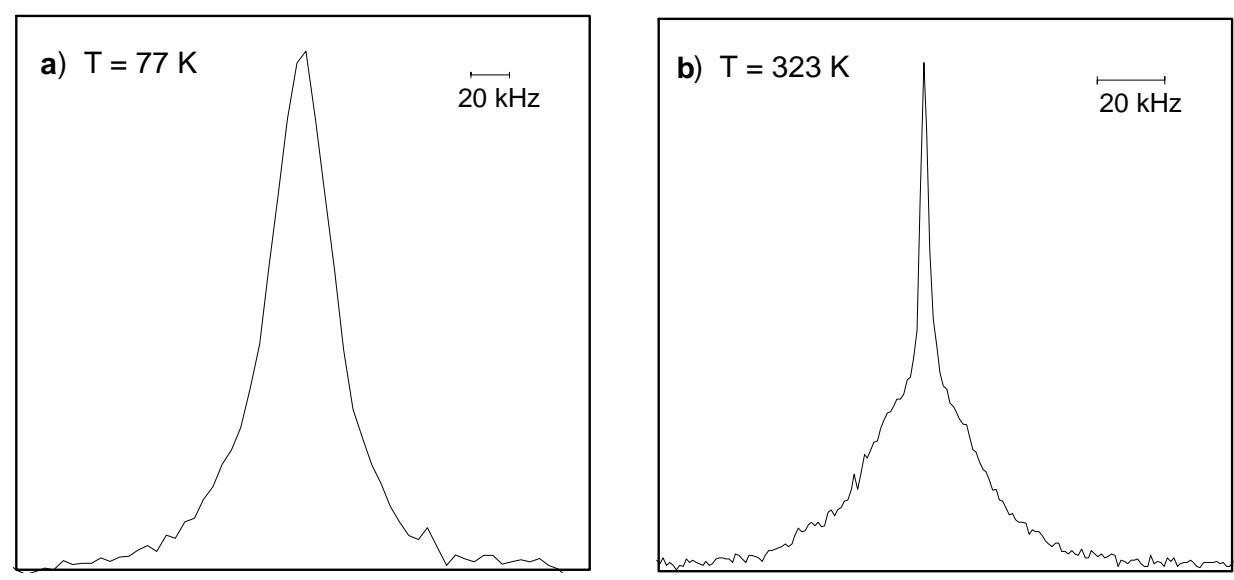

Figura 99 - Transformadas de Fourier do FID do ${ }^{1} \mathrm{H}$ da amostra POMA-EB em pó. Figuras a) e b) adquiridas, respectivamente, em $77 \mathrm{~K}$ e $323 \mathrm{~K}$. Medidas realizadas na freqüência $36 \mathrm{MHz}$.

Acima de $220 \mathrm{~K}$ a forma da linha é melhor ajustada por uma função do tipo:

$$
f(v)=A \frac{\sqrt{4 \ln 2 / \pi}}{\Delta_{B}} \exp \left[-4 \ln 2 \frac{\left(v-v_{0}\right)^{2}}{\Delta_{A}^{2}}\right]+B \frac{2}{\pi \Delta_{B}}\left[1+\left(\frac{2\left(v-v_{0}\right)}{\Delta_{B}}\right)^{2}\right]^{-1}
$$

onde, $A$ é a área da gaussiana, $B$ a área da lorentziana e $\Delta_{A}$ e $\Delta_{B}$ as suas respectivas larguras.

A dependência das larguras de linha, $\Delta_{A}$ e $\Delta_{B}$, com a temperatura, acima de 220 K, está mostrada na Figura 100, e fornece informações a respeito da dinâmica 
das cadeias poliméricas. Alguns autores ${ }^{[160-162]}$ definem o "grau de cristalinidade” $(K)$ por

$$
K=100 \frac{A}{A+B}
$$

De acordo com as medidas, $K \approx 80 \%$ em $323 \mathrm{~K}$, na POMA-EB.

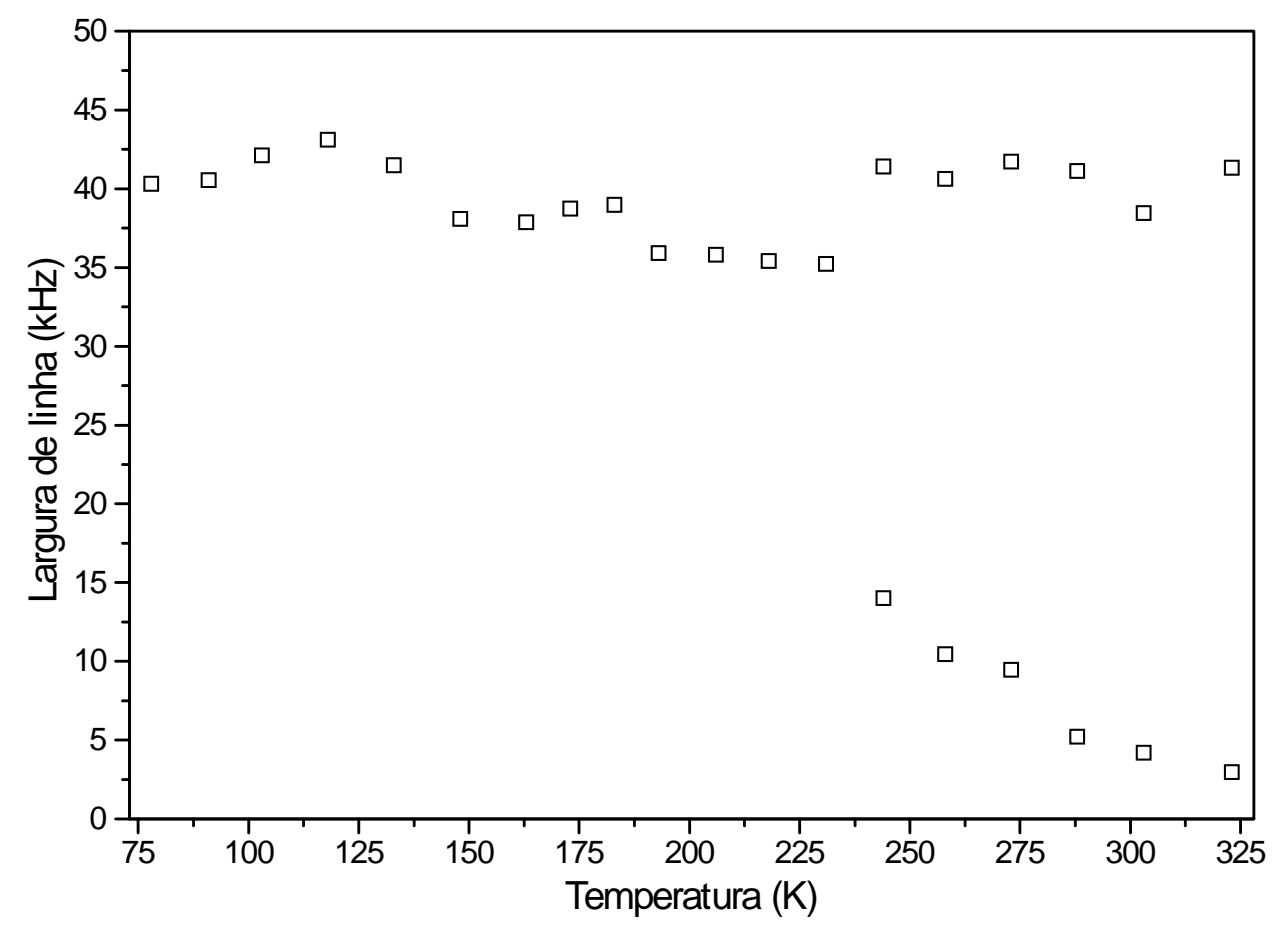

Figura 100 - Dependência com a temperatura da largura de linha, da Transformada de Fourier do FID, do ${ }^{1} \mathrm{H}$ da POMA-EB. Medida realizada em $36 \mathrm{MHz}$.

Acredita-se que a principal fonte de alargamento de linha neste material, fracamente dopado, é a interação dipolar magnética hidrogênio-hidrogênio (H-H). Em estruturas rígidas, a forma de linha, esperada por este tipo de acoplamento, é gaussiana e independente da temperatura. Entretanto, a partir dos resultados experimentais, observa-se uma mudança no comportamento da forma de linha em temperaturas acima de 220 K. Focalizando nossa atenção nesta região de temperaturas, observamos que o espectro de RMN pode ser decomposto em uma linha lorentziana estreita e uma linha gaussiana larga. Este fato é consistente com a interpretação usual encontrada na literatura, explicada pela presença de uma fase amorfa e outra cristalina na POMA-EB. Normalmente, a acentuada mobilidade das cadeias da fase amorfa, induz o processo de 
“motional narrowing”, cujo efeito principal é reduzir a largura da linha. Esta redução na largura da linha vem acompanhada de uma mudança na sua forma, fazendo com que a linha gaussiana observada na estrutura rígida, gradualmente se transforme em lorentziana, conforme a mobilidade da cadeia aumenta. De fato, observa-se, na região de temperaturas 220-323 K, uma diminuição gradual do parâmetro K e da largura de linha $\Delta_{B}$. A partir da hipótese de que a componente larga $(A)$ corresponde à fase cristalina e a estreita $(B)$ à fase amorfa, estamos interpretando o parâmetro $K$, como sendo uma medida do grau de cristalinidade da amostra.

Neste trabalho, não foram realizadas medidas de "Differential Scanning Calorimetry” (DSC) nas amostras estudadas, porém é razoável esperar que a temperatura de fusão da fase cristalina esteja acima da temperatura ambiente. Apesar de não termos a confirmação desta hipótese, vamos acreditar que na região de temperaturas, compreendida entre $220 \mathrm{~K}$ e $323 \mathrm{~K}$, as fases cristalinas e amorfas coexistem. O aumento do grau de cristalinidade, com o decréscimo da temperatura, abaixo de $250 \mathrm{~K}$, nos faz suspeitar de que a medida de DSC indicaria uma temperatura de descongelamento da fase amorfa na região 220-250 K.

Abaixo de $220 \mathrm{~K}$ é de se esperar que os movimentos das cadeias sejam bastante restritos, levando a fase amorfa a uma situação de “congelamento”. Neste caso, tanto a fase cristalina, quanto a amorfa, devem se comportar como estruturas rígidas, refletindo o fato da linha de RMN se tornar gaussiana em ambas as fases.

Passaremos agora a estudar o efeito da dopagem da POMA nos espectros de RMN. A Figura 101 e Figura 102 mostram os resultados obtidos para as larguras de linha nas amostras POMA dopadas com HCl e TFA-1. Os resultados obtidos para a POMA-TFA-24 são bastante semelhantes aos da amostra dopada por 1h e por isso não estão mostrados aqui.

O comportamento observado nas amostras dopadas é bastante similar ao da POMA-EB. No entanto, algumas diferenças merecem comentário. A temperatura, acima da qual se observa a componente lorentziana estreita, se alterou para $\approx 200 \mathrm{~K}$ na POMA-HCl e para $\approx 240 \mathrm{~K}$ na POMA-TFA-1, indicando que a temperatura de descongelamento da fase amorfa deve variar com a dopagem. O grau de cristalinidade, medido em $323 \mathrm{~K}$, diminuiu para $\mathrm{K} \approx 55 \%$ na $\mathrm{POMA}-\mathrm{HCl}$ e para $\mathrm{K} \approx 65 \%$ na POMA-TFA-1. 


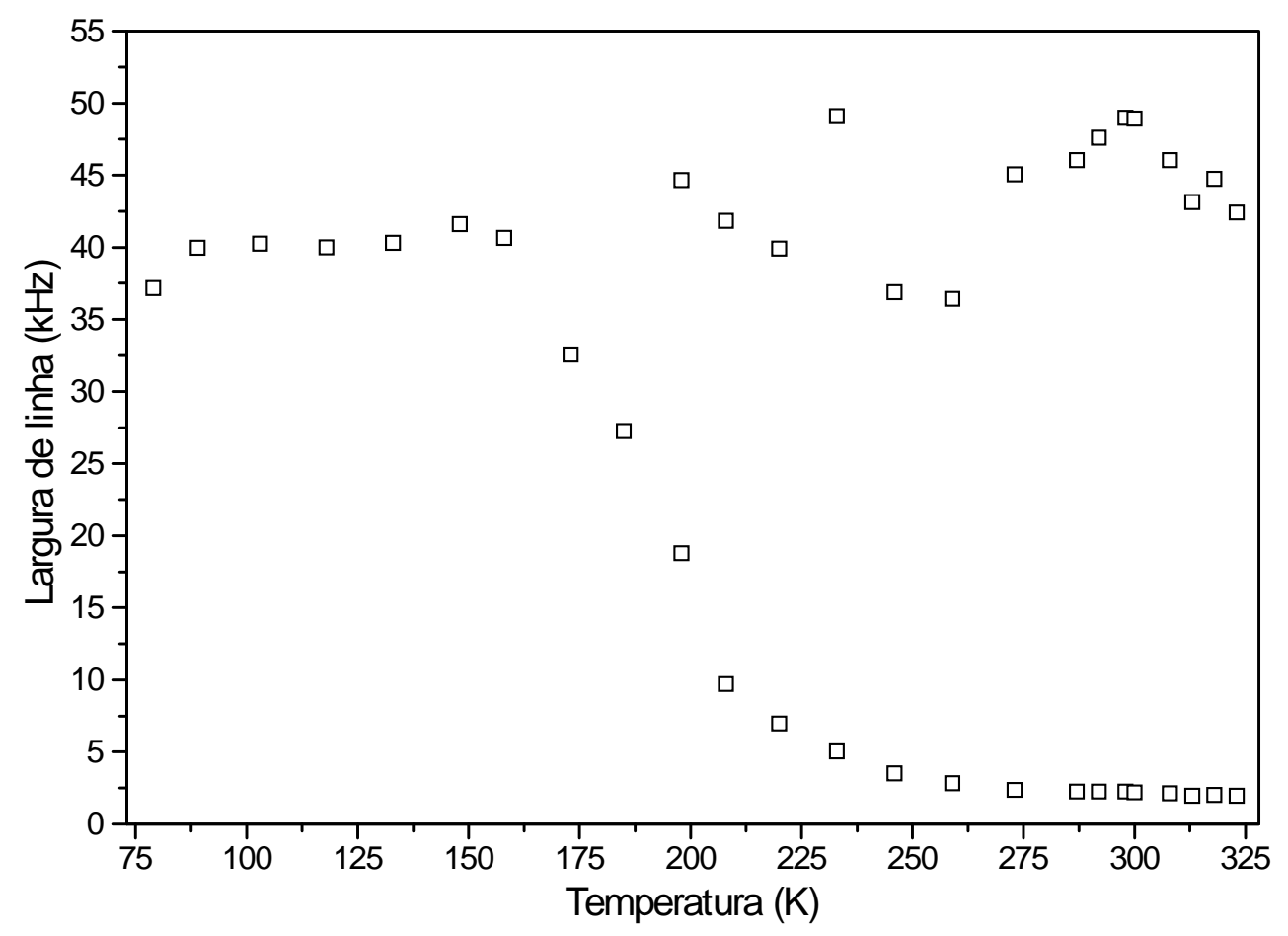

Figura 101 - Dependência com a temperatura da largura de linha, da Transformada de Fourier do FID, do ${ }^{1} \mathrm{H}$ na POMA dopada com $\mathrm{HCl}$. Medidas realizadas em $36 \mathrm{MHz}$.

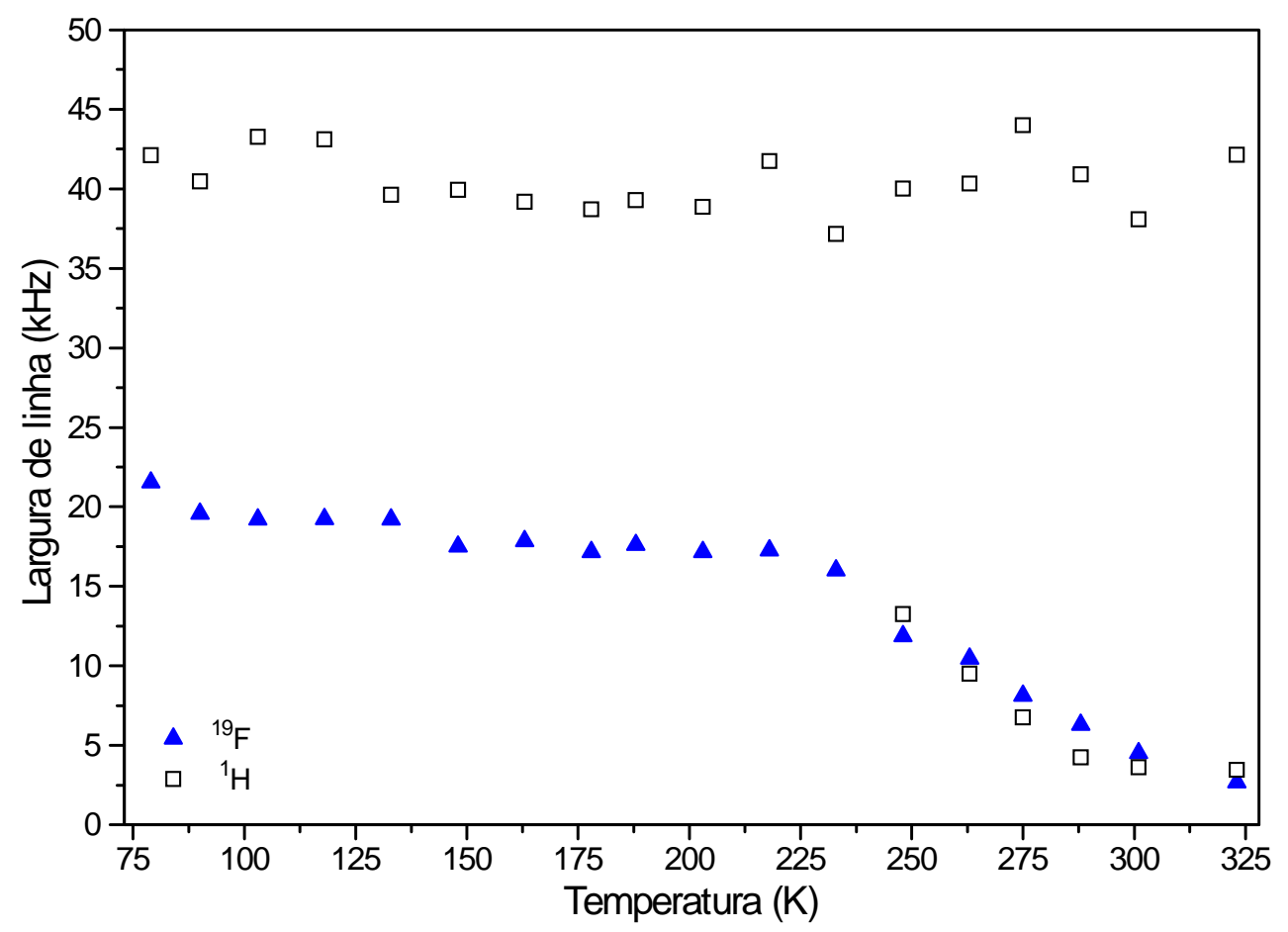

Figura 102 - Dependência com a temperatura da largura de linha, da Transformada de Fourier do FID, do ${ }^{1} \mathrm{H}(\boldsymbol{4})$ e do ${ }^{19} \mathrm{~F}(\bullet)$ na POMA dopada com TFA por $1 \mathrm{~h}$. Medidas realizadas em $36 \mathrm{MHz}$. 
Na Figura 102 são mostrados também a largura de linha, em função da temperatura, para o ${ }^{19} \mathrm{~F}$. Assim como no caso do ${ }^{1} \mathrm{H}$, esta linha apresentou uma redução em sua largura, em altas temperaturas. Entretanto, ao contrário do ${ }^{1} \mathrm{H}$, o ${ }^{19} \mathrm{~F}$ apresentou apenas uma componente espectral, para o sinal de RMN, em toda faixa de temperaturas estudada, indo de uma forma gaussiana, em baixas temperaturas, para lorentziana em altas temperaturas.

O principal mecanismo de alargamento da linha de $\mathrm{RMN}$ do ${ }^{19} \mathrm{~F}$, em baixas temperaturas, é a interação dipolar entre os flúors do grupo $\mathrm{CF}_{3}{ }^{+}$rígido. $\mathrm{A}$ largura de linha associada a esta interação pode ser calculada, utilizando o método dos momentos desenvolvido por Van Vleck ${ }^{[9]}$. Se os flúors $(I=1 / 2)$ estão separados por uma distância $d$, o segundo momento da distribuição gaussiana pode ser estimado através da expressão:

$$
\left\langle\Delta \omega^{2}\right\rangle=\frac{3}{5} \gamma^{4} \hbar^{2} I(I+1) \frac{2}{d^{6}}
$$

Substituindo, $d=2,2 \AA^{[162]}$ e $\gamma=2.5210^{4} \quad(\mathrm{~s} . \mathrm{G})^{-1}$, obtém-se $<\Delta \omega^{2}>=3,5310^{9} \mathrm{~s}^{-2}$ $\left(\approx 5,56 \mathrm{G}^{2}\right)$. A largura de linha correspondente, $\Delta v$, está relacionada com o segundo momento da distribuição gaussiana por $\left.(2 \pi \Delta v)^{2}=8 \ln 2<\Delta \omega^{2}\right\rangle$, de onde se obtém $\Delta v=22 \mathrm{kHz}$. Este valor está um pouco acima do medido em $200 \mathrm{~K}(\approx 18 \mathrm{kHz})$ mas, é bastante próximo daquele em $77 \mathrm{~K}$. Se as outras contribuições à largura de linha, como por exemplo o acoplamento heteronuclear F-H, forem desprezíveis, este resultado sugere que, em baixas temperaturas, o grupo $\mathrm{CF}_{3}{ }^{+}$não possui movimentos internos na escala de tempo do experimento de RMN. Portanto, o grupo $\mathrm{CF}_{3}{ }^{+}$pode ser considerado rígido abaixo de $200 \mathrm{~K}$.

A gradual diminuição da largura de linha do ${ }^{19} \mathrm{~F}$, acima de $240 \mathrm{~K}$, deve ser atribuído ao aumento da mobilidade das cadeias poliméricas, o que promove a modulação das distâncias F-F e também facilita a rotação do grupo $\mathrm{CF}_{3}{ }^{+}$. Observando a Figura 102, verifica-se que este efeito ocorre na mesma faixa de temperaturas em que o aumento de mobilidade das cadeias da fase amorfa produzem o estreitamento da linha de RMN do ${ }^{1} \mathrm{H}$. Aparentemente estes dois efeitos estão correlacionados. Entretanto, seria esperado que somente os flúors ligados às cadeias da fase amorfa contribuíssem ao estreitamento lorentziano de linha e, neste caso, aqueles ligados às cadeias da fase cristalina continuariam contribuindo ao espectro com uma distribuição gaussiana larga. 
O fato de termos observado apenas uma distribuição espectral lorentziana em altas temperaturas, pode nos levar a pensar que a molécula do dopante, que contém o grupo $\mathrm{CF}_{3}{ }^{+}$, está principalmente associada à fase amorfa do polímero. Uma outra possibilidade seria que, o aumento das flutuações lentas, que precede a fusão da fase cristalina, seja suficiente para promover o aumento da mobilidade do $\mathrm{CF}_{3}{ }^{+}$ligado às cadeias da fase cristalina. Estas flutuações lentas seriam ineficientes para modular a distância H-H, na escala de tempo do experimento de RMN, porém, seriam suficientes para abrir espaço intercadeias, aumentando os graus de liberdade do $\mathrm{CF}_{3}{ }^{+}$.

\subsection{2 - Tempo de Relaxação Spin-Rede $\left(T_{1}\right)$}

O estudo da relaxação nuclear spin-rede é muito útil para a caracterização da dinâmica das cadeias poliméricas ${ }^{[162]}$. Com esta finalidade, duas técnicas são freqüentemente utilizadas. A mais comumente utilizada é a técnica de “relaxação spin-rede no sistema de coordenadas do laboratório” (também denominada simplesmente por $T_{1}$ ), que é sensível a flutuações que ocorrem com um tempo de correlação, $\tau$, que satisfaz $\omega_{0} \tau \approx 1$, onde $\omega_{o}$ é a freqüência de Larmor do spin nuclear. Isto implica que a relaxação spin-rede, neste caso, seria sensível a flutuações com $\tau \approx 10^{-9} \mathrm{~s}$. A outra técnica, geralmente mais útil na elucidação da dinâmica das cadeias, é a "relaxação spin-rede no sistema de coordenadas girante" (denominada $T_{1 \rho}$ ), porque ela é sensível aos movimentos na faixa de kHz, característicos dos rearranjos lentos, que modulam a conformação das cadeias dos polímeros.

Neste trabalho, centraremos a atenção na medida do tempo de relaxação nuclear $T_{1}$ do ${ }^{1} \mathrm{H}$ e ${ }^{19} \mathrm{~F}$, nas amostras POMA-EB e nas amostras dopadas. As medidas de $T_{1}$ foram realizadas nas amostras em pó, utilizando o método de saturação e recuperação descrito no Capítulo 2. Os resultados dos tempos de relaxação $T_{1}$ do ${ }^{1} H$, para a amostra POMA-EB, são mostrados na Figura 103. Observando este gráfico nota-se que há pouca dependência desta relaxação com a freqüência de excitação. Neste gráfico observa-se também que, em baixas temperaturas (abaixo de $220 \mathrm{~K}$ ), o decaimento da magnetização é descrito por duas componentes exponenciais, e portanto associado a dois tempos de relaxação. Em temperaturas mais altas (acima de $220 \mathrm{~K}$ ), observa-se um decaimento exponencial, e a relaxação é descrita por um único tempo característico. 
A existência de duas fases na POMA pode se refletir nos resultados de relaxação spin-rede, evidenciando um comportamento não exponencial, abaixo de $220 \mathrm{~K}$. Uma hipótese é que a componente, cuja taxa de relaxação $\left(1 / T_{1}\right)$ é menor, está associada à fase amorfa e decresce com o decréscimo da temperatura. A taxa de relaxação maior, associada à fase cristalina, passa por um máximo em torno de $135 \mathrm{~K}$. Examinando a Figura 103 fica difícil verificar se ocorre alguma alteração na posição deste máximo devido a mudança na freqüência. Este máximo poderia ser indicativo da existência de um mecanismo de relaxação causado por mudanças estruturais dinâmicas da fase cristalina, ocorrendo com um tempo de correlação da ordem de $1 / \omega_{0} \approx 510^{-9} \mathrm{~s}$. Entretanto, estes resultados ainda são preliminares, por isso, fica difícil confirmar este modelo. Entretanto, como veremos a seguir, os resultados experimentais parecem indicar que a presença do polaron é fundamental para explicar as duas taxas de relaxação observadas.

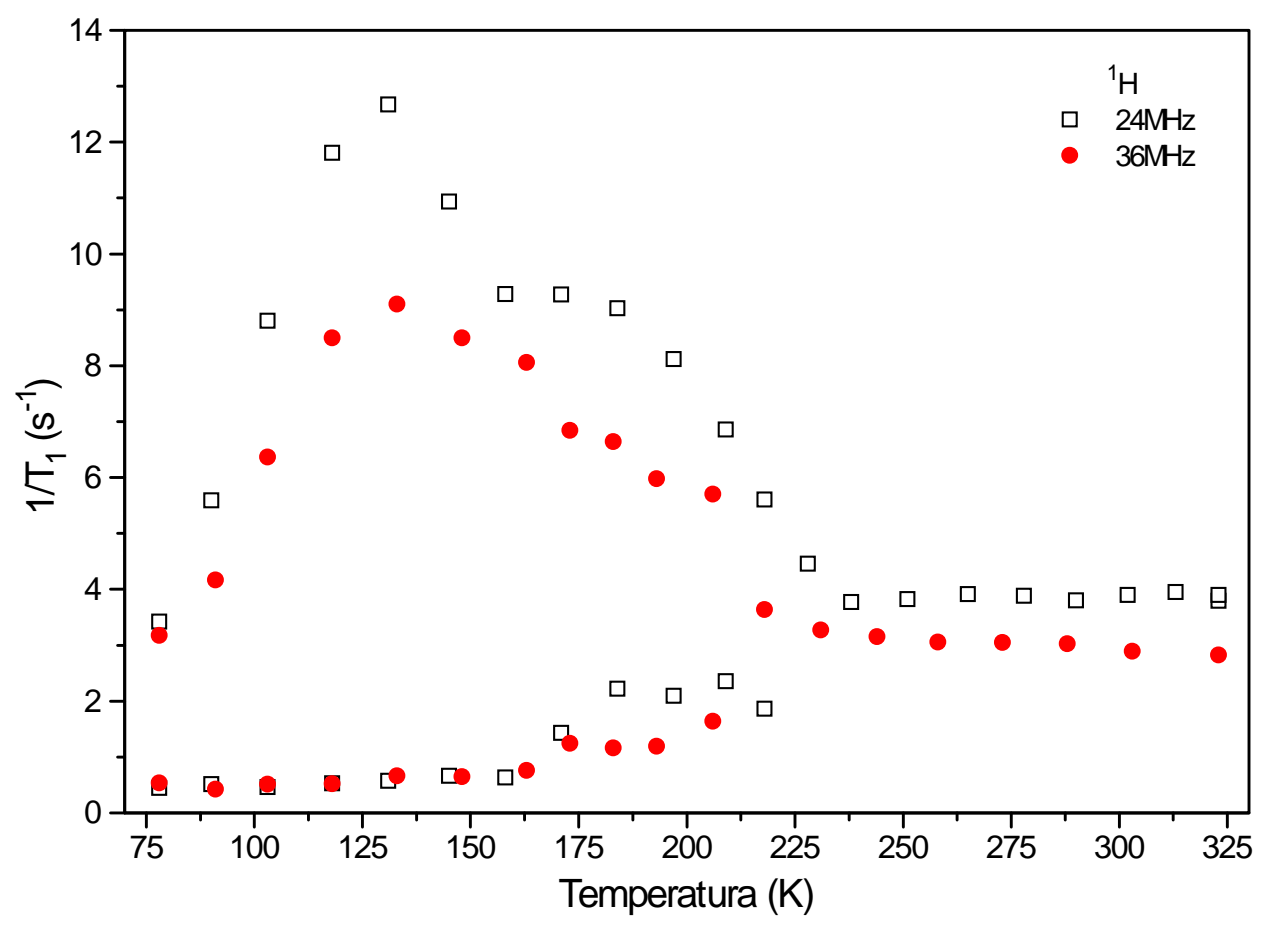

Figura 103 - Taxa de relaxação $\left(1 / T_{1}\right)$ do ${ }^{1} \mathrm{H}$, da amostra POMA-EB, nas freqüências de (•) 24 e (•) 36 MHz.

A Figura 104 mostra que, nas amostras dopadas, o comportamento não exponencial da relaxação se verifica em toda a faixa de temperaturas. São observados dois tempos de relaxação, um longo (maior que 300 ms) e outro curto (da ordem de 
$20 \mathrm{~ms}$ ). Ao se comparar estes resultados com os da amostra não dopada, constata-se que a dopagem não influência o tempo de relaxação longo, mas provoca uma diminuição acentuada do tempo de relaxação curto.

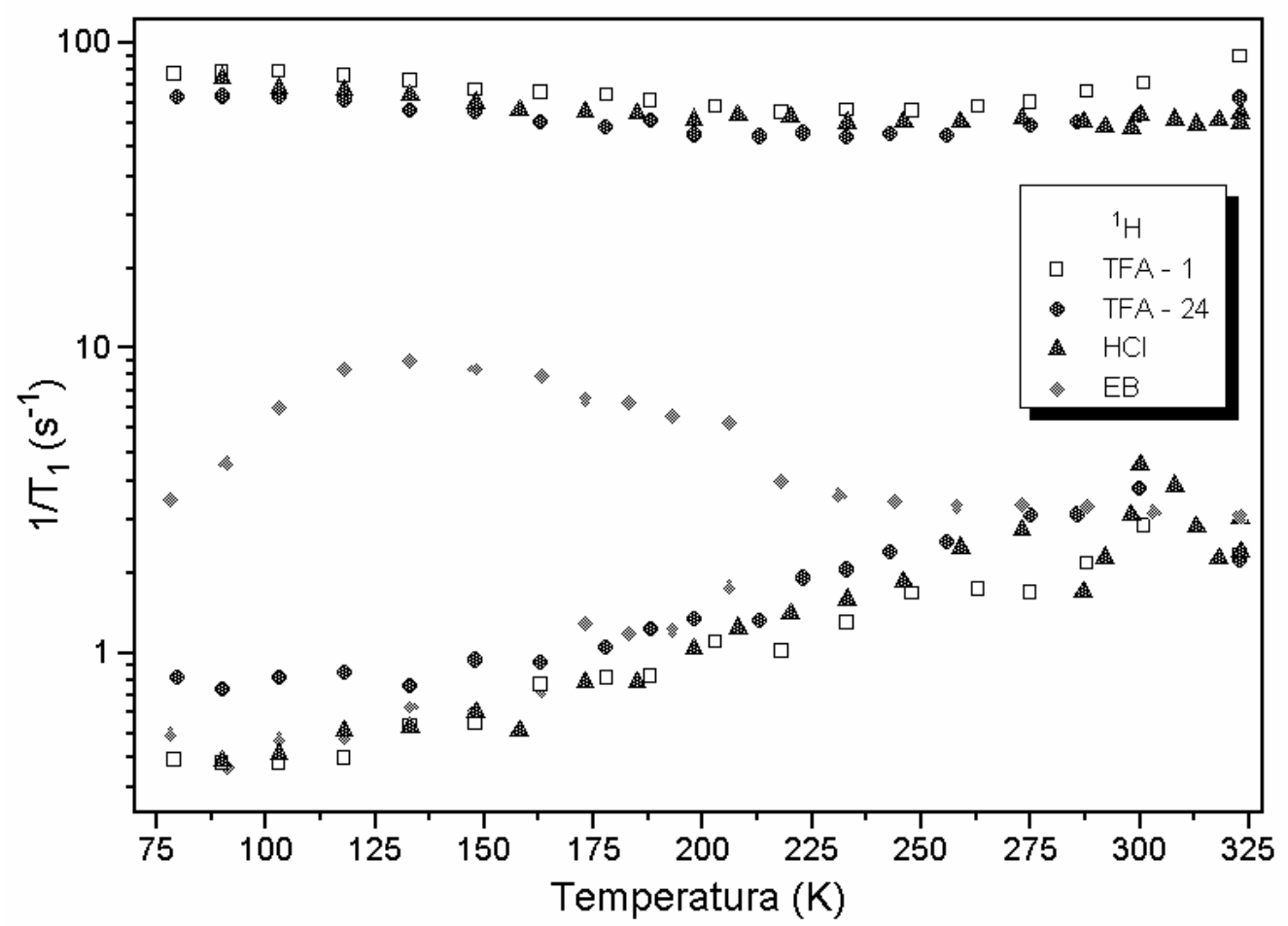

Figura 104 - Taxa de relaxação $\left(1 / T_{1}\right)$ do ${ }^{1} \mathrm{H}$, da amostra POMA EB $(\diamond)$ e POMA dopada com TFA (• e •) e $\mathrm{HCl}(\bullet)$. Medidas realizadas na freqüência de $36 \mathrm{MHz}$.

Através dos resultados, obtidos até o momento, é difícil elaborar um modelo conclusivo. A associação entre as duas taxas de relaxação com as duas fases do polímero foi baseada na hipótese, já levantada por outros autores, que o transporte de carga, nestes materiais, se faz predominantemente através das regiões mais ordenadas, ou cristalinas. Com a introdução do dopante, observamos que a taxa de relaxação maior é a que sofreu maior variação, enquanto que a taxa menor não se alterou de forma significativa. Considerando que este efeito seja devido à presença dos portadores de carga, cujo movimento predomina na fase cristalina, é razoável associar as duas componentes da relaxação com as fases do polímero: taxa maior com fase cristalina e taxa menor com fase amorfa. Com certeza, esta hipótese terá que ser cuidadosamente testada em novos experimentos. 
Entretanto, deixando de lado a hipótese de cristalinidade, pode-se supor, também, a existência de dois tipos de ${ }^{1} \mathrm{H}$ : um próximo dos polarons; e outro distante. $\mathrm{O}$ ${ }^{1} \mathrm{H}$ próximo dos polarons teria uma relaxação mais eficiente $\left(\mathrm{T}_{1}\right.$ curto), promovida pela transferência de energia para o reservatório de polarons. Esta hipótese é consistente com os fatos observados ao dopar a amostra, que provoca uma diminuição ainda maior da relaxação de tempo curto ( ${ }^{1} \mathrm{H}$ próximo dos polarons) e não altera a relaxação de tempo longo ( ${ }^{1} \mathrm{H}$ distante dos polarons).

Uma outra possibilidade, que poderia explicar a diminuição do tempo de relaxação curto, com o aumento da dopagem, seria a existência de algum mecanismo de relaxação nuclear via impurezas paramagnéticas. Este processo representa um mecanismo de relaxação bastante eficiente, e está exemplificado na literatura em uma variedade enorme de sistemas. As impurezas paramagnéticas presentes no material, mesmo em baixíssimas concentrações, podem provocar uma diminuição acentuada do tempo de relaxação spin-rede nuclear. Este processo é, em geral, independente da temperatura, o que coincide com o comportamento do tempo de relaxação curto observado aqui. No nosso caso, não temos indicação de contaminação das amostras com tais impurezas, nem tampouco os espectros de RPE indicaram a presença de outros radicais (ou íons) paramagnéticos, além do polaron. Já suspeitamos anteriormente, conforme os resultados de RPE indicam, que existe uma quantidade razoável de oxigênio molecular $(S=1)$ dissolvido no material. Entretanto, é difícil correlacionar esta hipótese com os resultados de RMN, mesmo porque, se a relaxação nuclear via oxigênio fosse um mecanismo importante, o mais provável é que ela deveria afetar as duas componentes da relaxação, e não somente aquela de tempo curto.

Um outro efeito, bastante estudado em outras classes de polímeros, porém pouco explorado nas polianilinas, é o efeito da hidratação da amostra sobre os tempos de relaxação nuclear do hidrogênio. Sabe-se que as polianilinas são bastante higroscópicas, por isso, suspeitamos que o efeito observado em $\mathrm{T}_{1}$, com o aumento da dopagem, pudesse estar correlacionado com a hidratação do material. Com a finalidade de verificar o efeito da remoção de água da POMA, realizou-se medidas de $T_{1}$, após secar a amostra dopada com TFA-1h. Para estas medidas separou-se, de um mesmo lote de amostra, uma parte que foi lacrada, em um tubo de pirex, à atmosfera normal, e uma outra parte que foi colocada em uma estufa a $60{ }^{\circ} \mathrm{C}$, durante um período de $12 \mathrm{~h}$, e após isto lacrada à atmosfera de Hélio. Os resultados obtidos estão mostrados na 
Figura 105. Verificamos que o tempo longo não sofreu alteração com o processo de secagem, por isso, o gráfico mostra os resultados em escala linear, a fim de melhor evidenciar o efeito da secagem sobre o tempo curto. Observa-se que o tempo curto ficou mais curto, após a secagem. Este resultado mostra claramente que a hidratação da amostra realmente afeta os tempos de relaxação spin-rede, porém, ela não explica a existência da componente de relaxação rápida que foi observada nas amostras dopadas. Apesar disso, é bastante curioso o fato de que a secagem tenha afetado apenas uma das componentes da relaxação, deixando inalterada a componente de relaxação lenta. Este fato merece um maior esclarecimento, o que deverá ser feito futuramente.

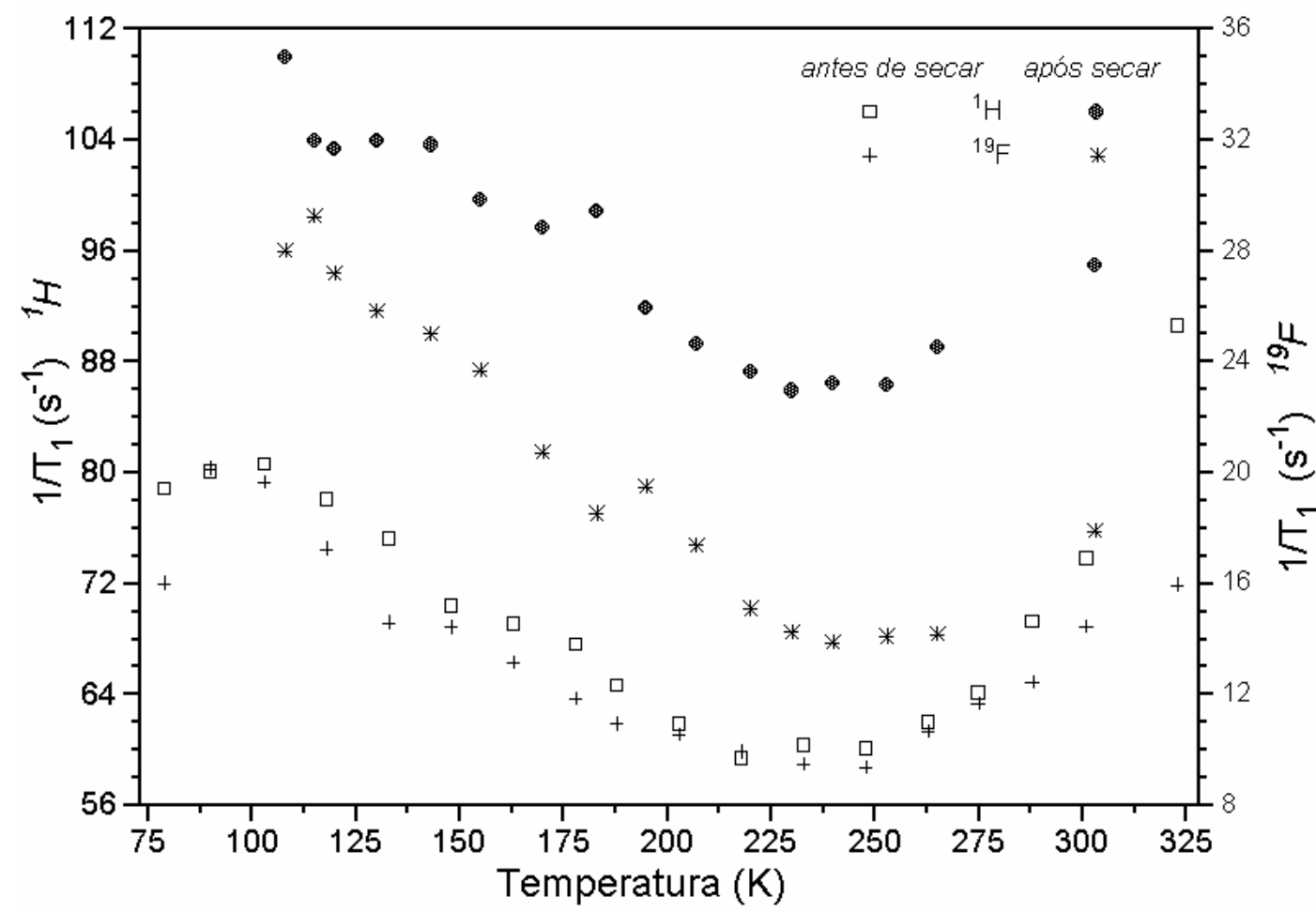

Figura 105 - Comparação entre as taxas de relaxação $\left(1 / T_{1}\right)$ de tempo curto, em

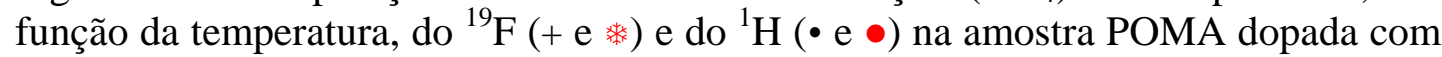
TFA por $1 \mathrm{~h}$. Medidas realizadas, em $36 \mathrm{MHz}$, antes e depois de secar a amostra a $60^{\circ} \mathrm{C}$ durante $12 \mathrm{~h}$.

Levando em consideração os argumentos colocados, a nossa idéia, no momento, é que o aumento da taxa de relaxação de uma das componentes deve-se, principalmente, a algum mecanismo de relaxação nuclear spin-rede intermediado pelos polarons. Já vimos anteriormente, que é bastante provável que a interação de troca 
polaron-polaron seja bastante intensa, em qualquer temperatura. Este argumento, associado ao processo de "exchange narrowing”, foi utilizado para explicar o estreitamento da linha de RPE com o aumento da dopagem. Neste aspecto, o conjunto de polarons, eficientemente acoplados entre si, se comporta como um reservatório térmico para a relaxação nuclear, desde que o acoplamento núcleo-polaron seja também eficiente. De fato, a interação hiperfina núcleo-polaron poderia ser responsável pelo acoplamento núcleo-rede.

Salientamos aqui, que o modelo proposto não requer que o polaron possua mobilidade para que a relaxação nuclear seja eficiente; basta que o acoplamento de troca entre polaron-polaron intracadeia seja suficientemente forte. Esta condição pode ser verificada tanto na fase amorfa, quanto na fase cristalina do polímero. Sendo assim, a relaxação do núcleo dependeria apenas de interações estáticas (hiperfina entre núcleo-polaron e de troca entre polaron-polaron) modulada pelas flutuações do spin eletrônico. Isto levaria a uma taxa de relaxação nuclear independente da temperatura, como foi observado experimentalmente. Todavia, esta idéia deverá ser melhor testada em experimentos futuros.

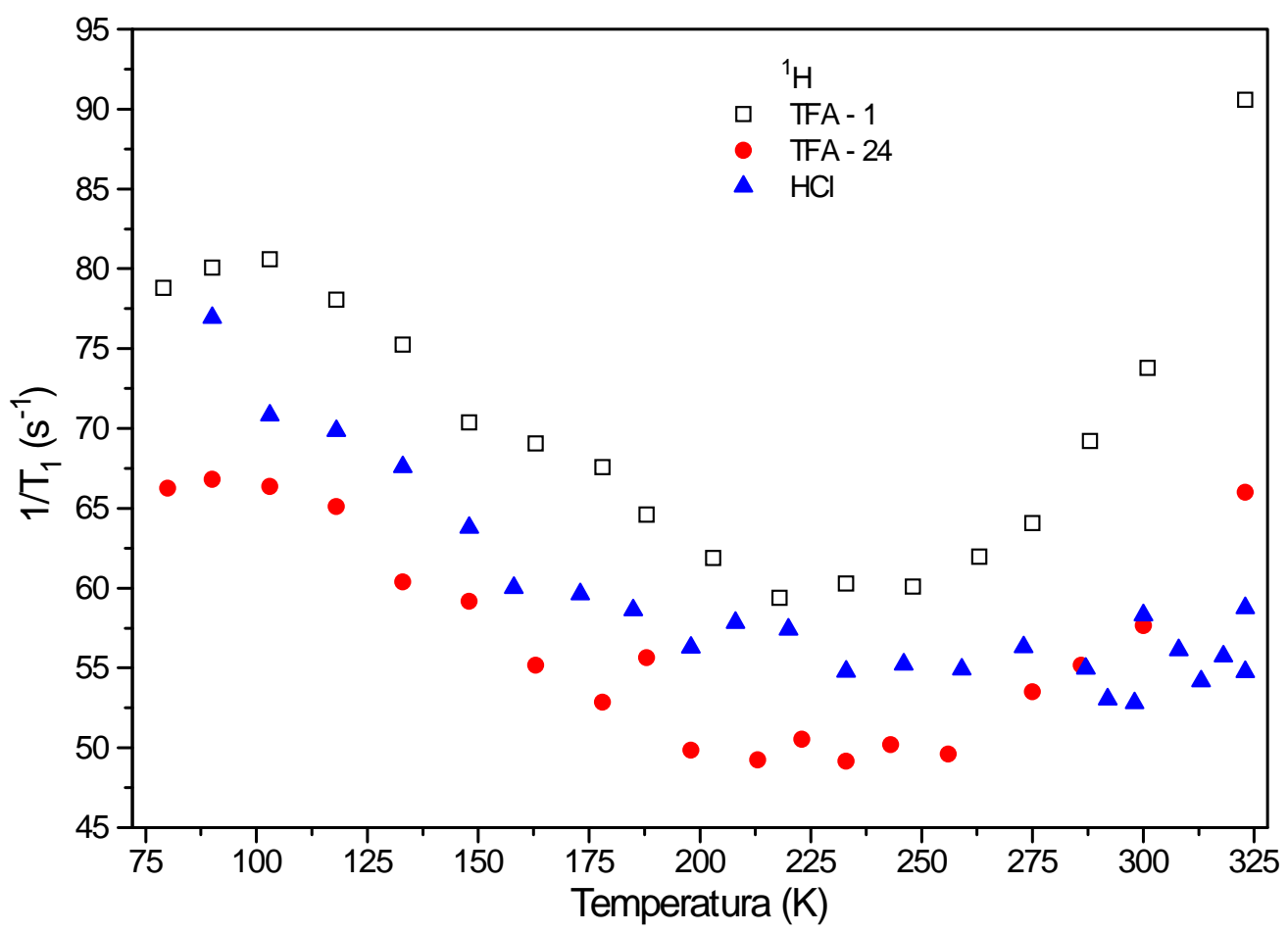

Figura 106 - Taxas de relaxação $\left(1 / T_{1}\right)$ do ${ }^{1} \mathrm{H}$, da amostra POMA dopada com TFA $(\bullet$ e •) e $\mathrm{HCl}(\bullet)$ na freqüência de $36 \mathrm{MHz}$. 
Se olharmos, com maior cuidado, o comportamento do tempo de relaxação curto com a temperatura, verificaremos, como mostra a Figura 106 em escala expandida, que nas amostras dopadas com TFA, o $1 / T_{1}$ decresce com o aumento da temperatura, passa por um mínimo em torno de $225 \mathrm{~K}$ e volta a aumentar em altas temperaturas. A amostra dopada com $\mathrm{HCl}$ mostra um comportamento distinto, o $1 / T_{1}$ se mantém praticamente constante acima de $225 \mathrm{~K}$.

Outros resultados mostram também, que a relaxação spin-rede do ${ }^{19} \mathrm{~F}$ (ver Figura 107) possui o mesmo comportamento, com a temperatura, que a componente de relaxação rápida do ${ }^{1} \mathrm{H}$. No caso do RMN do flúor, foi observado que a relaxação spin-rede pode ser descrita por uma recuperação exponencial, portanto, associada a um único tempo de relaxação. Ao se comparar os resultados do hidrogênio com os do flúor, nota-se que eles devem estar correlacionados entre si. É possível que um mesmo mecanismo seja responsável pela relaxação em ambos os casos. A Figura 105 mostra que o efeito da secagem (ou hidratação) também se reflete de forma similar para ambos os núcleos.

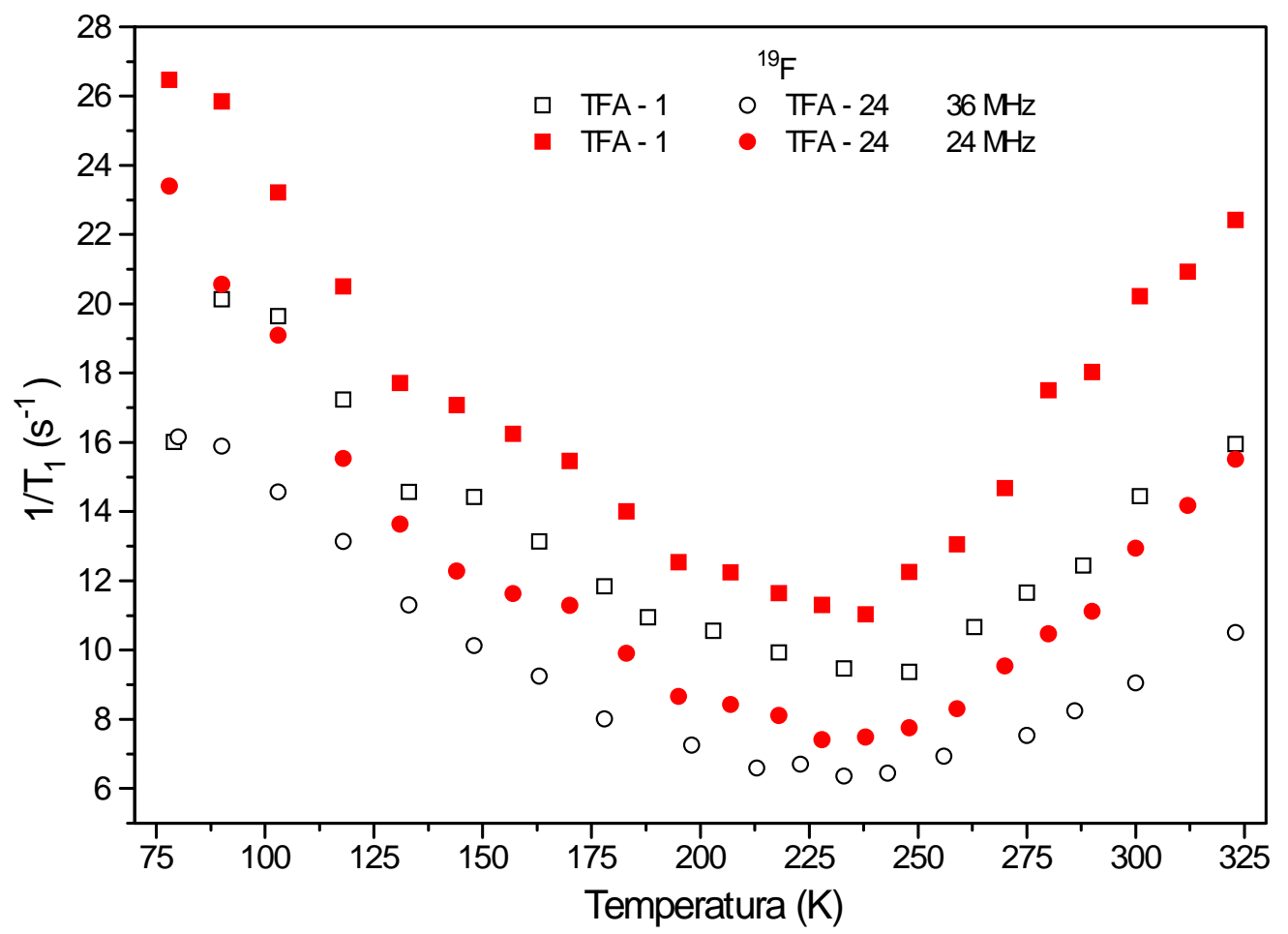

Figura 107 - Taxas de relaxação $\left(1 / T_{1}\right)$ do ${ }^{19} \mathrm{~F}$ da amostra POMA dopada com TFA, por $1 \mathrm{~h}(\bullet$ e •) e $24 \mathrm{~h}$ (• e o), nas freqüências de 24 e $36 \mathrm{MHz}$. 
A semelhança entre a relaxação do ${ }^{19} \mathrm{~F}$ e a da componente rápida do ${ }^{1} \mathrm{H}$, nos leva a imaginar uma outra interpretação dos resultados. Se considerarmos um cenário em que os íons flúors se localizam próximo do defeito da cadeia, e portanto próximos do polaron, é possível que interação hiperfina flúor-polaron seja eficiente, promovendo o acoplamento flúor-rede. Além disso, considerando que a relaxação nuclear spin-rede, através deste mecanismo, não requer que o polaron possua mobilidade, podemos interpretar as duas componentes de relaxação obtidas para o ${ }^{1} \mathrm{H}$ como sendo devidas, não às fases amorfa e cristalina do polímero, mas sim, à dois “tipos” de hidrogênios: aqueles ligados ao polaron e aqueles distantes do polaron. Os núcleos distantes do polaron teriam maior dificuldade de relaxar, enquanto que aqueles acoplados ao polaron teriam sua relaxação facilitada. Isto explicaria parte dos resultados, porém não fica claro porque a hidratação da amostra provoca o aumento do $\mathrm{T}_{1}$, tanto na relaxação rápida do ${ }^{1} \mathrm{H}$ como na do ${ }^{19} \mathrm{~F}$. Em outras palavras, por que a hidratação faz com que o mecanismo de relaxação nuclear, via polarons, perca a eficiência? Um outro aspecto do problema, levantado a partir dos resultados experimentais é: qual o significado do mínimo observado em $1 / T_{1}$, para ambos, os núcleos? Não sabemos responder esta pergunta, mas suspeitamos que este efeito secundário deve estar correlacionado com aquele já observado em RPE, onde se observou um máximo da largura de linha nas amostras dopadas com TFA. Ambos efeitos são observados na mesma temperatura e, em ambos a amostra dopada com $\mathrm{HCl}$ mostrou um comportamento diferenciado. É possível que o aumento na eficiência do espalhamento do polaron, pelas moléculas de oxigênio, que ocorre em temperaturas em torno de $220 \mathrm{~K}$, module o acoplamento núcleo-polaron, diminuindo ligeiramente a eficiência da relaxação nuclear via polarons.

Para concluir, podemos dizer que os resultados obtidos pelas técnicas de RMN permitem a obtenção de poucas conclusões definitivas. Em contrapartida, estes estudos apontam novos caminhos para a pesquisa e deixam muitas perguntas, interessantes, a serem respondidas futuramente. 


\section{7 - CONCLUSÃO}

Os primeiros testes mostraram que o "probe” projetado pode operar na faixa de freqüências de $10 \mathrm{~Hz}$ a $1 \mathrm{kHz}$ e com campo primário entre 0,01 gauss e 16 gauss. Para amostras de $0.05 \mathrm{~cm}^{3}$ e campos da ordem de 10 gauss foi conseguido uma sensibilidade da ordem de $10^{-7}$ emu. O movimento do "probe", relativo ao criostato, não introduz sinais espúrios, que possam prejudicar a sensibilidade do equipamento. Estas especificações são inferiores àquelas conseguidas com o uso de susceptômetros comerciais de última geração. Entretanto, se for considerado o custo e o fato de não haver a necessidade de manter as bobinas resfriadas a nitrogênio ou hélio líquido, as especificações deste "probe” são excelentes. Neste trabalho, verificou-se que o susceptômetro pode ser utilizado para estudar diferentes tipos de materiais: polímeros; supercondutores; e compostos intermetálicos.

Os resultados de Susceptibilidade Magnética AC (SMAC) e Ressonância Paramagnética Eletrônica (RPE), mostraram que o comportamento magnético dos polímeros Poliparafenileno (PPP) dopados com $\mathrm{FeCl}_{3}$, pode ser interpretado de acordo com 3 contribuições distintas, descritas a seguir.

Ao polaron estão associados comportamentos típicos dos portadores de carga, cuja mobilidade aumenta com o aumento da temperatura. Em baixas temperaturas, até cerca de $100 \mathrm{~K}$, o poloron está essencialmente localizado e a susceptibilidade magnética medida por RPE mostra um comportamento do tipo Curie-Weiss. O alargamento da linha de RPE, com o decréscimo da temperatura, é provocado pela interação hiperfina polaron-núcleo, que se torna mais eficiente com o aumento do grau de localização do polaron.

Os espectros de RPE mostraram que o íon Fe, pertencente à molécula do dopante, está associada no material de duas formas distintas. A linha observada em g = 4,3 
mostra a presença de íons $\mathrm{Fe}^{3+}$, magneticamente não interagentes e localizados em sítios de baixa simetria, possivelmente na molécula $\mathrm{FeCl}_{3}$ ligada à cadeia do polímero. $\mathrm{O}$ espectro de RPE mostra também uma linha intensa e larga com $g \approx 2$, que foi atribuída a íons $\mathrm{Fe}^{3+}$ magnéticamente interagentes. Estes últimos são responsáveis pela maior contribuição ao sinal de susceptibilidade magnética AC, evidenciando um comportamento magnético complexo nas amostras muito dopadas. Nestas, observa-se que a dependência da susceptibilidade com a temperatura não segue a lei de Curie-Weiss, possivelmente devido ao acoplamento do spin do íon $\mathrm{Fe}^{3+}$ com o dos íons vizinhos.

Os resultados de RPE e RMN na poli(o-metoxianilina) (POMA) mostraram que as propriedades magnéticas do material são fortemente afetadas pela dopagem. A largura da linha de RPE, associada ao polaron, diminui drasticamente com a dopagem, em toda a faixa de temperatura 4-300 K, evidenciando dois mecanismos distintos. A interação de troca polaron-polaron, modulada pelas flutuações de spin, é o mecanismo predominante em baixas temperaturas. Em altas temperaturas, o "motional narrowing” da linha é provocado pelo aumento da mobilidade do polaron. Em temperaturas intermediárias foi observado um comportamento anômalo. Em torno de $220 \mathrm{~K}$ a linha se alarga abruptamente, mostrando que as contribuições não seculares de $1 / T_{2}$, dominam a relaxação spin-spin nesta temperatura. O mecanismo proposto para a relaxação spin-rede, $1 / T_{1}$, nesta temperatura, foi o espalhamento do polaron por moléculas paramagnéticas de oxigênio.

Os resultados de Susceptibilidade Magnética AC na POMA foram realizados em baixas temperaturas (abaixo de $25 \mathrm{~K}$ ), de onde foi possível estimar a contribuição diamagnética da cadeia do polímero. Os valores medidos experimentalmente estão na mesma faixa de valores apresentados na literatura e dos obtidos pelo modelo semi-empírico de Pascal.

Através das medidas de RMN foi possível associar as componentes espectrais que compõem a linha de RMN, com as fases amorfa e cristalina do polímero. Os resultados mostram que estas fases coexistem na faixa de temperaturas entre $200 \mathrm{~K} \mathrm{e}$ $323 \mathrm{~K}$, e que o grau de cristalinidade depende da dopagem. Em altas temperaturas, o "motional narrowing” da linha é provocado pelo aumento da mobilidade das cadeias, o que ocorre tanto na fase cristalina como na fase amorfa do polímero. As medidas do tempo de relaxação spin-rede nuclear $T_{1}$, mostram que a relaxação dos núcleos ${ }^{1} \mathrm{H}$ e ${ }^{19} \mathrm{~F}$ é 
fortemente afetada pela dinâmica do polaron. Os núcleos em contato com os polarons, via interação hiperfina, tem sua taxa de relaxação aumentada por mais de uma ordem de grandeza. Os outros núcleos, isolados dos polarons, apresentam uma menor taxa de relaxação, e a sua relaxação ocorre através de mecanismos associados ao modos vibracionais locais da cadeia do polímero.

Para concluir, podemos dizer que os resultados obtidos permitiram a obtenção de novos conhecimentos acerca da relação entre transporte de carga e propriedades magnéticas dos polímeros condutores eletrônicos. Várias conclusões obtidas ainda necessitam de serem submetidas a novos testes experimentais, entretanto são muito importantes, porque indicam novos caminhos para o futuro da pesquisa. 


\section{ANEXOS}

Circuito analógico da ponte de indutâncias mútuas

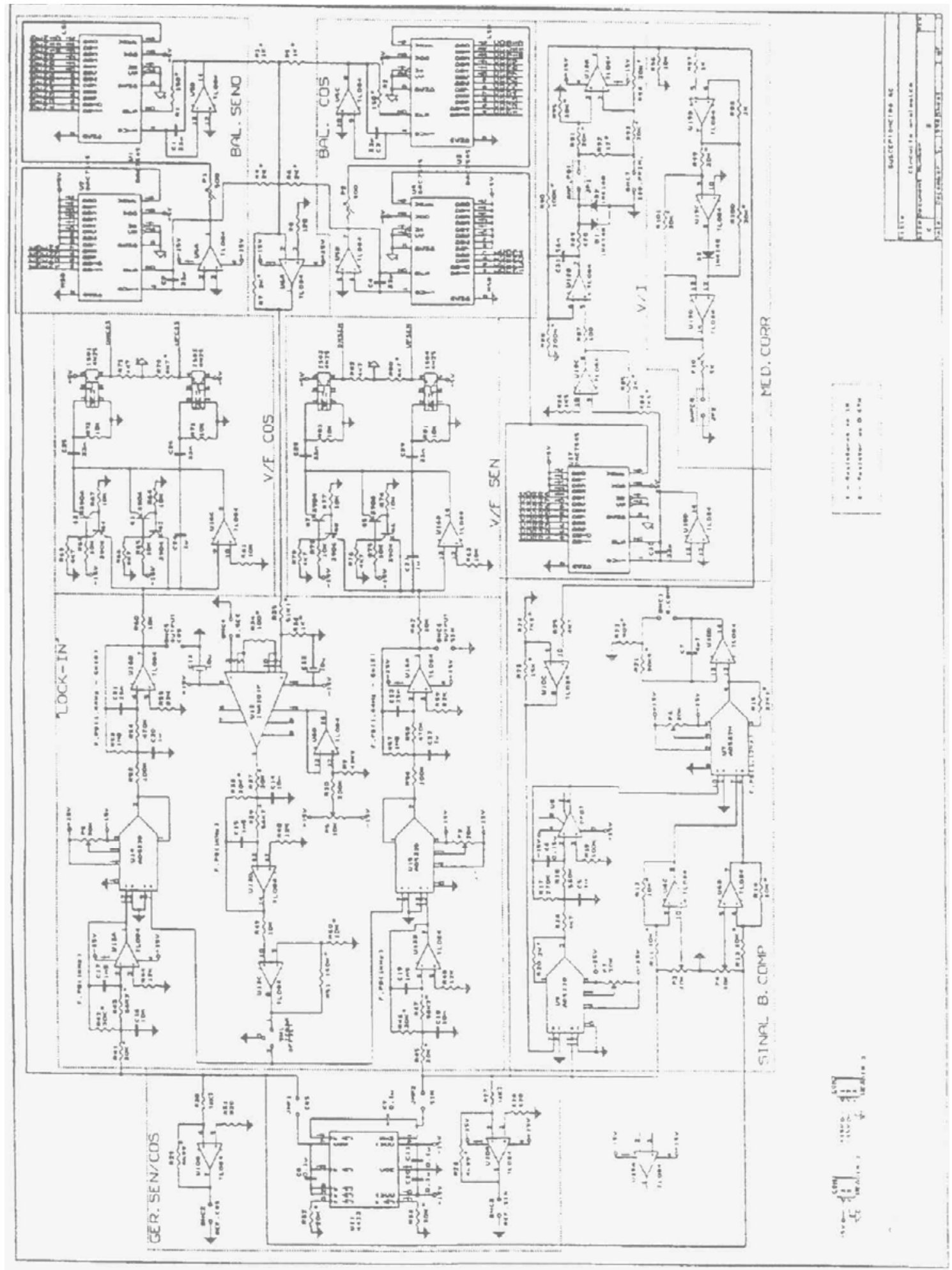


Circuito digital da ponte de indutâncias mútuas

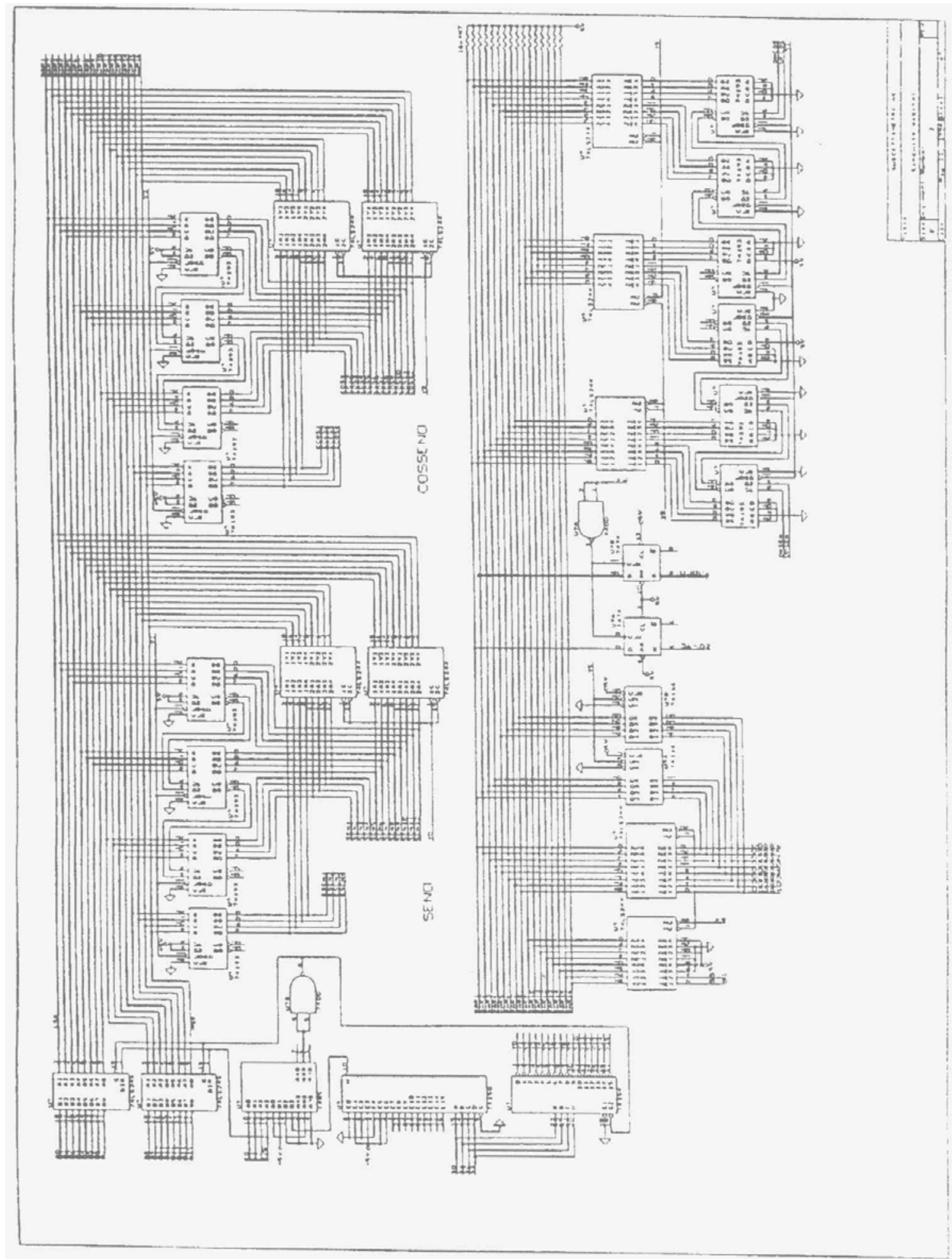




\section{REFERÊNCIAS BIBLIOGRÁFICAS}

[1] PAUL, E.W.; RICCO, A.J.; WRIGHTON, M.S. J. Phys. Chem., v.89, p.1441, 1985.

[2] MACDIARMID, A.G.; YANG, L.S.; HUANG, W.S.; HUMPHREY, B. Synth. Met., v.18, p.383, 1987.

[3] SCROSATI, B. Solid State Chem., v.18, p.1-17, 1988.

[4] ZOPPI, R.A.; DE PAOLI, M.A. Química Nova, v.16, n.6, p.560, 1993.

[5] DE SOUZA, R.R. Susceptômetro para Medidas Automáticas da Susceptibilidade Magnética AC. São Carlos, 1992. Dissertação (Mestrado), Departamento de Física e Ciência dos Materiais, Instituto de Física e Química de São Carlos, USP.

[6] DE SOUZA, R.R.; MAGON, C.J. Rev. Sci. Instrum., v.69, n.2, $1998 . \quad$ /No prelo/

[7] PAKE, G.E.; ESTLE, T.L. The Physical Principles of Electron Paramagnetic Resonance. 2.ed., Massachusetts, W.A. Benjamim, Inc., 1973.

[8] CARRINGTON, A.; MACLACHLAN, A.D. Introduction to Magnetic Resonance: With Applications to Chemistry and Chemical Physics. New York, Harper \& Row, 1969.

[9] ABRAGAM, A. The Principles of Nuclear Magnetism. Oxford, Clarendon, 1961.

[10] SLICHTER, C.P. Principles of Magnetic Resonance. 3 ed., Berlin, SpringerVerlag, 1990.

[11] GIL, V.M.S.; GERALDES, C.F.G.C. Ressonância Magnética Nuclear Fundamentos, Métodos e Aplicações. Lisboa, Fundação Calouste Gulbenkian, 1987.

[12] POOLE JR, C.P. Electron Spin Resonance: A Comprehensive Treatise on Experimental Techniques. New York, Interscience, 1967. 
[13] SARTORI, J.C. Construção de um Sistema para Ressonância Paramagnética Eletrônica em Baixa Freqüência: Banda L e Banda S. São Carlos, 1990. Tese (Doutorado), Departamento de Física e Ciência dos Materiais, Instituto de Física e Química de São Carlos, USP.

[14] MAGON, C.J. Ressonância Paramagnética: Teoria da Medida. Relaxação Eletrônica do Hidrogênio Atômico Intersticial em CaF2: Evidência da Difusão Espectral. São Carlos, 1977. Dissertação (Mestrado), Departamento de Física e Ciência dos Materiais, Instituto de Física e Química de São Carlos, USP.

[15] SOUZA, P.H. Ressonância Paramagnética Eletrônica em Ferritas de Cálcio e Nióbio: $\mathrm{Ca} 2 \mathrm{Fe} 2-x \mathrm{NbxO5}+x$. São Carlos, 1992. Dissertação (Mestrado), Departamento de Física e Ciência dos Materiais, Instituto de Física e Química de São Carlos, USP.

[16] PAGNANO, M.A. Automação de um Espectrômetro por Ressonância Magnética Nuclear Pulsada. São Carlos, 1993. Dissertação (Mestrado), Departamento de Física e Ciência dos Materiais, Instituto de Física e Química de São Carlos, USP.

[17] FRARE, P.L. Estudo de Condutores Iônicos Vítreos e Poliméricos por Ressonância Magnética Nuclear. São Carlos, 1996. Tese (Doutorado), Departamento de Física e Informática, Instituto de Física de São Carlos, USP.

[18] FUKUSHIMA, E.; ROEDER, S.B.W. Experimental Pulse NMR: a Nuts and Bolts Approach. Massachusetts, Addison-Wesley Publishing Company, Inc., 1981.

[19] JOHNSON, W.C. Linhas de Transmissão e Circuitos. Rio de Janeiro, Guanabara, 1980.

[20] MULAY, L.N. Anal. Chem., v.34, n.5, p.343R-61R, 1962.

[21] MULAY, L.N. Magnetic Susceptibility New York, John Wiley \& Sons, Inc., 1963.

[22] MULAY, L.N.; MULAY, I.L. Anal. Chem., v.36, n.5, p.404R-19R, 1964.

[23] HARTSHORN, L. J. Sci. Instrum., v.2, n.5, p.145-51, 1925.

[24] VAN VLECK, J.H. The Theory of Electric and Magnetic Susceptibilities. London, Oxford University press, 1932.

[25] MORRISH, A.H. The Physical Principles of Magnetism. New York, John Wiley \& Sons, Inc., 1965. 
[26] REIF, F. Fundamentals of Statistical and Thermal Physics. New York, Macgraw-Hill Book Company, 1965.

[27] KITEL, C. Introduction to Solid State Physics. 4.ed, New York, Wiley \& Sons, Inc., 1971.

[28] REITZ, J.R.; MILFORD, F.J.; CHRISTY, R.W. Fundamentos da Teoria Eletromagnética. 3.ed., Rio de Janeiro, Campus, 1982.

[29] OCIO, M.; HAMMANN, J. Rev. Sci. Instrum., v.56, n.7, p.1367-76, 1985.

[30] DEUTZ, A.F.; HULSTMAN, R.; RANENBURG, F.J. Rev.. Sci. Instrum., v.60, n.1, p.113-20, 1989.

[31] DUNDON, J.M; KRETSCHMAR, M.E. Rev. Sci. Instrum., v.49, n.3, p.406-7, 1978.

[32] BRODBECK, C.M.; BUKREY, R.R.; HOEKSEMA, J.T. Rev. Sci. Instrum., v.49, n.9, p.1279-81, 1978.

[33] WHITMORE, S.C.; RYAN, S.R.; SANDERS JR., T.M. Rev. Sci. Instrum., v.49, n.11, p.1579-82, 1978.

[34] KUMANO, M.; IKEGAMI, Y. Rev. Sci. Instrum., v.50, n.7, p.921-2, 1979.

[35] PILLINGER, W.L.; JASTRAM, P.S.; DAUNT, J.G. Rev. Sci. Instrum., v.29, n.2, p.159-62, 1958.

[36] PRASAD, M.; RAO, R.R.; CHAUDHURIA, K.R. J. Phys. E: Sci. Instrum., v.19, n.12, p.1013-16, 1986.

[37] MAXWELL, E. Rev. Sci. Instrum., v.36, n.4, p.553-4, 1965.

[38] FABBRICATORE, P.; GAMBARDELLA, U.; GÖMÖRY, F.; MUSENICH, R.; OCCHETTO, M.; PARODI, R.; POMPA, P. Rev. Sci. Instrum., v.62, n.7, p.1796-800, 1991.

[39] MCKIM, F.R.; WOLF, W.P. J. Sci. Instrum., v.34, n.2, p.64-7, 1957.

[40] STAHLBUSH, R.E.; $\quad$ BASTUSCHECK, C.M.; $\quad$ RAYCHAUDHURI, A.K.; SCOTT, J.C.; GRUBB, D.; GILLMAN, H.D. Phys. Rev. B, v.23, n.7, p.3393, 1981.

[41] CORSON, M.R. Rev. Sci. Instrum., v.53, n.10, p.1606-8, 1982.

[42] ANDERSON, A.C.; PETERSON, R.E.; ROBICHAUX, J.E. Rev. Sci. Instrum., v.41, n.4, p.528-32, 1970.

[43] CASIMIR, H.B.G.; BIJL, D.; DU PRÉ, F.K. Physica, v.8, n.5, p.449-60, 1941. 
[44] ZAHN, C.T. Rev. Sci. Instrum., v.34, n.3, p.285-91, 1963.

[45] VAN DE KLUNDERT, L.J.M.; DE ROOIJ, C.; CASPARI, M.; VAN DER MAREL, L.C. Cryogenics, v.15, n.10, p.577-89, 1975.

[46] HOCKMAN, A.J.; SENA, F.J.; GENTILE, P.S. Rev. Sci. Instrum., v.52, n.2, p.224-8, 1981.

[47] LAKESHORE PRODUCT CATALOG AND REFERENCE GUIDE Lake Shore Cryotronics, Inc.

[48] GSCHNEIDNER, K.A.; EYRING, L.R. Handbook on the Physics and Chemistry of Rare Earths: Alloys and Intermetallics. v.2, Amsterdam, North-Holland publishing, 1979.

[49] WOHIFARTH, E.P. Ferromagnetic Materials. v.1, Amsterdam, North-Holland publishing, 1980.

[50] BUSCHOW, K.H.J. Rep. Prog. Phys., v.42, p.1373-477, 1979.

[51] PURWINS, H.-G.; LESON, A. Advances in Physics, v.39, n.4, p.309-405, 1990.

[52] ASHCROFT, N.W; MERMIN, N.D. Solid State Physics. International Edition, United States of America, Saunders College Publishing, 1976.

[53] GSCHNEIDNER, K.A.; EYRING, L.R. Handbook on the Physics and Chemistry of Rare Earths: Metals. v.1, Amsterdam, North-Holland publishing, 1978.

[54] LETHUILliER, P.; PERCHERON-GUEGAN, A. J. Less-Common Met., v.46, n.85-9, 1976.

[55] TALIK, E.; HEIMANN, J.; CHELKOWSKI, A. J. Less-Common Met., v.138, p.L15, 1988.

[56] KAWANO, S.; UMEZAKI, H.; SHIBATA,T. Annu. Rep. Res. Reactor Inst. Kyoto Univ., v.7, p.99, 1974.

[57] GAMARI-SEALE, H; ANAGNOSTOPOULOS, T.; YAKINTHOS, J.K. $\quad J$. Appl. Phys., v.50, n.1, 1979.

[58] BAZELA, W.; SZYTULA, A. J. Less-Common Met., v.138, p.123, 1988.

[59] STALÍNSKI, B.; POKRZYWNICKI, S. Phys. Stat. Sol., v.14, p.K157-60, 1966.

[60] BUSCHOW, K.H.J.; FAST, J.F.; VAN DIEPEN, A.M.; DE WIJN, H.W. Phys. Stat. Sol., v.24, p.715-20, 1967. 
[61] SWIFT, W.M.; WALLACE, W.E. J. Phys. Chem. Solids, v.29, p.2053-61, 1968.

[62] NERESON, N.; OLSEN, C.; ARNOLD, G. J. Appl. Phys., v.37, n.12, p.457580, 1966.

[63] BERTHIER, Y.; DEVINE, R.A.B. J. Physique Colloq., v.40, n.5, p.C5-116, 1979.

[64] BARBARA, B.; ROSSIGNOL, M.F.; BOUCHERLE, J.X. Physics Letters, v.55A, n.5, p.321-2, 1975.

[65] MILlHOUSE, A.H.; PURWINS, H.G.; WALKER, E. Solid State Comm., v.11, p.707-12, 1972.

[66] VAN DAAL, H.J.; BUSCHOW, K.H.J. Solid State Comm., v.7, p.217-21, 1969.

[67] BARASH, Y.B.; BARAK, J.; KAPLAN, N. Phys. Rev. B, v.25, n.11, p.661621, 1982.

[68] MANO, E.B. Polímeros como Materiais de Engenharia. Ed. Edgard Blücher Ltda.

[69] MELO, C.P. Ciência Hoje, v.6, p.39, 1987.

[70] SOUZA, P.H. A Espectroscopia de Alta Resolução e Relaxação em Sólidos por RMN Aplicada ao Estudo de Compostos Híbridos SílicaPolipropilenoglicol-LiClO4 Condutores Iônicos e do Polímero Condutor Eletrônico Poliparafenileno dopado com FeCl3. São Carlos, 1998. Tese (Doutorado), Departamento de Física e Informática, Instituto de Física de São Carlos, USP. /No prelo/

[71] CHAMPAGNE, B; MOSLEY, D.H.; FRIPIAT, J.G.; ANDRÉ, J. Phys. Rev. B, v.54, p.2381, 1996.

[72] BREDAS, J.L.; CHANCE, R.R.; SILBEY, R. Phys. Rev. B, v.26, p.5843, 1982.

[73] KOVACIC, P; OZIOMEK, J J. Org. Chem., v.29, p.100, 1964.

[74] GIOTTO, M.V. Caracterização do PolyParaPhenilene (PPP) dopado com FeCl3, utilizando Espectroscopia de Alta Resolução por Ressonância Magnética Nuclear. São Carlos, 1993. Dissertação (Mestrado), Departamento de Física e Ciência dos Materiais, Instituto de Física e Química de São Carlos, USP.

[75] JONES, B.M.; KOVACIC, P.; HOWE, R.F. J. Polymer Science, v.19, p.235, 1981. 
[76] FROYER, G.; MAURICE, F.; BERNIER, P.; MCANDREW, P. Polymer, v.23, p.1103-5, 1982.

[77] PRÓN, A.; FATSEAS, G.A.; KRICHÈNE, S.; LEFRANT, S.; MAURICE, F.; FROYER, G. Phys. Rev. B, v.32, p.1839, 1985.

[78] PEO, M.; ROTH, S.; DRANSFELD, K.; TIEKE, B.; HOCKER, J.; GROSS, H.; GRUPP, A.; SIXL, H. Solid State Commun., v.35, n.2, p.119-22, 1980.

[79] MYERS, W.R. Rev. Modern Phys., v.24, n.1, p.15-27, 1952.

[80] WEINBERGER, B.R.; $\quad$ KAUFER, J.; $\quad$ HEEGER, A.J.; $\quad$ PRON, A.; MACDIARMID, A.G. Phys. Rev. B, v.20, n.1, p.223-30, 1979.

[81] WEINBERGER, B.R.; EHRENFREUND, E.; PRON, A.; HEEGER, A.J.; MACDIARMID, A.G. J. Chem. Phys., v.72, n.9, p.4749-55, 1980.

[82] BERNIER, P. Mol. Cryst. Liq. Cryst., v.83, p.57-65, 1982.

[83] BLEANEY, B.I.; BLEANEY, B. Electricity an Magnetism. 2.ed. London, Oxford University press, 1965. Cap.8, p.198-201.

[84] WAN, M.; LI, S.; LI, J. Solid State Commun., v.97, n.6, p.527-30, 1996.

[85] KUIVALAINEN, P.; $\quad$ STUBB, H.; $\quad$ ISOTALO, H.; $\quad$ YLI-LAHTI, P.; HOLMSTRÖM, C.; Phys. Rev. B, v.31, n.12, p.7900-9, 1985.

[86] CASTNER JR, T.; NEWELL, G.S.; HOLTON, W.C.; SLICHTER, C.P. $\quad J$. Chem. Phys., v.32, n.3, p.668-73, 1960.

[87] WICKMAN, H.H; KLEIN, M.P.; SHIRLEY, D.A. J. Chem. Phys., v.42, n.6, p.2113-7, 1965.

[88] GENIÈS, E.M.; BOYLE, A.; LAPKOWSKI, M.; TSINTAVIS, C. Synth. Met., v.36, p.139, 1990.

[89] HJERTBERG, T.; SALANECK, W.R.; LUNDSTROM, I.; SOMASIRI, N.L.D.; MACDIARMID, A.G. J. Pol. Science: Pol. Lett. Ed., v.23, p.503-8, 1985.

[90] MACDIARMID, A.G.; CHIANG, J.; HARPERN, M.; HUANG, W.; MU, S.; SOMASIRI, N.L.D.; WU, W.; YANIGER, S.I. $\quad$ Mol. Cryst. Liq. Cryst., v.121, p.173-80, 1985.

[91] TRAVERS, J.P.; CHROBOCZEK, J.; DEVREUX, F.; $\quad$ GENOUD, F.; NECHTSCHEIN, M.; SYED, A.; GENIES, E.M.; TSINTAVIS, C. Synth. Met., v.121, p.195-9, 1985.

[92] MACDIARMID, A.G.; CHIANG, J.; HUANG, W.; HUMPHREY, B.D.; SOMASIRI, N.L.D. Mol. Cryst. Liq. Cryst., v.125, p.309-18, 1985. 
[93] CHANCE, R.R.; BOUDREAUX, D.S.; WOLF, J.F.; SHACKLETTE, L.W.; SILBEY, R.; THEMANS, B.; ANDRE, J.M.; BREDAS, J.L. Synth. Met., v.15, p.105-14, 1986.

[94] WNEK, G.E. Synth. Met., v.15, p.213-8, 1986.

[95] SANAUWAERT, P.; LAZZARONI, R.; RIGA, J.; VERBIST, J.J. Synth. Met., v.18, p.335-40, 1987.

[96] HJERTBERG, T.; SANDBERG, M.; WENNERSTRÖM, O.; LAGERSTEDT, I. Synth. Met., v.21, p.31-9, 1987.

[97] MIZOGUCHI, K.; $\quad$ NECHTSCHEIN, M.; $\quad$ TRAVERS, J.P.; $\quad$ MENARDO, C. Synth. Met., v.29, p.E417-24, 1989.

[98] TRAVERS, J.P.; GENOUD, F.; MENARDO, C.; NECHTSCHEIN, M. Synth. Met., v.35, n.159-68, 1990.

[99] IIDA, M.; $\quad$ ASAJI, T.; $\quad$ NAKAMURA, L.D.; $\quad$ IKEDA, R.; $\quad$ INOUE, M.B.; INOUE, M. Synth. Met., v.48, p.1-6, 1992.

[100] MACDIARMID, A.G.; EPSTEIN, A.J. Mat. Res. Soc. Symp. Proc., v.247, p.565-76, 1992.

[101] REGHU, M.; CAO, Y.; MOSES, D.; HEEGER, A.J. Phys. Rev. B, v.47, n.4, p.1758-64., 1993.

[102] ANGELOPOULOS, M.; $\quad$ ASTURIAS, G.E.; $\quad$ ERMER, S.P.; $\quad$ RAY, A.; SCHERR, E.M.; MACDIARMID, A.G. Mol. Cryst. Liq. Cryst., v.160, p.151, 1988.

[103] ANDEREATTA, A.; CAO, Y.; CHIANG, J.C.; SMITH, P.; HEEGER, A.J. Synth. Met., v.48, p.91, 1988.

[104] NOGUEIRA, J.S. Síntese, Caracterização e Condução Elétrica em Polianilina e Poli(o-metoxianilina). São Carlos, 1995. Tese (Doutorado), Departamento de Físico-Química, Instituto de Química de São Carlos, USP.

[105] MALMONGE, L.F. Preparação e Caracterização de Blendas de Poli(Fluoreto de Vinilideno) com Polianilinas. São Carlos, 1996. Tese (Doutorado), Departamento de Físico-Química, Instituto de Química de São Carlos, USP.

[106] MACDIARMID, A.G.; CHIANG, J.C.; RICHTER, A.F.; SOMSIRI, N.L.D.; EPSTEIN, A.J. Conducting Polymers, Holland, Luis Alcacer ed., 1987, p.105.

[107] MATTOSO, L.H.C; MACDIARMID, A.G.; EPSTEIN, A.J. Synth. Met., v.68, p.1, 1994. 
[108] MALMONGE, J.A. Preparação, caracterização e estudo do mecanismo de transporte de cargas em blendas do copolímero P(VDF-TrFE) com poli(ometoxianilina). São Carlos, 1997. Tese (Doutorado), Departamento de Física e Ciência dos Materiais, Instituto de Física de São Carlos, USP.

[109] MATTOSO, L.H.C. Síntese, caracterização e processamento de polianilina e seus derivados. São Carlos, 1993. Tese (Doutorado), Departamento de Ciência e Engenharia de Materiais, Universidade Federal de São Carlos.

[110] MATTOSO, L.H.C.; FARIA, R.M.; BULHÕES, L.O.S.; MACDIARMID, A.G. J. Pol. Sci. Part A: Polymer Chemistry, v.32, p.2147, 1994.

[111] CHIANG, J.C.; MACDIARMID, A.G. Synth. Met., v.13, p.193, 1986.

[112] GINDER, J.M.; RICHTER, A.F.; MACDIARMID, A.G.; EPSTEIN, A.J. Solid State Commun., v.63, n.2, p.97-101, 1987.

[113] EPSTEIN, A.J.; GINDER, J.M.; ZUO, F.; WOO, H.-S.; TANNER, D.B.; RICHTER, A.F.; $\quad$ ANGELOPOULOS, M.; $\quad$ HUANG, W.-S.; MACDIARMID, A.G. Synth. Met., v.21, p.63-70, 1987.

[114] WANG, Z.H.; RAY, A.; MACDIARMID, A.G.; EPSTEIN, A.J. Phys. Rev. B, v.43, n.5, p.4373-84, 1991.

[115] RAGHUNATHAN, ANASUYA; NATARAJAN, T.S.; RANGARAJAN,G.; DHAWAN, S.K.; TRIVEDI, D.C. Phys. Rev. B, v.47, n.20, p.13189-96, 1993.

[116] ADAMS, P.N.; LAUGHLIN, P.J.; MONKMAN, A.P. Solid State Commun., v.91, n.11, p.875-8, 1994.

[117] PINTO, N.J.; KAHOL, P.K.; MCCORMICK, B.J.; DALAL, N.S.; WAN, H. Phys. Rev. B, v.49, n.19, p.13983-6, 1994.

[118] KAHOL, P.K.; PENDSE, V.; PINTO, N.J.; TRAORE, M.; STEVENSON, W.T.K.; MCCORMICK, B.J.; GUNDERSEN, J.N. Phys. Rev. B, v.50, n.5, p.2809-14, 1994.

[119] FITE, C.; CAO, Y.; HEEGER, A.J. Solid State Commun., v.70, n.3, p.245-7, 1989.

[120] JAVADI, H.H.S.; $\quad$ LAVERSANNE, R.; $\quad$ EPSTEIN, A.J.; $\quad$ KOHLI, R.K.; SCHERR, E.M.; MACDIARMID, A.G. Synth. Met., v.29, p.E439-44, 1989.

[121] CAO, Y.; HEEGER, A.J. Synth. Met., v.52, p.193-200, 1992.

[122] MIZOGUCHI, K.; OBANA, T.; UENO, S.; KUME, K. Synth. Met., v.55/57, p.601-6, 1993. 
[123] GENOUD, F.; NECHTSCHEIN, M.; SANTIER, C. Synth. Met. v.55/57, p.642647, 1993.

[124] SARICIFTCI, N.S.; HEEGER, A.J.; CAO, Y. Phys. Rev. B, v.49, n.9, p.598892, 1994.

[125] IIDA, M.; ASAJI, T.; INOUE, M.B.; INOUE, M. Synth. Met., v.55/57, p.60712, 1993.

[126] WANG, Z.H.; SCHERR, E.M.; MACDIARMID, A.G.; EPSTEIN, A.J. Phys. Rev. B, v.45, n.8, p.4190-201, 1992.

[127] LONG, S.M; $\quad$ CROMACK, K.R.; $\quad$ EPSTEIN, A.J.; $\quad$ SUN, Y.; MACDIARMID, A.G. Synth. Met., v.55/57, p.648-53, 1993.

[128] FEHER, G.; KIP, A.F. Phys. Rev., v.98, n.2, p.337-48, 1955.

[129] DYSON, F.J. Phys. Rev., v.98, n.2, 349-59, 1955.

[130] KODERA, H. J. Phys. Soc. Japan, v.28, n.1, p.89-98, 1970.

[131] WALMSLEY, L. J. Magn. Reson. A, v.122, p.209-13, 1996.

[132] PEREIRA, E.C.; BULHÕES, L.O.S.; PAWLICKA, A.; NASCIMENTO, O.R.; FARIA, R.M.; WALMSLEY, L. Phys. Rev. B, v.50, n.6, p.3648-51, 1994.

[133] PAWLICKA, A.; $\quad$ PEREIRA, E.C.; $\quad$ NASCIMENTO, O.R.; $\quad$ FARIA, R.M.; BULHÕES, L.O.S.; WALMSLEY, L. J. Magn. Reson. A, v.108, p.62-4, 1994.

[134] PAWLICKA, A.; $\quad$ PEREIRA, E.C.; $\quad$ FARIA, R.M.; $\quad$ BULHÕES, L.O.S.; NASCIMENTO, O.R.; WALMSLEY, L. Solid State Commun., v.91, n.12, p.953-6, 1994.

[135] PEREIRA, E.C.; PAWLICKA, A.; BULHÕES, L.O.S.; NASCIMENTO, O.R.; WALMSLEY, L. Solid State Commun., v.98, n.4, p.267-71, 1996.

[136] PARK, Y.W.; MOON, J.S.; BAK, M.K.; JIN, J.I. Synth. Met., v.29, p.E389-94, 1989.

[137] NOGUEIRA, J.S.; $\quad$ MATTOSO, L.H.C.; $\quad$ LEPIENSKI, C.M.; $\quad$ FARIA, R.M. Synth. Met., v.69, p.259-60, 1995.

[138] PAUL, A.; MISRA, T.N.; TALUKDAR, D. Solid. State Commun., v.99, n.9, p.633-6, 1996.

[139] LEPIENSKI, C.M.; FARIA, R.M.; LEAL FERREIRA, G.F. Appl. Phys. Lett., v.70, n.14, p.1-3, 1997. 
[140] ANAND, J.; PALANIAPPAN, S.; SATHYANARAYANA, D.N. $\quad J . \quad$ Phys. Chem., v.99, p.10324-8, 1995.

[141] KUBO, R.; TOMITA, K. J. Phys. Soc. Japan, v.9, p.888, 1954.

[142] MORIYA, T. Prog. Theor. Phys., v.16, n.1, p.23-44, 1956.

[143] DIETZ, R.E.; $\quad$ MERRITT, F.R.; $\quad$ DINGLE, R.; HONE, D.; SILBERNAGEL, B.G.; RICHARDS, P.M. Phys. Rev. Lett, v.26, n.19, p.1186-8, 1971.

[144] HENNESSY, M.J.; MCELWEE, C.D.; RICHARDS, P.M. Phys. Rev.B, v.7, n.3, p.930-47, 1973.

[145] ANAND, J.; PALANIAPPAN, S.; SATHYANARAYANA, D.N. Synth. Met., v.66, p.129-34, 1994.

[146] WERTZ, J.E.; BOLTON, J.R. Electron Spin Resonance: Elementary Theory and Practical Applications, New York, McGraw-Hill Book Company, 1972.

[147] SCOTT, J.C.; PFLUGER, P.; KROUNBI, M.T.; STREET, G.B. $\quad$ Phys. Rev. B, v.28, p.2140, 1988.

[148] SCHÄRLI, M.; KIESS, H.; HARBEKE, G.; BERLINGER, W.; BLAZEY, K.W. Synth. Met., v.22, p.317, 1988.

[149] RACHDI, F.; BERNIER, P. Phys. Rev. B, v.33, n.1, p.7817-9, 1986.

[150] AASMUNDTVEIT, K.; GENOUD, F.; HOUZÉ, E.; NECHTSCHEIN, M. Synth. Metals, v.69, p.193-6, 1995.

[151] TOURILLON, G.; GOURIER, D.; GARNIER, P.; VIVIEN, D. J. Phys. Chem., v.88, n.6, p.1049-51, 1984.

[152] NECHTSCHEIN, M.; SANTIER,C. J. Physique, v.47, p.935-7, 1986.

[153] ANGELOPOULOS, M.; RAY, A.; MACDIARMID, A.G.; $\quad$ EPSTEIN, A.J. Synth. Met., v.21, p.21-30, 1987.

[154] TRAVERS, J.P.; NECHTSCHEIN, M. Synth. Met., v.21, p.135-41, 1987.

[155] ALIX, A.; $\quad$ LEMOINE, V.; $\quad$ NECHTSCHEIN, M.; $\quad$ TRAVERS, J.P.; MENARDO, C. Synth. Met., v.29, p.E457-62, 1989.

[156] TRAVERS, J.P.; NECHTSCHEIN, M.; SAVALLE, A. Synth. Met., v.41-43, p.613-20, 1991.

[157] TRAVERS, J.P. Synth. Met., v.55-57, p.731-6, 1993. 
[158] TRAVERS, J.P.; $\quad$ LE GUYADEC, P.; $\quad$ ADAMS, P.N.; $\quad$ LUGHLIN, P.J.; MONKMAN, A.P. Synth. Met., v.69, p.229-30, 1995.

[159] MATVEEVA, E.S. Synth. Met., v.79, p.127-39, 1996.

[160] LEE, C.H.; LEE, C.E.; HAN, J.H.; SUH, K.S. Jpn. J. Appl. Phys., v.35, p.21458, 1996.

[161] JOHANSSON, A.; TEGENFELDT, J. Solid State Ionics, v.67, p.115-21, 1993.

[162] JOHANSSON, A.; TEGENFELDT, J. J. Chem. Phys., v.104, n.13, p.5317-25, 1995. 


\section{APÊNDICE SUPERCONDUTORES DE ALTO $\mathbf{T}_{\mathrm{C}}$}

O desenvolvimento de supercondutores de alto $T_{c}$ serviu para promover a técnica de susceptibilidade magnética AC. Foi neste período que houve um maior desenvolvimento dos susceptômetros AC, surgindo as pontes de indutâncias mútuas eletrônicas mais sensíveis e totalmente controladas por computadores.

Os supercondutores de alto $\mathrm{T}_{\mathrm{c}}$ são caracterizados por possuir campos críticos relativamente pequenos, e um campo de penetração também pequeno. Portanto, para a completa caracterização desses materiais, é necessário uma técnica de medida de magnetização de baixo campo. Como a técnica de susceptibilidade magnética AC pode ser utilizada sem campo DC e com um campo AC muito baixo, então ela preenche completamente este importante, e imprescindível, requisito.

Um dos principais objetivos da medida de susceptibilidade magnética AC, de amostras supercondutoras, é a determinação de sua qualidade. Na maioria dos casos, considera-se que quanto mais abrupta for a transição supercondutora melhor é a qualidade da amostra. Esta medida também é usada para diferenciar entre correntes inter e intra-granular.

A partir da observação do comportamento da susceptibilidade magnética em função da temperatura, pode-se caracterizar as fases supercondutoras existentes no material. Quando a amostra está na fase normal (não supercondutora) as componentes da susceptibilidade magnética são nulas. A partir da transição para a fase supercondutora, a componente real da susceptibilidade $\left(\chi^{\prime}\right)$ passa a ter um valor negativo e a componente imaginária $\left(\chi^{\prime \prime}\right)$ pode, ou não, ter um valor positivo, dependendo se há, ou não, a formação de um caminho para a corrente elétrica. Quando há a formação deste caminho, entre os grânulos do supercondutor, diz-se que houve a percolação da amostra.

Neste apêndice, serão mostrados alguns dos resultados, de susceptibilidade magnética AC, obtidos para amostras supercondutoras de $\mathrm{Bi}_{2} \mathrm{Sr}_{2} \mathrm{Ca}_{1} \mathrm{Cu}_{2} \mathrm{O}_{8}$. As amostra 
utilizadas estavam na forma de pastilha (Figura A1), pó (Figura A2) e filme (Figura A3) ${ }^{\text {ţ }}$. Estas medidas foram realizadas em função da temperatura, entre $5 \mathrm{~K}$ e 140 K, e com campo magnético AC de 0,5 gauss de intensidade e 98,9 Hz de freqüência. Não há campo magnético DC aplicado. O objetivo destas medidas foi a caracterização das fases supercondutoras da amostra, determinando suas temperaturas de transição.

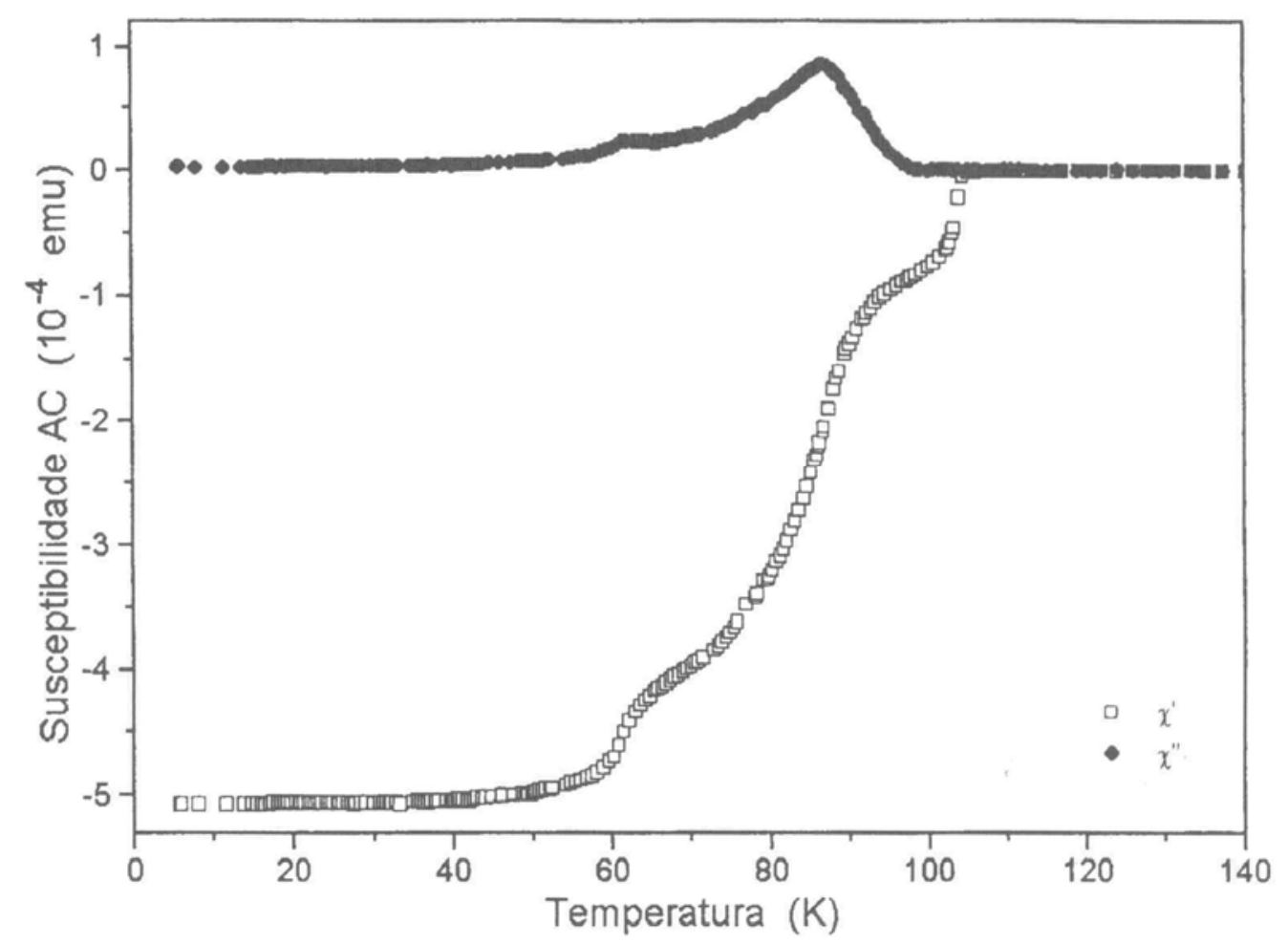

Figura A1 - Susceptibilidade magnética $\mathrm{AC}$ em função da temperatura pastilha supercondutora de $\mathrm{Bi}_{2} \mathrm{Sr}_{2} \mathrm{Ca}_{1} \mathrm{Cu}_{2} \mathrm{O}_{8}$. Campo magnético DC nulo, e campo magnético AC de 0,5 gauss de intensidade e freqüência de 98,9 Hz.

Na Figura A1 são mostrados os resultados das componentes real (dispersão - $\chi^{\prime}$ ) e imaginária (absorção - $\chi^{\prime \prime}$ ) da susceptibilidade magnética, obtidos para uma amostra de $\mathrm{Bi}_{2} \mathrm{Sr}_{2} \mathrm{Ca}_{1} \mathrm{Cu}_{2} \mathrm{O}_{8}$ na forma de pastilha. Nesta figura podemos observar, claramente, três transições de fase: uma, bem definida, em torno de $105 \mathrm{~K}$; e duas outras, largas, em torno de $85 \mathrm{~K}$ e $60 \mathrm{~K}$. Com base nesse resultado, acredita-se que esta amostra apresenta características da fase 2223 (transição em $105 \mathrm{~K}$ ), e que há uma

\footnotetext{
Estas amostras foram sintetizadas, no laboratório de materiais do IFSC, pelo aluno de doutorado Ms. Cláudio Luís Carvalho.
} 
existência predominante da fase 2212 (transição em torno de 85 K). O fato da transição em $85 \mathrm{~K}$ ser relativamente larga e de haver logo abaixo (em torno de $60 \mathrm{~K}$ ) uma outra transição, também larga, pode ser indício da existência de outras fases, de mais baixas temperaturas, coexistindo com a fase 2212. As temperaturas de transição das fases em torno de $85 \mathrm{~K}$ e $60 \mathrm{~K}$, são melhor determinadas observando os dois picos, bem definidos, existentes na curva de absorção. Estes picos, como mencionado anteriormente, são resultados da percolação da amostra.

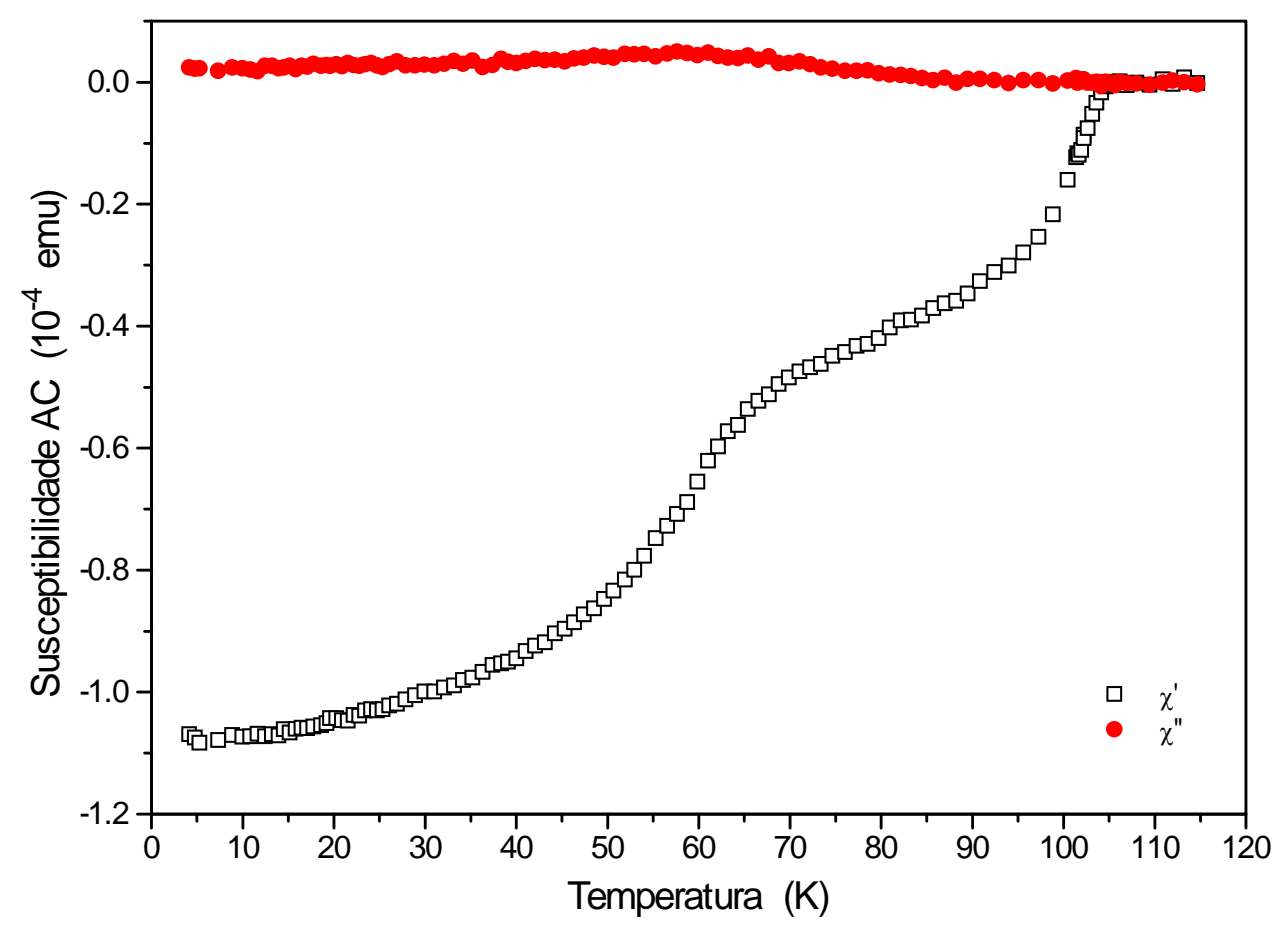

Figura A2 - Susceptibilidade magnética AC em função da temperatura da pastilha supercondutora pulverizada de $\mathrm{Bi}_{2} \mathrm{Sr}_{2} \mathrm{Ca}_{1} \mathrm{Cu}_{2} \mathrm{O}_{8}$. Campo magnético DC nulo, e campo magnético AC de 0,5 gauss de intensidade e freqüência de 98,9 Hz.

Na Figura A2 são mostrados os resultados de susceptibilidade magnética AC para uma amostra supercondutora na forma de pó. Este pó foi proveniente da pulverização de uma amostra supercondutora, cujos resultados de susceptibilidade, realizados antes da pulverização, estão mostrados na Figura A1. Os resultados para esta amostra em pó apresentaram transições largas a partir de $105 \mathrm{~K}$. Estas transições largas indicam que não é possível a existência de uma fase única, bem definida, em todo o volume da amostra. Observa-se também, a partir da componente de absorção, que a percolação da amostra não é bem sucedida. 
Uma das grandes dificuldades de se medir a susceptibilidade magnética de um filme fino é devido ao fato da intensidade de seu sinal ser muito pequeno. Isto é devido a baixa concentração de amostra, supercondutora, em um filme. Este sinal de intensidade reduzida, implica na necessidade de uma sensibilidade ainda maior do equipamento de medida.

A seguir, mostraremos os resultados de susceptibilidade para um supercondutor na forma de filme fino. Este filme foi obtido a partir de um pó, proveniente da trituração de uma pastilha de $\mathrm{Bi}_{2} \mathrm{Sr}_{2} \mathrm{Ca}_{1} \mathrm{Cu}_{2} \mathrm{O}_{8}$, que apresentava características da fase 2223. Os resultados da medida de susceptibilidade magnética AC em um filme fino, mostrados na Figura A3, foram obtidos com um campo magnético AC aplicado perpendicularmente ao filme ${ }^{\star}$. A partir destes resultados, observa-se a existência de transição de fase a partir de $75 \mathrm{~K}$, não sendo, portanto, observado características da fase inicial 2223 (transição em torno de $105 \mathrm{~K}$ ). Este resultado foi também confirmado através de medidas de resistência elétrica.

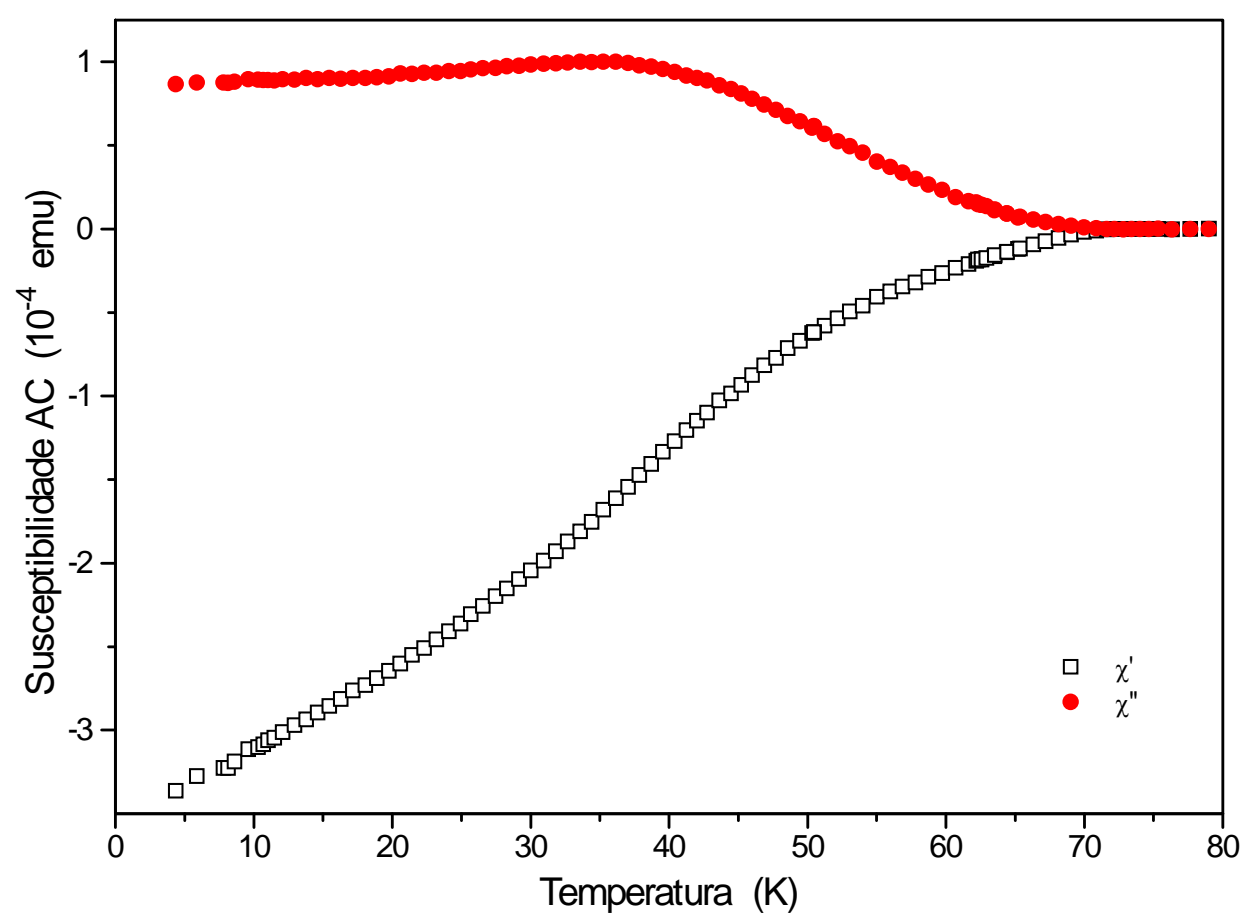

Figura A3 - Susceptibilidade magnética AC em função da temperatura do filme supercondutor de $\mathrm{Bi}_{2} \mathrm{Sr}_{2} \mathrm{Ca}_{1} \mathrm{Cu}_{2} \mathrm{O}_{8}$. Campo magnético DC nulo, e campo magnético AC, de 0,5 gauss de intensidade e freqüência de $98,9 \mathrm{~Hz}$, aplicado perpendicularmente ao filme.

\footnotetext{
× Devido ao limite inferior na sensibilidade de nosso susceptômetro, não foi possível realizar a medida com o campo magnético AC aplicado paralelamente ao filme.
} 